\title{
Not Just a Victim: \\ The Child as Catalyst and Witness of Contemporary Africa
}




\title{
Afrika-Studiecentrum Series
}

\author{
Editorial Board \\ Dr Piet Konings (African Studies Centre, Leiden) \\ Dr Paul Mathieu (FAO-SDAA, Rome) \\ Prof. Deborah Posel (University of Witwatersrand, Johannesburg) \\ Prof. Nicolas van de Walle (Cornell University, USA) \\ Dr Ruth Watson (Newnham College, Cambridge)
}

VOLUME 20 


\section{Not Just a Victim: \\ The Child as Catalyst and Witness of Contemporary Africa}

Edited by

Sandra J.T.M. Evers, Catrien Notermans

and Erik van Ommering

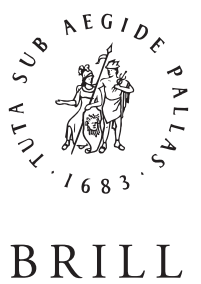

\section{LEIDEN • BOSTON \\ 2011}


Cover illustration: "Celebrating Independence”, Antananarivo, Madagascar.

Photograph by Sandra J.T.M. Evers, 1989

This book was published with financial support from WOTRO Science for Global Development.

This book is printed on acid-free paper.

Library of Congress Cataloging-in-Publication Data

Not just a victim : the child as catalyst and witness of contemporary

Africa / edited by Sandra J.T.M. Evers, Catrien Notermans and Erik van

Ommering.

p. cm. - (Afrika-studiecentrum series ; v. 20)

Includes index.

"This volume is based on a selection of papers presented at the 2008 conference,

"African Children in Focus: A Paradigm Shift in Methodology and Theory?"

organized by NVAS (Netherlands African Studies Association)"

ISBN 978-90-04-20400-3 (pbk. : alk. paper)

1. Children-Africa-Social conditions. 2. Children-Africa-Attitudes.

3. Children-Government policy-Africa. 4. Ethnology-Africa. I. Evers, Sandra.

II. Notermans, Catrien, 1966- III. Ommering, Erik van.

GN645.N675 2011

$305.23096-\mathrm{dc} 22$

2011005132

ISSN 0920-8607

ISBN 9789004204003

Copyright 2011 by Koninklijke Brill NV, Leiden, The Netherlands.

Koninklijke Brill NV incorporates the imprints Brill, Hotei Publishing,

IDC Publishers, Martinus Nijhoff Publishers and VSP.

All rights reserved. No part of this publication may be reproduced, translated, stored in a retrieval system, or transmitted in any form or by any means, electronic, mechanical, photocopying, recording or otherwise, without prior written permission from the publisher.

Koninklijke Brill NV has made all reasonable efforts to trace all rights holders to any copyrighted material used in this work. In cases where these efforts have not been successful the publisher welcomes communications from copyright holders, so that the appropriate acknowledgements can be made in future editions, and to settle other permission matters.

Authorization to photocopy items for internal or personal use is granted by Koninklijke Brill NV provided that the appropriate fees are paid directly to

The Copyright Clearance Center, 222 Rosewood Drive, Suite 910,

Danvers, MA 01923, USA.

Fees are subject to change. 


\section{Contents}

Acknowledgements

Ethnographies of Children in Africa: Moving beyond Stereotypical Representations and Paradigms

Sandra J.T.M. Evers, Catrien Notermans \& Erik van Ommering

1 Bending the Generational Rules: Agency of Children and Young

People in 'Child-Headed' Households .

Diana van Dijk

2 Using a "Kids Club Method" to Understand Experiences of Children Orphaned by AIDS in North-Central Namibia

Mienke van der Brug

3 Understanding Children's Well-Being and Transitions Through the Life Course: A Case from Ethiopia

Yisak Tafere

4 Kinning in the Imagination: Perceptions of Kinship and Family

History among Chagossian Children in Mauritius

Sandra J.T.M. Evers

5 From Home to the Street: Children's Street-ward Migration in

Cape Verde

Lorenzo I. Bordonaro

This is a digital offprint for restricted use only | ( 2011 Koninklijke Brill NV 
6 Gendered Work and Schooling in Rural Ethiopia: Exploring Working Children's Perspectives Tatek Abebe

7 In Between the Netherlands and Morocco: 'Home' and Belonging of Dutch Moroccan Return Migrant and Abandoned Children in Northeast Morocco

June de Bree, Oka Storms \& Edien Bartels

8 The Learning Experiences of Refugee and Asylum-Seeker Children: A Model for Meaningful Learning Cilel Smith

9 Reconceptualising Child Protection Interventions in Situations of Chronic Conflict: North Kivu, DRC

Claudia Seymour

10 Agency, Resilience and the Psychosocial Well-Being of Caregiving Children: Experiences from Western Kenya Morten Skovdal

About the Authors 269

Index 


\section{Acknowledgements}

This volume is based on a selection of papers presented at the 2008 conference, "African Children in Focus: A Paradigm Shift in Methodology and Theory?" organized by NVAS (Netherlands African Studies Association).

We would like to express our gratitude to WOTRO Science for Global Development and International Child Support for their funding. The African Studies Centre (ASC Leiden), and Marieke van Winden in particular, offered valuable logistical assistance during the conference and its aftermath leading up to this publication.

Thank you to Caroline Seagle for the English editing of the chapters.

Amsterdam, 2011.

Sandra J.T.M. Evers (VU University Amsterdam)

Catrien Notermans (Radboud University Nijmegen)

Erik van Ommering (VU University Amsterdam) 



\title{
Ethnographies of children in Africa: Moving beyond stereotypical representations and paradigms
}

\author{
Sandra J.T.M. Evers, Catrien Notermans \& Erik van Ommering
}

\section{Introduction}

"Children should be seen, and not heard"

The above maxim, though representing a Victorian value, was commonly pronounced in family homes up until a half century ago. It is based on the principle that a well-behaved child is a child who does not bother adults or disrupt their conversations. While such approaches have evolved considerably since then, in mainstream social science theory, children's voices usually are not heard. Wallowing as it were in a phase of innocence, immaturity and dependence on adult care and protection, children continue to be largely deemed unfit as sources of scientific inquiry. This notion that children are constantly in a 'developmental' stage has its roots in the 19th century; movements contending against child labour in favour of compulsory basic education inspired an interest in children within academic spheres, and research was institutionalised primarily in the pedagogical and paediatric disciplines. In this setting, Freud's ideas were launched, drawing unprecedented attention to the subjective experience of children and sparking questions of how to best raise a child, how 'normal' childhood could be defined, and what developmental stages children

This is a digital offprint for restricted use only | (c) 2011 Koninklijke Brill NV 
have to pass through in order to become responsible adults (LeVine 2007; cf. Hardman 2001). Followed by the influential cognitive theories of Piaget and the socio-cognitive formulations of Vygotsky in the 1960s, Western-based psychological approaches to the study of children and childhoods, albeit subject to fundamental internal critique and revision, continue to influence academic and public discussion today (Hardman 2001; LeVine 2007; cf. Woodhead \& Faulkner 2008).

The 1920 s marked an increased anthropological interest in the cultural variations of childhood across the globe. Notably Margaret Mead (1928) and Bronislaw Malinowski (1929) set the stage for an unremitting critique of universalist, psychological explanations of childhood, drawing on evidence of wide cross-cultural variations in experiences of childhood. Throughout the twentieth century, but particularly in the 1990s, this uneasy relationship between anthropology and psychology evolved. LeVine (2007) offers an important anthropological critique of psychologists' scant empirical base for generalising and interpreting childhood; he notes that, according to the UN Population Division (2005, in ibid. 2007, 250), in 2000, 88 percent of primary school-aged children globally lived in less developed regions of the world. Despite this claim, most psychological studies of children are conducted in the United States and a few other Western countries; as LeVine argues: the "resulting knowledge deficit has not been recognised by the child development research field" (ibid. 2007, 250). Resolving this crucial knowledge disparity through the study of children in non-Western contexts only became an impetus for research in the last two decades. In this regard, the current volume contributes to this project by offering extensive ethnographic analysis of children in various African contexts.

Over the course of the 2oth century, anthropologists have devoted their attention to such diverse child-related subjects as initiation rituals, parent-child relationships, infancy, play, education and learning, parental care, language, social relationships and participation, migration, illness and disability, child abuse, and violence (for extensive literature reviews see Lancy 2008; LeVine 2007; Montgomery 2008). While anthropological interest in children's perspectives can be traced back to Hardman in 1973, such an approach intensified in the 1990s following the work of sociologists James and Prout (1990) and Stephens (1995), amongst others. However, many authors agree that anthropol- 
ogy's potentially crucial contribution to the study of children has only begun to be realised (LeVine 2007, 255; cf. Hardman 2001; James 2007; Uprichard 2010).

Contributions to this publication thus unequivocally argue for an anthropology of children in which children's own perceptions are at the centre of analysis, ethical considerations and methodology. Such a focus is likely to benefit theoretical apprehension of children's lives. It is our epistemological stance that children are active interpreters of culture, simultaneously being socialised into and architects of their local social and cultural settings. We argue that the concept of a child should be defined within specific relational, cultural and local contexts, wherein categories such as age, gender and the criteria for defining a child vary considerably. As a result of the subjective experience of childhood across the globe, we consciously reject attributing age boundaries to what we conceptualise as 'the child'.

African children have historically remained on the margins of social and anthropological studies. They are often depicted as victims of war, poverty and illness, and not as agents who creatively deal with the possibilities and constraints of social life. This book offers a chance to learn more about African children's own ideas and experiences in a variety of contexts. Such an approach that takes children's perspectives and ethnographies as points of departure provides us with a wealth of analytical insights about children's worlds, while also contributing to our understanding of and theorising about adult social worlds. Moreover, implicated in this outlook are reflections on methodological considerations about how to most productively access and represent children's voices and views.

This book consists of ten qualitative studies that explore African children's own perspectives, agencies and interdependencies. We deliberately focus on Africa and on children living in difficult circumstances to counterbalance stereotypical images of the suffering African child needing help from adults. The chapters provide ethnographies of children's life worlds and the strategies they develop to help themselves. Addressing core issues of agency and structure, kinship and migration, knowledge transmission and learning, as well as applied research and ethics, the various chapters aim to give a range of methodological and theoretical insights. 


\section{Conceptualising Children and Childhood}

Across cultures, children are perceived, defined, and treated differently. This relativism has an immediate impact on the ways in which children in varying settings picture themselves, their roles and responsibilities, and their adult community members. As mentioned above, in Western contexts childhood is commonly conceived of as a period of innocence, play, care, and learning. Adulthood, on the contrary, tends to be characterised by labour activities and caring responsibilities. Over the past century, following the 1924 Declaration of Children's Rights, these rigid categories have become increasingly universalised and institutionalised, culminating in all but two UN member member states' ratification of the 1989 UN Convention on the Rights of the Child (CRC). Viewing the CRC as "by far the most fully endorsed product of UN efforts establish global standards for human life," Jason Hart $(2006,5)$ juxtaposes this endeavour with the anthropological project of enhancing "appreciation for the diversity of children's lives and childhood experience."

By drawing on an in-depth understanding of diverse African contexts, the current book demonstrates how international development organisations (including UN agencies) adhere to conceptions of childhood to the detriment of gaining deeper insight into the primordial roles children play within the societies in which they live. In chapter 1, Van Dijk critically discusses the Western-biased concept of childhood in her study of child-headed households. She demonstrates that using the (Western) concept of childhood, which defines a child as being under the age of 18 , can be problematic within African settings. She shows that while 'child' heads of households may be older than 18 , donors tend to continue labelling them as 'children' as they prefer to sponsor 'child-headed' households. Even in households where the heads are indeed younger than 18 , children perform tasks that are considered 'normal' for their age in the local setting though are viewed as 'child labour' in Western societies. There is thus a tension between needing both to be seen as independent (adults) in control of the household and dependent (children) in need of support from relatives and development organisations. The author found that appreciation of this local reality is not reflected in universalist definitions of the child and related desired or appropriate living conditions laid out by international organisations.

This is a digital offprint for restricted use only | ( 2011 Koninklijke Brill NV 
As with Van Dijk's study, authors of other chapters also view their research groups from this new paradigm of children as agents who navigate between structural constraints, hardships of daily life, their societal roles, and relations with peers and adults. Such a child-oriented approach does not imply a passive acceptance of potentially difficult circumstances children encounter, but rather a reassessment of what it means to be a child under such conditions, accounting for the manifold ways in which children are able to make a living, choose, act, and build resilience. As Morten Skovdal argues in chapter 10, the degree to which children and the challenges they face are conceptualised in Western terms sends an implied message to non-Western children that their own cultural repertoires and resources are not appropriate. Thus, it is not merely an ethical consideration to respect and assess the variation in human means of coping and sense-making across the globe, it is also a very practical tool that could improve the lives of children in need. Before intervening in children's lives, one first needs to understand how need is defined by the children involved, how children are capable of maintaining and improving their well-being, and how they find ways of coping and drawing upon resources that enable them to contribute to their own, and to their community's, survival. Self-evidently, it is also in the interest of academic knowledge production to consider locally produced social, cultural, political, and economical realities as opposed to perceiving these realities through the lens of child-protection or victimological representations.

True appreciation for children's lives does not begin by reading the CRC preamble, which states that the child "should grow up in a family environment, in an atmosphere of happiness, love and understanding," wherein a "spirit of peace, dignity, tolerance, freedom, equality and solidarity" is cultivated; nor is it shaped by defining children as 'at risk', 'vulnerable', or 'depressed'. ${ }^{1}$ Rather, we should be aware of the realities in which the majority of the world's children find themselves: a world in which children actively contribute to household economies, fulfil community tasks, and take on responsibilities that-in the West-would be considered inappropriate or problematic or anathema to

\footnotetext{
${ }^{1}$ Convention of the Rights of the Child, http://www.unicef.org/crc (accessed on 8 February 2010).
}

This is a digital offprint for restricted use only | (c) 2011 Koninklijke Brill NV 
human rights. As exemplified by Skovdal's chapter, we envision understanding children's own perspectives as a precondition for developing interventions aimed at improving their lives.

\section{Methodological Implications of a Child-Oriented Approach}

It was not until the 1990s that an increasing number of social scientists began to acknowledge the importance of studying children in their own right as a means of advancing our understanding of processes of socialisation and enculturation (Tonkin 1982; Frønes 1994; Qvortrup et al. 1994; Caputo 1995; Jenks 1996; Jenks 1996; Corsaro 1997; James 1998; Panter-Brick 1998; James, Jenks \& Prout 1998; Toren 1999; Christensen \& James 2000; Panter-Brick \& Smith 2000). By recognising children's world-views as meaningful to the academic endeavour, a rapidly growing field of interest developed under the heading of 'child-focused', 'child-centred' or 'child-oriented' research (used interchangeably here). While the majority of child-oriented literature involves children in the research design, research with children, as opposed to research on or about children, is still far from established (cf. Christensen and James 2000: 1). The present book seeks to advance this perspective, thereby primarily drawing on ethnographic research.

While the relevance of child-oriented studies can hardly be disputed, the ways to proceed methodologically are still subject to intense debate. Over time, several methods have been developed which are often labelled 'child-centred' and aim to stimulate children's participation in, and ownership of, the research process (cf. James 2007; Christensen 2008). However, as Samantha Punch (2002, 321) rightly wonders, if we stress children's positions as competent social actors, why would we need special 'child friendly' methods to communicate with them? Do we not run the risk of paternalising our research subjects when besieging them with sets of pencils, disposable cameras and diaries, instead of conducting in-depth interviews, life history exercises and participant observation? Would it even be worthwhile to design and formulate child-oriented research when, as adults, we would not even be able to grasp children's views? The chapters of this book reveal that due reflection on methodological 
quandaries must be central to any child-oriented study. The structuring and formation of theory and methodologies in child-oriented research are necessarily intertwined; thus development of paradigms on how children are conceived and studied should involve careful reflection on this interrelationship. Some key issues will be outlined below.

\section{Conceptualising Children in Methodology}

Over time, three scholarly perspectives have emerged within the field of childoriented research: scholars who see children as indistinguishable from adults, those who regard children as essentially different, and those who "perceive children to be similar to adults but to possess different competencies" and thus require adapted research methods (Punch 2002, 322). The problem with the first perspective is the obvious neglect of inherent power differences between adult researchers and child subjects. The second view, in turn, lacks research techniques that guarantee a full grasp of children's perspectives, as this supposedly remains impossible for adult researchers. The third conceptualisation seems to offer the most viable outlook, as it claims to command innovative methods capable of bridging the gap between adult and child perspectives while simultaneously accounting for power imbalances inherent to such relationships (ibid., 322-323). In addition to these adapted forms of participant observation, other innovative methods include pictures and diaries, sentence completion and writing, drawing, draw and write exercises, and various kinds of creative workshops (Punch 2002; O'Kane 2008). The authors of the various chapters in this collection draw on these innovative methods, reflect on them, offer critique, and propose alternatives and adjustments. Here, we will examine two methodological themes that recur throughout the book and are deemed essential to a child-oriented research design. These include dealing with both adult-child power discrepancies and challenges of interpretation and representation (or reliability) of data obtained from children. 


\section{Power}

In primarily "Western," adult-centred societies, children are often characterized as 'in development', 'immature', 'not yet entitled to vote', 'school aged', 'the next generation', or 'the future'. The deterministic nature of such categorizations reflects certain knowledge regimes about children. Raised within such regimes, children quickly learn to conceptualise themselves as categorically different from adults. This, in turn, affects how children produce and maintain their own subcultures, and the ways in which they are socialised and socialise themselves in opposition to adult members of society. Although these strategies vary across time and place, for an adult researcher, it is probable that she/he will encounter research subjects who will act according to culturally informed/ascribed notions of proper child-adult behaviour. Children commonly acknowledge that adults are, to varying degrees, in charge of their lives and must be obeyed or pleased. In other words, adults exercise power in terms of acting, defining and representing the world in ways that overrule children's own perceptions (cf. Kuik 1996). Therefore, for any adult researcher, it is critical to reflect on power disparities and on how these may affect, through research relationships, the generation of data and the production of knowledge. Although the same applies to researchers who work among adults, this should be of extra concern in child-oriented work in order to do justice to diverse cultural notions of childhood and adulthood.

\section{Interpretation and Representation}

As mentioned earlier, in adult-centred societies, it remains common to think of children's perceptions and ideas as unreliable or insignificant. As confirmed by the chapters in this book, recent literature on child-oriented ethnography has highlighted the value of taking children's perspectives seriously and acknowledging the (implicit) social and cultural roles and responsibilities that children have in constructing and changing society as a whole. Acknowledging their value for understanding wider social worlds, how do we elucidate children's perspectives? And how should researchers interpret and represent them? After addressing communication barriers between adults and children, the researcher 
needs to employ techniques that are capable of capturing children's perspectives. Yet how can these perspectives be integrated into theories originating from studies designed by adults? This obviously is not an easy task.

Students in anthropology and other social sciences are trained to formulate theory on the basis of data obtained from adults (Downe 2001). In doing so, they mainly depend upon verbal and textual resources (e.g. in-depth interviews or questionnaires). The chapters in this volume examine to what extent childoriented research methods are fit for producing data that can be transformable into text-based theory. In view of children's relatively short attention span and their limited or different vocabulary and understanding of words (Punch 2002: 324 ), the authors in this book adopt a wide range of unconventional and innovative methods to research children's views. Some examples include the Kids Club Method (chapter 2) and the development of board games (chapter 8).

As extended interview sessions and other conventional research techniques do not always allow researchers to fully grasp children's views, we are left with the challenge of making sense of children's non-verbal expressions, such as drawing, play, chatting, movements, and imagination. Nowadays, it is common practice to present children with drawing or photography exercises that, in turn, act as heuristic instruments or points of departure for children's verbal reflections. Yet such approaches again rely on the presumption that verbal data is of prime importance. Moreover, it remains problematic for adult researchers to translate child-produced understandings into common adult-centred and text-based academic understandings.

Psychologists, art therapists and social scientists have developed a range of visual techniques to capture children's world-views and perceptions. As Clark $(1999,40)$ mentions, it is often claimed that "(visual methods), in contrast to verbal interviews or written surveys (...), do not give a 'communicative advantage' to the adult researcher." However, such methods greatly increase opportunities for getting a clearer sense of what children think (Wagner 1999). By drawing upon visual resources, ethnographers are provided with "an opportunity to rethink anthropological knowledge in the light of understandings that may be accessible only by nonverbal means" (MacDouhall 1997, 292). A vital example hereof is provided by Van der Brug who, in dealing with sensitive issues such as AIDS and dying, managed to gather data through non-verbal 
elicitation techniques like drawing and art, precisely by establishing a Kids Club where she convened with the children on a regular basis. The Kids Club allowed children to be in a pleasant environment and enjoy playing and participating in the research.

Lisa Mitchell $(2006,61)$ argues that visual methods can be a valuable tool when seen as social, rather than individual, creations, and as "sites of cultural production, rather than as mere reproduction." Methods like drawing tend to be familiar and relatively non-intimidating to children, as well as being enjoyable. Furthermore, such methods may minimise power imbalances between an adult researcher and child informants, as children can engage in drawing exercises on their own, without direct contact with the researcher. However, upon critically examining claims about the child-centredness of visual methods, Mitchell (ibid., 62) argues that we should be aware that such methods "may be tied to both adult-ist and North American-centric assumptions about drawings and about children." In turn, non-verbal methods might not be straightforwardly applicable across cultures. Moreover, based on fieldwork in the Philippines, Mitchell (ibid., 70) concludes that visual techniques may "turn out to reveal as much about adults as they do about children." Through drawing exercises and a very careful analysis of the modes of production and consumption of these images, she was reminded that "broad social and economic patterns of inequality and paternalism and enduring legacies of colonialism are inseparable from the local production of drawings, even those done by children" (ibid., 69). Thus, drawing is not an innocent, child-oriented tool of research. It is infused with relationships of power, authority and difference between the adult researcher and the child. This needs to be acknowledged and integrated into the analysis. Such reflections call for a need to understand children not as isolated objects of analysis, but rather in relational terms: relative to their parents, peers and social and economic histories.

Similarly, insights derived from children's projective exercises in chapter 3 by Yisak Tafere demonstrate how children's perspectives deviate from those of their adult caregivers. The author argues that "parents tend to be out of touch with the lives of their children," a condition that imposes negative consequences on children's well-being. Tafere analyses verbal and non-verbal accounts of children in a meticulous study of the relationship between self-perceived 
well-being and key life transitions. He adopts a longitudinal 'life course' approach to integrate children's self-perceived well-being and well-becoming. Employing participatory methods such as individual and group interviews, body mapping, well-being exercises, and 'life-course-draw-and-tell' projects, the chapter investigates how educational transitions are affected by illness related to children's socio-economic status. Innovatively, Tafere adopts selfreporting methods through which children are allowed to elucidate their ideas and experiences, and demonstrate how these are subject to change. By comparing urban and rural settings, it is outlined how children construct contextualised images of "good" and "bad" life. As such, he confronts the presumption that data retrieved from children tends to be 'unreliable'. In contrast, it is shown that "children remain the best sources of data" when it comes to their own well-being and well-becoming. Thereby, children are not depicted in isolation, but always in relation to their environment that includes relevant adults and change over time.

In turn, Mitchell $(2006,63,69)$ proposes to consciously reflect not only on the content of an image, but also on the conditions under which an image is produced and consumed. In chapter 4, Sandra Evers argues that reflexive drawing techniques could be a valuable analytical tool in which children are not only asked to creatively express their views but also given agency in the interpretation of what they have depicted. This approach indeed showed that children have detailed insights into their family histories and contemporary society in which they live (see also chapter 7). In turn, carefully listening to children's perceptions and interpretations produced valuable research data.

It remains clear that researching children does not necessarily require the use of adopted or inventive methods. Children, like adults, can participate in interviews, answer questionnaires and live with participant observers (Christensen \& James 2008, 2). As it is work rather than play that African children generally share with adults, they may in some settings feel more at ease with formal interviews, reflecting the hierarchical relationship between adult and child, than with playing games with adults (Notermans 2008: 363-4). Depending on the research context and questions, appropriate methods should be adapted in order to better fit children's interests. Researching children should thus always examine the impact of adults within the proximate environment, both in order 
to avoid essentialising the child and out of ethical concerns. Methods, therefore, should mirror this careful reflection on power relations and sensitivities in the research context, and ethics should be a paramount consideration in any research with children. In the various chapters, power relations, ethics and methodological considerations are thus explored.

\section{Shifting from Research on Children towards Research with Children}

Theoretically, we argue in favour of child-centred research as exemplified in the various chapters in this volume. A key theoretical focus is formed by issues of structure and agency in view of children's roles and positions in society.

\section{Structure and Agency}

One of the main concerns of anthropologists in the field of child-oriented studies has been to stress children's agency: their own power to act in, and make sense of, their life worlds. However, it is also clear that children's lives involve both the exercise of agency as well as coping with its constraints due to certain social, cultural, political, legal, physical, or economic structures. Just like adults, children should be approached as humans who constantly interact with, and make sense of, their surroundings; simultaneously, children are also capable of exercising power despite being in situations of being less powerful.

As we disagree with a victimizing approach to African children, we put central emphasis on an agency perspective that attends to children's domains of creativity, inventiveness, resilience, and negotiation (cf. De Bruijn, van Dijk \& Gewald 2007). The pressing question in debating the relation between powerful structures and individual agency is whether individuals have freedom of choice, even in asymmetrical power relations. We must also ask whether individual activity is best described as determined by or determining of socially structured systems of domination. In our approach, we follow theorists such as Foucault \& Gordon (1980), Giddens (1984) and Jackson (2005) who emphasise that power is not the privilege of the dominant class but rather is also exercised by those 
who are dominated. Though children have often been seen as being dominated by powerful adults in social structures, this volume shows that children's life worlds are "the outcome of a dynamic relationship between circumstances over which they have little control and their capacity to live those circumstances in a variety of ways" (Jackson 2005, xi). Children have the power to "make a difference to a pre-existing state of affairs or course of events" (Giddens 1984, 14). While children may face set-backs when confronted with barriers related to their socio-cultural position in certain localities, they can simultaneously take advantage of a particular status attributed to youth whilst bearing responsibilities accordingly. By defining notions of a child as relational to any local context, current research and policy on children might be reassessed within a paradigm that conceptualizes children as 'culture-makers', both in theory and practice.

Lorenzo Bordonaro (chapter 5) explores the phenomenon of street children in Cape Verde by focusing on their relationships with heterogeneous home and street environments. In an analysis of children's decision making processes, Bordonaro shows how children's street-ward mobility involves opportunistic, rather than fatalistic, assessments of potential survival strategies. Children seize the opportunities offered by the street and thus realise a sense of liberty, autonomy and friendship that they would never have achieved at home. Consequently, the street should not be considered a problematic marker of identity, but rather a vital resource that children draw upon to support both themselves and often their peers or family members.

At the same time, Bordonaro is wary not to romanticise life on the streets, as he cautiously examines the worries and difficulties faced by his research subjects. However, he invokes the work of Mats Utas (2005) to note that 'victimcy' can also be quite an effective form of agency. Similarly, Seymour (chapter 9) proposes that to children who have been recruited to armed groups in the Democratic Republic of Congo, "outward expressions of vulnerability-such as recruitment or another form of perceived exploitation-may actually be the child's best means of protecting him or herself." Skovdal (chapter 10), in turn, shows how caregiving children also employ a variety of strategies to negotiate support, among which include displays of poverty or articulations of hunger. Accordingly, he confronts "the dominant discourse that views these children as 
victims in urgent need of psychological support." Correspondingly, Van Dijk (chapter 1) argues that children in child-headed households strategically play the victim by stressing their young age and suffering in order to get support.

Abebe (chapter 6) also points to the importance of children in the provision of food for themselves and relatives. He discusses children's perspectives of gendered work and schooling in rural southern Ethiopia, where subsistence agriculture has for generations met basic household needs. Drawing on childoriented ethnographic fieldwork, Abebe explores the social meaning boys and girls attribute to work, as well as how children combine work with schooling. The chapter situates children's work at the heart of family and community livelihood strategies, analysing the complex ways in which their material social practices are closely intertwined with processes of development and rapid sociocultural change. Abebe argues that paternalistic approaches that view working children as simple victims are not only unhelpful analytically but also from a policy point of view. They undermine the capacities and meaningful contributions children make to their families while simultaneously concealing how, through work, children can improve their social and economic independence, attend school, gain self-esteem and increase their potential for upward social mobility. By calling for a holistic approach to child labour, the chapter finally draws analytical attention to children's perspectives and experiences of work, how work is constructed differently geographically and how it reflects changes in the local, regional and global political economy.

In addition to the chapters mentioned above, several submissions stress the importance of understanding the roles of kinship and family configurations in child-oriented research. Children live their lives and make their choices in relation to older and younger relatives and peers. Though the African family has often been depicted as a place of safety and support, children are also quick to convey the problems and conflicts happening within families, and the ways in which they cope with them. Due to fosterage, migration, poverty, illness, or death, it is not unusual for children in Africa to grow up in households where their parents are physically absent. In a study on child fosterage in Cameroon, Notermans (2008) argues that we need children's information, not only to understand their own life worlds but also to reach a more complete and refined understanding of power relations between adults and children as well 
as among adults. Whereas adults in her study often described their family life as an ideal manifestation of African kinship, children rarely did the same. They expressed how kinship is experienced, what emotions were involved, or how hurt they felt when being separated from their mother $(2008,356)$. Children's narratives often reveal the various tensions and conflicts in family homes and kin networks that adults prefer to conceal: conjugal troubles, divorce, co-wife competition, illness, death, migration, witchcraft accusations, and other stressful situations fraught with painful feelings of sorrow and insecurity. These conflicts in fact highlight the power relations children have to deal with in their daily lives.

Though issues of migration recently received considerable scholarly attention, there is very little literature directed towards children's stories and experiences in relation to migration. Processes of migration are deeply embedded in family livelihood strategies in various African contexts (Findley 1997). The current system of global capitalism encourages the separation of parents and children, wherein adults from developing countries work in developed countries while their non-productive family members (the elderly and children) stay at home (Coe 2008, 224). Studies focusing on children's stories show that children articulate a more critical and emotional view of family separation than has been obtained in predominantly adult-oriented approaches (Coe 2008; Olwig 1999). In particular, Coe (2008: 225) argues that parents and children in Ghanaian transnational families have different notions of an idealized parent-child relationship and react differently to painful disconnections in the scattered family. Olwig $(1999,281)$ in turn shows that, in similar situations, children miss their parents and remain strongly dependent upon having a continual relationship with them.

In chapter 7, De Bree et al. draw attention to return migrant and abandoned children, who have been largely neglected in research. The chapter explores how Dutch Moroccan return migrant and abandoned children in Morocco construct notions of 'home' and 'belonging'. As these children often grew up in the Netherlands, the question arises as to whether they are able to feel 'at home' upon return to Morocco. The authors discuss children's agency in their constructions of 'home' and 'belonging', and how they reflect on their lives and cope with hardship and future aspirations. Similarly, in her discussion of 
Chagossian children in Mauritian migrant society, Evers (chapter 4) explains how children actively play a role in constructing an 'imagined community' of Chagossians living in diaspora since their eviction from the Chagos archipelago.

The centrality of children's backgrounds, reflections and aspirations in understanding children's worlds and lives is also demonstrated in the work of Smith (chapter 8). This chapter focuses on the learning experiences of refugee and asylum-seeking children within English schools. It explores children's learning experiences pre-, during and post-migration, and examines both circumstantial and consequential influences. Special attention is given to the way in which educators and children perceive of education and learning. Due to her dissatisfaction with the standard assessment tools and educational scaffolds to integrate the children in the schools and learning process, Smith developed board games which were adapted to the children's backgrounds, thus offering an innovative and child-oriented way of better assessing and teaching children who are newcomers to British society.

\section{Applied Research}

Smith's work is an excellent model of textured, qualitative research which is successfully translated to serve applied aims, as the data collected with the board games currently informs policy making for migrant children in British schools.

Chapter 9 by Claudia Seymour offers another example of how scientific research (in this case an anthropological study) is useful in enhancing understanding not only of the lived realities of children in conflict zones such as the Democratic Republic of Congo (DRC), but also of the ways in which efforts by international child protection actors may hamper, rather than improve, the well-being of children who have been recruited to the armed forces. Drawing on years of experience as a practitioner with various UN organisations in Liberia, the Central African Republic and the DRC, Seymour sets out to examine why, "despite a massive mobilisation of resources and generally good intentions, (...) the aims of child protection interventions are so rarely achieved." Child recruitment continues to confront international child protection actors with quandaries as to how to understand this phenomenon and tackle it in 
more effective ways. Seymour argues that, in order to achieve these ends, it is fundamental to re-assess the presumptions that underpin conceptualisations of children's lives amidst war. She employs anthropological and psychological literature to show how root socio-economic, cultural and historical factors of (voluntary) recruitment are generally disregarded as they stand in strong opposition to Western conceptualisations of the child as an innocent and passive victim of warfare (cf. Hart 2006, 6). Instead, Seymour draws on a wealth of empirical data to demonstrate that, as Hart (ibid., 7) puts it, "children are resourceful and develop the necessary competencies to deal with their environments." It is thus clear that young children do have a "capacity for choice" which has often been denied by policy makers and academics alike (ibid., 7). Again, it is reiterated that the mismatch between children's lived realities and the ascribed, normative presumptions of child protection actors poses fundamental ethical questions related to the latter's functioning in conflict zones, such as the Democratic Republic of Congo and elsewhere. Crucially, Seymour demonstrates that unveiling the choices that children face does not imply doing away with humanitarian interventions altogether; rather, she points to a fundamental paradigm shift that is required in order to design and implement such interventions.

Morten Skovdal (chapter 10) focuses on yet another poignant development that deserves ample attention: the devastating HIV/AIDS epidemic (see also Van den Brug's chapter). Skovdal employs participatory action research methods to develop culturally appropriate interventions aimed at directly empowering care giving children in Kenya. Skovdal touches upon the above mentioned opposing conceptualizations of childhood whilst reflecting on conflicting notions of childhood among Lua adults. Some of these adults have come to regard childhood as a 'time of duty and service', whereas others adhere to more Westerninformed conceptualisations of children as in need of schooling. Luo children, on the other hand, value the reciprocal nature of child-adult relationships; children give respect and live up to their responsibilities as helpers, while adults are seen to provide good advice and honesty. Accordingly, children construct positive identities that facilitate 'psychosocial coping and well-being', while simultaneously mobilising a variety of social support networks. 


\section{Conclusions}

To this day, children's perceptions and ideas are often viewed as unreliable or insignificant. African children have historically remained on the margins of social and anthropological studies or have been depicted as victims of war, poverty and illness and not as active agents who creatively deal with the possibilities and constraints of social life. This view, which is evolving, nevertheless belies the very adult realities, responsibilities and roles in the day to day lives of many children, particularly in non-western settings. Children can be heads of households or have fundamental social positions that would suggest they should prove invaluable sources of data as informants and first rank participants in research. Furthermore, because children are part and parcel of the construction of social and cultural configurations, research with children can provide insight into such societal processes.

Indeed our intent has been to underscore the value of taking children's perspectives seriously and acknowledging the (implicit) social and cultural roles and responsibilities that children play in constructing and changing society. Our examination of the issues set forth herein are meant to stimulate the development of methodology and ethical consideration in work with children, and to develop theory that goes beyond the image of African children as mere victims of societal harms.

\section{Bibliography}

Caputo, V. (1995), Anthropology's silent 'others': A consideration of some conceptual and methodological issues for the study of youth and children's cultures. In: V. Amit-Talai \& H. Wulff, eds, Youth cultures: A cross-cultural perspective. London: Routledge.

CoE, C. (2008), The structuring of feeling in Ghanaian transnational families. City \& Society 20(2): 222-250.

Corsaro, W.A. (1997), The sociology of childhood. Thousand Oaks, London \& New Delhi: Pine Forge Press.

Christensen, P. \& A. James, eds, (2008), Research with children. Perspectives and practices. New York \& London: Routledge. Second edition.

De Bruijn, van Dijk \& J.B. Gewald, eds, (2007), Strength beyond structure: Social and historical trajectories of agency in Africa. Leiden: Brill.

Findley, S. (1997), Migration and family interactions in Africa. In: A. Adepoju, ed., Family, population, and development in Africa. London: Zed Books. 
Foucault, M. \& C. Gordon, eds, (1980), Power/knowledge: Selected interviews and other writings 1972-1977 Michel Foucault. New York: Pantheon Books.

Frønes, I. (1994), Dimensions of childhood. In: J. Qvortrup, M. Bardy, G. Sgritta \& H. Wintersberger, eds, Childhood matters. Social theory, practice and politics. Avebury: Ashgate Publishing Limited.

Giddens, A. (1984). The constitution of society: Outline of the theory of structuration. Cambridge: Polity Press.

Hardman, C. (2001), Can there be an anthropology of children? Childhood 8(4): 501-517.

Hart, J. (2006), Saving children. What role for anthropolgy? Anthropology Today 22 (1):5-8.

Hirschfeld, L.A. (2002), Why don't anthropologists like children. American Anthropologist 104(2): 611-627.

JAMES, A. (1998), From the child's point of view: Issues in the social construction of childhood. In: C. Panter-Brick, ed., Biosocial perspectives on children. Cambridge: Cambridge University Press.

- (2007), Giving voice to children's voices: Practices, and problems, pitfalls and potentials. American Anthropologist 109(2): 261-272.

James, A. \& A. Prout, eds, (1990), Constructing and reconstructing childhood: Contemporary issues in the sociological study of childhood. London: Falmer Press.

James, A., C. Jenks \& A. Prout (1998), Theorizing childhood. Cambridge: Polity Press.

Jenks, C. (1996), Childhood. London: Routledge.

JACKsON, M. (2005), Existential anthropology: Events, exigencies, and effects. New York, Oxford: Berghahn Books.

KIRK, S. (2007), Methodological and ethical issues in conducting qualitative research with children and young people: A literature review. International Journal of Nursing Studies 44: 1250-1260.

KuIK, S. (1996), Mag ik op je rug? Van de kinderen en hun dagen met vriendschap en ruzie. Amsterdam: Het Spinhuis.

Malinowski, B. (1929), The sexual life of savages in North Western Melanesia. London: Routledge.

Mead, M. (1928), Coming of age in Samoa. New York: William Morrow.

Mitchell, L.M. (2006), Child-centred? Thinking critically about children's drawings as a visual research method. Visual Anthropology Review 22(1): 60-73.

Notermans, C. (2008), The emotional world of kinship: Children's experiences of fosterage in East Cameroon. Childhood 15 (3): 355-377.

O'Kane, C. (2008), The development of participatory techniques. Facilitating children's views about decisions which affect them. In: P. Christensen \& A. James, eds, Research with children: Perspectives and practices, pp. 125-155. London: The Falmer Press. Second Edition.

Olwig, K.F. (1999), Narratives of children left behind: Home and identity in globalised Caribbean families. Journal of Ethnic and Migration Studies 25(2): 267-284.

Panter-Brick, C., ed., (1998), Biosocial perspectives on children. Cambridge: Cambridge University Press.

Panter-Brick, C. \& M. Smith, eds, (2000), Abandoned children. Cambridge: Cambridge University Press.

Punch, S. (2002), Research with children. The same or different from research with adults? Childhood 9(3): 321-41.

Qvortrup, J., M. Bardy, G. Sgritta \& H. Wintersberger, eds, (1994), Childhood matters. Social theory, practice and politics. Avebury: Ashgate Publishing Limited.

Stephens, Sharon, Ed, (1995), Children and the Politics of Culture. New Jersey: Princeton Press.

Tonkin, E. (1982), Rethinking socialization. Journal of the Anthropological Society of Oxford 13(3): 243-256.

Toren, C. (1999), Why children should be central to anthropological research. Etnofoor 12(1): $27-28$. 
UprichaRd, E. (2010), Questioning research with children: Discrepancy between theory and practice? Children and Society 24: 3-13.

UTAS, M. (2005), Victimcy, girlfriending, soldiering: Tactic agency in a young woman's social navigation of the Liberian war zone. Anthropological Quarterly 78(2): 403-430.

Woodhead, M. \& D. Faulkner (2008), Subjects, objects or participants? Dilemmas of psychological research with children. In: P. Christensen \& A. James, eds, Research with children: Perspectives and practices, pp. 10-39. London: The Falmer Press. Second Edition.

Young, L., \& H. BARretT (2001), Adapting visual methods: Action research with Kampala street children. Area 33 (2): 141-152. 


\section{Bending the Generational Rules: Agency of Children and Young People in 'Child-Headed' Households}

Diana van Dijk

\section{Introduction}

Since the late 1980s, awareness has grown about the negative impacts of the HIV epidemic on children. Although the focus was first on children who were orphaned due to HIV, international attention shifted to 'orphans and vulnerable children' during the 1990 os because the problems children experience are not necessarily related to orphanhood. Among those perceived as most vulnerable are children living outside parental, adult or family care, such as in the case of child-headed households. Because of the expected increase in the number of child-headed households in sub-Sahara Africa, there has been much discussion about an appropriate response. ${ }^{1}$ These discussions focus largely on the question

\footnotetext{
1 The expected increase in the number of child-headed households is related to the peak in HIV-related deaths which is still to come. For more discussion see van Dijk $(2008,6)$.
}

This is a digital offprint for restricted use only | ( 2011 Koninklijke Brill NV 
of whether such households are an alternative option for (orphaned) children as opposed to foster care by the extended family, foster families or institutions. However, little is known about how children cope in child-headed households, how they experience their lives, or simply how they manage to get food on the table. In order to be able to provide appropriate support to child-headed households, insights are needed about children's own views and experiences and the ways they cope in this regard. This chapter focuses on a study on children's coping mechanisms in child-headed households in Port Elizabeth, South Africa. Let me first introduce one of the child-headed households I studied, the household of Aidan.

When I first met Aidan in 2004, he was eighteen years old and had been living with his two younger brothers (14 and 11) after their mother died about six months earlier. His two brothers had a different biological father. They resided in quite a large house, which had belonged to their maternal grandparents. The house was in a reasonably good state, although there was not much furniture. Aidan had a few items of his deceased grandparents and mother, among which two porcelain cups which he was very careful with. He slept with his brothers in the smallest bedroom, in which the walls were filled with drawings. Two bedrooms were rented out, one of which formerly belonged to his deceased mother. The kitchen had a stove, a defect fridge and some cooking utensils. However, he appeared not to use the kitchen often. Whenever I asked Aidan what he had cooked for himself and his brothers, he said that he was not able to cook for himself or them and that they often went to bed hungry.

At first I assumed that Aidan was no longer supported by or in contact with his relatives. However, I soon discovered that they were supported somewhat by their mother's sister, who bought them groceries every month. Aidan did not receive the rent from the tenants living in his house because his aunt argued that the house belonged to her. Aidan also received some financial support from his brothers' father, and one Child Support Grant (CSG) for his youngest brother. The groceries the aunt brought and the financial support were nonetheless not enough to last for a month. When they ran out of food, Aidan would send his brothers to ask for food from the neighbours. According to him, his brothers were still young and would cry when they would have nothing to eat. Aidan would try not to think about it and go to sleep when he was hungry.

Aidan was not particularly happy with the tenants in his home. His aunt did not consult the boys before she rented out the two rooms of the house. According to Aidan, she informed him about her plans, but did not listen when Aidan said he did not like the idea. He explained me that one of the tenants was an adult woman who bossed him around and often invited many friends or relatives. The other tenant was a young man who kept to himself. Although 
both tenants used the kitchen and cooked their food, they never shared it with the boys. Aidan said he felt a stranger in his own home as a result.

To make matters worse, at one point his brothers were taken to live with his aunt without his knowledge. While Aidan was absent for two weeks to visit relatives in a rural area in 2005, his two younger brothers stayed with her. However, when Aidan returned, she said that they would remain in her care. She did not discuss the matter with Aidan, but refused to bring the two boys back. According to her, Aidan could not take proper care of his brothers. Aidan, however, told his aunt he wanted his brothers to move back in with him. Aidan not only lost the company of his brothers, but also the access to support. His aunt did not bring him groceries any more, as she told him he was old enough to provide for himself. He also lost the financial support of the biological father and he was no longer eligible for a CSG.

Aidan said that he wanted the brothers to move back because he really missed their company. Aidan's aunt sent one brother back to him, after two and a half years of living separately. At that time the brother was 17 and had started disrespecting his aunt's authority and smoking marijuana. Put differently, because he started to misbehave, the aunt decided that Aidan had to deal with him. It seems therefore that she was not primarily concerned with the children's best interests. Other relatives of Aidan were also not very helpful. Aidan's biological father resided in another province and Aidan had not spoken with him for years. Relatives of his father's side or his mother's other relatives did not help him.

Several issues arise from Aidan's case. First of all, Aidan was 18 years old when his mother died, and according to most definitions, his household is not regarded as child-headed. A very common definition of the child-headed household is a household in which all the members are under the age of 18 (the age of majority in many countries, including South Africa). This means that when the oldest 'child' is over the age of 18 , the household is no longer considered child-headed. Being legally adult, however, does not mean that one is perceived of as an adult by others. In Aidan's case, for example, his aunt did not consider him an adult with whom she had to discuss and share things. She did not consult him about the care of his brothers, the tenants in his home, or the support he needed.

At first, it seemed that Aidan was getting support from his aunt, who visited the children every week and brought them groceries. This observation follows most assumptions that the extended family and community serve as (traditional) safety nets for orphaned children. However, numerous authors have pointed to the fact that 'traditional' family and community life have changed drastically 
in sub-Saharan Africa, due to demographic and social transformations (such as migrant labour, rapid urbanisation and modernisation) (NMCF 2001). The question is therefore whether these structures can still be expected to fulfil the supporting role they are attributed. Some authors argue that the extended family and community still fulfil this role but that the nature of the support may have changed. In this line of reasoning, child-headed households are sometimes referred to as a "new coping mechanism of the extended family" (Foster et al. 1997). Foster was the first person to make this point, as his research on child-headed households in Zimbabwe showed that most households are supported and visited by extended family members. However, the nature of these visits and the quality of the support remains unclear in Foster's study. As is already clear in Aidan's case, although children may seem to be supported by relatives, this support is not necessarily stable or sufficient.

Another issue related to viewing child-headed households as a "new coping-mechanism" of the extended family is that children are reduced to being objects of coping, instead of subjects who are themselves coping. Relatives or community members may think that a child-headed household is coping very well; however, only considering the coping outcomes for children is problematic, as it may merely reflect the view of whoever is judging the situation (Kabeer 2005, 440). When children do not have a say in the form of support given or are not consulted about care arrangements, what judgement can be made about their coping practises? In order to be able to provide appropriate support to child-headed households, insights are needed into children's own perceptions and coping strategies, and particularly the amount of agency children have in these situations. For the purposes of this study, agency is defined as the "ability to make and act on their own life choices, even in the face of others' opposition" (Kabeer 2005, 14). However, children's agency is not necessarily straightforward or recognisable as such. According to Kabeer (2005, $14-15$ ), agency is not just the 'observable actions', but also includes the 'sense of agency', which is the "meaning, motivation, and purpose which individuals bring to their actions." To analyse children's agency, I particularly focus on these meanings and motivations.

The social support that children receive or do not receive strongly influences the coping process. This is because individuals who receive social support are 
more inclined to both believe they can deal with the situation and seek social support. However, what support do child-headed households receive and how does this influence their coping abilities? Why are these children not taken in by extended family members, and how much influence do children have on their living arrangements? As discussed, children in child-headed households are perceived of as living in extremely vulnerable situations. They are often portrayed as and viewed to be in need of adult care and protection, incapable of running their own household. The tasks and responsibilities of these children are often seen as beyond the scope of their age. However, are children who run their own household viewed as children, or are they perceived of as (almost) adults because of their adult responsibilities? To gain insight into these questions I focus on children's narratives on the support they receive and seek, the choices they were able to make and their position as children with adult responsibilities.

I begin with sketching the background of my study on child-headed households in South Africa. This is followed by a discussion and defining of childheaded households. The role and the expected support from the extended family will then be discussed, as well as the apparent contradiction of children having to execute adult tasks and responsibilities. Subsequently, I discuss the contributing factor of choice in the formation of child-headed households, the support children receive and seek and the ways children shift between positioning themselves as too young or old enough depending on the context.

\section{A Study of Child-Headed Households in South Africa}

The research reported here was undertaken in the area of Ibhayi, one of the former black townships in Port Elizabeth, South Africa. Port Elizabeth is situated in the Eastern Cape where the majority of black people is Xhosa. The Eastern Cape is one of the poorest provinces, with 7 million inhabitants who are primarily Xhosa speaking. It has the second highest percentage of children living in poverty, and has among the highest percentages of orphaned children (22\%) and child-headed households (Meintjes et al. 2008, 64-68). 
The study had two aims. The first aim was to provide more insights into children and young people's own perspectives of coping in child-headed households. As there is no consensus as to what constitutes a child-headed household, the second aim was to conceptualise and characterise childheaded households. The research involved three periods of ethnographic fieldwork, culminating in a total of one and a half years, between December 2003 and May 2006. To locate child-headed households, I relied on the staff of a local non-governmental organization (NGO) that I was familiar with through research on a previous occasion (van Dijk 2002). This NGO, Ubuntu Education Fund (UEF), is a South African and North American collaboration. At UEF, counsellors who reside in Ibhayi offer emotional support to children in need. These counsellors are very familiar with the area, have established contacts in many primary and secondary schools, and are highly aware of the difficult circumstances of many children living in the Ibhayi communities. Two of these counsellors helped to locate child-headed households, and acted as interpreters as all the youngsters were isiXhosa speaking.

The oldest household member was the one who was identified by community members or the counsellors as the 'head' of the household; this individual remained the focus of this study. The younger children were often very shy, and it appeared to be very difficult to talk with them. Twenty households participated in this study, in which most household heads were under the age of 18 when the primary caregiver died or left the household. In fifteen households, the oldest sibling had one or more younger siblings to take care of, and two of them had to care for very young children (infants of a few months and a year respectively). In seven of the twenty cases, the oldest person in the household was 18 years or older when the household became 'child-headed'. However, all of them took over tasks and responsibilities of their former caregiver before he or she died or left, and some of them had been primarily responsible for the care of their ill (grand)parent(s) before they died. Consequently, these youngsters actually became the head of the household at a much younger age. Most information was gained through the 77 one-to-one interviews I conducted with the children and young people. In addition, I interviewed people working for $\mathrm{CBO}$ (community-based organisations) and NGOs in the area, staff 
from the local office of the Department of Social Development, and relatives and neighbours of involved child-headed households (after the approval of the young people had been obtained).

The interviews mostly had a conversational and informal form. This worked well with most children and young people because they were able to initiate the subjects they wanted to discuss. After a couple of meetings, most seemed comfortable talking with me and often started discussing subjects related to my research without my asking them directly. Almost all of the interviews were conducted in the homes of the children, in accordance with the wish of the participant him or herself. Children did not want to meet at their schools; this may have been because they wanted more privacy. To help children express their ideas, we often discussed the story or example of another child in a similar situation. We would also discuss my personal life, such as problems I encountered being a stranger in South Africa or being young in the Netherlands. These conversations were, besides being enjoyable, also very useful as they provided me with their personal views on several issues. Discussing more emotional subjects proved to be more difficult, however. Respondents often became upset when discussing their situation or the death of their parents. Therefore, I tried not to initiate these subjects and rather waited until the children would start talking about the death of their parents. The presence of the counsellors also helped in this regard. When the child became very emotional, the counsellors were able to comfort him/her.

Several ethical issues and methodological difficulties arose during my fieldwork which were mostly related to power differences between older and younger people and the harsh conditions children lived in. As I was conducting my fieldwork, I often felt weighed down by the difficult experiences of many children and often found myself very (emotionally) involved. By presenting the research with a clear reciprocal character (by offering small material and financial incentives) I felt that I reduced the power differences; this also helped children to buy food. In addition, I made informed consent continuous, which meant that before every interview I asked if they still wanted to participate. I always let the children choose where and when the interview would take place. Furthermore, by involving Ubuntu Education Fund and their counsellors, support to the 
child-headed households continued after the research had ended. ${ }^{2}$ As I will discuss below, defining child-headed households is not straightforward and this complicated the selection of the participants (van Dijk 2008, 52-54).

\section{Defining Child-Headed Households in South Africa}

There has been limited research on child-headed households in sub-Saharan Africa, and there are no reliable statistics about the number of such households. Some argue that the numbers are low, while others describe the amount of child-headed households as 'escalating' or 'overwhelming' (van Dijk 2008, 5). Around 3\% of South African households could be considered 'child-headed' according to the Nelson Mandela/HSRC Study of HIV/AIDS (Shisana and Simbayi 2002, 68). Based on the general household survey, Meintjes and Giese (2006: 69) state that $0.7 \%$ of all children were found to be living in childheaded households. These starkly different percentages show that estimates of the number of child-headed households in South Africa vary widely and should be interpreted with caution.

The differences in estimates are partly a result of using different definitions of child-headed households. As discussed, most definitions depart from the view that a child-headed household is a household where all members are under a certain age (usually 18). In such a definition, however, the head of the household is not identified. It is simply assumed that one of the children is the head. Other definitions of child-headed households do consider the 'head of the household', and when the head is under the age of 18 , the household is 'child-headed'. In such a definition, households can be child-headed in the presence of an adult who is incapable of fulfilling this role, for example due to illness. It is assumed that there are more households fitting the latter definition-wherein the adult figure is absent (due to illness) - than child-headed households without any adults at all. ${ }^{3}$ In addition, it is difficult to enumerate child-headed households

\footnotetext{
${ }^{2}$ For an elaborate description of the methodology and the ethical aspects of studying children in vulnerable circumstances see van Dijk (2008) \& van Dijk (2006).

${ }^{3}$ For more discussion on definitions of child-headed households, see van Dijk 2008 pp. 5-8; $32-34 ; 245-249$.
}

This is a digital offprint for restricted use only | (c) 2011 Koninklijke Brill NV 
because communities may be reluctant to acknowledge their existence; childheaded households are sometimes a temporary arrangement, and they may be under-represented in household surveys as generally an adult is required to complete the household questionnaire (van Dijk 2008, 6).

To escape the difficulties related to the concepts of 'childhood' some authors use different terms, such as 'sibling households' instead of 'child-headed households'. If one uses this term, there is no need to explore who the head of the household is, or whether the household members are children or not. However, children in child-headed households are not necessarily siblings, nor even related. To get away from the break-off age of 18 , some authors use the term 'youth-headed households' (Thurman et al. 2006). I have nevertheless chosen to use the term 'child-headed household', as it is the most widely used. The term 'child' in this context should first of all not be regarded as fixed in a biological age category. The term points to the social classification as a child and to her or his being of the same generation as siblings residing in the household. As I will show in this chapter, the participating children were all regarded socially as 'children', regardless of their biological age.

The complexity of defining a child-headed household also complicated the selection of participants. I initially chose to select those households that were labelled child-headed by my contacts. In this identification, the biological ages of the members of the household were almost never taken into account. Rather, if and how well they were taken care off by adult caregivers seemed most decisive. Consequently, their vulnerability seemed the most important characteristic. This meant that households were perceived as child-headed when they did not have an adult caregiver, or when a resident caregiver was unable to provide necessary care. However, as this definition resulted in an overwhelming number of households, I was forced to narrow the working definition with age restrictions. By mainly focussing on people under the age of 18 living together or who had been under the age of 18 when the household became child-headed, the number of households consisting of only siblings fitting this definition became much smaller. 


\section{Support to Child-Headed Households}

It is often stressed that members of the extended family will take care of children who have lost their parents. Foster $(2004,67)$ argues that, in the past, the sense of duty and responsibility of extended families in Southern Africa was "almost without limits". Although this may be a somewhat romanticised view, the extended family has always played an important role in supporting its members. Child rearing in the past was the collective responsibility of the traditional extended family (Barolsky 2003, 30). A child was socialised by the whole family and community and he or she could be corrected or disciplined by any adult. As a result of the historically communal nature of child-rearing, it is argued that responsibility for children was and continues to be not only linked to the nuclear family. Kinship obligations are generally viewed as determining who will take care of whom. However, particularly in South Africa, many demographic and social transformations have taken place, which have influenced family and community life. As a result of apartheid and migrant labour, many children have been separated from one or both parents. Informal fostering by relatives was and is common in South Africa in the event that the parents become absent, for example when they work elsewhere. The custom of informal fostering by relatives is often stressed as evidence of the extended family's willingness to care for children orphaned due to HIV/AIDS. Although many orphaned children may live with their extended families this does not necessarily mean that they are 'adequately' taken care of. Various authors challenge the dominant ideologies of solidarity in the African family (see for example Notermans 2008; Thurman et al. 2006; van Dijk \& van Driel 2009).

Some authors argue that the extended African family structure in South Africa is changing to a more 'nuclear' one, particularly in urban areas (Amoateng et al. 2007, 47-48). That the African family structure is indeed becoming more nuclear is a topic of debate; however, particularly in urban areas, extended family members do not necessarily reside together. The distinction between the nuclear family and the extended family has received criticism; Siqwana-Ndulo (1998), for example, states that the idea of the 'extended family' as it is used by many Western scholars is alien to the African household structure. Using the term 'extended family' assumes that households comprise of a husband, a wife 
and their children and that all other relatives are extensions of this core family. However, among the patrilineal Xhosa, all households that can trace relations through the father's side can be called 'home' (Siqwana-Ndulo 1998).

Although this criticism might be just, making a distinction between relatives who reside within the household and relatives outside the household remains useful. Because of urbanisation and work related migration, relatives may live in other neighbourhoods, towns, or provinces. Due to physical distances, relatives consequently have less contact. In my study, it was argued that because of this distance and a lack of resources, relatives may only support the family members they are living with. Furthermore, although from the above it may be expected that relatives from the father's side may be more inclined to support (orphaned) children, this seems not the case. In my study, relatives from both sides were expected to support related children, and there was no striking difference between the support of relatives from the mother's side or the father's side.

\section{Child Status with Adult Responsibilities}

From the above it follows that living in a child-headed household is very different from the idealised view of childhood and the extended family often portrayed in "Western" literature. Ideally, a child, particularly a girl, lives with her family until marriage. Although there are young men and women who no longer reside with family members before marriage, this still seems a rarity. Furthermore, although children are generally expected to help with the care of younger siblings, this type of care is usually mediated within the context of a broader family structure (Barolsky 2003, 30-31). This means that siblings are caregivers next to other providers of socialisation and care, such as parents and grandparents. The time spent on these tasks and the extent of responsibilities are also assumed to be much greater. What is more, some of the youngsters found themselves having to care for a sick and dying parent, which is not a common task for children.

Despite executing 'adult' tasks, running their own household, and sometimes being legally identified as adults (i.e. aged eighteen years or older) children 
or young people are not necessarily perceived of or treated as adults. First of all, childhood cannot be defined by biological age or period; adulthood is not necessarily reached when a child turns eighteen. Although physical immaturity may be a common feature of all children, the ways in which childhood is interpreted and socially institutionalised varies a great deal between cultures (James \& James 2001, 26). This can be compared to the distinction between 'gender' and 'sex'. Whereas 'sex' refers to biological constructions of femaleness and maleness, 'gender' refers to the socio-cultural categories of femininity and masculinity. Just as understandings of masculinity and femininity vary widely, there is also no such thing as a universal childhood. From this perspective, the term 'generational constructions' is sometimes used to point to social cultural meanings of childhood. The ideas about and characteristics of childhood and adulthood (i.e. generational constructions) result in generational rules and practices.

The generational rules constitute both formal and informal rights and obligations. The formal rules are restrictions related to biological age; for example, to access the Child Support Grant for dependent children, the caregiver needs to be at least sixteen years old. The informal rules relate more to social age or the generational constructions. These were most obvious in child-adult communication. Those perceived as 'children' are expected to show respect and humility towards 'adults' and not to defy or resist their requests and opinions or communicate with them in a direct manner. Furthermore, children are viewed of as unable to speak on their own behalf. The positions children can take up are not only dependent on 'age', and the expectations related to that, but also on different contexts and on purposes. As I will demonstrate in the section 'too young, or old enough', children position themselves differently in order to get what they want or need. The generational constructions and rules severely limit this room to manoeuvre, as I discuss below.

\section{'Choosing' to Live Alone}

In sixteen households, the primary caregiver of the children had died. According to the ideal picture of the extended family, these orphaned children should 
have been fostered and taken care of by their relatives. In four child-headed households, children stayed temporarily with relatives after the death or departure of their caregivers, or relatives stayed with them. In these cases, it seems that relatives were willing to foster the children. Some children argued that they did not like the way their relatives treated them, and therefore preferred to rather live alone. Some indicated that they did not like the idea of having to adapt to new rules. Noleta (aged 18) for example, had lived with her two younger siblings. After a burglary, the sister of her deceased mother asked them to move in with her for safety reasons. However, they had different ideas about raising the two younger siblings and running the household. After a number of disagreements, Noleta decided to move back to her own place. However, her aunt did not want her siblings to move back with her and they stayed at the aunt's house. In three other households, the youngest children were also fostered by relatives. Similarly as in the case of Noleta, the eldest children did not have a choice when relatives decided it would be best if the younger children moved in with them.

Because Noleta's siblings no longer lived with her, her relatives stopped supporting her with food. Noleta decided she needed to move in with her relatives in order to survive. Initially, she said that she could not move in with her grandmother, as her grandmother could not afford to feed another mouth. However, when I asked her again why she could not stay with her grandmother, she admitted that she did not want to adapt to her grandmother's rules. She explained that living with her grandmother meant that she could not invite her boyfriend or other friends over any more. Consequently, it appears that some children did not want to move in with relatives because they did not like the idea of their relatives having authority over them. Children and young people may not want to be controlled by an adult because they feel old enough to make their own decisions, which I will discuss in a later section.

It appears that choice is at least a contributing factor in the formation of child-headed households. However, the ability to make real choices implies that there are alternatives to choose from. Some children and young people said that they did not want to leave their homes because they were afraid it would be vandalised, or they feared losing their property if they moved in with relatives. The expectation of being treated badly was another reason for some 
children not to move in with relatives. The attitudes of the children and young people themselves may also be a contributing factor in the unwillingness of relatives to foster them. As I will discuss in a later section, children sometimes chose not to conform with certain norms or standards laid out by their relatives. Such behaviour may lead to less support and sympathy from relatives and neighbours.

Overall, living in a child-headed household cannot be regarded as a real choice as the alternatives were very limited. However, this is not to say that these children were merely victims of their circumstances. This is also apparent in the discussion below, where I consider difficulties in asking for support because of generational rules. While some children seemed not confident enough to ask for support from adults, others refrained from asking as a conscious strategy.

\section{Seeking Support or Not}

Some relatives and neighbours seemed very dedicated to supporting the children. In three of the twenty child-headed households, the children received groceries or a monthly amount of money from a family member. These relatives were in two cases sisters of their mother and in one case, the biological father of one of the children in the household. ${ }^{4}$ With this type of support, the children had enough to eat and could remain in school. However, only in one case did this support appear constant and regular. In most cases, the households did not receive monthly groceries or money, and other support was minimal. ${ }^{5}$ This was particularly evident in the particularly impoverished situations children and young people lived in. As in the case of Aidan, which is discussed in the introduction, in sixteen other households children frequently

\footnotetext{
${ }^{4}$ Children in child-headed households are not self-evidently orphans. Although in thirteen households, the oldest child still had one parent, only in one of these cases did this parent support his children.

${ }^{5}$ South Africa has a social security programme and poverty alleviation programmes and most households were eligible for some sort of support (van Dijk 2008, 98-107). Most child-headed households, however, did not receive any assistance from the Department of Social Development (ibid.: 159-162).
}

This is a digital offprint for restricted use only | (c) 2011 Koninklijke Brill NV 
went to bed hungry. Neighbours supported some households, mostly in the form of leftover food. Very few children occasionally had piece jobs or ran errands for neighbours for a few rand.

As indicated in the introduction, relatives or community members may think that children are supported sufficiently and somehow coping with the situation. However, children and adults do not necessarily have the same ideas about the support needed. For example, the minimal support of relatives and community members was mostly material. However, children and young people indicated the need of love and attention and someone who would listen to their problems and advise them. As discussed above, and illustrated in the case of Aidan, children are often not consulted about interventions or support. The lack of consultation frustrated children and negatively influenced their belief in their ability to act. Children and young people further indicated that they felt angry or disappointed in the lack of support from their relatives, as they felt their relatives should support them. In other words, they felt entitled to such support. This raises the question of whether they indicated that the support they received was inadequate or if they actively asked for support from relatives or neighbours.

Most children did not appear to ask for support from their relatives very often. This first of all relates to the generational rules. As argued before, children are not expected to communicate in a direct manner with seniors. Their reluctance to ask for support was also related to the expected outcome. The children that were not supported did not think their pleas would result in (more) support. Another reason for not asking support was that children said they felt weighed down by their situation and humiliated by having to ask or beg for food. Not asking for support was, however, also a conscious strategy. This is illustrated by the case of Norah (aged 21), who lived with a younger brother (aged 18). While she previously cared for two other, younger siblings, they were eventually taken by her aunt to live with her. I asked Norah if she asked her aunt for money or food when she found herself without any:

I went to her several times while I was living with the little ones, and now I feel sorry about going there because I feel like they will think that I am old enough, I can get bread, I can look after myself... 
Since Norah no longer cared for her siblings, she stopped asking her aunt for support. She assumed that because she had asked her aunt for support so often in the past, she could not go there any more, that she was too old to ask for support for herself. Two issues arise out of her explanation: One is that it is easier to ask for support for younger siblings rather than oneself. This point was also brought up by others. When younger siblings were taken out of the household, the oldest siblings felt that they could no longer rely on their relatives' support as they felt less entitled to it. The second issue arising from Norah's testimony is that one should not ask for support too often. Other children also referred to the latter; they feared that relatives or neighbours would 'get tired' or 'fed up' of them always asking for food. Not asking relatives or neighbours for help too many times is indeed a strategy. If they ask for help too often, relatives or neighbours might decide not to support them when they need it most. Consequently, the older children rationed their pleas for support, saving them for the worst times.

In conclusion, the reluctance to ask for support from relatives relates to generational rules, feelings of insecurity, negative expectations about the outcome, but also to well-considered reasons or motives. Furthermore, as discussed, children and adults often had different ideas about the required support. Because these ideas differed, children sometimes did not perceive certain forms of support from neighbours as support. Many children said that neighbours sometimes gave them some food or a small amount of money, but they usually had to do something in return. The children did not think that getting food in exchange for running errands was support. Some of the children occasionally had piece jobs. For example, Stephen, discussed above, earned some money by working in a taxi (mini-bus) during the weekends. However, jobs are very scarce in South Africa. Therefore children needed to find other ways of getting the money they required. Some of these strategies were inventive, such as making items which could be sold—such as clothes and brooms (from dried grass). The money the children made in these ways was however nowhere near enough to fulfil their basic needs. They therefore had to employ other strategies, such as cutting back on food intake. Some children engaged in strategies that they preferred to keep secret, such as petty crime (two children), criminal activities 
(one child), and prostitution (one girl). These strategies were the result of not having, or not being aware of, alternative strategies.

In the next section, I discuss how children challenged generational constructions by opposing or challenging the authority of adult relatives and neighbours.

\section{'Too Young' or ‘Old Enough'}

Although children were expected to follow the rules of communication when dealing with seniors, they did not always respect these rules. Some of my respondents openly disagreed with older people. Stephen (age 15), for example, lived with his younger brother Simp (age 11) since their mother died. They received material support from their biological father, and Leah, a close friend of their late mother, visited them daily. According to Stephen and Simp, she acted as their mother. The brothers said that she fulfilled that role rather well. Stephen emphasised that he was too young to raise his younger brother alone and he accepted Leah's help with household tasks. However, he did not accept all aspects of her support. One day, Stephen told me that they had had a huge disagreement. He thought that Leah intervened in his life too much, and told her that he was old enough to make his own decisions. As he explained:

I told her (...) I am old enough to look after myself, there is nothing I can't do for myself. She is only going to be here to keep an eye on me, and I have to make my own choices, she's never going to stop me.

Stephen argued that he was taking care of himself and was old enough to make his own decisions. On the other hand, he also said that he was too young to care for his brother and did accept Leah's support, as well as groceries and money from Simp's father. Although Stephen wanted Leah to support them, he did not like her telling him what to do. When I spoke to Leah, she explained that she did not accept his attitude towards her. Because Stephen was rude and disrespectful towards her, she did not visit the brothers for a few weeks. While they made up after some weeks, Stephen's disrespectful behaviour led to both brothers receiving less support. 
Zack (aged 18) seemed confident enough to openly disagree with his seniors, particularly when he perceived them as being nosy. Zack repeatedly complained about the interference of neighbours or relatives who, he claimed, only pretended to be interested in his well-being:

... sometimes my neighbours ask, how do we survive? Then I will say to them stop worrying about other people's business, mind your own business... (...)...they ask this because they want to stick their nose where it doesn't belong, if I tell them they will go to the next person and tell them...

According to Zack, his neighbours only pretended to be interested; they did not really want to help him, they just wanted to gossip about him with the other neighbours. Zack told his neighbours to stop interfering in his life. Although Zack may have been correct about the motives of his neighbours, I did not understand why he resisted them so openly. His resistance caused friction with the neighbours; they gossiped more and made rude remarks to Zack. For example, the neighbour whom Zack asked to leave complained to other neighbours that Zack had chased him away in my presence. Other neighbours accused Zack of stealing from them. Although this did not lead to police involvement, it demonstrated the worsened relations between Zack and his neighbours.

In another case, Zack seemed more successful in his resistance. Zack's aunt wanted to rent out rooms in his house (without consulting Zack) and sometimes potential tenants came to enquire about the rooms. Zack said that he told the potential tenants they had to talk to his relatives first: "you have to speak with the elders, and we don't know when they will come here." Zack did not tell the potential tenants that he was opposed to this idea but, by convincing them that they had to speak to his elders first, he delayed and even prevented the rooms being rented out. This was because his elders (i.e. his relatives) never came to the house to visit Zack.

Zack also had ways to manipulate my interpreter and me. He often stressed the precariousness of his situation and he pretended to be younger than he actually was. By drawing attention to his young age, he emphasised the difficult situation he lived in. Others also often stressed their youth and the difficulties they were facing, such as not having enough to eat. My interpreter thought that some children and young people were lying about having no food. However, most households did not have any stock of food (their cupboards were mostly 
empty), and they were consequently completely dependent on the food neighbours or others would give them. Therefore, I thought that most children were not lying, but merely exaggerating in order to gain my support. They knew how to obtain my sympathy and they used that knowledge. In other words, stressing their suffering was a strategic strategy.

Aidan (aged 18) also had ways of getting what he wanted or needed. The first time I met him, he was very frustrated with his biological father, who lived in Gauteng; he promised that he would arrange for Aiden's circumcision, but never did. When I met Aiden again in 2007, he had somehow managed to be initiated. He learned that some of his cousins (on his father's side) living near his father would be initiated during the upcoming school holiday, and he travelled to join them without informing his father that he was coming. Upon his arrival, he pretended that his father had promised to arrange everything for him. Aidan's father could no longer ignore him, as fathers are expected to arrange initiation for their sons, and he had to pay for everything. Aidan was thus rather inventive in obtaining the support he needed.

\section{Conclusions}

From the findings of the study, it is clear that child-headed households cannot be regarded as new coping mechanisms of the extended family. Contrary to popular assumptions, most children were not, at least not sufficiently, supported by their relatives. Children were not consulted about interventions and support arrangements, even though children and adults often had different views about the needs and appropriate support. The lack of support and consultation diminished children's beliefs in the ability to act and consequently negatively influenced their coping. I have illustrated this by examining their support-seeking behaviour; some children and young people seemed too insecure to ask for support or did not expect to be supported. Generational practices and rules further inhibit children and young people's room to manoeuvre in support-seeking behaviour. Youngsters in child-headed households were all perceived of as 'children' by their seniors, which made it extremely difficult for the children to communicate with adult relatives in a direct manner. 
On the other hand, although alternative options were mostly very limited, some children and young people appeared to have had some choices. Some did not want to conform to their relatives rules or authority. By choosing to live alone rather than with relatives, the children and young people particularly challenged dominant generational constructions. This is because they are expected to reside with their families until they reach adulthood. By living alone, they thus proved to their relatives that they could take up adult responsibilities. They further challenged or resisted generational rules by disparately positioning themselves as either 'too young' or 'old enough', depending on the context. They stressed their young age and suffering in order to get support. If they felt constrained in their actions by adults, they emphasised their maturity, and also openly resisted, confronted or fought with seniors. However, open resistance towards seniors mostly did not result in intended outcomes. This probably came from the fact that this behaviour is socially and culturally considered extremely disrespectful. The more subtle ways in which children resisted adult authority were more successful. Children received more support when they brought attention to their youth, when they lied about or exaggerated their situation, or when they secretively resisted adult expectations. In other words, by pretending to follow the generational rules, children were more able to get what they wanted.

By exploring the motivations and purposes of children's actions, or lack thereof, their agency becomes evident. Children developed carefully considered reasons and motivations for not asking support, for choosing not to live with relatives, or to resist or (seemingly) conform to generational constructions. Children and young people were hence able to bend the generational rules. Children use their agency cautiously; although children and young people are not powerless, their room to manoeuvre is limited by generational rules. This latter point should therefore be part of any study on children and childhood. Notwithstanding the many restrictions in their coping strategies, children and young people assess their options carefully and have well-considered reasons and motives for their actions. This means that in order to provide child-headed households with appropriate support, these coping strategies, needs and wishes of children and young people should always be the starting point. 


\section{References}

Foster, G. (2004), Safety nets for children affected by HIV/ AIDS in Southern Africa. In: R. Pharoah, ed., A generation at risk? HIV/AIDS, vulnerable children and security in Southern Africa, pp. 65-92. Monograph no. 109. Pretoria: Institute for Security Studies.

James, A. \& A. James (2001), Childhood: Towards a theory of continuity and change. The Annals of the American Academy of Political and Social Science 575(1): 25-37.

KABEER, N. (2005), Gender equality and women's empowerment: A critical analysis of the third Millennium Development Goal. Gender and Development 13(1): 13-24.

Meintjes, H. \& S. Giese (2006), Spinning the epidemic: The making of mythologies of orphanhood in the context of AIDS. Childhood 8(13): 407-430.

Meintjes, H., J. John-Langba \& L. Berry (2008), Demography of South Africa's children. In: P. Proudlock, M. Dutschke, L. Jamieson, J. Monson \& C. Smith, eds, South African Child Gauge 2007/2008, Cape Town: Children's Institute, University of Cape Town. pp. 64-70.

Nelson Mandela Children's Fund (NMCF) (2001), Report: A Study into the situation and special needs of children in child-headed households. Johannesburg: NMCF.

Notermans, C. (2008), The emotional world of kinship: Children's experiences of fosterage in East Cameroon. Childhood 15: 355-377.

Shisana, O. \& L. Simbayi (2002), Nelson Mandela/HSRC Study of HIV/AIDS: Household Survey 2002: South African National HIV Prevalence, Behavioural Risks and Mass Media, Cape Town: Human Sciences Research Council (HSRC).

Siqwana-Ndulo, N. (1998), Rural African family structure in the Eastern Cape Province, South Africa. Journal of comparative family studies 29(2): 407-17.

Thurman, T.R., L. Snider, N. Boris, E. Kalisa, E. Nkunda Mugarira, J. Ntaganira \& L. Brown (2006), Psychosocial support and marginalization of youth-headed households in Rwanda. AIDS Care 18(3): 220-229.

VAN DIJK, D. (2002), Hulle kan nie hulle hormone intoom hou nie. A study on gender, adolescents and sexual behaviour in relations to HIV in South Africa. Occasional paper 109. Nijmegen: CIDIN/ Development Studies.

- (2006), Researching children: Studying agents or victims? Methodological and ethical difficulties in a study among children and young people in South Africa. African sociological Review 10(2): 151-163.

-. (2008), Beyond their age. Coping of children and young people in child-headed households in South Africa. Leiden: African Studies Centre.

VAN DiJK, D.F. van DRIEL (2009), Supporting child-headed households in South Africa: Whose best interest? Journal of Southern African Studies 35(4): 915-927. 



\section{Using a "Kids Club Method" to Understand Experiences of Children Orphaned by AIDS in North-Central Namibia}

Mienke van der Brug

\section{Introduction}

Sub-Saharan Africa remains the epicentre of the HIV/AIDS epidemic; accounting for almost two thirds of all people living with HIV and for three quarters of AIDS deaths globally in 2008 (UNAIDS 2009). In 2008, more than 14 million children in this region had lost one or both parents to AIDS (UNAIDS 2009). Affected countries and aid organisations have often expressed their concern for the well-being of these children; as a result, several national policies and aid programs are increasingly set up to support children orphaned and made vulnerable by HIV/AIDS.

For the design and evaluation of these programs and policies, more insight is needed into how children experience and perceive the loss of parents to AIDS, and how they define their own sense of well-being. However, talking 
with children about the loss of their parents and HIV/AIDS is sensitive, and further complicated by the general unspoken atmosphere surrounding the issue of HIV/AIDS in Southern Africa. Children, particularly in the rural areas, are not accustomed to speaking openly with adults. As a consequence, when young AIDS orphans are interviewed by researchers, responses often remain limited. This lack of response was demonstrated in a study on perceptions of parental loss among child and adolescent AIDS orphans (see Daniel, Apila, Bjørgo and Lie 2007, 113); despite the open-ended design of interviews and questions, which would have otherwise provided ample space for respondents to discuss and emote, young children's responses were very minimal compared to those of older adolescents-mostly due to the sensitivity of the issue. Thus there appears to be a need for methodologies to assist researchers in talking about sensitive issues with children who are not used to voicing their opinions. It is also important to understand what effect participation in such research has on children.

This chapter is devoted to the use of a "Kids Club Method" as a means of conducting research on sensitive issues by dialoguing with children, and the evaluation and effects of this method six years later. North-Central Namibia is a heavily affected region, with a HIV prevalence level that is amongst the highest in the country. ${ }^{1}$ In $2003 / 2004$, I conducted a study on the experiences and perceptions of young orphans in North-Central Namibia on the loss of their parents and their changed life circumstances (Van der Brug, 2007). ${ }^{2}$ In order to create an environment in which children would feel comfortable and safe to talk about these sensitive issues, I set up an after-school Kids Club with young orphans which met over the course of several months. In 2010, I returned to Namibia to follow up on the 14 children who participated in the research.

1 The north central region has high percentages of HIV infections. In 2006 the HIV prevalence among pregnant women in Oshakati, a town nearby the research area exceeded 25\% (Ministry of Health and Social Services Namibia, ORC Macro, 2007).

2 The study 'World and Experiences of AIDS orphans in North-Central Namibia' was conducted in the context of masters research and for the Danish NGO, Ibis, which was assisting school boards in the setup of support networks for orphaned students and required information on how orphaned children experienced their situation. The study also formed the basis of the 'Children's Voices' project (by Ibis and a partner NGO, Positive Vibes) which operates in different parts of Namibia. This project aims to facilitate a dialogue between children and adults around the needs of children in the context of HIV and AIDS.

This is a digital offprint for restricted use only | (c 2011 Koninklijke Brill NV 
I wanted to understand how, after this six year period, orphans evaluated the Kids Club as a research method, and how they experienced their participation.

\section{Research Design}

This study was conducted in a rural village in the central part of North-Central Namibia, which consists of widely dispersed homesteads. Half of all Namibian orphans who lost their parents to AIDS are located in this rural region. ${ }^{3}$ Most inhabitants of the village where research was carried out belong to the Ndonga, one of the eight ethnic kin groups that together form the Ovambo people. The extended family is still the dominant pattern of household organization in this area (Unicef 1995). Many women run the household, as labour migration of men to central and west Namibia is common (Mendelsohn, El Obeid and Roberts 2000, 40). Children are considered important labourers in many household and agricultural activities, like collecting firewood and water, ploughing, cooking (mostly girls) and tending the animals (mostly boys).

Most of the orphans are taken care of by members of their extended family; often children are raised by grandmothers or aunts (SIAPAC 2002). In Namibia, an orphan is defined as an individual up to the age of eighteen that has lost one or both biological parents (SIAPAC 2002). This definition is used to classify the children in this study as well. Eleven orphans (five double orphans and six children who had lost one parent) between the ages of nine and eleven years old participated in the 2003/2004 study. One child was living with his surviving parent, while eight orphans were taken care of by their grandmother, aunt or great aunt on the mother's side, and two children were living with relatives of the father. This extended kin network for children relates to the matrilineal structure of the Ovambo community (Malan 1980). Children mainly 'belong' to the clan of the mother and usually have a better position and more status within their mother's family than that of their father.

${ }^{3}$ Namibia had about 115,000 orphans in 2003 , which was twelve percent of the estimated population of children in 2001 (IPPR 2003). Two thirds of these children are supposedly children orphaned by AIDS. The 2008 estimates for orphans stand at about 150 ooo, of which close to 100 ooo lost one or both parents to AIDS (UNAIDS 2008).

This is a digital offprint for restricted use only | (c) 2011 Koninklijke Brill NV 


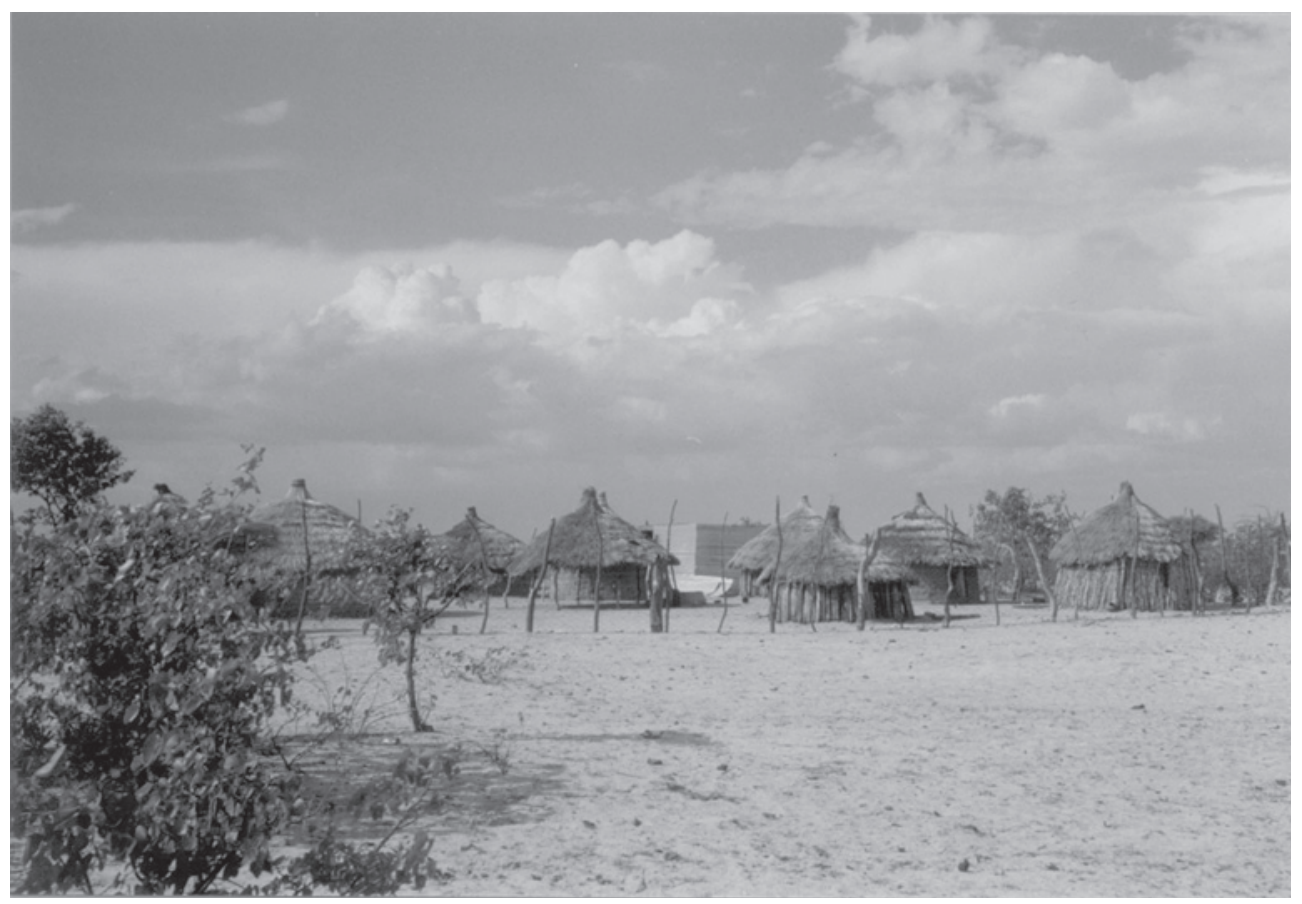

Figure 2.1 Homestead in North-Central Namibia (photo by the author)

Generally, children will be taken in by the father's family when the mother's family is unable to do so.

Since schools offer good access to children, the 2003/2004 study was conducted at a primary school, and child respondents themselves were selected by the teachers. The teachers did not know the family backgrounds of all pupils in their classes, though selected some children who they knew were orphans and chose 'supposed' orphans on grounds of poor clothing and a lack of food, since many AIDS orphaned children live in impoverished households. ${ }^{4}$ During the research it turned out that three of the fourteen selected children were not orphans; they came from families with financial difficulties arising from having a physically handicapped or mentally ill parent. Two afternoons a week, during three months, the interpreter, fourteen children and I gathered in one

\footnotetext{
${ }^{4}$ Children orphaned by AIDS are often living in impoverished households. Disease and death of household members in a productive age has led to extra costs and a reduction of income (see "home visits").
}

This is a digital offprint for restricted use only | ( 2011 Koninklijke Brill NV 
of the classrooms of the school. The club took place during the 'study' period, wherein students do homework at school. I visited the children at home twice to meet and interview their caregivers and observe their home situation. The children's teachers were interviewed as well.

In the follow-up study of 2010, the participants were between the ages of sixteen and eighteen. Seven adolescents were staying in the same household as in 2003/2004, while the other seven moved to a new place of residence. Three were staying at boarding schools in different towns in northern Namibia; one boy was staying on the premises of the garage where he was employed; two girls moved into the household of another relative; and one girl was taken in by people from her church. One orphan who had previously lost a parent to AIDS had since lost her other parent to the disease in 2009. All fourteen adolescents were interviewed, and eight of them were visited at home. Four focus group discussions were held with six adolescents who were attending the same secondary school.

\section{Ethical Issues}

Ethical issues are the cornerstone of research with children (Johnson 1998). Particularly in research with children on sensitive issues, a strong focus on ethical issues is needed. Children's rights and children's well-being have priority over the interests of the investigator. In 'Ethical Standards for Research with Children' issued by the American Society for Research in Child Development, the first principal follows that the investigator should not use research procedures that may harm the child, either physically or psychologically. When talking with children about the loss of their parents and problems in their current life situation, I had to make sure that the children were not harmed when discussing these sensitive issues. I used a sensitive approach to minimize the risk of harm which was characterized by transparency, trust, a careful set-up of the topics to be addressed, evaluation, and consultation with staff from schools, NGOs, governmental organizations and other people who are knowledgeable about the children's life situations. A researcher should also examine the availability of and work together with professionals, such as counsellors. 
As mentioned by Clacherty and Donald (2007, 161), accessing caregivers or parents and gaining informed consent can be a challenge in the Southern African context due to illiteracy or absence. In this study, the caregivers or parents were asked consent for the participation of their child in writing, as suggested by the school Principal. The children had to bring a letter from the Principal home with them. Many caregivers did not, however, receive the letter or return it to the school; in these cases, caregivers were asked for consent in person during home visits. Children were asked for consent during the first meeting of the Kids Club; it was explained and repeated during all sessions that participation was voluntarily and that they could stop at any time. Anonymity was guaranteed by not using the real names of children, and I explained to the child respondents that I would not reveal anything about what they said to their parents, caretakers or teachers. Hill (1998) describes this as 'network confidentiality': keeping the information provided by a child or a young person 'secret' from relatives, family or other people they know who may express an interest in what a child has said during a consultation.

Transparency in interactions with children is important as well. To make the research transparent for the children I explained the set-up of the Kids Clubs and gave the children calendars with the dates of the various activities. Because I did not know the background of the children at the beginning, I gave a general explanation of the aim of the research: I wanted to know more about their lives. As the research progressed, I became more specific and explained that the research examined their situation and experiences of being an orphan. This method, called the "shallow cover" by Fine and Sandstrom $(1988,20)$, has the advantage that children do not act according to the aim of the research; on the other hand, it can be disadvantageous in that children may develop their own ideas of what the researcher is looking for. In this study, children's ideas about the research generally seemed to follow the main aim. When the children were asked if they knew why they were in the Kids Club, one girl answered: "maybe it is because I am an orphan," a response with which the others agreed.

Deciding whether or not to pay or reward children represents another ethical issue. As Fine et al. $(1998,25)$ state, while payment could show that the time of children is valued, it could also be seen as manipulation or create an instrumental relationship. I decided not to pay the children for participating in 
the research. The Kids Club was popular, and other children asked if they could participate; several caregivers inquired as to whether they could enrol the other orphans they were taking care of. ${ }^{5}$ Paying the children of the Kids Club might have made their position even more distinct. The children were rewarded by receiving a few gifts and I organized some festive activities for them.

\section{The Role of the Researcher}

The children in this study were very shy in the beginning; they were very hesitant to answer questions and held their hands in front of their faces when addressed directly. Obedience to and respect for adults are often emphasized to children, such that young people are not used to speaking up or voicing their opinions to adults (LeVine et al. 1994). At school, teachers contribute to this power distinction by showing an authoritative attitude. To create a more equal relationship with children, and in order to be able to talk about sensitive issues, the attitude of the researcher is important. I tried to establish a confidential relationship with the children by being friendly and empathetic, and I participated with children in informal interactions like games and songs during the Kids Club. I also encouraged the interpreter to be empathetic and friendly, as the interpreter communicated directly with the children. Various authors have described the empathic attitude that researchers should adopt, suggesting that a researcher should be prepared to join and be genuinely interested in the children, as well as adopt a patient and not too authoritative attitude (Bleeker \& Mulderij 1984, 98). In turn, he or she should be emotionally involved, have the skill and ability to listen to the children and establish and maintain trust, which is critical for successful research (Fine et al. 1988, 21,22,55). Researchers must also look at their own ideological baggage, including preconceptions about children's abilities and roles (Johnson 1998, 21). Also, it should be understood that children experience much of their contact with adults in

${ }^{5}$ It was not possible to include more children in the Kids Club because children had to be involved from the beginning, it was neither possible to form a control group with these children because of time limitations.

This is a digital offprint for restricted use only | ( 2011 Koninklijke Brill NV 
subordinate positions of power; the researcher should therefore stay in the physical proximity of children, by sitting, for example, with them on the floor rather than in a chair above them (Caputo 1994, 33). Most children responded to this empathic attitude and showed increasing confidence in their behaviour towards the interpreter and me. Some children gave me little presents and wanted to sit close; when asked to draw 'someone you love very much' and 'the people that help you', the interpreter and I myself were drawn. These reactions are however also related to the life situations of these children; many of these children receive little personal attention at home. The researcher should handle these attachment processes with care, keeping in mind the temporary aspect of most research.

\section{The Kids Club}

Each session of the Kids Club consisted of a group discussion, drawing and discussing the drawings with children individually; these activities were alternated with games or songs to correspond with the short attention span of children. ${ }^{6}$ The structure of the Kids Club and each individual session followed a similar pattern. First, more general and positive subjects were discussed, which led into the sensitive issues, and followed again with less sensitive, positive subjects. It was felt that such a set-up would prevent a situation from occurring wherein children were suddenly confronted with sensitive subjects at the end of the session, and tried to ensure that children would leave the Kids Club with a positive feeling. Below, the Kids Club method will be discussed in more detail, pointing specifically to sub-methods used such as group interviews, drawings and visits to children's homes.

\footnotetext{
${ }^{6}$ Children proposed songs and dances themselves, and songs and games based on the activity guide 'Psychosocial Well-Being for Children and Adolescents. Activity Manual for Children Care-givers' by UNICEF (2002) were used.
} 


\section{The Themes of the Kids Club}

It is clear that themes and questions used to research children's perceptions and experiences should be in accordance with their everyday life worlds, knowledge and age. To set up themes for the Kids Clubs that were relevant for the orphans, I made use of teachers' and caregivers' manuals about children affected by AIDS. ${ }^{7}$ I also discussed children's life situations with the staff of Ibis. In the first twelve Kids Club meetings themes such as 'friendship' and 'family' were discussed to gain insight into the role of friends in the lives of children, friendship and kinship as possible coping mechanisms, children's home situations, and perceptions of family. We also spoke about difficult things that can happen in families, and people in the children's lives that were important to them. The second part of the study, in which only seven children participated, consisted of four Kids Club meetings. ${ }^{8}$ Here we discussed topics as children's knowledge of and experience with HIV/AIDS, losing parents, problems that children experience within their home and school situation, and children's ideas of safe places and future hopes. In the final session, with the complete group of fourteen children, the theme, "people that help me" was the focal point.

\section{Group Interviews with Children}

In order to interview children on sensitive issues, an environment should be created wherein children feel confident to speak. As mentioned by Scott (2008, 92), the context of research is important because the place where interviews are carried out is likely to influence the way children respond. By speaking to the children at school instead of their homes, the children were freer to talk about their home situation. During the first sessions, we sat on chairs in a group circle. However, this classroom setting proved to be an uninviting atmosphere to talk about personal issues. The chairs and tables were put aside, and during

7 'Building resiliency among children affected by HIV/AIDS' by Mallmann (2003), 'Psychosocial Well Being for Children and Adolescents. Activity Manual for Children Care-givers' by UNICEF (2002).

${ }^{8}$ The selection criteria are discussed in the paragraph "Group interviews with children".

This is a digital offprint for restricted use only | ( 2011 Koninklijke Brill NV 
group discussions, the children sat in a circle on carpets. This created a more relaxed atmosphere in which the children felt relaxed and talked more freely.

Interviewing children in a group and convening the group over a long period of time has several advantages. While one-on-one contact can be intimidating for children, group interactions often facilitate communication. Similarly, seeing the group during a longer period of time supplies more attentive and personal information (Blagbrough 1998, 34). The size of the group is also important. While I started the Kids Club with fourteen children because I expected that some children would drop out shortly after, this did not happen: fourteen proved too large for group discussions. The second part of the Kids Club took place with only seven children, which improved the dynamics of the group discussion considerably. ${ }^{9}$ A maximum of eight children for a group discussion is often recommended (Scott 2008, 100). In turn, differences in age and gender between children should be acknowledged in focus group discussions; as such disparities might have an effect on what is said by the children (ibid.). In this study, there were few age differences, and boys and girls were not interviewed separately because most topics did not appear to be gender sensitive.

In the first sessions, children were shy and only responded to personal questions rather than those posed to the whole group. The size of the group, the translating process and the reticence of the children made answering questions a lengthy process. It caused the first series of group interviews to be somewhat boring to the children. Due to the smaller group size during the last sessions, and because the children became more used to each other, students finally began to participate actively. In these sessions, sensitive and personal subjects were discussed. I used open-ended questions in which children were not pressured to give answers. Sometimes, sensitive questions were introduced with: "Many children experience...how do you experience this?" The advantage of this method is that children feel at ease in knowing that their experiences are not unique and they won't stand out of the group. The disadvantage is that they are somewhat lead-in questions. The conversation below is an example of talking about the sensitive topic of HIV/AIDS.

\footnotetext{
9 I selected orphans from different family situations, and did not invite the non-orphans since we discussed the impact of the loss of parents.
}

This is a digital offprint for restricted use only | (c) 2011 Koninklijke Brill NV 


$\begin{array}{ll}\text { Question: } & \text { Have you ever heard of HIV/AIDS? } \\ \text { Boy 1: } & \text { I don't know, but I heard about it. } \\ \text { Boy 2: } & \text { I didn't even hear about it; it's my first time. } \\ \text { Girl 1: } & \text { I heard about it. I just heard that people get very thin and then } \\ & \text { their eyes come out. } \\ \text { Girl 2: } & \text { I didn't hear about it. } \\ \text { Girl 3: } & \text { I just heard that people get thin, have big eyes and can't walk. } \\ \text { Girl 4: } & \text { I also heard about it. I heard when people are having sex, they } \\ & \text { get it. (All laugh) } \\ \text { Boy 1: } & \text { Some die of AIDS. } \\ \text { MvdB: } & \text { How do you know people die of AIDS? } \\ \text { Boy 1: } & \text { I just heard it from a family member talking. } \\ \text { MvdB: } & \text { Can you tell me a bit more about this? } \\ \text { Boy 1: } & \text { I just heard them talking about it. }\end{array}$

When discussing this question, children started to giggle and whisper. After Boy 1 mentioned that people could die of AIDS, he walked away uncomfortable from the circle to put something in his bag. I did not ask further, since the issue of death from AIDS appeared a very difficult topic for him to discuss. We had a short break before we continued with the group discussion, in which Boy 1 joined again. During later conversations with children about HIV/AIDS, it appeared that children knew more about the disease than they initially let on. The topic of AIDS-related death and dying was however no longer mentioned. During the evaluation at the end of the session, the children told me they were happy they now knew more about HIV/AIDS. I mentioned that if children wanted to talk about things that were bothering them, or about the issues that were discussed, they could always come to me or to the interpreter. The children did not do this.

\section{Drawings}

The use of drawing as a research method enables children to express their ideas in a visual and concrete way instead of reacting verbally. While some children found it difficult to answer a question, they made a drawing about the subject without hesitation. Shy children also seemed more at ease in expressing themselves through their drawings, as drawings are less open to critique and judgement than verbal answers to a question. Another advantage is that most children enjoyed drawing. The children drew enthusiastically, with concentration, and 
they often wanted to stay longer to finish the drawing. Drawings can also be used to start a conversation. The translator and I would sit with each child individually, and ask the child if he or she wanted to talk about what they had drawn. This way children could interpret and explain their ideas about their work. The children evaluated this method positively: "I like to draw and talk about the drawings," one of the children said.

Children were given specific drawing assignments. While the subject of the first drawing exercise was aimed at gaining insight into the daily lives of children and their positive experiences, later assignments were meant to give children the chance to express uncomfortable or difficult aspects of their lives. Examples of such assignments might include: "Make a drawing about something you will never forget," and "Things that happen in the family that are not pleasant." One girl made a drawing about the death of her father. The girl never mentioned his death before this exercise, and it seemed she did not want the other children to know. She held the drawing upside down when she handed it in and hid it under the stack of drawings. This was thus a topic which the child felt more comfortable drawing privately rather than discussing openly. She spoke to me about her drawing:

Girl: $\quad$ My father passed away. He was sick. These are the people that came. My mother was there. My father was not married; he was staying in the family house with his father, his parents. I stayed with granny. Mother came from Windhoek and together we went to my father's house.

MvdB: $\quad$ Do you sometimes think about your father?

Girl Yes, often.

MvdB: $\quad$ Did you see him often?

Girl: $\quad$ No. Even though he did not visit me often, I miss him a lot.

Some children that sat near each other copied each other's drawings. For example, when asked to "Draw the one you love very much," three boys made an almost identical drawing of their grandmother. The explanations of their drawings were also identical; they love their grandmother because they are living in her house and she gives them money and food. Drawing together supplies possibly less useful data in terms of representing a particular child, but can give information on the views of children concerning different and equal experiences, diversity and uniformity (Christensen et al. 2008, 163). 


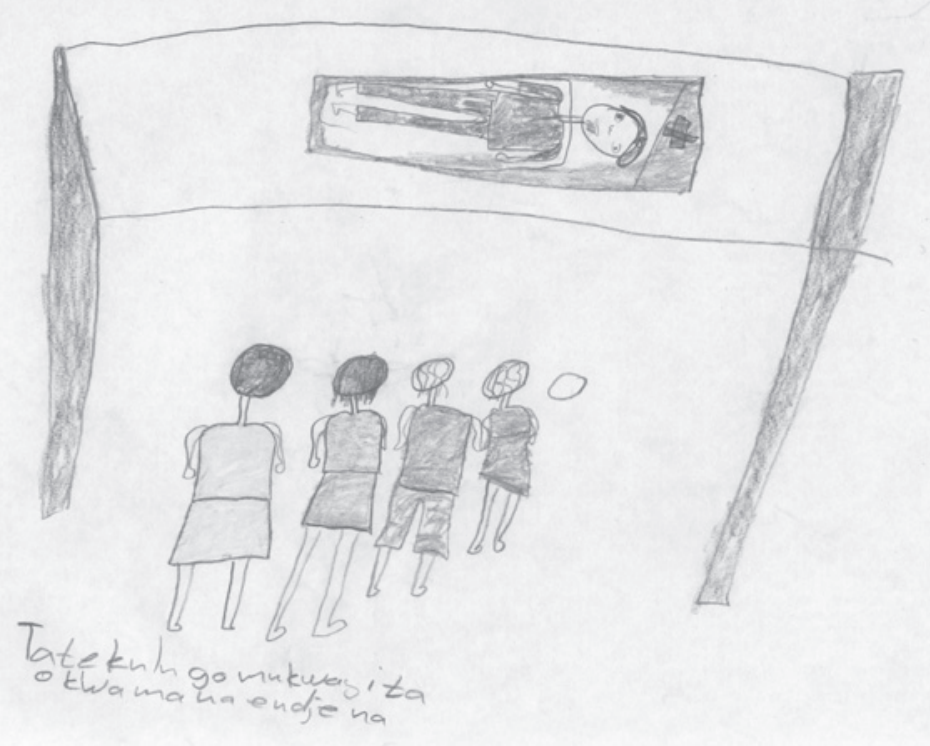

Home Visits

Figure 2.2 Death of Father

When the initial study was conducted in 2003/2004, there was limited access to antiretroviral drugs in Namibia. Because of disease and the death of household members of a productive age, the number of household labourers decreased and less money flowed into the household from external sources. This caused an increase in poverty among already poor communities in rural North-Central Namibia (Matanyaire \& Timpo 1999, 23). Caring for AIDS-orphaned children adds to the costs of the household. The financial situation of the eleven households that took care of the orphans in this study differed, however. Four households in this study were considered to be among the poorest; they did not own cattle and only possessed a small piece of land. These were households in which the grandmother often cared for a large number of children. Five households owned medium-sized fields with cattle. These households were in a better position due to the financial help coming from other family members, or because the main caretaker had an extra income. Two orphans in this study 
were taken in by middle-class households where the main caregivers could support the household financially.

HIV/AIDS had a negative influence on the food security of many households in the North-Central region (Matanyaire et al. 1999). As a grandmother explained: "All the people that supported the family died. The orphan's mother and her uncle, they used to support the family, but they died. Now I only have my pension. We have to depend on buying cornflower because the millet [from the field] won't be enough for the whole year." HIV/AIDS also influences children's access to education. For HIV/AIDS affected households, payment of fees and buying school uniforms and materials is often a burden. A grandmother told me how difficult it is for her to set aside money for the school fees of her orphaned grandchildren: "The school should not let the children pay because I am not getting enough money. I sell my chicken, eggs and Marula oil. This is the only way to get money to pay school fees."

During the household visits, the home situation of the children could be examined; caregivers were interviewed and children were observed. There were almost no opportunities to talk with the children; often the children were not present as their caregivers expected them not to interfere in adult conversations. The home visits revealed large differences in the way caregivers dealt with foster children; the powerlessness of some of these children could be observed by the way they were treated by their caretaker. Characteristics of special social environments (the home and the school) are critical in determining children's experiences and activities (Mayall 1994, 127). Researching children in both their school and home environments is essential in understanding children's experiences and their life-worlds. Children may show different behaviour in these different settings; for example, one girl showed bossy and dominant behaviour at school, though was shy and introverted at home due to the unpredictable behaviour of her mentally ill mother. Also, it was found that information provided by children about their home setting at school could be less reliable, as the influence of peer pressure within schools might alter their representations. During the Kids Club, one boy made it seem as though he was still living with his grandmother, just like the other children in the group. However, during the home visit, it became clear that in fact the boy's grandmother had died half a year ago, and that he was now staying with his younger sister and cousins in an

This is a digital offprint for restricted use only | ( 2011 Koninklijke Brill NV 
impoverished household. There was a lack of food, clothes and blankets. This kind of information can only be retrieved when the child is seen in multiple settings.

\section{Orphans' Experiences within their Home and School Situations}

While the aim of this chapter is primarily to describe and reflect on childfocused methodologies and their uses, I will highlight some of the more general results of the research in order to better contextualize the research setting.

The death of parents to AIDS imparts several life changing circumstances for children. Many children are forced to move away to the households of grandmothers, aunts or grand-aunts, or other kin networks. Orphans interviewed in this study had different experiences with the way they were treated within their households. Some children indicated that they were treated fairly, while others reported negative experiences. These latter children suggested they were treated badly by relatives and indicated that they are expected to do more and harder tasks because they are orphans. One of the girls demonstrated this point as follows:

"I feel so bad when somebody does not treat me the same as the ones who have their own mothers. In our house, there are some children that are treated well, and others that are treated badly. We, who are all orphans, we are not treated the same. Maybe it is just the way of other people treating you bad when you lost both your parents. Sometimes they can say: There is no food for you here. Maybe you can look for your father and mother if they have food."

All orphans experienced a heavy workload. With the loss of adults in the household, children (particularly girls) have to do more household chores and agricultural tasks. Some children also worked in the fields of other households to earn money for their own household. All orphans indicated that they had little time to do their homework.

Some HIV/AIDS-affected households must cope with daily food shortages by eating fewer meals. One particularly poor household could barely afford one meal a day. The division of food in the household can also be a problem. Some 
children mentioned that they prepared their breakfast in the evening, but that it was regularly stolen by other children in the household, so that they had to go to school without breakfast. Several children had trouble concentrating in school because of their low energy due to a lack of food. One girl said; "Sometimes you are looking at the teacher, but you didn't hear anything, you are just thinking about food. Your mind is not in the class. Sometimes they ask you: 'do you understand?' Then I say 'yes', but I didn't hear anything." Some orphans were bullied by other children at school because they looked poor and because other children knew that they wouldn't be punished as orphans do not have parents to protect them.

\section{Loss of Parents}

Children also commented on the more general impacts of losing parents. Many children cited the loss of care and attention, remembering how their parents would bring them food and clothes. When a parent dies, children lose a person that would otherwise take care of them; children are thus less positioned to meet elementary needs of food and clothes. Children often had these needs in their minds; they thought about it at school and in other moments of daily life. One boy mentioned: "There are things that make me sad. Because when my mother came from Windhoek, she used to bring me clothes and chips and things like that. And now there is nobody." Several of the children in the Kids Club lost their parents when they were too young to remember them. These children know almost nothing about their parents, and as one girl put it, "nobody tells me."

Orphans' perceptions of family seem to be less based on the notion of a nuclear family than non-orphans. When asked to make a drawing about family, the non-orphans made a drawing of their nuclear family, while the orphans would draw different compositions; some made only a drawing about themselves or their siblings, while others would draw their deceased parents, their current caretaker or their cousins. Most orphans who experienced the loss of their parents were worried that their current caretaker might die as well. The children wondered where they could live if their current caregiver were to die. A few children did not want to stay in their current home because they were 
afraid that their position would get worse. One boy feared that his cousins would have more power over him when his ailing mother died; two orphans were afraid that an aunt with whom they did not get along would take over the household; and other children were afraid they would be left alone in the house or sent away once a parent died. One boy related: "If my grandmother dies I have nowhere to stay because I don't know if the housemaid will chase me, I have no idea. But I don't think anybody wants to take that responsibility." In addition to constantly repositioning themselves within the complicated and changing socio-economic landscape they live in, AIDS orphaned children face existential problems of fear, loneliness and anxiety as well.

The lack of openness about HIV/AIDS that marked the reactions of most teachers and caretakers of the children in the Kids Club was also seen in the reactions of the children; talking about death through AIDS was a very sensitive issue to discuss (see Group Interviews with Children). The children's knowledge of HIV/AIDS was very limited since they were not informed by their teachers or caretakers. Children searched for information on HIV/AIDS themselves; they looked in books from older siblings or cousins, and indicated that they wanted to be more aware of HIV/AIDS in order to protect themselves: "I want to learn about HIV/AIDS, so when I grow up, I can protect myself against this disease," one child said. When the children of the Kids Club were asked what they wanted to do in the future, most of them chose an occupation related to the HIV/AIDS epidemic. One girl wanted to bring awareness to the situation of orphans by becoming a minister one day, while another girl wanted to become a counsellor so she could read the bible to sick people and help them when they had problems. Other children wanted to become doctors or nurses to help ill people.

\section{Evaluation of the Kids Club}

The aim of the Kids Club was to create a comfortable and safe environment in which children felt free to discuss sensitive issues, and was designed to minimize risks of negative effects. The Kids Club research in 2010 focused on evaluating the effectiveness of this approach in mitigating negative impacts 
of sensitive discussions. The fourteen respondents were now adolescents, and research centred on how they experienced taking part in the research.

\section{Evaluation of the Kids Club}

In the 2003/2004 study, I encouraged children to evaluate every session of the Kids Club so I could change and improve the research methods. However, children always evaluated the methods positively. It was not clear whether the children were too shy to express their opinion, were just not used to expressing their views, or whether they were really pleased with the methods. I therefore evaluated the methods with them again in the follow up study in 2010. All adolescents remembered the Kids Club, and they mostly recalled the nice things and "a lot of enjoyments," as one girl put it. These included the songs and games, the drawing and the home visits. As in the 2003/2004 study, most of the adolescents mentioned that there was nothing about the Kids Club they did not like, except for three who disliked the group interviews, and one who disliked the drawing assignments. Two adolescents evaluated the group discussions negatively because it was difficult for them to understand the questions. One girl did not feel comfortable participating in the group interviews: "I am a very shy person; I am not courageous enough to answer questions." She preferred individual interviews and speaking only with the researcher and the interpreter. This was in accordance with my experiences during the Kids Club, where I observed that withdrawn children made a limited contribution to the discussion and seemed too shy to answer questions in a group. The girl who did not like the drawing assignments explained: "I don't know how to draw." It is thus important in interviews that questions are in accordance with the age and life-worlds of children so as to avoid feelings of insecurity. Shy children should also be interviewed individually. When using drawings as a research method, it is also important to stress that the assignment is not about the drawing skills of the children.

Participating in the Kids Club was generally evaluated positively. At the end of the research in 2004, all children wanted the school to continue with the Kids Club because, as one girl said, "It is good to talk with each other about our problems, it helps." In the follow-up study, the adolescents explained that after 
the research had finished, they had continued themselves with the Kids Club. They came together after school in one of the class rooms to hold a session. The adolescents had different memories about the duration (two months, a few weeks); how often they would come together (4 days a week, 1 day a week); which activities they carried out (play games, or tell each other funny stories); and how many children would come together (several members of the original group, only a few). Some of the testimonies were as follows:

In the beginning we still used to meet to do our Kids Club. We continued with playing games and telling stories to each other. We used to tell about our situation. When you have problems with your family or with your friends, we discuss it, and we solve it. (Girl)

I was always thinking about the Kids Club. I liked the club very much. Then we used to come together by our own. And sometimes one of the teachers used to teach us. We used to come together but we would only come together in the class room and play games. But we would not explain and not discuss about things like with you. (Girl)

A few adolescents started looking for other clubs to join after the Kids Club ended:

When I realized that the Kids Club would not come back, I joined the Window of Hope club. When I started schooling in my new town I heard about another club. I was thinking maybe the Kids Club is working together this club, so I joined them. It was a lot of enjoyment, just like the Kids Club. (Girl)

In the year following the termination of research, the children of the Kids Club came together on some occasions. When one of the boys wanted to drop out of school in grade 6, some children of the Kids Club came together and tried to convince him not to leave. The boy stayed in school for a few more years, and eventually dropped out in grade 9 .

He wanted to drop school. We called him during the study time and gave him advice not to drop school. Then he proceeded in grade 6. (Girl)

As is mentioned in the section on 'ethical issues', transparency in interacting with children is important. In the 2003/2004 study, I explained the aim of the research clearly and what would happen to results of the study. Six years later, half of the group could not remember why they had been selected for the Kids Club. The others remembered that they had been participating in the Kids Club 
because the group was there to help children who lost their parents; some mentioned the Club was intended:

To treat orphans well, make them feel good, so that they can't think about bad things, like the death of parents. (Girl)

To make life better for one and another. When you come home from school, maybe there is hunger, maybe there is no food to eat. And then when you come to the Kids Club there is something to eat. And you can share ideas with each other, motivate each other and give each other advice. (Boy)

Most of the adolescents could also not remember why I had been writing down things they told me, while others had different explanations. Some thought that I was taking notes to take it with me when I went home, while others thought I would read it when I was missing the children of the Kids Club. Still others figured I would write a report or tell my friends, family and neighbours about the Kids Club. When I explained what had happened with the results, ${ }^{10}$ all mentioned that it made them feel good and proud. They had different explanations for this:

Now the people can read our stories. If a person is acting badly toward the orphans in her house, she has to behave better when she has read our stories. (Girl)

I feel good that our stories are shared with other people beyond this country. (Girl)

When people read about me, they are going to learn about children that have lost their parents. (Boy)

Then the government will know how to help the orphans. (Boy)

It is good that people will know what kind of things children are experiencing in their lives, and how children feel about it. (Girl)

It's a memory of when I was young. (Girl)

It makes me a happy guy that my drawings are in a book. (Boy)

Thus, the Kids Club also gave the children a forum to discuss difficulties which they could not express elsewhere.

${ }_{10}$ The thesis was published as a book; a report was written for the NGO Ibis, and the Namibian Ministry of Education; and the research formed part of the "Children's Voices" project (see footnote 2, above). 


\section{Effects of Participation}

Participation in the Kids Club seems to have had positive effects on the children, both when the Kids Club was active in 2003/2004 and later on. In a follow-up study on the children after six months (following the initial study), caregivers expressed that the children showed more self-confidence after the research. In the 2010 study, seven caregivers were asked if they had noticed any change in the children after participation in the Kids Club. Some did not remember any changes, others noticed a change. Two caretakers mentioned that their child was more interested in going to school as a result of the Kids Club, and two other caretakers mentioned that their child was withdrawn and quiet before participating in the Kids Club, but afterwards and ever since, happy and more interactive. Some adolescents mentioned that the Kids Club had been important for them because they could forget their problems:

Sometimes I was disappointed. When I came to the Kids Club, I feel fine again. (Girl)

During that time, I was always stressed. When I came to the Kids Club, I felt better, because every time you were asking some questions. (Girl)

If I would not have been in the club, then I would still have been sad and thinking about the loss of my parents. (Boy)

When a child is in the Kids Club, especially those who lost their parents, it helps to forget what is happening in her life. The child is concentrating on the things that she does in the Kids Club instead of thinking of parents that passed away. In her mind, there are things that are comforting her. (Boy)

Some also mentioned that being in the Kids Club helped them get through a difficult situation or made them feel freer to talk:

The Kids Club helped me to be free, free to say what I wanted. I got more information on how to communicate. I was always afraid to say something at school. In the Kids Club I learned how to be free when you want to say something. (Boy)

It gave me courage to battle the situation I was in and it helped me to get out. (Girl)

The adolescents remembered that they became friends with other children from the Kids Club. While some still see their friends from the Kids Club regularly, others have since moved away and now have less contact:

This is a digital offprint for restricted use only | ( 2011 Koninklijke Brill NV 
I missed the Kids Club because of the good times that we used to have together, with my friends. Now we don't really come together as it was in the Kids Club. (Boy)

A recurrent theme in evaluations of the 2010 adolescents was the importance of encouraging each other, and how they would give each other advice during Kids Club. This is interesting as children very rarely gave each other actual advice in group interviews: they would mostly just tell their story. However, the sharing of their stories was apparently remembered as encouraging and helping:

When we had Kids Club meetings, it helped us encouraging each other. (Girl)

We used to talk about how to behave yourself and how to deal with others. (Girl)

The ideas that we used to share: like how to overcome challenges that we are facing. (Girl)

We were able to come together with other children who lost their parents and give each other advice. (Girl)

I was thus left wondering whether the adolescents thought it to be important for children who lost parents to AIDS to talk about their problems. All adolescents considered it important because, on the one hand, children can receive assistance and advice when they talk about their problems, and on the other hand, it helps children to emotionally deal with their problems. In the words of some respondents:

Sometimes when one is having a problem, but there is no one to tell; they can even end up not going to school because of the problem. (Girl)

It is important that the problem will not overcome you. If you talk to the other he will encourage you, or he can give advice, so that you will be ok. (Boy)

It is good if you talk about it, then you don't have to think about the death of your parents, because you are sharing it with people. (Girl)

It can be a relief. If you keep quiet about your problems, it will effect you, it eats you up. If you are able to share it with others, they may be able to advice you, on how to overcome that. (Girl)

Some children lose their focus when they lose their parents. They need some kind of fun, so that they can feel comfortable, even when they are in school. (Boy) 
It is interesting to note that the Kids Club also offered the adolescents a reflexive tool to think about their lives and challenges.

\section{Conclusion}

This chapter describes how a Kids Club, or the "Kids Club Method," was used to talk with children orphaned by AIDS about sensitive issues surrounding their changed life situation emerging from the loss of their parents. This method was particularly useful within a pre-existing context in which there is a lack of openness in talking about HIV/AIDS and death, and in which children are not used to voicing their opinions to adults.

The results from the 2003/2004 study in northern Namibia showed that children orphaned by AIDS are in a vulnerable position. Many children are taken in by caregivers living in households already impoverished by HIV/AIDS. Some orphans are treated with less respect than non-orphans in the household. Children expressed missing their deceased parents, and were often worried that their current caretaker would die.

Results of this study revealed that various aspects of the Kids Club appeared to have helped children talk about sensitive and personal issues. Meeting with children as a group over a longer period of time provided the opportunity to build confidence and to develop an open relationship between the children themselves, and between the children and the researcher and interpreter. Within this context, attention to ethical issues and an empathetic attitude of the researcher and interpreter is crucial. The setting where meetings take place also plays an important role; while children had more opportunities to talk about their home situation in a school setting, they were more restricted in the domestic arena. General subject-areas, such as friendship and family, offered a basis upon which to relate more personal and difficult experiences, while also giving some insight into the daily lives of children. The use of various methods (e.g. drawings, group discussions) offers children the possibility to express themselves in different ways. Indirect methods such as drawing and talking about drawings are particularly suitable for shy children; however, group discussions have the advantage of allowing children to share their experiences 
with each other. To adequately address the difficult lives of these children, attention should be paid to the different living situations and contexts of the child. In this research, home visits provided crucial information; for instance, the social desirability and appropriateness of questions and answers could be obtained and understood within the domestic context, and conversations with caregivers offered a clearer background to the experiences of the orphans.

A follow-up study, six years later, showed that participating in the research was evaluated positively by the (now) adolescents. The Kids Club was seen as a place where children could forget about their problems, and where children built friendships. The adolescents experienced the sharing of their stories as a way of encouraging each other and giving each other advice. The follow-up study further showed that children's evaluations of the research methods used in the Kids Club yielded more information than their 2003/2004 evaluations. While in the 2003/2004 study children evaluated all methods positively, in the 2010 study, a few adolescents mentioned they did not like the group interviews or drawings. The evaluation of research methods with children is an important issue to further consider, especially in regard to research with children who are not used to openly expressing their opinions.

\section{References}

American Society for Research in Child Development (SRCD) (n.d.), Ethical issues for research with children. URL: http://www.srcd.org/ethicalstandards (accessed 22 November 2010).

Blagbrough, J. (1998), Collecting information from child domestic workers: Some ethical issues. In: V. Johnson, E. Ivan Smith, G. Gordon, P. Pridmore \& P. Scott, eds, Stepping forward: Children and young people's participation in the developing process, pp. 34-36. London: Intermediate Technology Publications.

BleEker, H. \& K. Mulderij (1984), Wie is er bang voor kinderen? In: Over participerende observaties. Pedagogiek op je knieën. Aspecten van kwalitatief-pedagogisch onderzoek, pp. 79-99. Meppel \& Amsterdam: Boom.

CAPUTO, V. (1994), Anthropology's silent 'others'; A consideration of some conceptual and methodological issues for the study of youth and children's cultures. In: V. Amit-Talai \& H. Wulff, eds, Youth Cultures, pp. 19-40. London \& New York: Routledge.

Christensen, P. \& A. James (2008), Childhood diversity and commonality: Some methodological insights. In Research with children: Perspectives and practices, pp. 156-172. London, New York: Routledge.

Clacherty, G. \& D. Donald (2007), Child participation in research: Reflections on ethical challenges in the southern African context. African Journal of AIDS Research 6: 147-156.

This is a digital offprint for restricted use only | ( 2011 Koninklijke Brill NV 
Daniel, M., H.M. Apila, R. BJøRGo \& G.T. Lie (2007), Breaching cultural silence: Enhancing resilience among Ugandan orphans. African Journal of AIDS Research 6: 109-120.

Fine, G.A. \& K.L. SAndstrom (1988), Researchers and kids, pp. 13-35 \& Participant observation with preadolescents, pp. 49-59, In: Knowing children, participant observation with minors. London \& New Dehli: Sage Publications.

HiLl, M. (1998), Ethical issues in qualitative methodology with children. In: D. Hogan \& R. Gilligan, eds, Researching children's experiences: Qualitative approaches, pp. 11-22. Dublin: Children's Research Centre TCD.

IPPR (2003), Review of welfare grants. Report prepared by the Institute for Public Policy Research for the Ministry of Women's Affairs and Child Welfare, Windhoek, Namibia.

Johnson, V. (1998), Summary and introduction. In: V. Johnson, E. Ivan Smith, G. Gordon, P. Pridmore \& P. Scott, eds, Stepping forward: Children and young people's participation in the developing process, pp. 21-28. London: Intermediate Technology Publications.

LeVine, R., S. Dixon, S. LeVine, A. Richman, H. Liederman, C. Keefer \& T. Brazelton (1994), Child care and culture. Lessons from Africa. Cambridge, Cambridge University Press.

Matanyaire, E.J. \& E. Timpo (1999), The impact of AIDS on farming communities in Namibia. Windhoek.

Malan, J.S. (1980), The Wambo. In: The peoples of South West Africa, pp. 75-92. Pretoria: HAUM Press.

MALLMANN CPS, S.S (2003), Building resilience in children affected by HIV/AIDS. Cape Town: Maskew Miller Longman, Catholic AIDS Action.

MAYALL, B. (1994), Introduction \& children in action at home and school. In: Children's childhoods observed and experienced pp. 1-12 \& 115-127. London: Falmer Press.

Mendelsohn, J., S. El Obeid \& S. Roberts (2000), A profile of North-Central Namibia. Environmental profiles project, prepared for the Ministry of Environment and Education. Windhoek: Gamsberg Macmillan Publishers.

MINISTRY OF HEALTH AND SOCIAL SERVICES NAMIBIA, ORC MACRO (2007), 2006: Namibian and Demographic Health Servey: Priliminary Tables. July, Calverton.

SIAPAC (2002), A situation analysis of orphan children in Namibia. Prepared by the Social Impact Assessment and Policy Analysis Corporation (SIAPAC) for the Ministry of Health and Social Services and UNICEF, Windhoek.

ScotT, J. (2008), Children as respondents; The challenge for quantitative methods. In: P. Christensen \& A. James, eds, A research with children, perspectives and practices, pp. 87-109. London: Falmer Press.

UNAIDS (2009), AIDS epidemic update. Geneva.

UNAIDS (2008) Country Situation Namibia. URL: http://data.unaids.org/pub/ FactSheet/2008/ sao8_nam_en.pdf (accessed 22 November 2010).

UNICEF (1995), Children in Namibia. Reaching towards the rights of every child. Windhoek: UNICEF.

UNICEF (2002). Psychosocial Well-Being for Children and Adolescents. Activity Manual for Children Care-givers. Geneva.

VAN DER BRUG, M. (2007), World and experiences of AIDS orphans in North-Central Namibia. Leiden: African Studies Centre. 



\section{3}

\section{Understanding Children's Well-Being and Transitions Through the Life Course: A Case from Ethiopia}

Yisak Tafere

\section{Introduction}

In trying to understand children's well-being and life transitions, researchers have become engaged in different methodological and theoretical approaches. In most cases, key transitions in a child's life and his/her well-being have been treated as separate categories. For instance, a lot of studies have explored children's 'educational transition' or 'health' as an aspect of well-being. Rarely do these fora coincide in academic studies.

Although standardized and adult-centred methods have been widely used by researchers, recent trends indicate that a major analytical shift has been made to incorporate children's perspectives. Involvement of children in such studies includes participation in interviews, group activities and self-reporting.

This is a digital offprint for restricted use only | (c) 2011 Koninklijke Brill NV 
This study aims to contribute to the existing theoretical and methodological debates surrounding our understanding of the lives of children in Ethiopia. Using the 'life-course' approach, it attempts to explore children's well-being and key transitional periods as more integrated and interrelated aspects of their lives. I have taken 'educational transitions' and 'health' as representatives of children's 'key transitions' and 'well-being', respectively. Moreover, as data have been generated through the participation of children and by using different methods, this chapter attempts to reflect on whether children could be 'reliable' sources of information in constructing their life courses. In this chapter, I argue that a life-course perspective helps to understand children's well-being and transition in an integrated way, and that children themselves remain the best sources of data when it comes to their own lives.

This study draws on the longitudinal Young Lives ${ }^{1}$ study among children aged 12-13 in two communities in Ethiopia. The paper starts by reviewing theoretical and methodological debates on children's well-being, transitions, life-course perspectives, and participation in research. It further sets out the relevant country background and research contexts. Subsequent sections analyse the research results and discuss major findings. Finally, brief concluding remarks are provided.

\section{Theoretical and Methodological Background}

\section{Child Well-Being, Transition and the Life Course}

Disparate methodological approaches, varied research contexts and a diversity of scholarly perceptions have left the definition of 'well-being' open to debate.

\footnotetext{
${ }^{1}$ Young Lives, run by Oxford University, is an innovative longitudinal research project investigating the changing nature of childhood poverty. Young Lives is tracking 12,000 children in Ethiopia, India (Andhra Pradesh), Peru and Vietnam over 15 years through a quantitative survey and participatory qualitative research, linked to policy analysis. Young Lives is core-funded by the UK Department for International Development (DFID) for the benefit of developing countries. Sub-studies are funded by IDRC (in Ethiopia), UNICEF (in India), the Bernard van Leer Foundation (in India and Peru) and Irish Aid (in Vietnam). The views expressed here are those of the author. They are not necessarily those of the Young Lives project, the University of Oxford, DFID or other funders.
}

This is a digital offprint for restricted use only | ( 2011 Koninklijke Brill NV 
A review of the literature on well-being by Camfield et al. (2008) reflects the diversity of 'definitions' that emerge within different contexts. An example is the conceptualisation of well-being by the Research Group on Well-being in Developing Countries ( $\mathrm{WeD})^{2}$ as having, doing and thinking (McGregor et al. 2007). People's well-being can be explained in terms of what they have control of (having different resources), what they can do with what they have (usage of what they possess) and their perceptions of what they posses or what they do.

Multiple approaches are used to measure well-being (Camfield et al. 2008). For instance, while researchers use Gross Domestic Product (GDP) to measure economic resources, cognitive outcome measures might be used for child development indices. Over the past several years, an understanding of children's well-being has emerged as one component of many new approaches to study children's lives. Research carried out within 25 European Union countries indicates that children categorised their well-being according to their material situation, housing, 'health', subjective well-being, 'education', relationships, civic participation, and risk and safety (Bradshaw 2007). The New Index of Child and Youth Well-being (Land et al. 2001) includes the following seven quality-of-life domains: Material well-being, social relationships, health, safety/ behavioural concerns, productive activity (educational attainments), place in community (participation in schooling or work institutions), and emotional/ spiritual well-being.

When studying children's well-being, two challenges and analytical questions are evident. First, should we study childhood as 'well-being' or 'wellbecoming'? Second, with regard to methodology can children provide adequate data about their lives? The first question is discussed here, while the latter will be addressed later.

Any paradigm change in the study of children's well-being has to ensure a shift from focusing on 'well-becoming' (attaining eventual well-being in adulthood) to 'well-being' (attaining well-being during childhood) (Ben-Arieh

\footnotetext{
2 The Research on Well-being in Developing Countries (WeD) at the University of Bath (UK) conducted research in four countries: Bangladesh, Ethiopia, Peru and Thailand, 2002-2007. The author was a member of the research team in Ethiopia.
} 
2006, 7). In other words, it is necessary to move beyond the outcomeoriented, adult centred approach and focus more on child-centred, contextspecific processes. The former focus is in direct opposition to the view that children are a form of human capital. The first approach also analyses outcomes rather than the quality of everyday life of the child; as such, it regards childhood as a stage to get through-or even to 'endure'-for the sake of certain, preferred adult gains (Ben-Arieh et al. 2001). Qvortrup (1999) describes 'well-being' as the present life of children whereas the 'well-becoming' is oriented towards achievement of well-being during adulthood (in Ben-Arieh et al. 2001).

While recognizing the importance of the new shift-from children's wellbecoming to well-being, it is nevertheless difficult to think of one independent of the other. Children are in a state of 'transition' in life, and their present wellbeing and future well-being are inseparable. Transitions are considered to be important turning points or events involving delicate, multifaceted processes of 'becoming somebody' (Eccelestone et al. 2005). The most common transitions for children of this age may be related to education, work, rites of passages (ritualized processes of transition from one identity to another), societal roles, and responsibilities.

'Well-being' and 'transitions' (e.g. 'becoming') strongly interact over the life course of children, thus any attempt to understand one without the other is fraught with difficulty. The problem, of course, is to find an 'appropriate' approach that would help us to understand both 'being' and 'becoming' as integrated components of children's lives. The life-course perspective can answer this.

According to Giele \& Elder $(1998,22)$ a life course is defined as "a sequence of socially defined events and roles that the individual enacts over time." It follows individuals as they undergo transitions, commonly focusing on patterns as well as outcomes of various patterns, including health and 'well-being' (Giele \& Elder 1998, 26). The life course is not a purely individual matter but also relates to the historical context and cultural dynamics in which these biographies unfold; it thus addresses the complex interplay between biography and history. According to Giele \& Elder (1998), the life course approach was developed in response to an effort to understand the implications and impacts of social change on individual lives. Riley 
$(1998,29)$ argues that life changes (e.g. ageing and succession of cohorts) are in a continuous interplay with shifts in societal structures.

To understand how earlier events influence the present (and might impact upon the future), and to understand the processes by which various life changes occur, it is essential to have accurate data about both the past and the present. This presents the need to collect longitudinal data (Scot and Alwin 1998, 99-103). The life course perspective explicitly emphasizes the need to consider individual lives from the point of view of trajectories of events and experiences. While it covers all stages of human life, this perspective also applies to specific age levels, e.g. childhood, adolescence, adulthood, or old age. Health, education and family matters which developed during key stages of of growth often impact deeply upon children's life chances. For instance, children facing health problems would potentially be disadvantaged in their educational pursuits. Earlier life experiences affect later life outcomes, implying that present and future well-being are strongly interlinked. For these reasons, I am proposing a 'life course perspective' which is longitudinal and multilevel, as useful in understanding children's well-being and transitions both as processes and outcomes.

\section{Children's Participation in Research}

Attempts to understand child well-being have been rooted in the culture of developed countries (Ben-Arieh 2006, 2). As a result, much of the methodological debates reviewed here are from studies conducted by Western researchers and in Western contexts where adults have been the main source of information about children. Children were simply taken as 'members' of the larger 'household', usually considered as a unit of analysis in itself. Studies of households are conducted as if children are auxiliary members whose presence contributes, for example, to the measurement of household size (Scott 2000).

Recently, however, there has been a growing interest in including children's perspectives-primarily using qualitative participatory methods (for example, see Scott 2000; Clark 2005; Ben-Arieh 2005; Fattore et al. 2007; Komulaninen 2007). The attitude that 'children should be seen, not heard', is being confronted by "the growing demand for research that involves interviewing 
children" (Scott 2000, 98). However, children's participation in research may go beyond verbal exchange to involve observations, interviews or activity-based discussions (Clark 2005). Ben-Arieh argues that the best source of information on children's daily activities and lives is the children themselves (Ben-Arieh 2005, 582). This is mainly because "there are likely to be differences in the meanings which adults and children attribute to well-being, based on time and generation" (Fattore et al. 2007, 11).

Moreover, involving children in research might also be considered to be part of exercising their rights. Ben-Arieh $(2005,575)$ maintains that "if children are granted only partial legal and civil rights and the partial ability to participate in decision-making about their lives, then they should participate at least in the same proportion in the study of their well-being."

Researchers debate the extent to which children should participate in research. Some are sceptical of the "ambiguity of the child voice" (Komulaninen 2007). Drawing on a research project on young people with communication difficulties, Komulanine $(2007,11)$ argues that "listening to children is beset by practical and ethical ambiguities that result from the social-ness of human interactions, discourse and practices." Despite the idea of 'children's voices' as being a powerful symbolic device, it is nevertheless 'socially constructed' with obvious adult influences, which makes the children's voices ambiguous. For James (2007) the problems go as far as creating conceptual and epistemological challenges. 'Giving voice to children' would pose a threat for future childhood research because of questions of representation, authenticity, the diversity of children's experiences and children's participation in research (James 2007, 261). She further argues that asking children does not guarantee that their views will not be 'dismissed' later by adults. Even the questions asked may be reflections of adult conceptions of childhood, not of children's own perceptions of daily life. For instance, child well-being measurements are based on standardized measures of satisfaction identified as important to (adult) researchers, to which individual children are asked to respond (Fattore et al. 2007, 12). This further complicates the role of adult researchers in influencing studies of children's well-being.

A new approach to the study of childhood should open up theoretical and conceptual space in which 'speaking' needs to ensure that children's voices and 
views are heard. James $(2007,262)$ suggests that "giving voice to children is not or only about letting children speak; it is about the social world that children's perspectives can provide." Conversely, she warns that taking "research by children as authentic" is problematic as it fails to address important challenges; James $(2007,263)$ explains that it remains a "challenge offered to childhood studies by anthropology's own history and by what anthropological research with children has, in the future, to confront." Thus looking for authentic voices of children is problematic because "(a)uthenticity implies authority, reliability, and trustworthiness: Original words, thoughts, and so forth gained first hand" (ibid., 265).

As the debates reviewed above suggest, understanding children's lives is not an easy task. What remains at the centre of these debates are questions related to the influence of both adults and researchers, as well as the ambiguity and 'authenticity' of children's voices. However, these challenges could be overcome by using different methods, including participatory approaches (Scott 2000) and child-focused activities. I argue that children's views would be more useful in understanding their experiences of 'well-being' and transitions over the course of their lives.

\section{The Study}

\section{Country Context}

Ethiopia is one of the poorest countries in the world with low quality child healthcare and education. It is the third most populous country in Africa, with a population of nearly 74 million according to the national census of 2007 conducted by the Central Statistics Authority (CSA). Children aged 11-16 constitute 15.49 percent of the total population with the same gender ratio as that of the whole population (CSA 2008). It seems very appropriate to strive for a better understanding of the lives of such a large proportion of the Ethiopian population.

As in many cases, studies on child education and health have largely been based on surveys and on adults-centred methods in Ethiopia, with the 
exception of a handful of recent qualitative studies (cf. Camfield \& Tafere 2009; Tekola in press; Poluha 2007). As discussed above, children's participation in research is also a means in which they can exercise their rights; thus childcentred approaches remain the focus of this study. This chapter thus provides an innovative approach to children's perspectives as it considers children's well-being, educational experiences and key transitional periods over a long period of time (the 'life course' method).

\section{Research Context}

As of 2002, this study began following two cohorts of children and is planned to continue over the next 15 years. The 'Younger Cohorts' include 2,000 children born in 2000/1; in turn, 1,000 'Older Cohorts' were born in 1994/5. These children were drawn from 20 communities selected from five regions, where more than $95 \%$ of the Ethiopian population lives. The sampling of the communities was based on household poverty, ethnic and religious diversity, rural/ urban living divides, and other markers of difference. In each community, 100 younger cohorts and 50 older cohorts and their caregivers were included in the longitudinal research.

For the qualitative research component, five communities (three rural and two urban) from the five regions were sub-sampled from the surveyed children. Twelve (6 older and 6 younger) children were drawn from each community as longitudinal cases, with an additional eight children from each community selected as backups.

This paper draws upon data from 12 older cohort children (and eight backup children), aged 12/13, from two communities ${ }^{3}$ of Atkilt-tera from Addis Ababa and Leki from Oromia Region. At Atkilt-tera, poor people with different ethnic and religious backgrounds live together. This community is centred around a nearby market for vegetables, which has both positive and negative effects on adults and children; it is a source of income for daily workers, store-owners and petty traders in the community, though at the same time the rotting veg-

\footnotetext{
${ }^{3}$ Real names of communities have been replaced by pseudonyms to ensure their anonymity.
} 
etables have a major impact on human health. The Leki community, situated in the Eastern part of Oromia Region, is inhabited predominantly by Oromiffa speaking Orthodox Christians. Most households earn their living through agriculture, irrigating fields and fishing. Such livelihood strategies easily drawn in child labour. While there is one primary school and a health post in the community, there are no kindergarten schools.

\section{Methods}

The main purpose of this study is to understand children's well-being in relation to key transitions, using life course methods. Data were generated mainly through qualitative methods involving both group activities and individual interviews. Individual interviews with children followed group activities to discuss, in detail, their well-being, education and relationships over the course of their lives. Caregivers were also asked about the lives of their children.

Children's group activities/discussions aimed to help children recall their past and present experiences relevant to their whole life courses. Five children participated in each group activity/discussion. Two groups of boys and girls from each community were organized separately as some of the drawings and discussions appeared to be gender sensitive. The group activities involved body mapping and a well-being exercise (Johnston 2006), and individual activities entailed the life-course-draw-and-tell method and interviews.

\section{Body Mapping}

The main purpose of this exercise was to explore how the body (e.g. bodily experiences) might impact upon children's current sense of well-being. This could be past or present experiences affecting their physical, psychological, social or other aspects of their lives.

In order to generate data, the children were first asked to think, on their own, about anything that might have happened to their body that affects their present situation. Second, the children drew the body of one volunteer child lying on the floor on top of a big flip chart. Each child wrote down what had 
happened to her/his body parts, with each event on a post-it note, which was then fixed on the outline of the body. For example, if anyone suffered from headaches, the child put a note on the head of the drawing. In the third step, the facilitator asked each child to discuss how and why his/her illness/injury happened. Issues related to how it affected his/her life in terms of health, schooling, relationships, etc. as well as how he/she tried to deal with it, were discussed. Each child's experiences were noted for further exploration in the life-course-draw-and-tell exercises. Finally, children were asked to rank the type of illness/injury they experienced.

\section{Well-being Exercise}

The well-being exercise was used to gather information about what children consider a 'good' or 'bad' life for peers of the same age and gender, living within their community. As 'well-being' and 'ill-being' sometimes appeared to be difficult concepts to gauge, 'good life' and 'bad life' were used instead during the fieldwork. During the pre-fieldwork piloting, these latter concepts were translated into local languages and interpreted back into English. There were four steps to the process: The first was to ask children to think about a child of their age who was not doing well. The second step was to draw the 'child in mind' with the features that constituted a 'bad life'. During the third step, based on the individual drawings, participants discussed the findings. The final step was ranking the indicators of a 'bad life' in a group with the help of the researcher.

The same steps were followed in the well-being exercise, which examined the characteristics of a who was 'doing well'. Both drawings of a 'bad life' and a 'good life' were done on the same piece of paper, divided vertically into right and left sides. This was so that it was easy to compare a child who lives a 'good life' with one who lives 'bad life'. Finally, individual drawings were collected for further discussions with the respective child in the process of constructing her/his life course. 


\section{Life-course-draw-and-tell}

This individual exercise of life-course-draw-and-tell followed the group activities of body mapping and well-being exercise. The purposes were to explore what children remember as important moments of their past (both happy and sad) and why these were memorable; in turn, the aim was to examine how children feel about their current situation and future expectations, including the extent to which these were shared by their parents, what support/resources they would need to achieve their goals, and what could prevent them. The following steps were adopted:

- Step one: Drawing a time-line

Children were provided with a blank piece of paper to depict their timeline (i.e. to draw a line representing their life course) starting with number zero (time of birth) and continuing each year up to the present and future. The 'future' time covered children's projected transitions, such as finishing school, having jobs, and getting married. They were then asked to think about their past and present lives, closing their eyes for a minute. Facilitators helped them draw 'happy memories' above the line and 'sad memories' below the line corresponding to the age at which they occurred. The children were then asked to think about the future and fill in the major changes they think will happen in the future, with drawings and/or written notes.

- Step Two: Discussions

The time-line of each child was used to discuss the major experiences that had happened in the past and present, as well as what might happen in the future. The main issues addressed for the past/present events were: The happy or sad things they experienced, what made them this way, and who had helped them cope with the sad events. Future events included both positive expectations or concerns/worries. The main issues discussed in the time-line involved aspects of well-being (such as health, family death, relationships) and key-transitions (such as schooling, work, future job, marriage, moving to other areas, etc.). Children discussed their future in terms of expectations or worries concerning their current situations as well as perceived future opportunities and constraints. 


\section{Researchers and Research Ethics}

Two field researchers were involved in each group activity. One facilitated the group activities and discussions while the other took notes. Female researchers ran the girls' session, while male researchers were involved in boys' group. There were conscious reasons for this separation; in certain group activities, like body mapping, it was anticipated that some girls might find it difficult to discuss some issues related to their bodies openly with male researchers.

This study was conducted in accordance with Young Lives ethical guidelines as approved by the Central and Departmental Research Ethics Committee at the University of Oxford. A number of principles laid out by guidelines were considered. First, during the sampling, it was necessary to consider and include every individual, regardless of gender, ethnicity or rural/urban divide. Second, care was taken to ensure that children were respected, valued, and listened to, and that their perspectives were included in the research. Third, informedconsent was sought from the principal caregiver or competent child and we recorded their oral permission to be included in the research, assuring their right to withdraw from the study at any time. Fourth, as a fair return for the time they spent, children were provided with refreshments during group activities and some money as incentives for purchasing school materials. Finally, pseudonyms were given to children to respect anonymity and confidentiality.

\section{Analysis of Results}

This section highlights the main findings related to health and education as produced through the life course perspective. Data generated through different participatory methods are extracted, described and analysed. The discussion focuses first on how children value, rank, and experience health and education, and second on how health, well-being and education are interlinked over the course of children's lives. In the second half of the analysis, both children's and caregivers' perceptions children's lives will be discussed. 


\section{Well-being and Education: Experiences and Perceptions}

Using the body mapping method, children revealed problems of illness and/or injury, the causes thereof and the effects on present well-being (see Figure 3.1). The main health problems reported by children through body mapping were headaches, stomach-aches, tonsillitis, tuberculosis, flu/common colds, breathing problems, abdominal pain, skin diseases, neck-swelling, injuries, malaria, typhoid, and eye problems. Figure 1 from Atkilt-tera depicts that many children have faced illness around their head and stomach.

Of primary importance within life course theory is the presupposition that people's experiences are affected by their socio-cultural and physical contexts (Gilele and Elder 1998). Children's experiences of ill/well-being and school transitions were thus contextualized according to shifting spatial and social conditions.

Perceived causes for health-related problems were attributed to poor environmental and household sanitation, heavy work, unclean water, poor housing, and poor nutrition. Children from Atkilt-tera were especially affected by their unclean environment, particularly related to rotting fruit and dirty, overcrowded houses. In Leki, children were considerably affected by malaria, injuries and headaches that are directly related to working for cash in farms and irrigated fields; they also suffered from stomach-aches due to drinking unclean water.

The continued impact of illnesses is the result of insufficient access to proper health care and medications in the communities. The small health-post in Leki community has no pharmacy, and as there are no drugs available, children either have to remain at home until their health 'improves' or visit traditional healers. Children are unable to fetch medication from urban areas because their parents cannot afford the costs of travel and health care. Consequently, the chronic nature of their illnesses was apparent, impacting their school and future life prospects.

In the well-being exercise children were asked to draw and discuss indicators of their ill/well-being. During the rankings, education emerged as the top indicator of well-being, while inability to attend school displayed ill-being. However, variations in the location of residence (rural/urban) and gender revealed 


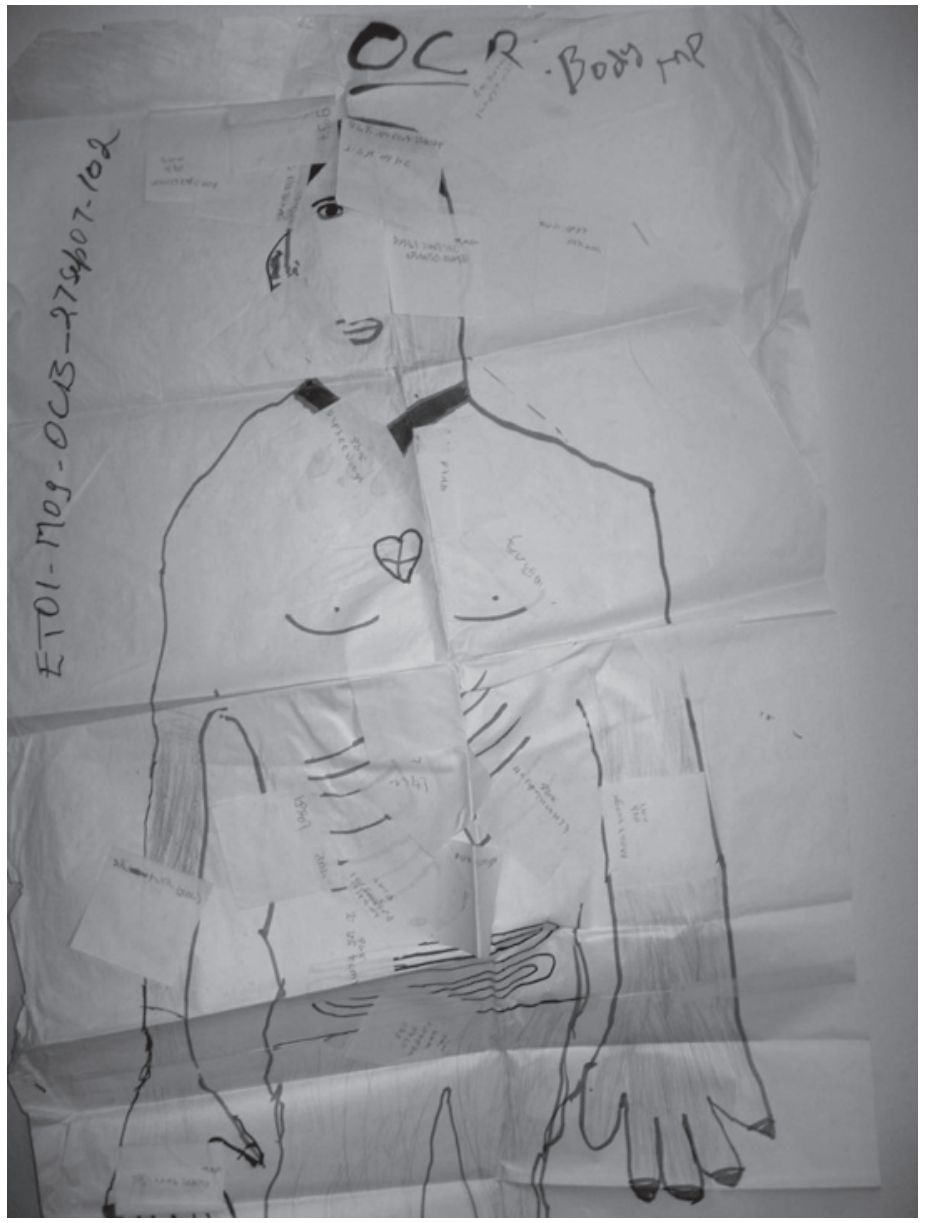

Figure 3.1 Body-Mapping of Boys in Atkilt-tera

some differences in these perceptions. While urban children considered access to education, having educational materials, food, good housing, clothing, and entertainment as important, rural children, on the contrary, gave more value to farmland, livestock, housing with corrugated iron, and the production of vegetables. This suggests that children value more what is important in their respective communities. Urban children hoped that education would help them fulfil their ambitions once they have grown up, while rural children considered land and livestock a means to everything.

Similarly, children from rural and urban areas have significantly different perceptions about ill-being. Rural children ranked lack of resources like farm- 


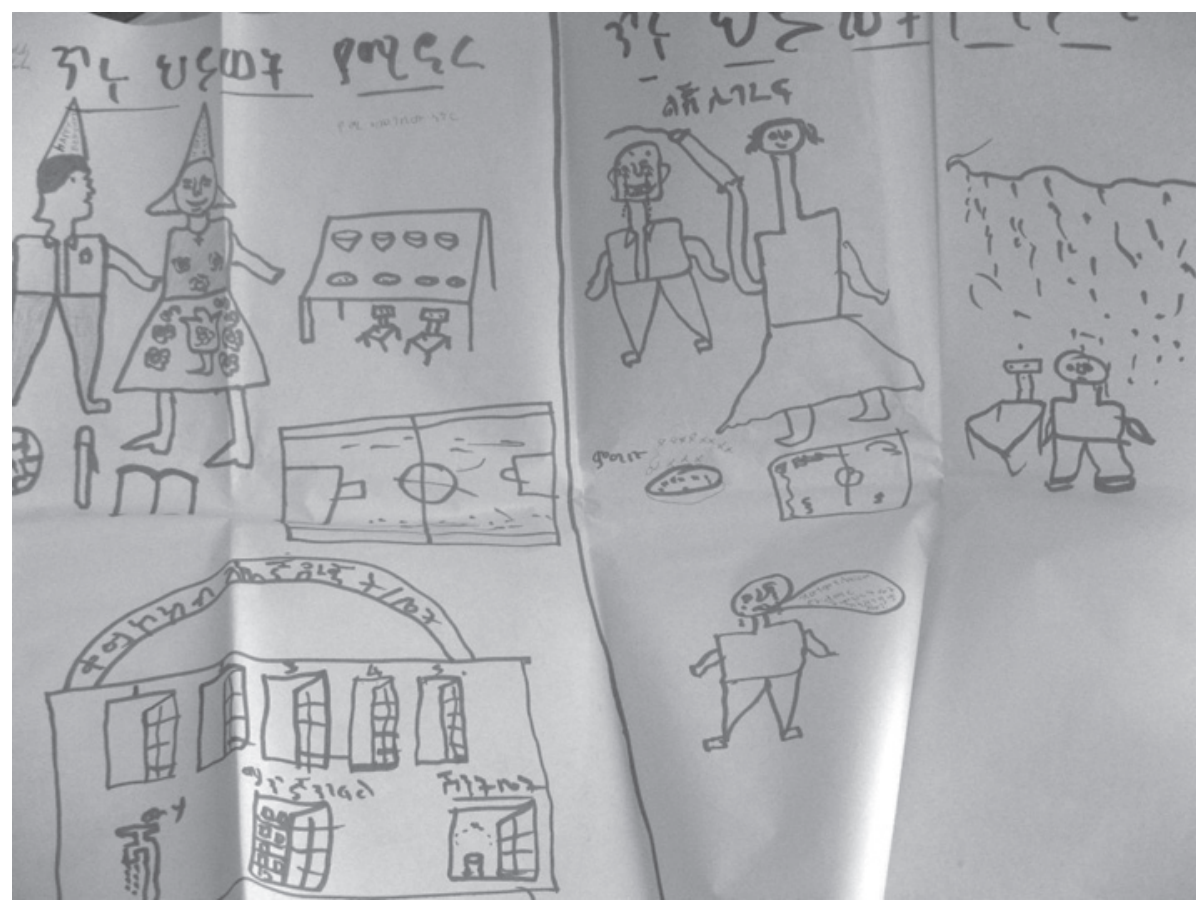

Figure 3.2 Meku's Well-Being Exercise

land, food, livestock, clothing, and housing as causes of a 'bad life'. While rural girls emphasized a lack of food, housing and clothing, boys focused more on resources like land, livestock and housing. Urban children of both sexes related a bad life to a lack of proper education, loss of parents, bad behaviour, and inadequate food. Figure 3.2, drawn by a boy from one of the urban communities, illustrates what children depict to represent their well-being and ill-being.

The child described his drawing as follows: The left side of the drawing represents 'a child living a good life'; the child has a good relationship with his family, in which the mother is giving him a flower. He has good clothing, a book and a pen, as well as a variety of foods on the table. His school is clean, with windows and a big playground. In contrast, the drawing on the right side illustrates 'a child living a bad life'; the child has bad family relationships and sadness, illustrated by being beaten by a parent. He has bad clothing, no school materials, no access to education, and lives in a very dirty area.

For drawing both 'well-being' and 'ill-being', children focused on resources (human and material) that affect their present and future lives. Let us now see 
how children's health and education interact over the course of their lives. First I will give an overview of typical responses by the children, and then illustrate these with specific cases.

Once they described their health experiences through the body mapping exercise, and indicated the importance of education through well-being activity, children attempted to depict these factors together using the lifecourse draw-and-tell time-line. Children described their educational transitions as important periods in their life course, and related other life experiences as either positively or negatively affecting their schooling. From the individual educational time-lines, it was observed that more than half of the children from the two communities had never achieved the expected grade level in school according to their age: Most were still below grade six at the age of 12-13. Several children had dropped out at least once, usually due to health problems. Nine out of the twelve children had faced illness that affected their schooling. For example, as Desse, a boy from Leki, stated, "I had to start schooling at the age of 11 because I was continuously ill during my childhood." Another child, Lemlem, a girl from Atkilt-tera, stated that "because of tuberculosis I had to drop out of kindergarten, which made me lag a grade behind my friends."

Children reported that those who can afford to do so visit health clinics when they get sick. In contrast, even for a broken leg or arm, most of them resort to traditional healers; some parents in turn provide herbs or hot food to sick children, believing that this will heal them. Being sick thus involves staying home for several days which affects school attendance. Hence, the impact of illness on education is particularly evident for poor families.

This latter point is further illustrated by an example; Figure 3.3 (see below) has been adapted ${ }^{4}$ from Ayu's life-course-draw-and-tell time-line, and emphasizes the interaction between health history and educational trajectories. Ayu's 'happy memories' started with boiling coffee at the age of four, and being second in a her class at the age of ten. Nevertheless, her time-line suggests that she rarely experienced what she perceived to be a 'good life'. Ayu recalled many 'bad memories' which are often related to illness, heavy work and dropping out

\footnotetext{
${ }^{4}$ Original drawing is changed into this format for reading convenience.
} 
of school. Since she was five years old, she has had continous health problems. Her work history involved baking injera (local bread) at the age of nine and daily labour since the age of eleven. Although she started schooling at the age of seven, she was still in the second grade at the age of thirteen. She experienced continuous pain in her neck, which continues to the present.

According to her time-line, Ayu already realises that her educational transitions will be greatly affected in the future by other transitions, namely marriage and having a child. She expects to marry at 17 , have a child at 19, complete school at 21 and become a teacher at 25. Finishing school and having a job will therefore be attained at a later age.

\section{Caregivers' Observed Reflections and Children's Own Perceptions}

We have seen how children try to depict their life trajectories through the life course method. However, part of this study involves examining how, parents and caregivers separately define, understand and perceive of their children's ill/well-being, relationships, transitions, and future hopes. The findings suggest that children's perceptions are not necessarily shared by their caregivers.

Children described their past experiences related to early illnesses, deaths in the family, education, and family relationships. While children as young as age four were able to talk about their experiences (see Figure 3.3) it became clear that many children's responses came from first consulting their family members. Thus knowledge of some earlier childhood experiences, of which the children were less aware, evidently came from the caregivers. Genet, a girl from Atkilt-tera, had an ambiguous memory of both the death of her father and her past, serious illness. While a family member said, "her father died when she was five", the child claimed, "I was told that my father died after celebrating my seventh birthday." The following example also suggests a difference in how children and their caregivers perceive of the past and present; Ayu (see also Figure 3.3) stated:

I have had neck-swelling since the age of six, but my parents never took me to clinic. I miss classes and usually drop-out. I am still in grade 2 at the age of 13 . When I see my friends learning in higher grades, I get disappointed. 


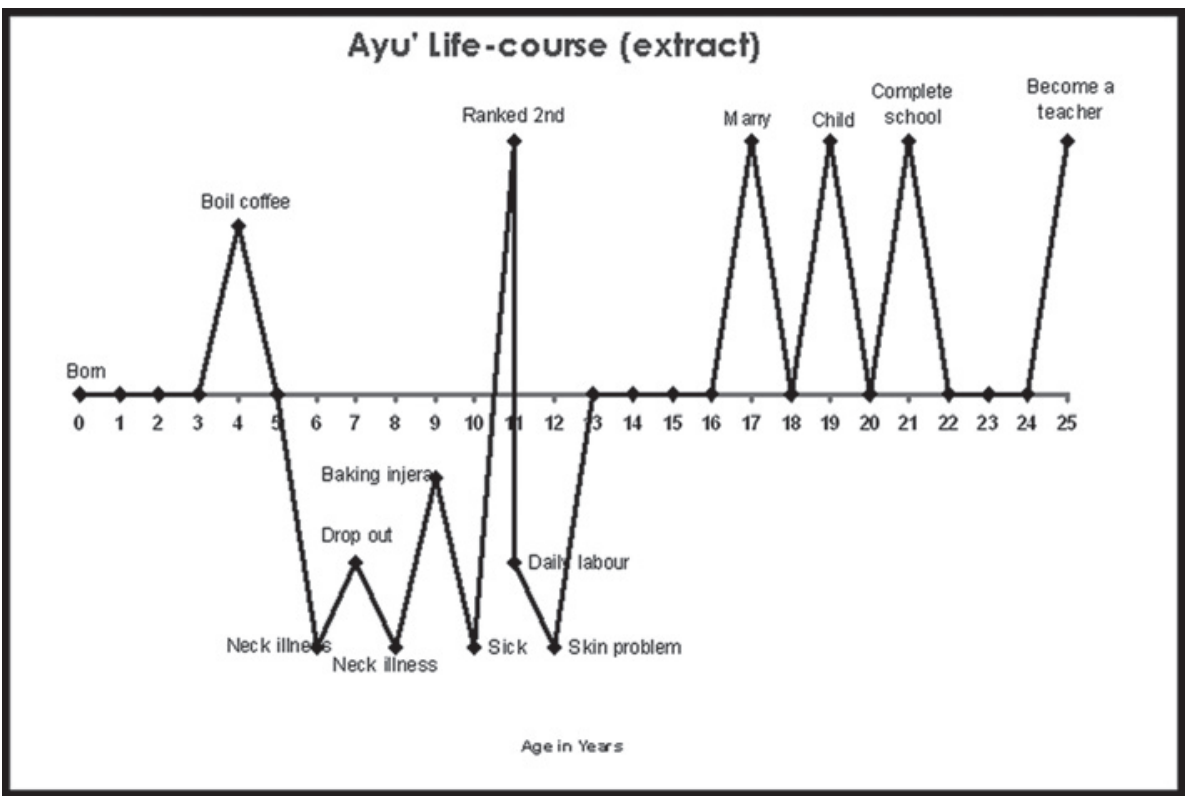

Figure 3.3 Ayu, Age 13, Life Course (adopted)

My parents send me to do daily labour and they are happy getting money. I fear that my health situation may deteriorate and this may hamper my future education and other aspects of my life.

But, Ayu's mother said,

Sometimes my daughter does daily labour, getting up to 7 birr (0.55 USD) a day. I usually advise her to focus more on her education than on dailylabour. She failed in class repeatedly because she did not realize the importance of education. While her friends are in grade six, she is only in grade 2 and she regrets that.

The caregiver believed that the child was not successful in education because she "does not realize the importance." The girl, on the contrary, believed she was lagging behind her friends in school because of her illness and work obligations. Instead of providing her with proper medical care, her parents were happy because she generated income from daily labour.

Caregivers' and children's views of the future also vary. Most parents wished for their children to have good jobs, such as becoming a doctor, a teacher or a pilot, or to go abroad. Some children had similar views, but 
most differed. For example, Bereket, a boy who works in a garage from Atkilttera said,

My grandmother wants me to be a pilot, but I do not think it will be good. Criminals may enter the plane with bombs and destroy the plane and it may be risky. So I do not want to be a pilot. I want to be an engineer or professional garage worker (mechanic).

The child associates his future with his present experiences. He wants to continue as a mechanic but in more a professional way. But his grandmother insisted, "I want my grandson to be a pilot and live abroad. He can be a big man with a great status."

In the study, a particularly interesting finding was that some children have totally different perspectives of their whole life course as compared to their caregivers. An example is an orphan child who did not know when her parents died, has been enormously overburdened by work and saw little of hope of future school success. She narrated her story as follows:

I heard that my mother died when I was one-year old. I usually think of my mother and cry. Presently, I have little time to study and usually get sad. I hate learning and my educational performance is deteriorating. Even in the classroom I usually think of household chores and daily labour that I have to perform after schooling. I am working just as if I were a donkey. If I refuse to work they beat me. I may not achieve my educational goals (the child was crying at this point) and am very dissatisfied with my current life. I have been having severe headaches as a result of workload and harassment.

The girl, Asnu, felt sad due to the death of her mother and her work-burden negatively affecting her school performance and health. She was also pessimistic about the future. However, the caregiver, her uncle, had a different perspective of her situation and admitted that he does not understand her 'internal feelings'. He said:

Her (Asnu's) mother died when she was four months old. The death of her mother has had no impact on her present life because she did not know her. Daily labour work is important for her because she cannot live and get medication without money. The work she does has no negative impacts on her health, as it is simply weeding, digging, etc. It is difficult to know her internal feelings about her future. She might face abduction and get married early. 
The caregiver seemed to be out of touch with the life of the child. He failed to see how the death of her mother and her heavy workload might negatively affect the child's life.

The above discussed cases are some of the many findings that suggest both children and parents understand children's well-being and key transitions in the life course very differently. This will be discussed more extensively in the next section.

\section{Discussion}

At this point I want to raise three issues for discussion and develop my argument based on the results presented above. The first issue deals with understanding 'childhood' as 'being' or 'becoming'. The second concerns the use of the life course perspective to understand children's well-being and transitions. Thirdly, the question of considering children as the main sources of data of their own lives will be examined.

\section{'Well-Being-in-Transition': Integrating Child Well-being and Transition through the Life Course Method}

In the study of children's well-being, some researchers (cf. Ben-Arieh 2005) strongly argue that understanding children's lives requires a change of approach. In his defense of the life course principle, Riley $(1998,30)$ insists that "(n)o single phase of a person's life can be understood apart from its antecedents and consequences." Instead of considering children as adults 'in-becoming' or the 'future generation', it would be more appropriate to take childhood as "a phase of itself" (Ben-Arieh 2004, 576). From the well-being perspective, 'becoming' presupposes that children are understood as moving into adulthood; thus wellbeing indicators might be biased as they focus on adult standards, thus overshadowing children's understandings of their own well-being.

However, people pass through key life transitions, of which childhood is a particularly influential period. Understanding the well-being of children while considering childhood as 'a stage itself' potentially raises two difficul- 
ties. First, determining childhood itself could be contentious due to the fact that it requires 'contextualization'. While there might be 'universal' models of childhood, there are no universal experiences of it. For example, in this study we have seen children from poor families obliged to combine both working for cash and education, whereas in other (perhaps "Western") contexts the former activity might reflect adult-oriented obligations. The life course approach advocates understanding human lives within specific contexts of different "social-historical and geographic locations" (Giele \& Elder 1998).

The second difficulty related to isolating childhood as a research category is that it tends to overlook the fact that children's past lives greatly affect their present and future lives. Children's life stages are so intertwined that it remains hard to draw a clear boundary between them. In this study, children have literally drawn their life courses, putting their experiences of well-being at certain stages. Instead of focusing on either 'well-being' (Ben-Arieh 2005) or human 'well-becoming' (e.g. human capital theory), I argue that we need to consider children's 'well-being-in-transition.' Children are in a constant state of transition, and their past, present and future well-being are thus inseparable.

I further argue that the life course approach is the best suited theoretical framework for understanding and interpreting children's 'well-being-in-transition'. Through the body mapping method, children constructed their health history, while the importance of education was visualised through well-being exercises. We found that children consider education to be both an indicator of well-being and a transition in life. Health and well-being coincide in all life transitions of children. The time-lines developed by the children, using the life-course-draw-and-tell method, showed that both health and educational transitions are interrelated and act as key indicators of well-being. Hence, the life course approach and corresponding life course-draw-and-tell methodology helped us to understand children's well-being and transitions, here redefined as children's 'well-being-in-transition'. This confirms that earlier experiences shape well-being later in life (Giele and Elder 1998). 
Children Construing Life Course: From Group Activities into Individual Interviews

The other issue arising from the paper concerns the role of children in providing data about themselves. Researchers have advocated the need for children's full involvement in research (Scott 2000) using different methods, such as interviews and activities (Clark 2005). Ben-Arieh (2005) considers children to be the best source of information about themselves. In this study, children were the main sources of data regarding their lives. Group activities, such as body mapping and the well-being exercise, helped children reveal and enhance their memories; the result was an enabling process wherein children constructed their own perceptions of well-being as they relate to life transitions. These were then super-imposed on the 'life course draw-and-tell' time-line. Accordingly, moving from group methods to individual life course constructions was essential.

In this study, we have seen that children's perspectives of their own lives differ significantly from the those of their parents. In some respects, parents tend to be out of touch with the lives of their children. Adults tend to forget what children consider to be 'important' aspects of their lives. Based on these data, it is clear that children's perspectives provide better reflections of children's wellbeing in the communities studied. Sufficient evidence suggests that children are able to construct their lives differently from their caregivers. However, this study also recognises certain limitations of related to the information provided by children. While children failed to recall experiences from their early childhood, this is quite natural; this should not question the ability of children to provide accurate, dependable data. Adults should therefore not claim to be a 'reliable' source of data just because children cannot recall, or have ambiguous memories of, their early childhood. As this study has shown, most caregivers fail to understand the real experiences and perceptions of their children; as such, there is no guarantee that caregivers will accurately represent data on the early childhood of their children.

Moreover, researchers often question the 'authenticity' (e.g. Komulaninen 2007) or the 'ambiguity' of children's voices (e.g. James 2007). I argue that researchers' inabilities to understand children's lives does not put children's voices in doubt, but rather suggests a methodological limitation and challenge.

This is a digital offprint for restricted use only | ( 2011 Koninklijke Brill NV 
Such a problematic requires, alternatively, developing a new methodological approach which would enhance child participation in research, helping us to better understand them. It is the duty of researchers to adopt a clear perspective and devise appropriate methods to comprehend 'voices of children as given by children' instead of looking for 'authenticity' - which is often conditioned by the standards and expectations of adults or caregivers. This chapter has tried to contribute to the academic debates surrounding the study of children by providing empirical evidence which indicates that children are the best source of data about themselves.

\section{Conclusions}

In this chapter, I have tried to provide evidence that suggests that the life course perspective is useful in understanding the well-being and life transitions of children. The life course theory subscribes to the fact that past, present and future lives of children are intertwined. In so doing, this perspective has helped us to understand children's well-being and life transitions as integrated components of their lives, which I call children's 'well-being-in-transition.'

One hallmark of this perspective is that human experiences are contextualized in place and time (Giele \& Elder 1998). Children living in the "West" and in developing countries experience well-being and life transitions within different environments that thus require analysis in their own contexts. This chapter has provided a unique understanding of children living in specific contexts in time and space, and calls for related studies that go beyond the traditional 'universal' models of children's lives.

As the data reported here were mainly generated by children themselves, this study also shows that children remain essential sources of information. This, however, requires considering two issues. Some of the early childhood life experiences could only be obtained from adults as these were beyond the memory of children. Moreover, the generation of strong data from children necessitates the use of different methods. Methodologically, therefore, this paper advocates the importance of group activities that precede the individual construction of their lives through the life-course-draw-and-tell. 
Beyond the theoretical and methodological contributions, this paper sheds light on the understanding of children's lives in Africa and particularly in Ethiopia. First, we rarely have qualitative research involving children and this paper makes important contributions to initiate better studies in the future. Secondly, in Ethiopia children are often dubbed 'present flowers and future fruits', which focuses more on their 'well-becoming' rather than present 'well-being'; this chapter disputes this perspective. Despite adoption of child rights conventions intended to ensure children's well-being and key school transitions, very little has been done practically to meet these aims. Understanding children's 'wellbeing-in-transition'-instead of conceptualising 'well-being' and 'transitions' as mutually exclusive categories-would assist policy-makers in addressing the needs of particularly disadvantaged children growing up within a context of poverty.

\section{References}

Ben-Arieh, A. (2006), Measuring and monitoring the well-being of young children around the world. Paper commissioned for the EFA Global Monitoring Report 2007, Strong foundations: Early childhood care and education. United Nations Educational, Scientific and Cultural Organization.

- (2005), Where are the children? Children's role in measuring and monitoring their wellbeing. Social Indicators Research 74:573-596.

Ben-Arieh, A., N.H. Kaufman, A.B. Andrews, R. Goerge, B.J. Lee \& L.J. Aber (2007), Measuring and monitoring children's well-being. Amsterdam: Kluwer Academic Press.

Bradshaw, J., P. Hoelscher, \& D. Richardson (2007), An index of child well-being in the European Union. Social Indicators Research 80:133-77.

CAmfield, L., N. Streuli \& M. Woodhead (2008), Children's well-being in contexts of poverty: Approaches to research, monitoring and participation. Young Lives' Technical Note \#12.

CAmfield, L. \& Y. TAFere (2009), 'No, living well does not mean being rich': Diverse understandings of well-being among 11 to 13 year old children in three Ethiopian communities. Journal of Children and Poverty 15(2):117-136.

Central Statistics Authority (2008), Ethiopian census 2007, Draft. Addis Abba, Ethiopia.

Central Statistical Agency (2006), Ethiopia demographic and health survey, 2005. Addis Ababa, Ethiopia.

Christensen, P. \& A. James, eds, (2000) Research with children: Perspectives and practices. London: Routledge.

Clark, A. (2005), Listening to and involving young children: A review of research and practice. Early Child Development and Care 175:489-505.

Ecclestone, K., G. Biesta, H. Colley \& M. Hughes (2005), Transitions through the Lifecourse: Political, profession and academic perspectives. Paper presented at the Annual TRLP/ ESRC Conference, University of Warwick.

Fattore, T., Mason \& E. Watson (2007), Children's conceptualization(s) of their well-being. Social Indicators Research 80:5-29.

This is a digital offprint for restricted use only | (c) 2011 Koninklijke Brill NV 
Federal Democratic Republic Ethiopia (1995), FDRE Constitution. Addis Ababa, Ethiopia.

GIELE, J.Z. \& G.H. ELDER, EDS, (1998), Methods of life course research: Qualitative and quantitative approaches. Thousand Oaks: Sage.

HorrocKs, C. (2002), Using life course theory to explore the social and developmental pathways of young people leaving care. Journal of Youth Studies 5:325-336.

Johnston, J. (2008), Children's perspective on their young lives: Reports on methods for sub-studies. Young Lives' Technical Note \#10.

Kuh, D., Y. Ben-Shlomo, J. Lynch, J. Hallqvist \& C. Power (2003), Life course epidemiology. Journal of Epidemiology and Community Health 57:778-783.

Kumlainen, S. (2007), The ambiguity of the child's 'voice' in social research. Childhood 14: $11-28$.

Land, K., V.L. Lamb \& S.K. Mustillo (2001), Child and youth well-being in the United States, 1975-1998: Some findings from a new Index1. Social Indicators Research 56: 241-320.

LlOYD-SHeRlock, P. \& C. LOCKe (2008), Vulnerable relations: Life course, well-being and social exclusion in Buenos Aires, Argentina. Ageing \& Society, 28:779-803.

McGregor, J.A. (2007), Researching well-being: From concepts to methodology. In I. Gough \& J.A. McGregor, eds, Well-being in Developing countries: New approaches and research strategies. New approaches and research strategies. Cambridge: Cambridge University Press.

Mortimer, J.T. \& M.J. Shanahan, eds, (2004), Handbook of the Life Course. New York: Springer.

RiLEY, M.W. (1998), A life course approach: Autobiographical notes. In: J. Giele \& G. Elder, eds, Methods of life course research: Qualitative and quantitative approaches, pp. 28-51. Thousand Oaks: Sage.

Roberts, H. (2000), Listening to children: And hearing them. In: P. Christensen \& A. James, eds, Research with children: Perspectives and practices, pp. 225-240. London: Routledge.

SсотT, J. \& D. Alwin (1998), Retrospective versus prospective measurement of life histories in longitudinal research. In: J. Giele \& G. Elder, eds, Methods of life course research: Qualitative and quantitative approaches, pp. 98-127. Thousand Oaks: Sage.

ScotT, J. (2000), Children as respondents: The challenges for quantitative methods. In P. Christensen \& A. James, eds, Research with children: Perspectives and practices, pp. 98-119. London: Routledge.

TAFere, Y. \& L. CAMField (2009), Community understandings of children's transitions in Ethiopia: Possible implications for life course poverty. Young Lives Working Paper \# 41. Oxford: Young Lives.

TeкоLA, B. (in press), Eliciting the hidden variables: Issues in a child-centred qualitative approach to the study of poor children's risk and well-being in urban Ethiopia. 



\section{Kinning in the Imagination: Perceptions of Kinship and}

\section{Family History among Chagossian Children in Mauritius}

Sandra J.T.M. Evers

\section{Introduction}

This chapter discusses how Chagossian children attending primary school in Port Louis, Mauritius, reflect on their kinship and family history in relation to their imagination of the place where their ancestors come from. ${ }^{1}$ The expulsion

\footnotetext{
${ }^{1}$ It should be noted that the concept of Chagossian children refers to children who claim to have at least one (great)grandparent (sometimes even parent) who dwelled in the Chagos archipelago. All children in the research identified themselves as being Chagossian despite the fact that they usually were of mixed ancestry. The concept of Chagossian children does not include the 'children' of the first generation Chagossians, who are now often grown-up. In Mauritius this group is conceptually included in the term Zanfan Chagossien. In the context of the primary schools, however, it was usually employed to refer to children in the school and not their parent(s). The children having an ancestral link with Chagos called themselves just Chagossian (Chagossien).
} 
of their (grand)parents from the Chagos archipelago resulted from secret negotiations between the American and British governments, when Chagos formed part of British colonial Mauritius. When the Mauritians came to negotiate their independence in 1965, the British demanded surrender of the Chagos islands territory in exchange for a three million pound indemnity. This transaction allowed the British to make Diego Garcia (the largest of the Chagos islands) available to the United States. The US then established a military base on Diego Garcia. As the US desired a military base 'without civilians', the transaction triggered the forced clearance of the entire population of approximately 2,000 people to the Seychelles (also a British colony at the time) and Mauritius, where the majority of about 1,500 Chagossians were relocated (Marimootoo 1997; Vine 2006, 137,161,167).

Jean, ${ }^{2}$ ten years old, reflected on this eviction as follows:

The English have taken the land from the Chagossians and made it a dependency of Mauritius. Then the English took Chagos back and the Chagossians came here. The Chagossians were unhappy. That was because their land was pulled away from them. They were not adapted to Mauritius because they did not know anybody. They did not have much money and no work. Afterwards they almost all died, two or three went to England, because the English allowed it. And maybe they are also dead. Now the children follow this example and go to England. I will also go there...

Since the forced expulsion from the Chagos archipelago, Chagossians have been engaged in a campaign advocating their right of return, largely driven by high profile litigation brought before the British Courts. However, due to the length of their exile, the displaced generation may never see the day of their long awaited homecoming, particularly in view of the 22 October 2008 judgment of the House of Lords which struck down the 'right of return' principle as not 'feasible'.

Our research addresses how Chagossian children imagine Chagos and Chagossians dwelling overseas; specifically, we focus on the role of children in constructing the 'imagined community' of Chagossians in diaspora. Such an

2 To protect the privacy of the children, their names are pseudonyms. 
analysis can only be viewed within the context of a broader narrative centred on the Chagossians' identification as being 'deeply rooted' in the Chagos islands, which constitutes the linchpin of their argument in favour of return to the archipelago. ${ }^{3}$ This chapter thus highlights how Chagossian children, often living in deprived conditions in Mauritius, weave their family networks together through their relations with Chagossians living with them, and through a process termed 'kinning in the imagination'. This concept refers to a situation wherein interactions with relatives overseas solely occur in the children's imaginations and not through regular, day-to-day physical contact.

\section{Theoretical Orientations}

Our query centres around two theoretical issues that have often been neglected in cognitive and anthropological theory. The first stems particularly from the cognitive sciences, wherein research on children's imaginations characteristically focuses on how children imagine a 'fantasy world' and is typified by studies on pretend play (cf. Harris 2000). Other studies analyse children's memory of the actual past which they have experienced (cf. Piolino et al. 2007). By combining these approaches, this study looks at children's abilities to imagine an actual past event (or location), which they have not personally experienced. It examines how children reconstruct this past based on sources around them, and how they bring these sources together in creative ways.

The second angle of the study examines how children anchor themselves in their family history and create senses of belonging to 'imagined communities'. Benedict Anderson's (1983) seminal work is pertinent here; however, Anderson builds his theoretical framework of 'imagined communities' on adult lives and realities. Children are crucial to such processes as they are socialized in

\footnotetext{
${ }^{3}$ I would like to thank Marry Kooy for sharing her research data (this 'we' in this chapter refers to the joint fieldwork) and discussing this chapter extensively with me. It should be stressed, however, that I am responsible for the interpretations and conclusions of the study as presented in this chapter. We express our appreciation to the Mauritian Ministry of Education \& Human Resources and the Government Teachers Union (GTU) for their assistance during the research. We are grateful to teachers, children, their families and everyone else who participated in this study. Thanks also go to Catrien Notermans, Erik van Ommering and Caroline Seagle for their valuable editorial advice.
} 
these communities and play active roles in the intergenerational transmission of what is deemed to be the 'essence' of these groups. The question remains, however, as to how these 'imagined communities' are acquired, conceived, constructed, and produced by Chagossian children. Epistemologically, children should therefore not just be seen as 'culture takers' but also as 'culture makers'.

The cognitive sciences could gain from a fuller consideration of cultural, social and economic contexts in shaping children's imaginations of the past. Most studies take an adult-centred, laboratory oriented approach wherein children are tested without allowing the benefit of their own creative input, or factoring in the context of their particular socioeconomic settings. Even in anthropological studies, kinship and family history are usually studied from an adult perspective. Very few studies adopt a child-oriented approach in which voice is given to children (see, for example, Brannen \& O'Brien 1996; Christensen et al. 2000; Dunn \& Deater-Deckard 2001; Hallden 2003; Mason \& Tipper 2008; Moore, Sixsmith \& Knowles 1996; Morrow 1998; Notermans 2008).

\section{Methodological and Ethical Issues}

Fieldwork for this research was conducted from August 2007 until April 2008 in Port Louis, Mauritius by Marry Kooy and the author. Methodologies were adapted to the children and consisted of participant observation, home visits, photo elicitation, and reflexive drawing exercises in which children expressed their views. In all, more than 250 drawings of pupils coming from different family backgrounds were collected and discussed with the children. Forty-one Chagossian children (22 girls and 19 boys) following grades five and six are at the core of this chapter. These pupils formed part of the 'repeaters class' (children who failed the primary school exam) and represent about $90 \%$ of all Chagossian children attending these classes.

In order to meet the necessary ethical standards of working with children, the project was pre-vetted by the Mauritian Ministry of Education \& Human Resources and the Government Teachers Union (GTU), an organisation that represents primary school teachers. Following approval, we were introduced to the school directors who in turn presented us to the teachers and children. Teachers and children participated on a voluntary basis. 
Reflexive drawing exercises gave children the agency to guide their own creative expression of ideas and interpretations of their family's past, anchoring these within a time and place of their choosing. ${ }^{4}$ We attempted to keep in sight the impact of adult-child power relations (cf. Mitchell 2006) and constantly reflected upon this in order to improve our methodologies to suit the children.

Children are always relational to peers and adults around them. Their drawing can in no way be perceived as products that are not influenced by their social worlds (including the researchers in this case). We viewed the exercises as creative, imaginative processes directed by the children. Therefore, we did not isolate the children in laboratory like settings. One-on-one assignments and interactions with the researchers are also problematic as the power component of the relationship then becomes even more accentuated and acutely felt by the child. Physical separation of the children was deemed artificial and possibly counterproductive, while not eliminating the influence of peers and authority figures.

The influence of peers and adults was nevertheless closely monitored during the research and recorded where necessary. This was the case with teachers' reactions during the first drawing assignment on children's images of the place where their ancestors come from. Mauritian teachers generally have a very directive approach to teaching and learning, which was one reason why this drawing exercise was performed at the beginning of our visits to the schools. Neither children nor teachers were informed in advance of the nature of the assignment. We were introduced to the classes by the school director ('head teacher') and explained that the assignment would constitute the first activity. We asked the teachers not to say anything to the children after the presentation of the assignment, which was stated in the following terms: 'Draw the place where the grandparents of your grandparents come from.' Teachers were usually quite alarmed upon hearing the 'complicated' assignment. One said: 'Please come back in six weeks so I can prepare them,' and another: 'I do not

${ }^{4}$ In the schools where we worked, children principally learned how to copy from pictures, they were not given free expressive assignments, as a teacher remarked reflecting afterwards on our assignments: 'I had no idea that they could do such a drawing and that this is in their heads.' We were informed after return from the field that some teachers continued our approach to drawing with the children. 
think that they are intelligent enough.' Teachers had to restrain themselves from intervening to provide additional instructions to the children.

In school, children learn that their ancestors originate from Africa, Asia and Europe. With the drawing exercise, we hoped to assess what family origin children primarily thought of when confronted with such a question. We therefore asked them to draw the 'place' and not the 'places' where the grandparents of their grandparents come from; it was hypothesised that using the plural would trigger many of them to reproduce the normative discourse of (mixed) Mauritian origins. It was intriguing to note that none of the children asked for clarification of the term 'place' in the singular and, following a short pause for reflection, had little trouble commencing with drawing. Of the more than two hundred children who performed this particular exercise, only two drew more than one place of origin. Once they had produced the drawing, they would be invited to describe and discuss what they had depicted.

Children took to the drawing exercises enthusiastically and were often surprised that we expressed an interest in their stories. After the drawing exercises, a sample of children was followed over a longer period of time, which included home visits. Permission for these visits as well as the research was sought with and provided by the caregivers of the children. During research, children were constantly reminded that they were not obliged to work with us and that it should be enjoyable for them. The information they gave us was treated with confidentiality. In our experience, they enjoyed the time we spent with them, and they seemed eager to share their experiences and ideas with us. When we asked whether we could keep the drawings, they were thrilled that we found their work interesting enough to keep, and the prospect of sharing their work with a wider audience also appealed to them.

As the children put their ideas to paper, we observed that the drawings began to interact with them, in a way. New ideas emerged based on what they saw developing on their papers, confirming Willats' $(2005,190)$ observation that '...transformations from scenes to pictures do not just take place in one direction as they do in cameras and computers. Instead, drawing by even the youngest children involves some feedback from the picture. In humans, in contrast to cameras and computers, producing a drawing depends on a continual interplay among the scene, the picture, and the pictorial image as it emerges during the 
course of the drawing process.' Some ideas might have been too complicated to put on paper; some mentioned for example that they wished to draw animals but they were just too difficult to depict.

Drawing proved a highly useful means of getting a snapshot of the children's imaginative processes about their family's past. The utility of this method again recalls Willats' $(2005,240)$ observations of the work Arnheim (1974): '(i)nstead of seeing drawing as a mechanical process, similar to the production of pictures by photography, Arnheim saw drawing as a graphic language, and his account of the creative nature of drawing comes close to Chomsky's account of the creative nature of verbal language.' Drawing was a way of sharing ideas with us (see also O'Kane 1998; Christensen \& James 1999) and facilitated communication between the children and the researcher (cf. Boyden \& De Berry 2004). We also wished to continue the relative agency of the child brought about during the drawing process afterwards; thus the interpretations of the drawings were carried out by children themselves during our discussions of their work and ideas about the ancestral place(s). We asked as few questions as possible to give the children the opportunity to independently determine the direction of their narrative. Usually, these meetings began with long silences, the child staring at the floor or otherwise averting the gaze of the researcher. Silence appeared to be a necessary starting point for children to assert their agency. After this moment, most children began speaking about what they had drawn. In turn, once the researcher expressed a strong interest in their opinions, their enthusiasm usually increased as they related their tales. ${ }^{5}$

\section{Drawings and Stories of the Chagossian Children}

Before analysing the setting in which the children live and delving into the data of the study, an example of the drawings and narratives of two Chagossian girls will be presented:

\footnotetext{
${ }^{5}$ Children spoke principally Creole (sometimes with some English) during their conversations. The Creole was usually translated by the teacher when the researcher did not fully understand.
} 
Lilli is a skinny, shy girl with a dark complexion. She has just turned twelve and is in grade six of primary school. She has been drawing with great care and seems eager to discuss her work.

Lilli: You see, this is Chagos. That is the place where my grandparents come from. It is beautiful there. The sun always shines and there are many birds in the sky. They are so free flying around. There is sugar cane, water, fruits on the trees, fish in the sea and always food on the fire. You know people cook with wood there. The houses are made of wood and have grass on the roofs. See that is me looking through the window. I am going to live in Chagos one day. You see, I am all happy there. My father is also happy. Now he is a prisoner and you know, he will be so happy to come with my mother and me to Chagos. You see,...there are no prisons in Chagos. My mother goes and gets the water and then carries it on her head. That is what my grandmother did there so mum will have to learn that as well. Oh, I guess I will have to practise that also. I have no idea how to do that.

SE: Who else will go to Chagos with you?

Lilli: My grandfather is already dead but my grandmother will come. She is there as well on the drawing, but you cannot see her. She is resting inside. You see, grandma is very old and cannot walk very well. Now she lays on the bed in our house in Roche Bois, but our house is not as nice as the houses in Chagos. If it rains we all get wet. Grandma will be so much happier in Chagos. Then, eh let me think... I have two brothers as well. But they won't come with us. One is in England. He worked with my father until he had enough money to go there. I am not sure what he is doing there. My other brother is now doing the work my father used to do. He works at night but I have no idea what kind of work he does. He also wants to go to England. He says Chagos is boring. I tell him he can swim there. But he says he can swim anywhere. I tell him how happy he will be in Chagos. Now he is always angry. He likes beer... a lot.

SE: What will you be doing in Chagos?

Lilli: I will be doing all kind of important things. Things I cannot do here. My teacher says I am hopeless. I cannot pass the exam. So this will be my last year in school. Then I will have to work. And I will take care of my mother and grandma. They need me. I always feel bad when I go to school. Mum is also sick a lot and then I need to help her. That is why I do not go to school very often. I cannot pass the exam anyway, so it does not really matter.

A few weeks after this interview, I meet Lilli again with her friend Anne at the public beach of Pereybere, although I must confess I did not immediately recognise her:

Lilli: Hi, do you not know who I am? You came to my school and I made a drawing for you. 


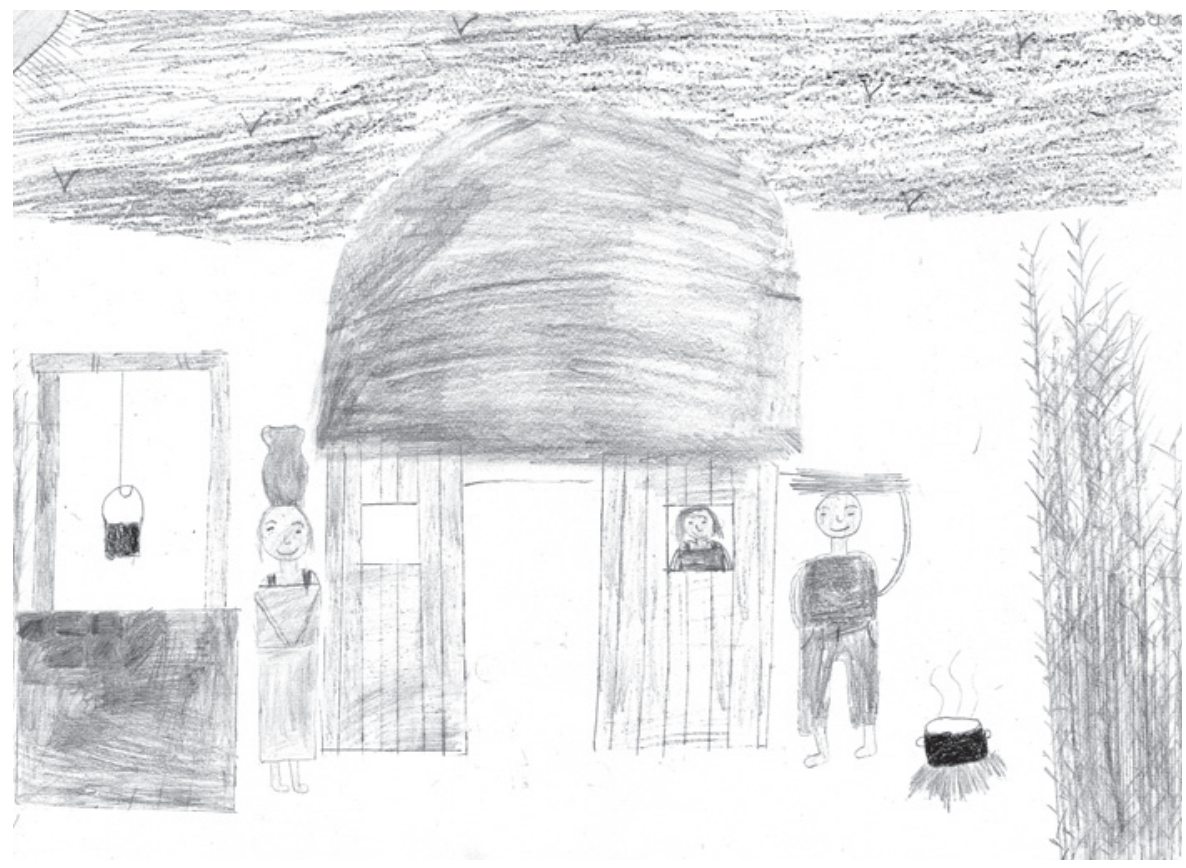

Figure 4.1 Lilli's 'Ancestral Place'

SE: Oh yes, I remember. You look so different now that you are not wearing your school uniform.

Lilli: You mean that I look sexy.

She is wearing a red bikini with pink flowers and a mini skirt that accentuates her small waist.

SE: Yes, I guess that is it. You came all the way from Roche Bois?

Lilli: Yes, by bus. A friend paid for me. He is over there.

She is pointing towards a man who looks to be well into his mid-twenties, her senior by more than ten years.

Lilli: His friend paid for Anne. Anne and I like the beach.

Anne is one year younger than Lilli and is in grade five. Anne places the origins of her grandparents on Salomon, part of the Chagos islands.

Anne described her drawing as follows (Figure 4.2):

Anne: This is where my family comes from and where I will live when I am older. I will be very happy there. Here I am swimming in the sea with my friend. There are lots of fish in the sea to eat and lots of fruits in the trees. Look, here are the trees with the coconuts. If we are thirsty

This is a digital offprint for restricted use only | (c) 2011 Koninklijke Brill NV 


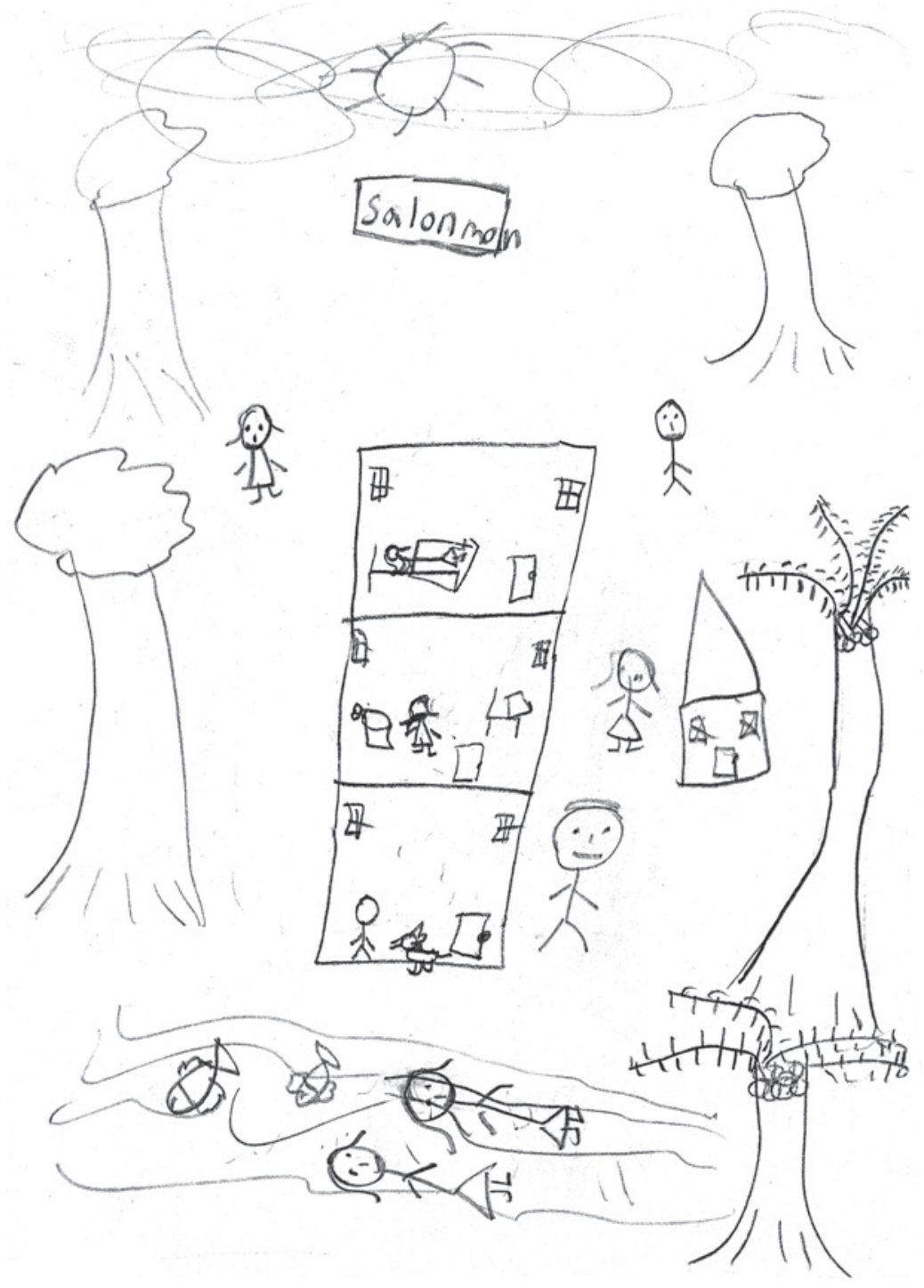

Figure 4.2 Anne's 'Ancestral Place'

we drink the water inside. I think that the friends of my mother also will go with us to Salomon that is why I have put them everywhere. They always come to our house. We all sit outside together. Our house in Roche Bois is of iron and is too small for us all. It only has one room. But in Salomon we will have lots of space. You know... what you see is a flat (bâtiment en étage). People are building this for us right now. It will be beautiful when we go there. I have never been in such a building. But I am sure they make it very strong. We will

This is a digital offprint for restricted use only | ( 2011 Koninklijke Brill NV 
have proper tables, chairs and beds there. And you know what? We will even have a television. I will have a dog that stands in front of the door to check whether people are allowed to come in.

SE: What will you be doing when you live there?

Anne: Swim, I would just swim everyday. There is no school. There is no need for it. We will find everything we need right there. That seems so nice. Now my mother always complains we do not have enough money. My dad has no work. She sometimes goes away and then comes back with some money. We buy food for it together. But that does not make her happy. She does not like to work. It makes her sad. So she can also swim the whole day once we are there. We can rest on the beach together. She will not be tired anymore. At night we will sleep in nice beds and when it gets cold, we will have blankets.

SE: It sounds like a nice place.

Anne: Yes, I cannot wait until I can go. I will not have to go to school and not think about getting money for my mother. I will be so happy. Here we cannot be happy. We have nothing and I think people do not even like us. We are too poor.

The analysis of these cases and data of the other Chagossian children will form the nexus of this chapter. The above girls see life in Chagos in sharp contrast to their daily realities in Mauritius. Before elaborating on the children's imagination of Chagos, their kin living outside Mauritius and their family history, we will look into Mauritian society and history. This section focuses in particular on the social and economic position of the Creoles and Chagossians in Mauritius.

\section{Settling in Mauritian Plural Society}

With the exception of French and British plantation owners, the initial settlers of the Chagos islands originated from the African continent and Madagascar. They arrived in the archipelago during the eighteenth century as slaves to perform forced labour on private copra plantations. After the abolition of slavery in 1835 , these ex-slaves continued working for their former masters (Scott 1976, 23; Powe 1996, 640; Walker 1986, 9; Winchester 1985, 39). At the time of their eviction from Chagos, the former slave population could trace its family history in Chagos for several generations (cf. Vine 2006). This chapter concentrates on the Chagossians who were relocated to Mauritius, where they dwell in the outskirts of Port Louis. 
The Republic of Mauritius is situated in the Southwest Indian Ocean approximately 2000 kilometres from the South East coast of Africa, and approximately 900 kilometres East of Madagascar. Arab traders probably already knew of its existence by the 1oth century, but it was officially 'discovered' in 1505 by Portuguese sailors and successively claimed by the Dutch (who arrived in 1598 and named it Mauritius in honour of Prince Maurice of Nassau), the French and later the British. The Mauritian nation is conditioned by the fact that the island was uninhabited prior to the arrival of the Europeans during the 16th century, who started the settlement process with the import of slaves principally brought in from Madagascar and Mozambique to toil on the sugar plantations. After the abolition of slavery in 1835 , followed by a four year 'apprenticeship', they were freed and survived through fishing and other activities. Their descendants are referred to as Creoles.

The Creoles form about $28 \%$ of the current population of Mauritius, and generally belong to the poorer segments of Mauritian society. Most Mauritians consider the Chagossians to be Creoles as well. Interestingly enough, the Creoles, together with the descendants of the former French colonial rulers, form the administrative category of 'general population'. These so-called Franco-Mauritians represent about $2 \%$ of the population. Most of the Creoles in Mauritius are Roman Catholics. The other ethnic groups present include Hindus, descendants of former indentured labourers who replaced the slaves upon abolition of slavery on the sugar plantations (52\%), Muslims (15\%) and Sino-Mauritians (3\%). Mauritius has about 1.2 million inhabitants; this is quite substantial for a country that measures only 1865 square kilometres. English is the official language of Mauritius, principally spoken in the political administration and in the education system, whereas French is dominant in the private sector economy and Mauritian media. Mauritian Creole is the vehicle of communication in everyday life (Eisenlohr 2006: 30). Besides these languages, many ancestral languages are spoken including Hindi, Tamil, Telugu, Urdu, Arabic, Marathi and Mandarin. The Chagossians principally speak their own Creole which is linguistically very close to Mauritian Creole.

The various ethnic groups tend to live inside their own 'social worlds'. In particular, the Indian population in Mauritius often draws upon their cultural and religious (Hindu or Muslim) roots as justification for the official protec- 
tion of their 'ancestral traditions'. Eriksen $(1998,49,122)$ also sees Mauritius as a compartmentalised society; he identifies kinship and religion as the most important criteria of ethnicity. Although he notices a trend towards more interethnic marriages in the future, the family currently remains the principal socio-economic reference: '(i)n a society where employment opportunities and financial support are channelled through kinship and metaphoric kinship organisation (that is, ethnic organisation), it can be a very serious thing indeed to disobey parental orders. (...) Since endogamy is crucial for both ethnic identification and organisation, interethnic marriages are a grave threat indeed to Mauritian society' (Eriksen 1998, 122). Thus, many families in Mauritius, but particularly the Franco-Mauritians and Indians, continue to follow principles of ethnic endogamy. In general, Chagossians are Roman Catholic and marry fellow Chagossians but also Mauritian Creoles (cf. Jeffery 2006).

Creoles lack 'a singular homeland from which to construct an identity' (Boswell 2006, 11). 'Creole' is associated with cultural 'mixing' and hybridity, therefore creolization is a process resisted by many Mauritians. According to Boswell $(2006,11)$, Creoles belong to a negatively designated category and 'their identity has become a resource for the construction of other ethnicities on the island.' Boswell argues that: '( $t$ )he homeland "requirements" form a part of dominant group's discussions on identity and also part of the process necessary to identify subaltern groups. In this context, Creole is a sort of anticategory, useful for other groups to define themselves and as a means to establish hegemony' (ibid.; cf. Palmyre 2007, 78). Mauritians of other groups entertain essentialised ideas about the Creoles: They are people with curly hair, who live in poverty and have social problems, a condition which is seen as a 'primordial element of Creole personality,' therefore in public discussions, instead of looking to causes like colonialism or unemployment, people tend to emphasize that Creole 'are bound to participate in negative social behaviour' because 'it is in their nature' to do so (Boswell 2006, 159).

In the 1990s, the socioeconomic situation of the Creoles was categorically referred to as the 'malaise Créole', or the Creole predicament (Boswell 2006). Currently, however, under the stewardship of the charismatic Catholic priest, le père Grégoire, Creoles are more assertive in claiming their rights; this 
manifests in reconstructing their identity by recognizing and tracing their African roots, stressing the African origins of sega songs (which are so popular in Mauritius), gaining political consciousness and challenging 'state-inspired notions of culture and identity' (ibid., 61-76, 150).

During our fieldwork, Chagossians were also seen as people who have curly hair, who were considered lazy, unemployed and socially marginalized. They supposedly spend their days playing drums, singing and dancing, as this quote of a male teacher of Indian descent symbolises: 'They are just like Creoles but ten times worse. They are lazy and do not like to work for their money. They resent living in Mauritius as they were betrayed and paid the price for our independence. They await their return to Chagos. In the meantime, they try to skin Mauritius and the Mauritians as much as they can, play their music and live in the same backward way as their slave ancestors did.' Vine (2006, 227,233) speaks about a 'double exclusion' as Chagossians represent 'the bottom of the bottom'; they are seen 'first, as Chagossians who gave up their homeland so the rest of Mauritius could have its independence, and second, as members of the minority Afro-Mauritian Creole population' (see also Eriksen 1986, 59).

\section{The Harsh Realities of Life in Mauritius: Neighbourhood and School}

This social marginalisation is echoed in the living circumstances of the Chagossians. About 3,800 Chagos islanders and their descendants live in the poor neighbourhoods of Port Louis and surroundings: Cassis, Roche Bois, Pointe aux Sables and Baie du Tombeau. These areas, principally inhabited by Creoles, are generally considered to be dangerous (cf. Boswell 2006, 140). About a third of Chagossians live in ramshackle houses of ill-fitting corrugated metal sheets. Forty percent of households lack indoor plumbing and there is no running water in $26 \%$ of the houses (Vine 2006, 240).

Upon their arrival in Mauritius, Chagossians encountered a society already struggling with unemployment. Job security like they knew on the Chagossian plantations was no longer a given. In the Mauritian sugar industry, additional workers were not needed. There was no copra industry to work in, and compe- 


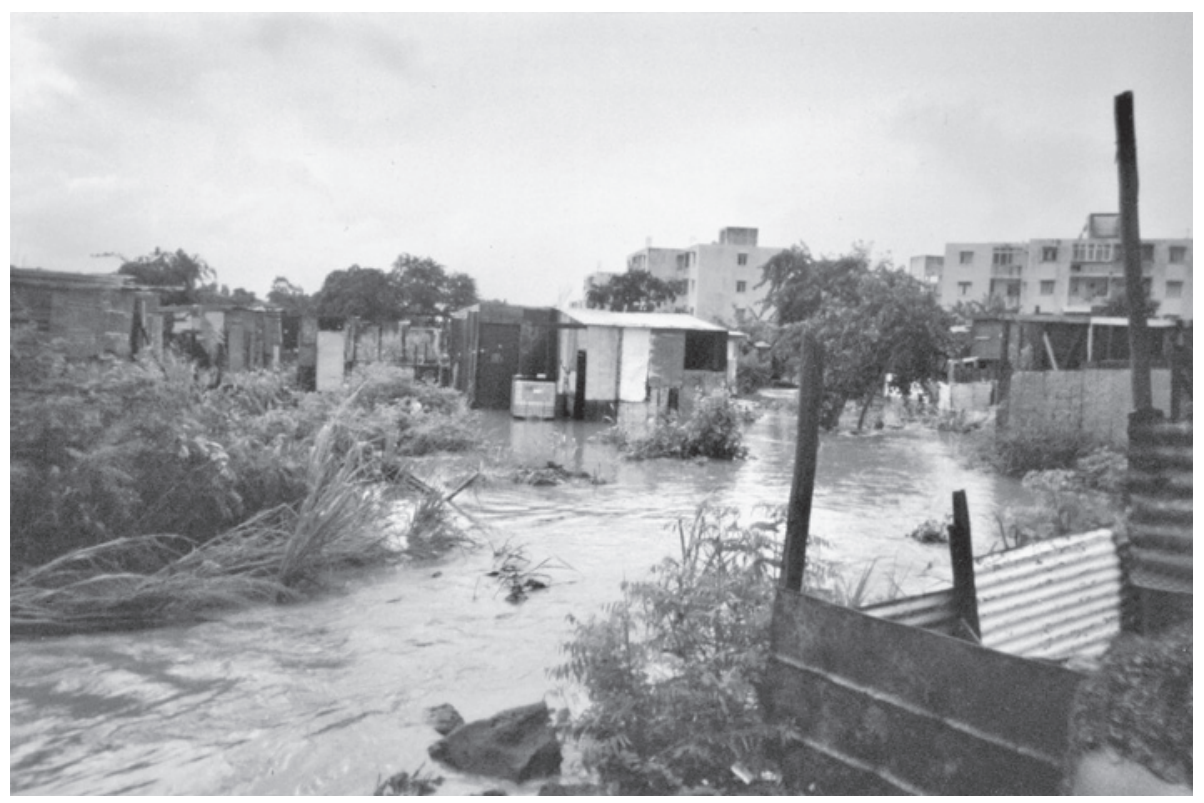

Figure 4.3 Picture taken by Daniel (11 years) showing Chagossian dwellings just after the floods of March 2008

tition in fishing was fierce. The Mauritian economy was being diversified with manufactures in new Export Processing Zones and increasing tourism, though jobs in these sectors demanded more educational background than the majority of Chagossians had (Vine 2006, 217,223,231). According to a survey of Vine, just over a third of the first generation and less than two-thirds of the second generation were working in 2002/2003, most of them in manual labour jobs, as dockers, domestics, casual construction workers and factory workers. Vine (2006, 224) points out that Chagossians are chronically indebted, which incites many to resort to crime, particularly petty theft, drug trafficking and prostitution. He writes: 'Prostitution appears as an ongoing employment opportunity of last resort for Chagossians with relatively few other opportunities' (cf. Johannessen 2005, 22).

In their drawings and stories, the children often report broken family bonds. Based on their stories, it seems that the majority of Chagossian children live in matrifocal families where particularly grandmothers, mothers and aunts act as the household authority figures. They also indicated that they rarely reside with both biological parents; the father often had left the house when the children

This is a digital offprint for restricted use only | (c) 2011 Koninklijke Brill NV 
were still very young and the mother typically was supported by her sisters and mother. As we did not visit all the children in their homes, it should be stressed however that there might very well be a distinction between the image that the children portray of themselves and their actual living situation. Our focus in the study was on the children's perceptions of their kin groups, family history and current lives. Factual studies on the livelihoods of the Chagossians have been undertaken by Jeffery (2006) and Vine (2006).

\section{Educational Opportunities and Pitfalls}

Education is highly valued by most Mauritians and seen as part of the escape route out of poverty. Indian Mauritians in particular invest a lot of money into the education of their children; already in primary school, their children follow private tuition classes after school hours. The Creole groups, however, are seen as having less of an impetus to let their children study (Hollup 2004). Many Creoles feel marginalized in the education system and most do not move on to secondary and tertiary education. Lilli and Anne (cf. cases infra) actively

reiterated that, for them, schooling was of little use to their future; they both had the idea that their teachers had no faith in them. The vast majority of Creole children already fail in their educational trajectories at primary school (cf. Palmyre 2007, 37).

From the age of five, children receive six years of free tuition for primary school which terminates with the Certificate of Primary Education Examination (CPE exam). In 1980, 47.3\% of all children in primary school passed (MES 1991,10 ) and in 2006, the percentage rose to $67.9 \%$ (Ministry of Education, Culture and Human Resources 2008, 34,35). Primary schools can be divided into two broad categories, schools where more than $40 \%$ of pupils pass the CPE exam and schools where less than $40 \%$ of the children succeed in doing so. The latter category of schools is referred to as ZEP schools (Zones d'Education Prioritaires). In 2007, there were 30 ZEP schools out of 289 primary schools. Unsurprisingly, ZEP schools feature prominently in the poorer quarters of Port Louis. While they are principally frequented by both Creole and Chagossian children. There is no specially designed educational policy for Chagossian 
pupils as they are deemed to share poor school performance with their 'fellow' Creoles.

We worked with teachers and children in several ZEP schools and witnessed the persistence, good will and devotion of teachers and liaisons officers working under highly adverse circumstances. It is clear that the ZEP policies spring from noble philosophies. Study data, however, confirms that many children in ZEP schools think that they have little chance to learn in school and that they feel stigmatised by the label 'ZEP pupils' which they consider as a confirmation of their negative self image. As one Chagossian girl (ten years old) pointed out so strikingly: 'I have a real problem. Nobody wants me, not at home and not at school. I am at a ZEP school. That is a special school for stupid children like me.'

Thus, the failure in school of Creole and Chagossian children may be characterised as a double edged sword; on the one hand, children and their caregivers feel that, as Creoles, they have less opportunity than others groups (which feeds their own insecurities), and on the other hand, motivation to engage intensively in the educational trajectory is undermined by the defeatist sentiment that they will fail anyway and will not succeed in getting government scholarships. When this is tied in with their challenging living conditions and school environments, it is not difficult to understand why Creole children and their caregivers have less faith in the educational system and their chances to succeed than their fellow Mauritians.

The public sector and the educational sector are dominated by Indian Mauritians. In the schools where we worked, the Indian Mauritian teachers appeared to be the majority. One can wonder how this impacts on the children, as one 'Creole' girl of ten remarked: 'Creoles can never become teachers, they are just not smart enough for it.' The mediation of the message that this girl read from interacting with her teacher is reinforced by the Hindu dominant presence in the modern media. The children in ZEP schools rarely have internet access and do not have the ability or interest to read newspapers. They however do commonly have access to radio and television which is dominated by Indian programmes and films (Eisenlohr 2006, 215). In primary schools, classes in Oriental languages like Hindi, Mandarin and Arabic are offered, which are 
mainly attended by children of that specific background. English is the language of instruction.

In history and geography classes, children are taught the basics of Mauritian history and learn about the background of the diverse population. In the school textbooks for Standard IV to VI, the history of Mauritius is described in a few chapters. First it is mentioned that Mauritius was discovered by Portuguese traders and then visited by Dutch sailors who settled on the island, after which the French came to develop agriculture. It describes how slaves were brought from Madagascar, Mozambique, and Senegal, who had to work very hard in the fields and who lived in slave huts made of wood and thatch. Slaves who ran away were severely punished by their masters when they were caught (Ministry of Education, History \& Geography Std V 2008, 54,55). During the terminal year of primary school, children learn about the British, the abolition of slavery and the arrival of Indian labourers. Chinese shops on sugar estates are also mentioned. The last page is about the independence of Mauritius (Ministry of Education, History \& Geography Std VI n.d.). Throughout the curriculum, emphasis is on national pride and 'unity in diversity'. However this seems more wishful thinking rather than a substantiated argument, as this point is not expanded upon for the children and certainly not reflected in reality.

While in school, children learn about their specific origins, languages and (material) culture. Creoles, however, are represented as lacking an explicit anchoring in place. Nor do they have founding myths or heroes (Palmyre $2007,78)$. In the school manuals, Creole history is portrayed in simplistic, one-dimensional terms: They were the slaves of Mauritius. While this study argues that Chagossian children clearly insist on having an 'anchoring in place': Namely, the Chagos archipelago, such an assertion is left mostly unacknowledged in the school curriculum. Only in the textbook for Standard VI (History \& Geography curriculum) is the Chagos archipelago mentioned: 'Some people from Mauritius went to live and work in these islands. The main activity of the islands was fishing. In Agalega and in the Chagos Archipelago, there were also many coconut trees. Coconuts were sent to Mauritius to make oil. Some of the islands also sent guano (fertiliser) to Mauritius' (n.d., 33). In Philip's Atlas of Mauritius for Primary and Lower Secondary Schools (2007) there is a small map 
of Diego Garcia in the section 'outer islands'; it shows a US Military Base and several names of places, some with the added label 'ruin'.

\section{Imagining Chagos}

Next to information communicated to the children in school books, their sources for images about kin and places overseas are very much anchored in people. Imagination is at the root of these social processes. People are perpetually 'reading each others' minds' in the sense that they consciously and unconsciously assess what other people are thinking in order to make sense of the person (Bloch 2008). Children also construct their ideas based on information they deduct from people and observations of the material and non-material world and events around them (cf. Harris 2000). In turn, information received by children on a daily basis is processed, remembered or forgotten. As is the case with adults, information and events are rarely remembered as they were received and/or occurred in reality (Bloch 1998, 114). In this fieldwork, we assessed the ideas of Chagossian children about Chagos, a place where they have never been. In their drawings and narratives, they intertwined past, present and future, referring to events that they had experienced themselves and stories of things they had not. In this regard, it should be stressed that, like adults, children's imaginations constantly evolve as both spoken and visual information is processed.

The location of the story in the past or present can not necessarily be deduced from the tense in which the children speak. It was very common for children to speak of the past but still use a present tense. Children's perceptions of time and place differ from those of adults (cf. Kuik 1999). This became clear from the stories children told about their family histories, in which they easily incorporated current experiences, such as warnings for an incoming cyclone, or an accident that had happened the previous week. They also integrated themselves as active participants in the stories, and used pronouns like 'we'; for example, they would say 'we were very poor,' 'we have to wash our cloths with our hands,' 'we sell vegetables to buy food' or 'we do not have much 


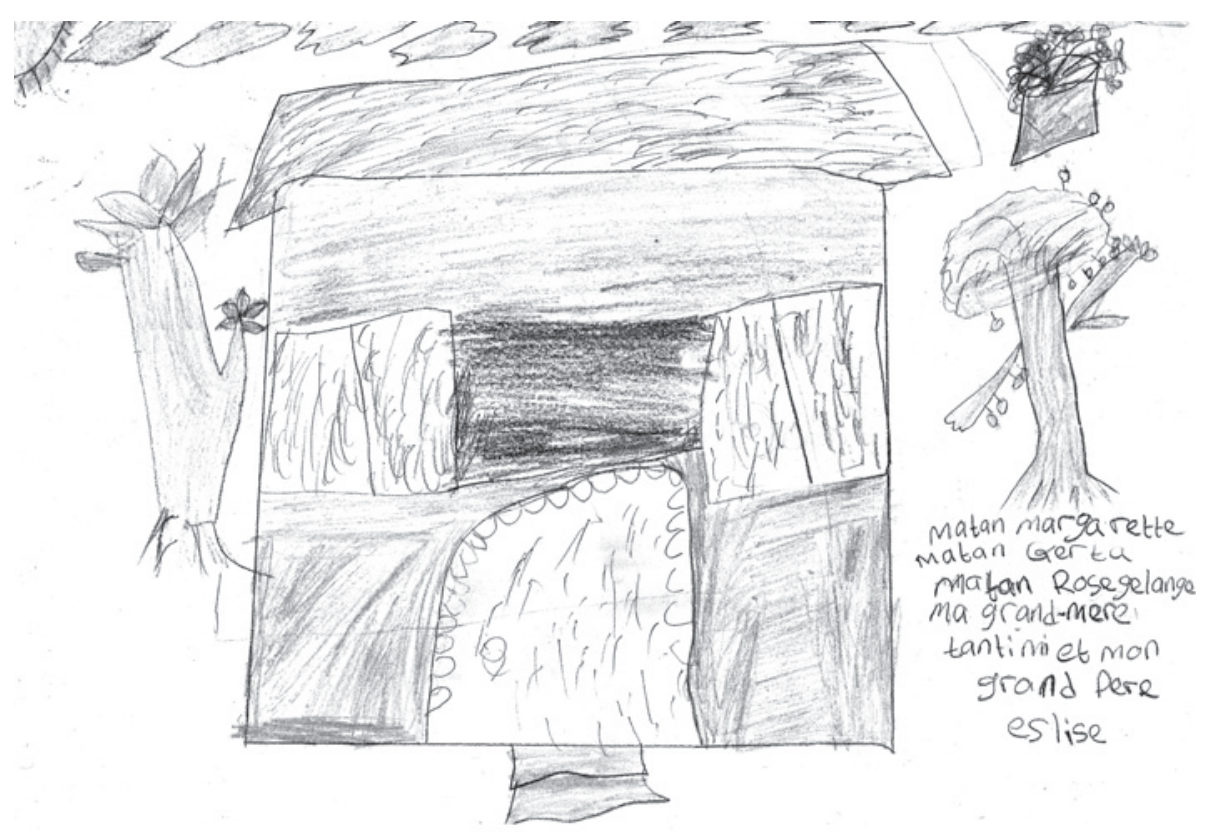

Figure 4.4 Elle (ten years) wrote down the names of family members who would be living in Chagos together

to eat, there are many mosquitoes, it is very hot and dirty.' These types of statements were particularly commonplace among the Chagossian children. They identified with their family members in the drawings and stories and seemed to take part in the activities and experiences of their relatives. ${ }^{6}$

While over two-thirds (78\%) of the Chagossian children identified family members in their drawings, none of the other children classified as 'Creole' did. This was principally because the Chagossian children did not depict the past but rather the future when they thought of Chagos; they imaged that they might visit the archipelago or even live there one day. The other 'Creole' children, more clearly, drew places (in Africa, for example) of the past-where often slavery was part and parcel of the setting. None of the Chagossian children did this.

\footnotetext{
6 Thus, the use of 'we' is not only an indication of the time span in which the story takes place, it also is indicative of the personal involvement of the child.
} 
Chagossian children, in fact, entertain an idealized version of Chagos. They did not refer to the slave-laboured plantations on Chagos or the downsides of life in the archipelago. The children imagined Chagos as a beautiful place, where flowers, fruit trees, vegetables, animals (particularly birds) and fish are plentiful. The life-styles of the people in Chagos were described in leisurely terms. Children indicated that food is readily available, leaving ample time for relaxation. In the drawings and stories of the children, people thus spend their time sitting, resting, walking, swimming and particularly watching television.

For Chagossian children, Chagos as a physical place is very important as they contrast paradisiacal Chagos to their challenging lives in Mauritius. The eventual return to Chagos by their grandparents, parents, uncles and aunts, who are now dispersed between Mauritius (3800 people), the Seychelles (500 people), and the UK, (6oo people) (Chagos Refugee Group 2008, 12), is envisaged as a family reunion (cf. Figure 4.4). In Chagos, they will all live happily together. The children's idealized version of Chagos underpins the narratives of adult Chagossians. Johannessen (2005, 6,54) underlines the importance of these narratives as they strengthen notions of belonging. In the stories narrated by Chagossians about their eviction and current lives in Mauritius, words such as sagren (defined by them as 'sorrow'), latristes ('sadness') and lamizer ('misery' and 'poverty') are often used. Johannessen sees these concepts, which refer to different personal experiences, as constituting 'an interconnected vocabulary generally agreed upon and possibly communicable' (ibid., 30; cf. Vine 2006, 252-255). In her study, 'How a plantation became paradise', Jeffery (2007, 951) speaks of 'a standardized mythico-historical narrative' which, as expressed in songs, represents a romanticized, collective imagination that remains crucial to the current, shared identification as 'Chagossian'.

Thus, Chagossian children incorporate narratives and experiences of adults and peers around them, processing these in dynamic ways. In their drawings and narratives, past, present and future merge into one imagined Chagos; this Chagos is waiting for them, it is a place where they will be valued and welcomed. Their imagination provides them with the opportunity to create a place away from the hardships in Mauritius, where they can walk 'side by side' with their grandparents in a safe and beautiful environment. As one boy framed it: 'Grandfather would like to go back because when he left his island he was 
crying.' (see his drawing, Figure 4.5, depicting the grandparents walking with canes). In this respect, two key concepts recur in virtually all conversations with the children: Happiness (boner) and togetherness (ansam). It is impressive to witness how well children can piece together the core elements of the socioeconomic position of their kin. The eviction from Chagos is described as the breaking apart of the kin groups, a reality that can only be rectified by a right of return of all Chagossians to the archipelago.

\section{The Gendered Perspectives on the 'Family Reunion'}

Almost all Chagossian children have people in their drawings to whom they refer as grandparents, great-grandparents, uncles, aunts, cousins and parents, brothers, and/or sisters. In addition, 'friends', 'children' and 'other women' are also mentioned at least once, but all other people are referred to within the formal frame of kinship.

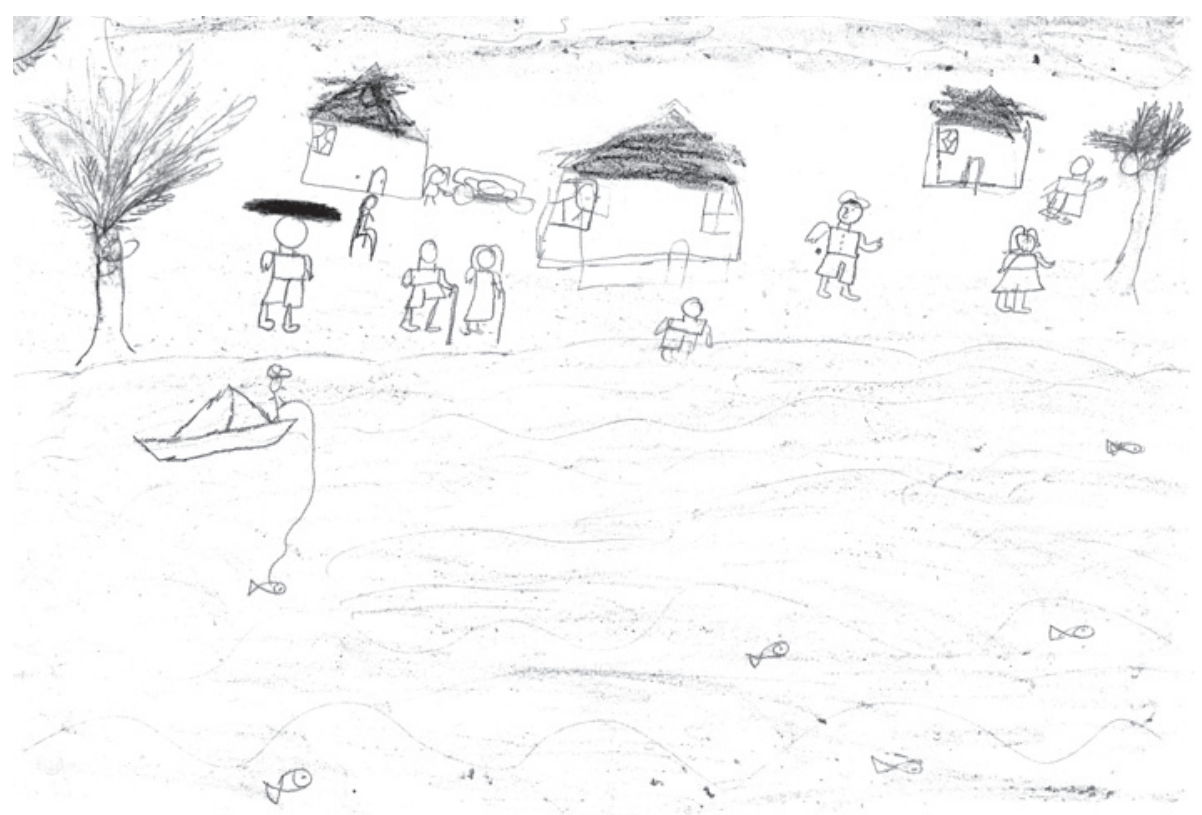

Figure 4.5 Oliver depicting the 'family reunion' in Chagos

This is a digital offprint for restricted use only | ( 2011 Koninklijke Brill NV 
That being said, girls primarily drew and narrated in detail about the family they would dwell with in Chagos. In their narratives, they expressed their longing to meet relatives who were living elsewhere, usually the Seychelles or England. Girls' drawings, in particular, are permeated with the longing for lost relatives. They miss family members who live far away from them: 'I have never seen my grandmother from my father's side; she lives in the Seychelles.' Statements like this were common. Family unity is symbolised by the many drawings where the family members all live under one roof. In photo elicitation exercises, children principally photographed family members. However, gender differences were also discernible in this exercise; while girls photographed their household members, boys seemed more interested in visualising their material environment (particularly Chagossian houses) and their brothers or, more precisely, their brothers' motorcycles.

Girls often feel a tremendous responsibility towards the well-being of their family. They have heavy tasks at home; as Lilli also mentions (cf. case above) they have to deal with feelings of guilt when they leave their family to go to school. Some of the girls cling to the prospect of living in Chagos one day, and they tell their stories with big smiles. Even with the very real constraints to their agency, the girls do find ways to develop their own coping strategies in conclave with each other, and they derive a certain amount of pleasure from attending school and from their leisure time. When life becomes too difficult to deal with, they can day-dream about Chagos. So for them, the perceptions of the past are projections into an imagined future in Chagos.

While boys would also like to see Chagos, they do not necessarily envisage living there. They project themselves into a future where indeed relatives are present but they simultaneously have their eyes on other prerequisites for their future well-being. They deem the possession of wealth to be their ticket to a happy future and solution to their problems. They emulate the ambitions of their brothers or other male family members. As one boy remarked: 'many went to England, I will follow this example. First I will make lots of money, buy many things like a motorcycle and a mobile phone. People will think I am important then. When I am really grown up, then I can go to Britain and join my older brother there. That will be a good life.' This route is an option for the Chagossians as they do qualify for both Mauritian and British citizenship. 
Thus, whereas boys and girls alike do imagine a 'family reunion' in Chagos in the near future, the boys do not automatically see Chagos as their future place of residence.

\section{'Kinning in the Imagination'}

Through their daily interactions with kin living with them, Chagossian children construct images of other Chagossians overseas; together, these Chagossians continue to reproduce the 'imagined community' of Chagossians, despite living in diasporic conditions. Anderson (1983) claims that these imagined communities' can evoke emotion and deep feelings of loyalty in people, particularly within the context of widespread ethnic and national structures of allegiance. Amit $(2002,16)$ builds from this observation, mentioning that communities 'are not coldly calculated contracts, but embodied, sensual and emotionally charged affiliations.' Indeed, such seems to be the case for Chagossian children living in Mauritius, who spoke about Chagos with incredible enthusiasm.

As we observed, Chagossian children were very active in reflecting on 'lost' kin; the 'family reunion' they described was depicted as crucial to both their own happiness and that of their extended families. They were engaged in a process which could be described as 'kinning in the imagination' as opposed to 'kinning' in real life. The concept of 'kinning' is principally used in adoption studies and refers to the process wherein adopted children are made into 'kin' and their new parents into 'parents' by actively engaging with each other on a daily basis, over a longer period of time (Howell 2006). Mason and Tipper (2008, 446-450) describe this daily interaction as 'doing kinship' which, due to perpetually engaging in this process, 'kinning' can be achieved through emotionally evaluating each other as kin despite the absence of biological link.

By telling stories about 'lost kin', Chagossian relatives living with the children seem to trigger a daily process of 'imagined kinning' within the children. It should be stressed, however, that this does not mean that imagination plays no part in kin relations in Mauritius as it is part and parcel of any social process; it is argued here that 'kinning in the imagination' refers to the imaginative interaction with relatives in the absence of actual physical contact with them. 
The majority of the children made reference to relatives overseas; they explained in detail what they would do once reunited with them. In reality, the children rarely if ever actually see these relatives due to the financial limitations related to buying a plane ticket to visit Mauritius. The fact that the other Creole and Indian Mauritian children did not engage to this extent in 'imagined kinning' does not mean that they do not have fantasies about overseas relatives. However, Chagossian children appear far more inclined to do so due to the discursive input of adult Chagossians and transmission of the message of the 'imagined' Chagossian community or 'nation'. This very specific message of unity is also a crucial discursive platform upon which Chagossians can eventually make claims to return to the archipelago. Thus, while the social environment in which children live and the importance that caregivers attach to the transmission of ancestral knowledge through storytelling is crucial to children's perceptions of Chagos, the (emotional) involvement of the children in this narrative is also a crucial stimulus in the 'reproduction of knowledge'. Children become involved in this reproduction from an early age. Nelson (1993) argues that children as young as the age of two or three already engage in a collaborative recollection of the past, typically in a narrative relation with a parent.

It should be stressed, however, that despite the heartfelt commitment of these children both to their distant relatives and immediate family, their longing to belong to a unified community was also born of their wish for a better life and therefore connected to the harsh social and economic realities of living in Mauritius. I agree with the plea of Amit (2002) to not overemphasise the symbolic meaning of community as it receives its meaning precisely through the day-to-day realities and experiences that construct it. He acknowledges the conceptual, imagined dimension of 'community' but goes on to argue that 'when this idea of community is not also invested with social content and context, that is to say when it is not realized in actual social relations, it is difficult to account for the emotive valence which is attributed to it' (Amit 2002,17 ). This is in fact what we see with the Chagossian children. Social and economic hardship and marginalisation, accompanied by feelings and narratives of loss and desperation voiced by Chagossian adults in their daily lives incite them to engage in the process of 'kinning in the imagination'. 
A child necessarily occupies a world with socio-cultural structures dominated by adults (Hockey \& James 1993). In processes of informal learning, children learn by living alongside older members of the family or community, observing and joining them in their activities (Paradise \& Rogoff 2009, 105). However, they also learn by becoming involved in the stories and dramatizations of older family members, which provides them the opportunity to participate, in an imagined way, in their experiences (ibid., 122). Narratives thus allow people's past experiences to be revitalized and made relevant for today's life and creation of community. Paradise \& Rogoff (2009) highlight the personal and emotional commitments of children to acquire skills and learn messages necessary to cultivate a sense of belonging to the community (ibid., 130).

Narratives are important in familiarizing children with what Barbara A. Misztal $(2003,15)$, in her discussion of social remembering, calls a 'mnemonic community': A group that socializes people into what should be remembered and what should be forgotten. This can be done through recounting shared experiences which implicitly dictate what is considered memorable and what is not (Misztal 2003, 15). Indeed, as argued above, first generation Chagossians depicted Chagos as paradise, a message which resonates with their grandchildren and which they virtually all remember. In the same manner, tales of harsh aspects of life in Chagos were omitted from the discursive and creative framework of these narratives, to such an extent that children fail to mention negative aspects of life in the archipelago.

Narratives about Chagos are principally transmitted to children via their female kin; Grandmothers, with whom many children live, are crucial in this regard. Indeed, it was a group of grandmothers who first drew attention to the harsh socio-economic circumstances of the Chagossians. Older female members of the family related the incident of eight Chagossian women who engaged in a hunger strike in Port Louis in March, 1981. They were supported in their cause by hundreds of principally female demonstrators (cf. Vine 2006, 299). These women succeeded in placing the Chagossian fate politically on both the Mauritian and international agenda. Indeed they also succeeded in transferring this message to the children. 


\section{Conclusion}

This chapter draws attention to the importance of the studying children to distil their notions and roles in the construction and perpetuation of (imagined) communities. They are the ones who are socialised within these communities and themselves actively engaged in the process of fuelling the imagined community' with meaning and indexical vigour. In other words, children embody and are connectors of kinship networks and notions of belonging. In addition, they have their own ideas of their family's past, present and future and the meaning of kinship, both in their relations to people living close to them and those in distant places.

For the Chagossian children, Chagos as a geographical place is crucial to them as a marker of their identity which sets them aside from the 'other Creoles'; it is a place that is primordial to their sense of 'Chagossness'. They do not see Mauritius as an extension of Chagos. In fact, their relations with Mauritius have been very problematic from the outset. The Chagossians feel betrayed by the 'Mauritians' as they gained their independence at the expense of the Chagossians. Whereas for the Mauritians, independence meant freedom from colonial powers, for the Chagossians it signified eviction from the place they consider their homeland. It is therefore far from surprising that the children and grandchildren of the first generation Chagossians see Mauritius as a place where they do not belong. It is a place where they have to fight for their existential and literal survival as a people. Chagossian children deal with this conundrum by imagining a better life away from Mauritius and by 'kinning in the imagination' with lost relatives who cannot live with them.

\section{References}

Adler P. \& P. Adler (2003), Peer power: Preadolescent culture and identity. New Brunswick: Rutgers University Press.

Aмiт, V., ed., (2002), Realizing community: Concepts, social relations and sentiments. London \& New York: Routledge.

ANDERSON, B. (1983), Imagined communities: Reflections on the origin and spread of nationalism. London \& New York: Verso. 
Arnheim, R. (1974), Art and visual perception: A psychology of the creative eye. The new version. Berkeley \& Los Angeles: University of California Press.

BLOCH, M. (2008), Durkheimian anthropology and religion: Going in and out of each other's bodies. In: H. Whitehouse \& J. Laidlaw, eds, Religion, anthropology and cognitive science, pp. 63-80. Durham: Carolina Academic Press.

- (1998), Autobiographical memory and the historical memory of the more distant past. In: How we think they think: Anthropological approaches to cognition, memory, and literacy, pp. 114-131. Oxford: Westview Press.

Boswell, R. (2006), Le malaise Créole: Ethnic identity in Mauritius. New York \& Oxford: Berghahn Books.

BOYDEN J. \& J. DE BERRY (2004). Youth on the front line: Ethnography, armed conflict and displacement. London: Berghahn Books.

Brannen J. \& M. O'Brien, eds, (1996), Children in families: Research and policy. London: Falmer Press.

Chagos Refugees Group/UK Chagos Support Association (2008), Returning home: A proposal for the resettlement of the Chagos Islands. URL: http://www.letthemreturn.com.

Christensen, P. \& A. James (1999), Childhood diversity and commonality: Some methodological insights. In: Research with children: Perspectives and practices, pp. 160-178. London: Falmer Press.

Christensen P., A. James \& C. Jenks (2000), Home and movement: Children constructing family time. In: S. Holloway \& G. Valentine, eds, Children's Geographies, pp. 139-155. London \& New York: Routledge.

Cohen, A. (1985), The symbolic construction of community. London \& New York: Routledge.

Dunn, J. \& K. DeAter-DeCKard (2001), Children's views of their changing families. York: Joseph Rowntree Foundation.

Eisenlohr, P. (2006), Little India: Diaspora, time, and ethnolinguistic belonging in Hindu Mauritius. Berkeley: University of California Press.

Eriksen, T.H. (1998), Common denominators: Ethnicity, nation-building and compromise in Mauritius. Oxford \& New York: Berg.

-. (1986), Creole culture and social change. Journal of Mauritian Studies 1(2): 59-72. Moka, Mauritius, MGI.

GARDELlA, A. (1982), The process of social formation on the island of Rodrigues, Indian Ocean. PhD Thesis, London School of Economics and Political Science.

Hallden, G. (2003), Children's views of family, home and house. In: P. Christensen \& M. O'Brien, eds, Children in the city: Home, neighbourhood and community, pp. 29-45. London: Routledge, Falmer.

Harris, P. (2000), The work of the imagination. Oxford: Blackwell Publishing.

Hockey J. \& A. JAmes (1993), Growing up and growing old: Ageing and dependency in the life course. London: Sage Publications Ltd.

Hollup, O. (2004), Educational policies, reforms and the role of teachers unions in Mauritius. Porsgrunn: Telemark University College. (Hit Publication no. 8).

Howell, S. (2006), The kinning of foreigners. Transnational adoption in a global perspective. New York \& Oxford: Berghahn Books.

Jeffery, L. (2007), How a plantation became paradise: Changing representations of the homeland among displaced Chagos islanders. Journal of the Royal Anthropological Institute 13: 951-968.

. (2006), The politics of victimhood among displaced Chagossians in Mauritius. PhD thesis, University of Cambridge.

—. (2006), Historical narrative and legal evidence: Judging Chagossians' high court testimonies. PoLAR: Political and Legal Anthropology Review 29: 228-253.

Johannessen, S. (2005), Contested roots: The contemporary exile of the Chagossian community in Mauritius. MA Thesis, University of Oslo.

Koester, D. (1997), Childhood in national consciousness and national consciousness in childhood. Childhood 4: 125-142. 
Kooy, M. (2008), Piecing together utopia: The case of the Chagossian children in Mauritius. MA Thesis, VU University Amsterdam.

KuIK, S. (1999), The magical power of words: About children, their conflicts and their bodies. Etnofoor 12: 53-72.

Marimootoo, H. (1997, May-September). Diego files, serial. Week End (Mauritius).

Mason, J. \& B. Tipper (2008), Being related: How children define and create kinship. Childhood 15(4): 441-460.

Mauritius Examination Syndicate (MES), (April 1991), Determinants of performance in primary schools with special reference to failures at CPE level (Unicef Funded Research Project, Réduit).

Ministry of Education, Culture and Human Resources (n.d.), National Literacy and Numeracy Strategy (NL \& NS). URL: http://www.gov.mu/portal/site/ education/menuitem.o1 7 e502688c15504631e691048a521ca/?content_id=1a5b8ooe 57af7010VgnVCM1000ooca6a1 2 ac RCRD (accessed 3 March 2009).

Ministry of Education, Culture and Human Resources (2008), Draft education \& human resources strategy plan 2008-2020.

Ministry of Education and Scientific Research (n.d.), History \& geography, Standard IV.

Ministry of Education, Culture and Human Resources/NCCRD (2008), History \& geography, standard $V$. (School pupils' textbook Mauritius primary education).

Misztal, B.A. (2003), Theories of social remembering. Maidenhead, Philadelphia: Open University Press.

Mitchell, L.M. (2006), Body and illness: Considering visayan Filipino children's perspectives within local and global relationships of inequality. Medical Anthropology 25(4): 331-373.

Moore, M., J. Sixsmith \& K. KNowles, EDS, (1996), Children's reflections on family life. London: Falmer Press.

Morrow, V. (1998), Understanding families: Children's perspectives. London: National Children's Bureau.

Nelson, K. (1993), The psychological and social origins of autobiographical memory. Psychological Science 4: 1-8.

Notermans, C. (2008), The emotional world of kinship: Children's experiences of fosterage in East Cameroon. Childhood: A Global Journal of Child Research 15(3): 355-377.

O'Brien, M., P. AlldRED \& D. Jones (1996), Children's constructions of family and kinship. In: J. Brannen \& M. O'Brien, eds, Children in families: Research and policy, pp. 84-100. London: Falmer Press.

ODEROI (January 2008), Indicators for monitoring the ZEP project based on a survey of ZEP schools submitted by Indian Ocean Child Rights Observatory (ODEROI: Observatoire des Droits de l'Enfant de la Région de l'Océan Indien. Commissioned by the Ministry of Education, funded by the UNDP).

O'Kane, C. (1998), Children and decision-making: Ethical considerations. In: V. Johnson, E. Ivan Smith, G. Gordon, P. Pridmore \& P. Scott, eds, Stepping forward: children and young people's participation in the developing process, pp. 36-41. London: Intermediate Technology Publications.

Oosterling, H., Slager, H. \& R. van de Vall (2007), Intermediale reflecties. Rotterdam: DAF Cahiers.

Palmyre, D. (2007), Culture créole et foi chrétienne. Bruxelles, Lumen Vitae, Beau-Bassin (Mauritius), Marye Pike.

Paradise, R. \& B. Rogoff (2009), Side by side: Learning by observing and pitching in. Ethos 37(1): 102-138.

Philip's Atlas of Mauritius for Primary and Lower Secondary Schools (2007).

Piolino, P., M. Hisland, I. Ruffeveille, V. Matuszewski, I. Jambaqué \& F. Eustache (2007), Do school-age children remember or know the personal past? Consciousness and Cognition 16(1): 84-101.

Powe, E. (1996), The lore and lure of the British Indian Ocean Territory. N.p.: Dan Aiki Publishers. 
Sсотт, R. (1976 (1961)), Limuria: The lesser dependencies of Mauritius. Westport, CT: Greenwood Press.

SvaŝEK, M. (2002), Narratives of "home" and "homeland": The symbolic construction and appropriation of the Sudeten German Heimat. Identities: Global Studies in Culture and Power 9: $495-518$.

UnesCo/UniCEF (2003), Monitoring learning achievement. A joint Unesco/Unicefproject. Towards Quality Education For All. A Survey of 9 year old children in the Republic of Mauritius.

VINE, D. (2006), Empire's footprint: Expulsion and the U.S. military base on Diego Garcia. PhD Thesis, City University New York, Graduate Faculty in Anthropology. Published in 2009 as Island of Shame: The Secret History of the U.S. Military Base on Diego Garcia. NJ: Princeton University Press.

Walker, I. (1986), Zaffer Pe Sanze: Ethnic identity and social change among the Ilois in Mauritius. Vacoas, Mauritius: KMLI.

Willats, J. (2005), Making sense of children's drawings. New Jersey, London: Lawrence Erlbaum Associates, Publishers.

Winchester, S. (1985), The sun never sets: Travels to the remaining outposts of the British Empire. New York, Prentice Hall Press. 


\title{
From Home to the Street: Children's Street-Ward Migration in Cape Verde
}

\author{
Lorenzo I. Bordonaro
}

\section{Introduction: Alex’s Puppy}

Alex $^{1}$ is eleven years old and comes from Porto Novo, the main village on Santo Antão, an island in the Cape Verde archipelago. His childish face

\footnotetext{
${ }^{1}$ Most of the names of the children and young men I have been working with have been changed in this text. I have also omitted the names of the social workers and psychologists I interviewed in NGOs and outreach facilities. In a few cases though, the real names of street boys have been maintained, as I am sure that they would very much appreciate being represented and their story witnessed. Earlier versions of this paper were presented at "The Politics of Youth Mobilisation" workshop, Copenhagen, February 2008, organized by the Danish Institute for International Studies, at the "Children on the Move in the Developing World" workshop, May 2008, organized by the Development Research Centre at the University of Sussex and at the "African Children in Focus" conference, Leiden, September 2008, organized by the Netherlands African Studies Association. I would like to thank Nicolas Argenti, Dorte Thorsen, Ann Whitehead, Sam Punch, Jens Aagaard Hansen and Cecilie Lanken for their comments on these occasions, as well as Catrien Notermans for reviewing an earlier version of this chapter. Funding for research in Cape Verde has been provided by the Fundação para a Ciência e a Tecnologia of the Portuguese Ministério da Ciência, Tecnologia e Ensino Superior.
} 
and short stature make him look much younger than he claims to be. $\mathrm{He}$ argues that he was living on the streets in Porto Novo and came to Mindelo because "there is more movement, more people, more tourists, more money." His father, of whom he has no memory, emigrated to Spain when he was just a baby. Alex has three older brothers and one younger one; his mother is disabled.

I met Alex for the first time on a Saturday night in Praça Nova, the main work-place for young street people in downtown Mindelo. He was wandering with an older boy, asking passers-by for spare change. He ran away one week earlier, arriving in São Vicente as a stowaway on a ship, the Ribeira de Paul. He told me that he now slept on the street. After our first meeting, I tried to get institutions and NGOs involved in Alex's case, attempting to contact his family and having him somehow returned home. He looked naïve and much younger than the other kids I knew.

A few days later, as I strolled through Praça Nova, looking for Alex, I met a group of children, led by Redy, a vivacious, exuberant kid I had known for some time. Redy used to live with his family but now makes money and finds extra food on the street. I explained that I was trying to get Alex back to his mother in Porto Novo. Defiantly, and almost angrily, Redy asked me, "Why the hell do you want to send him back to Santo Antão if he doesn't want to go? He has already run away from there five times! If you take him back, he will just run away again!" All the boys confirmed that it was not the first time he had run away. "He comes here to São Vicente, and then goes back, but he keeps running away from home!” they told me.

When I finally found Alex, I asked him what he really wanted to do. "I don't want to go back to Porto Novo," he told me with a smile. "I want to stay here, on the street." Later that night, when I was talking about Alex's case with Xana, a young prostitute, she remarked: "At times it is better to stay on the street than with your family.” I later went back to Praça Nova and observed Alex playing with some younger street children, amid a crowd of strolling people, wondering about the right thing to do. Should I bring him back to his household (where apparently nobody cared about him and conditions were dire), ask ICCA (the Cape Verdean Child and Adolescent Protection Institute) to intervene, starting a process that could bring Alex to a street-child facility 
(from where he would run away as soon as he could), or leave him to live on the street, with a future as a car washer or jail inmate?

Later that week, I was told that Alex was living at Nho Djunga, the oldest, most famous street-child outreach facility on the island. I called Dona Kátia (a social worker at Nho Djunga whom I had previously met and interviewed) for some news. "Yes," she told me, "he's with us now. We are already in touch with SOS Children's Village in Praia, and he will be sent there." Kátia got in touch with a social worker in Porto Novo to inquire about Alex's family. "We have decided," she told me, "that returning him to his family is impossible at the moment and we are going to send him to Praia." I asked her if I might go and visit Alex at Nho Djunga. She agreed and asked me to hold. After waiting for some time, she came back to the telephone and told me Alex had left without permission: "Now we'll have to look for him..." I finally met up with Alex at Nho Djunga the following day. From what Alex told me, he was told that he would be sent back to Porto Novo. He told me that he missed his mother, and wanted to go back to her. Apparently no one discussed the chance of being sent to Praia with him.

For several days I did not see Alex in the streets. However, later that week, I found him again in Praça Nova. From morning until night, I saw him around, begging. I asked him where he had been for the last few days, and whether he was still staying at the Nho Djunga. He told me he wasn't staying there any more: "There you are not allowed to play like here, in the street. There you have to go to school, then you eat, and then you have homework. You never play!" I asked, "So where have you been these days? I haven't seen you around" He replied candidly, "Home." Amazed, I inquired, "Home? What do you mean?" I found out he had been back to his mother's house in Santo Antão to see a puppy a friend had sold him, which he had taken there earlier that week. "So you've been there twice?" I asked. "Yes," he replied. We went to go sit on a bench in Praça Nova and I bought him a hamburger at a kiosk. "How's your mum?" I asked him. "She's doing fine," he answered.

In this chapter I will examine children's reasons for engaging with, moving to and living on the streets of Mindelo, arguing that it is only in terms of autonomous mobility within a heterogeneous and profoundly divided 
urban and social space that we can better understand what is commonly defined as the phenomenon of "street children." Alex's case (quoted above) is remarkably emblematic in this regard. Below, I consider the 'street' as a potentially effective survival strategy for young people that can be adopted but does not define or identify a clear-cut set of actors. According to these assertions, I suggest that the relationship between actors and the street environment must be viewed as opportunistic rather than fatalistic. I argue that such a lens can significantly assist researchers in their quest to understand children's decision-making processes by better identifying children's motives for migrating to or staying on the street-even when alternatives may be available.

Kristin Ferguson (2006) recently proposed to approach the issue of 'street children' from a similar angle. As I do, Ferguson refers to the movement of children from home to the street as "child street migration," claiming that the phrase 'street working children' might better reflect children's activities on and experiences of the street $(2006,706)$. Acknowledging that children are involved in labour migration for self or household support, Lorraine Young (2004) points out that children moving to large city streets in SubSaharan Africa (a phenomenon she defines as "street-ward migration") are perhaps the most visible group engaging in autonomous independent movements (Young 2004, 472-4). Analysing the reasons why Bangladeshi children move to the streets, Conticini and Hulme (2007), also use the notion of 'migration to the street' and acknowledge that such mobility can be an empowering process. They write, "Street life not only involves vulnerability, but also processes of empowerment through which children exercise their personal agency and develop innovative coping behaviours (Conticini \& Hulme 2007, 205)."

Considering street-ward mobility as autonomous migration does not mean ignoring relevant pushing factors that entice young people to move to the street (household structure, poor parenting, corporal punishment). The reasons for any kind of migration are always multiple, and obviously cannot be limited to rational economic decisions. The point is not to give a romanticized or mythical picture of street life, while ignoring social and economic constraints. We know from other contexts that when structural conditions translate into nega- 


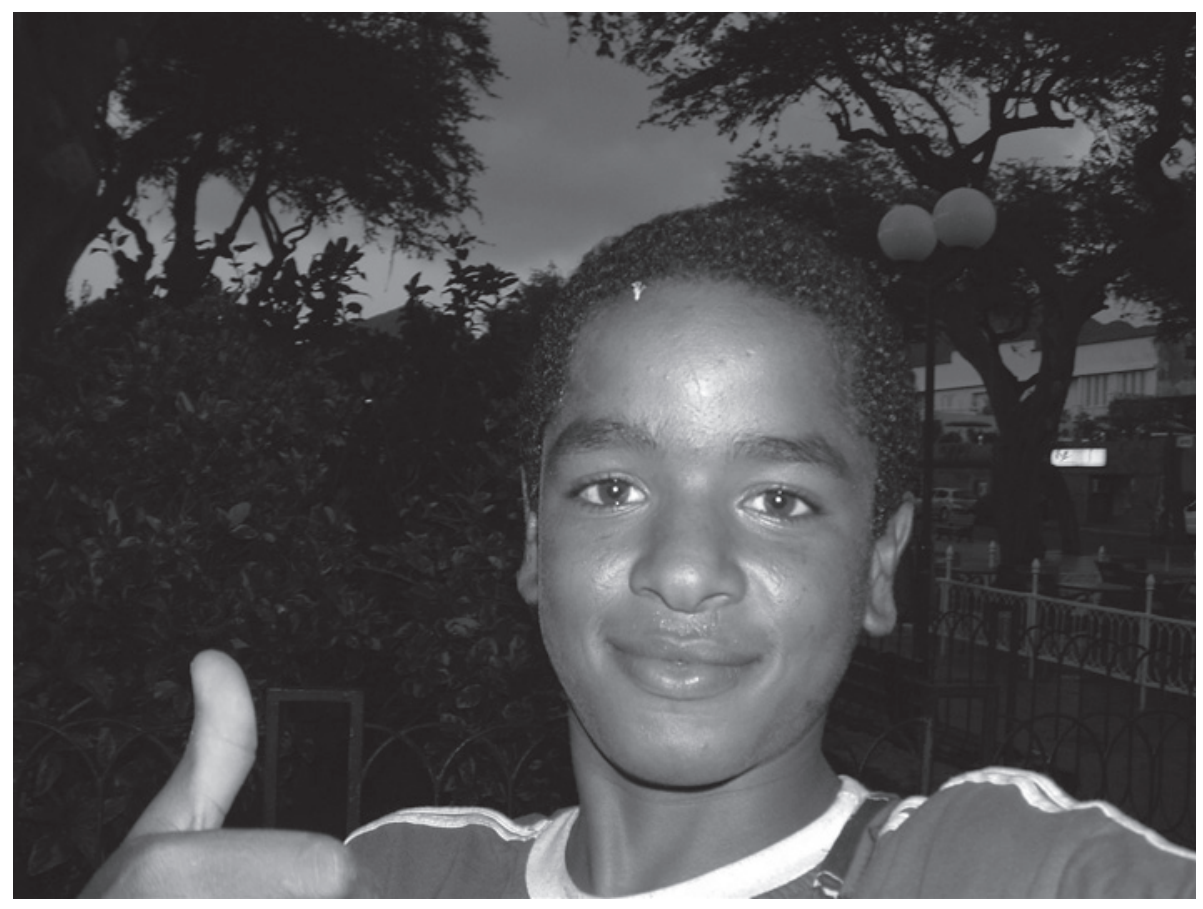

Figure 5.1 Self-portrait by Helton. Mindelo, July 2007

tive family environments, some children choose to actively engage in streetward migration (Young 2004, 485). Nonetheless, it was exactly within these conditions that I found considerable evidence of children's agency, coping strategies and autonomy in decision-making.

A photograph from my fieldwork metaphorically captures the ambivalence of this perspective. Notably it is not a picture I took myself but a foreground self-portrait that Helton, a fifteen-year-old boy who had been living in the street of Mindelo since when he was nine, took with my camera (see picture 1). His smile illuminated by the camera flash, the raised thumb, direct gaze: Everything effectively conveys self-confidence and a virile, bragging toughness. Still, another element attracts our attention in this picture.

As the picture was taken in the evening, Helton's shining, poised face emerges in theatrical contrast to the darkness of the background, the gloomy trees of the main square in downtown Mindelo, blowing in the night wind. The effect is indeed involuntary. Even so, the contrast between Helton's 
triumphant face in the foreground and the dim landscape in the background is a remarkable visual metaphor of the tension between street children's agency and victimization, which is one of the hardest theoretical and moral conundrums of anthropological research focusing on children in difficult conditions. As in Helton's self portrait, my objective is therefore to find the right balance between the background and the foreground, making agency and constraint, resilience and suffering, fit (even if in contrast) into the same picture.

\section{Methods}

While this chapter deals primarily with the issue of street children and youth in the town of Mindelo, ${ }^{2}$ it is part of a wider project I am carrying out on street youth and juvenile delinquency in Praia and Mindelo, the two largest urban areas in Cape Verde. Interviews with a wide range of actors involved with both street children and youth 'deviancy' in general were carried out (NGO personnel, project leaders, social workers, police officers, lawyers, attorneys and local politicians). I tried to build a dialogue with children making a living and/or living on the street, sharing in their daily lives through participant observation without overstraining the relationship with formal interviews. Prison inmates were also interviewed. In some cases, relatives of street children and former street children were interviewed as well. Moreover, since street children cannot be understood without a critical examination of domestically based childhoods (Hecht 1998, 21), several areas in the periphery of both towns were visited and addressed in the research.

Let me go back to Helton's self-portrait. In another way, this picture illustrates both one of the difficulties faced and methods employed in my research. Street children in Cape Verde, though limited in number, have been targeted in the last decade by an increasing number of 'projects'-each based on some

\footnotetext{
${ }^{2}$ Precisely because I conceive the engagement with the street in terms of mobility and practice rather that territoriality and essential identity, the number of street-engaged boys in Mindelo is difficult to quantify. Very roughly however, I worked with a group of boys varying between 20 and 40 , aged between 11 and 20.
}

This is a digital offprint for restricted use only | (c) 2011 Koninklijke Brill NV 
kind of field research. Even though most of these projects did little for the street boys themselves, the frequent, stubbornly repetitive questionnaire-based research achieved the result of making children fed up with researchers, legitimately suspicious, quite closed in on themselves and unwilling to answer any further direct inquiries about their lives. Though more classic ethnographic methods were also used in my research (such as informal interviews and participant observation) visual methods, particularly photo elicitation (cf. Harper 2002), proved highly effective for overcoming the difficulties mentioned above. As Young \& Barret (2001) stress, visual methods can be particularly important for developing cumulative insights into the street child's urban environment from the his/her perspective, as well as introducing a relaxed, fun atmosphere and allowing the children to take control of the process without imposing adult influence (Young \& Barret 2001, 142).

Despite repeated warnings from people I knew in Cape Verde, I therefore lent my camera out to the boys I was working with. I taught some of them how to use the camera in basic mode, and let them take pictures of themselves and the street environment. Later on, I had the boys comment on the pictures they had taken. Besides turning research into a relaxed, amusing activity, making for enthusiastic participation by the boys in research activities, the visual documents provided insight into the children's self-perception and frequently elicited comments and memories that would have been difficult to obtain otherwise.

\section{Homes}

As with Alex, at the beginning, interviews and dialogues with children and youth in Cape Verde revealed that, running away had been a choice for many of them, and they seemed to consider street life relatively satisfactory. Many insisted that they preferred to stay on the streets instead of being at home or in street-child outreach centres. In order to understand why the street could be appealing to some children, I will trace life on the streets of downtown Mindelo to the outskirts of the town, providing a glimpse of both urban areas and the households the children grew up in, arguing that (despite the domestic 
ideology prevailing in child-focused social interventions) as Panter-Brick points out, children are not necessarily better off living with their families $(2002,161)$.

Since the 1990s, Cape Verde has undergone dramatic economic and political transformations that have brought about a considerable increase in urban populations and a growing social class distinction. The two main towns (Praia \& Mindelo) have rapidly expanded in the last decades. Mindelo went from around 51,000 inhabitants in 1990 , to more than 74,000 in 2008 , while Praia, the capital city, went from 71,000 in 1990 to 130,000 in 2008 (INE 2008). All national indicators point to a growing income disparity and social class polarization. Though the middle class has grown considerably in recent years, there is a certain stratum of the population still living in conditions of extreme poverty. According to the 2000/2001 national statistical survey, $37 \%$ of the Cape Verdean population is considered 'poor'. Of this, 54\% are considered 'very poor', accounting for $20 \%$ of the whole population. Even though $70 \%$ of the poor population lives in rural areas, it is in the urban areas that poverty is more severe (INE 2002).

Mindelo's urban structure reflects the increasing polarisation of its population. Climbing one of the hills surrounding the plain where the city is built around the harbour, one has a dramatic view of the more than 60,000inhabitant town. Middle and upper class families occupy the older, central areas of town and the recently developed areas, while sprawling, unplanned neighbourhoods spread over the less valuable land. The newest houses were built on the slopes of the hills enclosing the town, creating a large and growing periphery with little if any basic infrastructure, where poverty and unemployment are widespread. It is in these latter areas that most social issues associated with childhood and youth have become highly visible in the last decade.

Due to the high mobility of the younger Cape Verdean population and the peculiar features of the Cape Verdean household (Rodrigues 2007; Grassi \& Évora 2007), many children grow up in single parent families (usually singlemother households). It can be particularly difficult for working women to cope with this situation, especially when the support network of the extended family is unavailable, which is the case for some recent migrants who have moved to Mindelo from the nearby island of Santo Antão. Many children are actually 
left to themselves during a large part of the day; in a few cases, they are even locked in their houses while their parents are working.

\begin{abstract}
Nailson is now 16 and lives in an outreach facility in São Vicente. He was born in São Vicente but grew up in Santo Antão. He is the eldest of 13 brothers and sisters. When Nailson was 2 months old, his parents moved to Santo Antão, in Ribeirão, a neighbourhood of Ribeira Grande. His father went there to work as a farmer and took his family with him. After a few years, his mother left and Nailson stayed with his father, who had to work and left him at home alone with two of his younger brothers for long periods. His father even used to stay away for several days. Their mother could not help them, as she had too many children: Five by one man and four by another. His father had five more children by another woman. It was their grandmother who gave them something to eat now and then (From my field-notes).
\end{abstract}

As in the case of Nailson, the only parent dies, migrates or simply is no longer capable of caring for the children, who are left with a grandmother or, more rarely, an aunt (Giuffré 2007; Rodrigues 2007). As the grandmother grows older or cannot provide adequate care and attention, children may come into closer contact with opportunities on the 'street'. It is often a peer who, already living on the street, gradually absorbs them into street lifestyle. Children eventually decide not to go back home or to only go back sporadically. However, in some cases, the relationship with the mother or grandmother is preserved, even if the child is no longer living with her. Actually, in many single-mother households, children are asked to make a contribution.

Francisco is now 13. He lived on the street from 6 to 8 and is now living and studying in an outreach facility. "When I was born, my mother left me at the hospital, while my father, who died one year ago, vanished. It was only a few years ago that I met my mother. My grandmother (father's mother) took care of me, but she had little food to give me and my brother, who was three years older than me. I took to the street. My grandmother was worried and asked the police to look for me. The police eventually found me and brought me back to my grandmother. But I didn't do anything! Anyway I didn't want to stay there, so I ran away again. Rua sabi (the street is good). In the street I was never hungry. People liked me; they gave me food and money. We went there, near the Clube Nautico, to cook our food. The older ones beat us, to steal our money. That's true. But on the street nobody is in charge (na rua ninguin manda). Now and then my brother and I gave some money to my grandmother. My father died a year ago. He worked at the docks. One day, when I was living on the street, I went to see him. He asked me why I wasn't with my grandmother. He bought me homemade yoghurt and told me to go

This is a digital offprint for restricted use only | ( 2011 Koninklijke Brill NV 
back home. He worked very hard, from morning to night; he could not take care of me."

The relationship with the family can therefore be multifaceted. Some young people live totally alone on the street, keeping all they can earn for themselves. Others share a part of the money they make with their mother or grandmother, in a way acting as autonomous workers, but keeping a link with the household. The street is often an environment where children can earn money, contributing to the family income. In some cases leaving home for the street can be an altruistic move in response to chronic poverty; attempting to support the extended family powerfully illustrates children's agency in constructing their own social lives.

Eric is 13 years old and makes a living washing cars, begging and pushing hash on the street. He earns about 500 escudos a day. Though I saw him sleeping on the street several times, he claims that he lives with his mother, father and three brothers, the youngest of whom is 4 . He gives 300 escudos to his mother and keeps the rest for himself. "You know, to buy some fruit juice..." His mother doesn't work, but his father does, as a painter. Eric has been washing cars for a year now. "I liked school, but my mother could not provide for all of us. I was the oldest one and had to go and earn a living."

I often observed young boys leaving their slums in the periphery, reaching the city centre, spending the day in the street begging, and going back home at night. Street begging can also be a kind of part-time activity or a 'summer job' for many children, carried out after school or during vacations.

Martinho is 11. I met him in the city centre, where he was begging for money and food. He lives in Ribeirinha in a shanty, just bought for 40,00o escudos, with his father, mother and four brothers (aged two, four, six, and nine). His father, he claims, does not work. His mother, on the contrary, is a domestic worker in a house in Bela Vista, earning 10,000 escudos a month. She's been ill for a while though and unable to work. So at the moment there is no food at home and, since it is the summer school holiday, Martinho goes to the city centre every day looking for food. "I don't like it very much on the street. The older ones beat the younger ones. At night I always sleep at home."

In Mindelo, only boys live on or become closely engaged with the street as independent agents. This does not mean that girls do not appear on the street; rather, in this context they are generally non-independent-carrying out economic activity for the household as street sellers, mostly accompanying their 
mothers. The different roles assigned to boys and girls within the household and the Cape Verdean gender ideology explain why the street population is entirely masculine.

Though I did not carry out specific research into female children, gender appears to be a relevant element of differentiation in low-class young people's life strategies. Girls usually remain at home until they are much older than child street migrants, as they play a crucial role in the management of the household, such as cleaning, cooking and looking after younger siblings. Conflicts generally arise later, in their early teens. When girls leave home, sex work can be a shared survival strategy in which access to conspicuous consumption is gained, a crucial component in defining youth identities, especially in early and later adolescence. There is practically no institution dealing with female runaway adolescents-whether involved with prostitution or not. This is probably because young girls quite easily turn into young mothers; most of them move back to their mother's or grandmother's house after getting pregnant.

Economic poverty, however, was not the only reason for boys moving onto the street. Actually, economic poverty is never a sufficient cause for street-ward migration and there are several thousand boys living below the poverty line that do not migrate to the streets. As in several other contexts, non-economic factors play a decisive role in children's decisions to move to the streets (Lucchini 1997; Conticini \& Hulme 2007).

Another crucial motivation for street migration in Mindelo is violence and corporal punishment within the family. ${ }^{3}$ Several children I interviewed said that they had left home due to domestic conflicts or violence. This is also given as one of the reasons why children are afraid to go back home, as they are often scared of being punished for running away.

${ }^{3}$ Conticini \& Hulme in their analysis of Bangladeshi children's reasons for moving to the street claim that "the perception of street-living children held by the general public, policy makers and many social scientists in Bangladesh is filtered through, and conditioned by, a dominant narrative which posits that children are on the street because their parents or guardians cannot meet the household's basic material needs. The role played by violence within the household and the strength of the social bonds built by children on the street are too often ignored by commentators on this 'problem' in Bangladesh.... Our main finding is that the breakdown of social relationships within the household, and not economic poverty, is the main cause of child migration to the street" $(2007,203,207)$. 
I met Wilson in Praça Nova, where he was asking passers-by for spare change. As a newbie to the street, the 'street veterans' were constantly chasing him off. I approached him and tried to talk to him. He was scared and the first thing he said was that he didn't want to go back home. He was 11. It was difficult to understand what had happened to him. I gathered that he had been living with his mother and had run away. His parents broke up. He was reluctant to go back to his mothers' house and scared that his father might beat him for having run away. He finally agreed to give me his father's address and allowed me to go and talk to him. The following day I took a taxi to Horta Seca neighbourhood to meet Wilson's father. Domingo was born in Santo Antão, had no job and was basically surviving by selling grog (sugar-cane spirit) at his place, which he had converted into a small bar. When Wilson was 1 year old, Domingo told me, his mother had gone to Praia and left her son with him until he was 5 . Since she had come back, Wilson had lived with her in São Vicente, running away now and then. Wilson's mother, Domingo claimed, had no job either. He said that she had a disordered life, "she always goes around", frequently leaving the children alone. She beat Wilson, who, for this reason, had already run away from home several times before. Wilson was unregistered and had never been to school.

While reports on street children in Cape Verde (e.g. Anjos \& Varela 2005) and most social-workers I talked to described the street as a really violent place where children were constantly victims of physical and sexual abuse, most children I interviewed said that they had migrated to the street exactly because of the violence (usually physical) they had to endure at home. For most street children the street was perceived of as safer than their homes. According to a recent anthropological survey, $40 \%$ of the street children that claimed to be victims of any form of violence said that the family household was the main context of maltreatment (Anjos \& Varala 2005, 36).

According to a social worker at the Centro de Acolhimento Nocturno (an outreach facility for children at risk), causalities leading to the street-ward migration can be identified within the family. Unemployment or irregular jobs, the social worker claimed, were common among low-income families, who could not or were not interested in providing adequate parenting for their children. Sometimes, she maintained, children were asked to look after themselves in the street, scavenging food for themselves and the family. Alcoholism and maltreatment were often causes of child abandonment. She said that many children claimed to have run away because they were severely beaten by their parents. Other social workers pointed to similar causes; according to another social worker employed in the religious NGO, Operação Carinho: 
...there is a general lack of responsibility towards children. They are somehow left to themselves. They are allowed to circulate freely in the street, even at night, and nobody really cares. Some of them are victims of maltreatment by their own parents or step-parents. Some others are sent out into the street to beg, as their mothers don't want to work. The fathers are usually absent and working mothers cannot really look after their children. There are cases of mothers with four children, no man, and unemployed. As a matter of fact, most street children still have a family or a relative and a house in São Vicente!

In turn, a social worker at ICCA confirmed, "Often children don't find a home where they live and look for it outside, on the street." A psychologist working at the same institution broadened the debate, pointing out that Cape Verde does not really provide social support for families:

There is a wide range of factors (like drugs, alcohol, etc) determining social difficulties that bring about what we call 'dysfunctional families.' Families are economically weak, and for this reason some children don't want to go back home. What we need here is social support, limiting poverty and hence child abandonment. With children and adolescents on the street...the problem is that on the street they have their vices, they can eat whatever they want, they have all the space they need. How can we convince them to go back to a 'dysfunctional family'?

An experienced social worker at the Centro Juvenil Nho Djunga (an outreach facility for children at risk) gave me a similar 'family-blaming' perspective:

It is usually the case that poorer families have many children. Then the father does not want them and the mother does not want to take care of them... Or the mother has too many children, and the father doesn't give anythingsome fathers give up their jobs so as not to have to pay child support. For example, there are many people here from Santo Antão. The mother comes first to find a job, then calls her children to join her. But these children always stay at home alone, and little by little get attracted by the city. At times children don't go to school so that they can go to the city centre begging for money and then they go back home.

Or, in the words of another social worker from the same institution:

Children go onto the street due to irresponsible fatherhood and/or motherhood. In the large majority of cases however, the fathers don't accept their responsibility and run away. The relationship that led to pregnancy wasn't a close one and when the woman got pregnant, the man took off. And the mother is left alone. In some cases, there comes a time when the mother thinks that her child is just terrible and, so to speak, she opens her hands and 
lets him go out onto the street one day, then another, and he ends up staying there. For some mothers it is even simpler. The child stays on the street, he eats there... And a vicious circle starts here. The child goes and comes back, goes and comes back, till he finally stays. We always think that the family protects children, but sometimes the children are beaten or they don't have clothes or food.

Most social workers' analyses correctly pointed out the difficulties that children had to cope with within their households-making them increasingly detached from their homes and involved with the street. However, these analyses seldom acknowledge that street-life, besides being a solution to problems children face within their households and neighbourhoods, could be appealing in itself; though not devoid of dangers and perils, it is a fascinating environment and social world.

\section{The Appeal of the Street}

When dealing with inexperienced social workers (and researchers), passers-by and tourists, street-engaged children did not hesitate to play the part of victims, somehow corroborating to their own advantage the image of poverty and victimhood commonly ascribed to them. In other contexts, for instance whilst conversing with other boys, or with people not directly involved in the 'rescue industry', children did not portray street-life in such a 'victimizing' light. 'Victimcy,' as Mats Utas (2005) shows, can be quite an effective form of agency. Though dire family conditions and poverty can be crucial 'pushing factors,' we should not forget other reasons why children move to the street, what we might call the 'pulling factor' (cf. Lucchini's 'ludic factors' 1997, 6). As Lorraine Young has underlined, by "focusing solely on issues of poverty as the reason why children take to the streets... street children are viewed as innocent victims on whom social, economic and political conditions are imposed forcing them onto the streets. This diminishes children's autonomy in the decisionmaking process and neglects other factors, which might influence their migration decisions (2004, 473)."

Given the limited economic resources within the household, it is not surprising that one of the central motivations for children to run away or to spend 
time on the street is the economic opportunities and relative food affluence. Street working children's economy consists basically of begging and service labour in the informal sector, indulging sometimes in pick-pocketing, shop lifting and very rarely in marijuana pushing. Children and young people also show a great capacity for grasping the opportunities the street can offer. Due to the nature of their economy, for example, street children survive best when there is more 'movement': In contexts where people gather to participate in cultural events or where tourists converge. Mobility of street children in Cape Verde therefore follows a seasonal agenda, reflecting the fluctuations of global tourism, the holiday calendar of Cape Verdean migrants and the national programme of festivals and cultural events.

This combined strategy can be highly effective for the streetwise, to the point that in specific periods of the year, when the "movement is good" as they say, the children's problem is not making money, but hiding money, to avoid being robbed by the older children at night. A social worker at the Nho Djunga centre related to me the following vignette:

There was a boy who was in the street and we found a job for him as a smith. He earned 100 escudos a day. One day I met him, and he told me, "I should go back to the street. I go there, to the city centre and I can easily get about 800 escudos a day!

Several trusted bar-owners in downtown Mindelo act as 'banks' for children, keeping their money safe and giving it back to them when they need it. Street working children in this sense are independent economic agents seeking to 'work' where opportunities are better. Given the conditions of extreme poverty of numerous households both in the rural areas and in the outskirts of towns like Mindelo and Praia, it is not surprising that the street appeals to some children.

In conversations with the boys, however, the economic advantages of the street were never considered as separate from independence and love of freedom, two of the most cited reasons for moving to and staying on the street. Actually, liberty and autonomy are key values for children living on the streets of Mindelo, and several of them praised the street as a space of freedom. Consider these short passages from interviews I had with street children and former street children: 
You ask me if the street is good. When you are on the street you think that it is a good life. You are tranquil. When you move onto the street and you run away from home, yes, this is good. You don't have to go to school, you never lack food and you never lack friends and life together. In the street you live like a rebel. You are tranquil. You are free. You know, at times you only know your neighbourhoods. You go downtown, and all that movement fascinates you.

(Inmate, S. Vicente Prison, former street child)

You see, on the street there are some good things. We always have money in our pockets, we buy a lot of junk food and we cook on the beach. Life on the street can be easy. I have never tried to go back home. I like staying on the street because of the money, because of the food. Of course I had something to eat at home as well, but I love to cook my own meals, I love to be on the street, to eat hidden away...the street is good, better than my home, that's what I told my mother.

(S. Vicente, street child, 13)

I started to sleep on the street. I also liked to stay with my mother, but I just wanted to go onto the street. We were a group, together with ${ }^{* *},{ }^{* * *}$ and the others. We did a lot of things together. We smoked. The street is good. You don't work. You can get your money, you can smoke, you are at ease, nobody is in charge, you can stay awake at night and go to sleep whenever you want.

(Inmate, S. Vicente Prison, former street child)

Even when the boys indicated money as a crucial motivation for migrating to the street, what really seemed at stake was, in most cases, autonomy and greater freedom. These feelings of empowerment and liberty experienced when running away make street life extremely attractive. In several interviews, curiosity and the wish for independence were clearly pointed out as initial motivations for running away.

I was born in São Vicente, in Bela Vista, and both my parents were born there as well. I ran away from home when I was 7 or 8 years old. My parents were living together at that time, and they both had a job. My father worked at the City Hall (even though he used to drink a lot) and my mother worked in a driving school. But I was always alone at home, and so I went to the city centre to look for some food. I started to sleep there, and then I was afraid to go back home, I was afraid they would beat me. I was fine with my parents, but I wanted to get out, to see other things. At that time there was a neighbour of mine, a boy called Chiquinho, and he told me, "Let's go and ask for 
bread." And that's how it all started. I went onto the streets, I met other boys there, I started to do some bad things.

(Former street child, now inmate in outreach facility)

Actually, the street in Mindelo is a key space of socialization, opportunities and adventure for any child or adolescent. In the peripheral neighbourhoods of town, the outdoor space, the 'corner,' is often a meeting place, a playground, a place to talk, sit and drink. Especially in the late afternoon and the evening, the streets of these neighbourhoods are crowded with children playing, adolescents chatting and building relationships and old people sitting outside their houses watching the world go by. Due to increasing criminalization and stigmatization of the street within the last decade, negative attitudes towards the street are evident among middle and lower-middle class people. Children of these families are often 'confined' to their houses. Many people involved in social youth programmes claim that they have to bring people 'out of the street' and not let them hang around aimlessly all day. The street is increasingly demonized as a place of inactivity, of threat and crime, and portrayed as dangerous and morally ambiguous. As Tobias Hecht states, "the street is perceived as a threat to the moral values adults seek to inculcate in children (1998, 20)." Many children reported peer influence as a key element in the decision-making process leading them to the street. According to most interviewees, peers invited children to join "the group" on the street; those with more experience usually teach less-experienced children the basics of street life.

My father and mother raised me. They are both still alive. My father used to work at the harbour, and when he went to his workplace, he passed in front of the praia de yacht. It was there that I first met the other street children, and they were the ones who convinced me to move to the street. It is always like this. You meet a friend who tells you what life on the street is like. On the street you feel freer, you get the vice of money-you get to know money-you know many vices... I didn't want to go back home. And when they brought me by force, I didn't want to stay there, I ran away again. They used to beat me. But my mother was very worried when I ran away from home. When I went onto the street, I had no problem within my family. It is just that the others convinced me. They gave me some dollars, some clothes, I was feeling very strong.

(Former street child, now inmate in outreach facility) 
The peer group is indeed a crucial aspect of kids living on the street. Though conflict and sporadic fights can break out now and then, having a group of friends and belonging to it is a key element of survival on the street. Friendship is considered one of the greatest appeals of street life by most former street youth:

Since I left my home, the other boys in the street have been my family. And the friends you make on the street...that is good. The relationship you have with your friends on the street is something you cannot forget.

(Inmate, S. Vicente Prison, former street child)

As Conticini and Hulme stress "issues such as the social bonding that children experience on the street, the formation of urban sub-cultures and the evolution of their self-perception are significant in understanding the attachment that children develop to the street and the difficulties they face in reintegrating into their former households $(2007,205)$." In Mindelo, small groups of peers are often seen coordinating their efforts on the street, sharing and cooking food together, travelling together from one island to the other, and playing together as a group. As among the entire population of street children, there is a sort of loose, age hierarchy within these groups, expressed in terms of both respect and fear. Older street youth can be serious threats to younger street children. Theft and physical violence by "the older ones" are commonly reported by younger boys as one of the greatest dangers of the street, especially at night. As a result, younger children commonly keep their sleeping sites secret, or change them very frequently.

One of the strategies for overcoming this menace is for younger boys, during the initial stages of getting involved with the street, to engage in a close relationship with an older boy, who will 'protect' and educate them. This kind of relationship is frequently expressed in parental terms, like a father-son relationship. It is actually a symbiotic relationship, in which the younger streetchild, more successful at raising money by begging due to his age, shares a part of his income in exchange for protection and expertise, enjoying some of the privileges the older boy has acquired during his career (better working places, more comfortable sleeping places, etc).

In conclusion, we should not overlook, that street-ward migration, like any form of child and adult migration, may succeed or fail. Surviving and 
living at ease on the street is a matter of acquired competence, of becoming 'streetwise.' In some cases, street-ward migrants simply fail, and go back to their families or other relatives, or prefer to stay in outreach facilities. Those who become streetwise (the success stories, so to speak) are quite at ease on the street and, despite the availability of alternatives, stubbornly refuse to leave the street, even though they may repeat that they absolutely want to leave.

The street has its perils, too. Increasingly, within the last decade in Cape Verde, crack addiction has brought several street boys to prison for petty crimes after turning sixteen. However, if able to avoid cocaine addiction and the legal system, street children often grow into working street youth, making a living in the informal street economy or in the informal economy at large. At this point, a clear distinction between former street children and low class youth from the city slums becomes impossible to make and practically irrelevant.

\section{What Kind of Agency?}

On the basis of key research findings from empirical literature on street children in Colombia, South Africa, Brazil, Honduras, Ethiopia, Sudan, Nepal and Indonesia, Veale, Taylor \& Linehan (2000, 137) conclude that: "without discounting the deprivations and hazards that exist in the street, children often cite what can only be described as positive features of the street environment that offer solutions to problems in their lives at home." Considering street children as independent child migrants helps us to understand their moving to the street as an exercise of agency; moving from victimization to an actor-centred perspective allows us to better understand children's motivations for running away from their homes. Paralleling what can be claimed for most voluntary migrants, most children in Mindelo turn to the street to find a solution to basic problems; in general, they are looking for a better life, and trying to improve their living conditions. Given these former conditions, and from the main actors' perspectives, the street appears as the solution, not the problem.

Even though independent child migration has usually been understood within a children's-rights framework that pictures child migrants as vulnerable, 
passive, and exploited victims, dependent on adult migrants, recent investigation has shown that even though "children are often regarded as being unable or unlikely to be making independent decisions when they migrate, for a proportion of independent child migrants this is part of a set of the child's own objectives and strategies (Whitehead \& Hashim 2005, 36; Iversen 2002)." As in other forms of independent child migration, mobility can be a process of liberation and empowerment for street children in Mindelo.

Dealing with categories of social actors such as working street children or independent child migrants, we are confronted with an ethical and theoretical conundrum stemming from regarding children as autonomous actors. It is their autonomy that is troubling, because it questions an iconic picture of the child as a dependent and vulnerable being, and therefore necessarily as a potential victim. But this is not the only issue. Once we acknowledge children as social agents, our concern is how to conceive children's agency, their capacity for self-reflection and their autonomy in decision-making, without portraying them as 'romantic heroes' and ignoring social and economic constraints that effectively limit their agency. In exploring the daily lives and the life trajectories of street children, it is important to find the right balance between examining social and economic constraints, individual suffering and agency. As Sam Punch underlined, it is crucial to recall that often migration is for children "a coping strategy to enable them to get by within the structural constraints that they face. They can assert their agency to a certain extent but it is within structural limits $(2007,15)$."

Not to be caught between the victims-or-heroes Scylla and Charybdis, we have to either acknowledge child street migrants' agency as a 'tactical agency,' as Alcinda Honwana (2005) defines it, drawing upon Clausewitz's (1989) distinction between strategy and tactic, or as 'thin' agency, as Natasha Klocker proposes, referring to "decisions and everyday actions that are carried out within highly restrictive contexts, characterised by few viable alternatives $(2007,85)$." It is within this theoretical framework that we might better assess and acknowledge decision-making processes like those leading children and youth in Mindelo to engage in street-ward migration; in doing so, we recognize the value of their efforts to improve their lives as active social agents. 


\section{References}

Anjos, J.C.G. dos \& J.C.M. Varala (2005), Diagnóstico da situação de vulnerabilidade das crianças em situação de rua face às IST/VHI/SIDA. Praia: Instituto Caboverdeano de Menores and CCS/SIDA. Unpublished Report.

Clausewitz, C. von (1989), On war (ed. and trans. M. Howard \& P. Paret). Princeton, NJ: Princeton University Press.

Conticini, A. \& D. Hulme (2007), Escaping violence, seeking freedom: Why children in Bangladesh migrate to the street. Development and Change 38(2): 201-227.

De Certeau, M. (1984), The practice of everyday life. Berkeley: University of California Press.

Ferguson, K.M. (2006), Responding to children's street work with alternative incomegeneration strategies. International Social Work 49(6): 705-717.

GIUfFrè, M. (2007), Mulheres que ficam e mulheres que migram: Dinâmicas duma relação complexa na ilha de Santo Antão (Cabo Verde). In: M. Grassi \& I. Évora, eds, Género e migrações Cabo-Verdianas, pp. 193-215. Lisbon: ICS.

Grassi, M. \& I. Évora, EDS, (2007), Género e Migrações Cabo-Verdianas. Lisbon: ICS.

HARPER, D. (2002), Talking about pictures: A case for photo elicitation. Visual Studies 17(1): $13-26$.

Неснт, T. (1998), At home in the street. Street children of northeast Brazil. Cambridge: Cambridge University Press.

Honwana, A. (2005). Innocent and guilty. Child-soldiers as interstitial and tactical agents. In: A. Honwana \& F. de Boeck, eds, Makers and breakers: Children and youth in postcolonial Africa, pp. 31-52. Oxford \& Dakar: James Currey \& CODESRIA.

INE Instituto Nacional de Estatísticas (2002), Inquérito às Despesas e Receitas familiares (IDRF). Praia: Instituto Nacional de Estatísticas.

—. (2008), Resultados da revisão das projecções demograficas- Cabo Verde 2000-2020. Praia: Instituto Nacional de Estatísticas.

Iversen, V. (2002), Autonomy in child labor migrants. World Development 30(5): 817-834.

KLOCKer, N. (2007), An example of 'thin' agency. Child domestic workers in Tanzania. In R. Panelli, S. Punch \& E. Robson, eds, Global perspectives on rural childhood and youth: Young rural lives, pp. 83-94. New York: Routledge.

Lucchini, R. (1997), Entre fugue et expulsion: Le départ de l'enfant dans la rue. Working Papers ISES 287. Fribourg: Université de Fribourg.

PANTher-Brick, C. (2002), Street children, human rights, and public health: A critique and future directions. Annual Review of Anthropology 31: 147-71.

Punch, S. (2007), Migration projects: Children on the move for work and education. Paper presented at the workshop Independent Child Migrants: Policy Debates and Dilemmas, Development Research Centre on Migration, Globalisation and Poverty, University of Sussex and UNICEF Innocenti Research Centre, 12 September 2007, London.

Rodrigues, I.F. (2007), As mães e os seus filhos dentro da plasticidade parental: Reconsiderando o patriarcado na teoria e na prática. In: M. Grassi \& I. Évora, eds, Género e Migrações CaboVerdianas, pp. 123-146. Lisbon: ICS.

UtAs, M. (2005), Victimcy, girlfriending, soldiering: Tactic agency in a young woman's social navigation of the Liberian war zone. Anthropological Quarterly 78(2): 403-430.

Veale, A., M. Taylor \& C. Linehan (2000), Psychological perspectives of 'abandoned' and 'abandoning' street children. In: C. Panter-Brick \& M.T. Smith, eds, Abandoned Children, pp. 131-45. Cambridge: Cambridge University Press.

Whitehead, A. \& I. Hashim (2005), Children and migration. Background paper for DFID Migration Team.

Young, L. \& H. BARret (2001), Adapting visual methods: Action research with Kampala street children. Area 33(2): 141-152.

YounG, L. (2004), Journeys to the street: The complex migration geographies of Ugandan street children. Geoforum 35: 471-488.

This is a digital offprint for restricted use only | (c) 2011 Koninklijke Brill NV 



\section{Gendered Work and}

Schooling in Rural Ethiopia:

\section{Exploring Working Children's \\ Perspectives}

Tatek Abebe

\section{Introduction}

The issue of child labour is complex and multifaceted. These complexities relate to discourses on childhood and deep divisions within academia and policy-makers in terms of whether children should work, what kind of work is advantageous and the nature of the work considered to be appropriate. Scholars have argued that child labour is contentious not only because many children work illegally, but also because their work concurrently involves interdependent realities of survival, socialisation, participation, abuse, and exploitation (Invernizzi 2003). As the growing body of literature on which this chapter draws also reveals, dualistic thinking about working children as being either competent actors or vulnerable, dependent victims are rather facile. Instead such children should be seen as both social actors and 
victims of socio-cultural and politico-economic transformations (e.g. Katz 2004; Aitken et al. 2006; Panelli et al. 2007; Abebe \& Kjørholt 2009).

Recent debates within social studies of childhood acknowledge the complexity of (working) children's life worlds and highlight the usefulness of interdisciplinary approaches in theorizing their childhoods. Social studies of childhood problematise and transform the 'natural' category of the child into a 'socialcultural' category (Jenks 1996). In their influential book, Theorizing Childhood, James et al. (1998) argue that, whereas there is an overlap between children's daily lives in terms of, for example, work and play activities, the perspective of childhood as socially and culturally variable does not overrule the view of children being a structural feature of society. Theoretical approaches in childhood studies of agency-structure, being-becoming, and local-global are critiqued as creating false analytical separations in exploring the multiple and often overlapping arenas of children's everyday lives (Punch 2003; Holloway \& Valentine 2000). Although children's work in Africa has made researchers recognise that they have agency (Schilkdrout 2002), this agency is structurally highly circumscribed. In ethnographic studies of how children combine work with school (e.g. Reynolds 1991; Boyden 1994), work with play (e.g. Katz 2004) and all three together (e.g. Nieuwenhuys 1994), it is suggested that children should not necessarily be perceived only in terms of their work, as mere subjects of exploitation (Punch 2003). Although children can often be seen as labouring, their play involves equipment and skills that are local and hence, unlike their work, possibly more invisible for researchers to discern (ibid.). Furthermore, as Katz $(2004,17)$ points out, children's mimicry in play is a manifestation of the skills they acquire through experimentation in their present-day tasks and potential adult roles. As such, "(a)n element of play is almost fused with the work of children - they work at play and they play at work-temporally, metaphorically and imaginatively" (Katz 2004, 60).

This chapter ${ }^{1}$ is inspired by these debates, which mark an epistemological and methodological break in social studies of childhood (Holloway \& Valentine 2000, 5). It explores how shifts in the livelihood strategies of peas-

\footnotetext{
${ }^{1}$ I would like to thank Sandra Evers for her critical and insightful comments on earlier versions of this chapter.
}

This is a digital offprint for restricted use only | ( 2011 Koninklijke Brill NV 
ant households alter the work patterns of children, with particular emphasis on the spatial contexts of their exploitation, their perspectives of gendered work, and how they combine work with schooling in Ethiopia. The chapter begins by presenting three competing theories of children's work/child labour, namely child labour as a problem; socio-cultural perspectives on work; and the political economy of child labour. Secondly, I briefly discuss the methods I have used to gain insights into the lives of working children and argue in favour of the ethical significance of listening to their (gendered) views on what they deem to be vital for their everyday lives. Thirdly, by historicizing the shifts in communal and family livelihood trajectories, I discuss children's participation in diverse forms of economic activities in rural agricultural settings, situating these within ongoing debates in childhood studies concerning the social, cultural, economic, geographical and political contexts of child labour.

\section{Debates on Child Labour}

The first of the three approaches is framed in different yet interrelated strands of ideas that point directly or indirectly to the conclusion that children should not work. One dimension is captured by the works of international organisations in which interventions are aimed at guaranteeing children's well-being, as well as safeguarding their rights. UNICEF, the leading actor on behalf of world's poor children, for example, views that childhood is a "time for children to be in school and at play, to grow strong and confident with the love and encouragement of their family and caring adult. (As such), childhood is a precious time in which children should live free from fear, safe from violence and protected from (work) and exploitation" (UNICEF 2004, 3 emphasis added).

UNICEF's argument resonates with images of 'proper childhood' in the Western world, proposing that children "should have a care-receiving, safe, secure and happy existence and be raised by caring and responsible adults" (Panter-Brick 2000, 4). It is believed that children should develop their full potential-specified in terms of outcomes in adulthood such as educational achievement, economic security and a lack of antisocial habits-in school 
contexts rather than in work (Burman 1994; Boyden \& Levison 2000). This strand views childhood as a period of dependence and vulnerability, and emphasises parental responsibility both morally and economically. Childhood is constructed as being reserved for learning and leisure outside the market forces of the adult world (Ennew et al. 2005). Employment has no place in this view and, although children may work to learn and for their own benefit, their involvement in paid work for economic gain or for that of others is deemed inappropriate (ibid.). Such an approach also fits with the modernisation perspective in which a high incidence of child labour is seen as a sign of underdevelopment, whereas the dissonance of childhood from the performance of valued work is considered to be a yardstick of modernity (Nieuwenhuys 1996). This view tends to depict any other kind of contrasting childhood as 'abnormal', 'lost' or 'stolen' (Punch 2003, 277-78; Bourdillion 2006, 1202). I will return to the implications of such constructions to the livelihood strategies of children later on.

The second set of arguments posits that children's work has its own sociocultural meanings and contexts. Bourdillion (2006) and Nieuwenhuys (1994) suggest that children's work needs to be understood in light of different material and cultural conditions and seen as varying according to the age, capability and gender of the children involved. Any attempt to prevent children from working is Eurocentric, as their work is an integral part of everyday life and is indispensable to family livelihoods. This approach, while asserting the right of children to protection from exploitation (Ennew et al. 2005), sees childhood as interdependent with the adult world, with children gradually moving into the activities of adults as their competencies develop and as opportunities arise (Bourdillion 2006, 1202). Thus, work is taken as an initiation into adulthood, and employment is seen as having a growing place in children's lives (ibid.).

A further argument is that children have the right to benefits arising from work appropriate to their age (whether paid or unpaid), and poor children are often harmed rather than protected by being prevented from working (Ennew et al. 2005). They benefit from working to earn the resources required to spend on food, shelter and clothing and, instead of being an obstacle to education, the money they earn is vital to pay for school fees and uniforms (Bass 2004). Also, work and schooling are not necessarily irreconcilable, as 
many boys and girls manage to combine both activities, even when formal education may not be in their best interests (Ansell 2002; 2004). As Nieuwenhuys (1994) argues, the expansion of schooling has not reduced children's work but has simply added to their duties and responsibilities. The prolongation of schooling and its growing prominence actually excluded some children from certain arenas of adult social life and restricted their opportunities to learn essential life skills (Katz 1991; Porter 1996; Schildkrout 2002).

Apart from social and cultural factors, scholars have recently highlighted a third approach, that is, children's work needs to be sufficiently grounded in particular ecological, economic and politico-historical contexts. Much of the argument stems from the works of feminist geographers (and others) who pursue a dialectical approach between the livelihoods of young people and the need to situate these in contemporary market-led development that disadvantage poorer societies (Robson \& Ansell 2000; Katz 2004; Robson 2004; Ansell 2005; Aitken et al. 2006). The macro-economic policy changes imposed by the International Monetary Fund (IMF) and the World Bank, which forced poor countries to open up their economies in response to the 'Washington Consensus', are seen as having had negative impacts on the lives of children even in remote villages (Katz 2004; Abebe 2007; Abebe \& Kjørholt 2009). As Jenning (1997 in Boyden \& Levison 2000) points out, the consequences of Structural Adjustment Programs (SAPs) are consistent with processes which increase women's unpaid work in both the home and the community. Furthermore, in general, work that is shifted onto women tends to be either shared by children or completely laid upon children working under women's supervision. This means that children's local work cannot be detached from material realities but needs to be situated in intersecting geographical scales and contexts (Aitken et al. 2006) within the 'global space economy' (Robson 2004, 228). The crux of the argument, therefore, is the "articulation between global processes and the localised experiences of individual children... to re-introduce social reproduction as an important (but often missing) aspect of debates around globalization" (ibid., 227).

How do the lives of children in rural Ethiopia fit within these complex debates? What do children's own perspectives of their working lives reveal? In what follows, I aim to go beyond considering child labour as something 
one is either in support of or opposed to and instead explore the hugely differentiated situations in which children work. In doing so, I examine the contexts that lead to children engaging in work themselves; the dynamics that may turn work into exploitation as well as the implications this has for their schooling. This requires attention to the changing forms of interand intra-generational relationships and presentation of a more nuanced account on how children's work reflects geo-political, economic and cultural (including gendered) conditions, and attends better to structural inequalities (Burman 2006).

\section{Researching working Children's Perspectives}

The empirical material upon which I draw is derived from eight months of child-focused, ethnographic fieldwork exploring the daily, working and spatial lives of disadvantaged children in two peasant associations ${ }^{2}$ in Gedeo, southern Ethiopia. The research examines how, in the contexts of AIDS and deepening rural poverty, children negotiate their socio-spatial lives through the various livelihood strategies they are involved in, both in their own right and as an integral part of (extended) family livelihoods (Abebe 2008).

In this research, I used a wide range of research methods, including observation, dialogues, multiple interviews, in depth- and focus-group discussions, field notes, story-writing, photo-essays and household visits. Working children were approached through schools and their teachers who, in addition to being interviewed, arranged for me to attend classes to conduct observations and acquaint myself with potential research participants. Multiple interviews and in-depth group discussions were held in three separate phases of fieldwork (January-April 2005, February-April 2006 and October-November 2007) with 46 children (18 girls, 28 boys) aged 9-16 years, who were either attending school or had dropped out of school. These methods were meant to capture the

2 A peasant association is the lowest administrative unit in rural Ethiopian contexts, consisting of households and villages that are grouped together according to geographical proximity, and for administrative convenience, tax collection and service delivery. 
complexity of children's seasonal work and explore continuity and change in their livelihood strategies. The meetings for interviews and focus group discussions took place outside the school premises, including at village football fields, in the community literacy centre, the children's homes and farms as well as in shai bet-local cafes-one of which was owned and run by a child participant. These places were chosen based on the desire to include sites of everyday life in the research, and to enhance opportunities for semi-participant observations and informal conversations.

In Grades 6 and 7 classrooms, where I taught social studies as a volunteer, 140 children composed essays in their spare time about their livelihood strategies, life aspirations, family and inter- and intra-generational relationships. Story-writing is a method that stimulates young people's particular talents, affording them greater control over the research process than most methods (Ansell 2001). It is more confidential and less confrontational and is best suited to overcome the power hierarchies inherent in, for example, focus group discussions (Robson \& Ansell 2000). Examples of topics on which children composed stories include 'what I did yesterday', 'my domestic work', 'my contributions to family' etc. In agreement with Ennew \& Plateau (2004), who argue that children-centred methods do not solely rely on children by ignoring adults, I sought and took into account other stakeholders' views and perspectives on education and work. I held interviews and dialogues with parents, community members and social workers in order to "put children in the picture" (Ennew \& Plateau 2004, 34-35).

The empirical material I gathered in Amharic-the medium of fieldwork and lingua franca in Ethiopia-was transcribed verbatim by a research assistant and subsequently translated into English by myself. In interpreting the data, emergent themes from the field were compared and contrasted with field notes as well as with my own knowledge of Ethiopian studies. In addition, although the purview from which the empirical materials are derived is local, my analyses move between local and global processes. In what follows, I will first contextualise the process of livelihood transitions within the wider sociohistorical and political transformation of the region, and then situate children's perspectives of what they do in terms of work, where, with whom and how, and, most importantly, what they think about their involvement in different types of activity. 


\section{Historicizing Livelihoods and Education in Gedeo}

Gedeo District lies within the multi-ethnic Southern Regional State of Ethiopia and has an estimated total population of 820,944 , of which $14 \%$ are urban dwellers (CSA 2005). The data provided by the Central Statistics Authority (CSA) indicates that for total area of $1330 \mathrm{~km}^{2}$, Gedeo has one of the highest rural population densities in Africa-618 people per $\mathrm{km}^{2}$. This figure is higher (about 680 people per $\mathrm{km}^{2}$ ) in the highland countryside which is more suitable for mixed farming of enset (local staple) and cereals compared to lowlands. The average rural household has 0.3 ha of land, compared to the national average of 1 ha of land and an average of 0.89 ha for the Southern Regional State, making Gedeo one of the most chronic land-shortage districts in Ethiopia. Land holdings are not only scarce but also becoming increasingly fragmented. This is due to rapid population growth and the fact that significant numbers of boys, who traditionally inherit land from their patrilieage, have come of age and entered into adulthood. Shortage of land has also forced many rural men to be engaged in share-cropping contracts with wealthier households who own big farms as well as in non-farm related jobs including off-farm migrant labour in urban areas.

Livelihoods in Gedeo are built on mixed subsistence farming of enset, maize, and commercial crops such as coffee, khat (a mild stimulant leaf) and a variety of fruits and vegetables. Coffee and khat are destined for local and international markets, but more significantly, and as I will elaborate below, child labour is very crucial in their production. Enset, also known as the 'false banana', produces non-edible fruit, but the trunk and root are processed as food. It takes four to six years for the plant to build up a sufficient store of carbohydrates before it is suitable for use as food. Compared to other food crops, enset is drought-resistant and gives high yields per unit of land and, hence, it can support high density of population (Hamer and Hamer 2004; Tadesse 2002).

Historically, the Gedeo were dominated by rulers from northern Ethiopia and one of the many subjugated ethnic groups under what Merara (2003) calls the 'nation-building project'. The livelihood transition which began taking shape in the early 1960 involved a significant emphasis on the production of cash crops (coffee and khat) at the expense of staple food crops, namely enset, based on the 
ideal that the expansion of exportable products and competition in the global market is necessary for rapid economic development. Enset production was subsequently marginalized, even though its shade provides coffee beans with the most conducive environment for their gradual ripening (Tadesse 2002). At the same time, farmers who formerly produced both food and cash crops were tactically made to concentrate on the production of coffee alone. This state of affairs was sustained during the Marxist regime (1974-1991) through its centrally planned economic system, and continues today through the ideology of national development, namely the Agriculture-Led Rural Development (ALRD). Although the Gedeo region produces key resources for export-coffee and khat-which together constitute over 80 percent of Ethiopia's revenue; the interest of the State has been mainly in extracting the resources with peasants receiving very little in return. Elsewhere, I have also analysed the ways in which restructuring of the global coffee market-following the collapse of the International Coffee Association (ICA) in 1989 that regulated supply and price-is having enduring impacts on local coffee producers (cf. Abebe 2007). Due to undue reliance on a single main farm output, or 'monoculture' in economic terms, families in Gedeo become extremely vulnerable when their produce faces unstable and ever declining prospects in national and international markets.

Not all Gedeo children are sent to formal institutions specialising in education. Although children are supposed to start schooling at the age of seven, many of the participant children who attended Grades 6 and 7 were, for example, 15 years or older. This was due to the common problem of repeating Grades and drop-outs, with most children tending to start school at a later age. Almost $65 \%$ of all school-age children in the region are enrolled in primary schools, and $17 \%$ in secondary schools (CSA 2005), although these data conceal the prevailing high drop-out and low completion rates. Recently, missionary schools have become increasingly important agents of education and socialisation for children. The indigenous people regard the orthodox religion (the Ethiopian Orthodox Church), which has a unique history in the north of Ethiopia, as an imposition by the Amhara culture at the expense of their own traditional religions and belief systems (see Tadesse 2002). Religion has also been used to conceal power asymmetries and exploit the resources of the 'pristine South' 
through the neftegna-gabar system, which is a form of patron-client relationship (Brogger 1984; Bevan \& Pankhurst 1996). As a result, the more recent, rapid expansion of Protestantism, initially introduced by foreign missionaries, but later embraced and cultivated by the local people, is seen as a form of resistance to the status quo imposed by earlier rulers. However, the expansion of faith-based schools was a powerful means of spreading the Christian gospel, through which children were taught Western values and lifestyles. It has also become a source of inequality in education, as enrolment into such schools was based on religious affinity; children who are not followers were neither eligible for financial support nor to receive stationary materials.

\section{Age and Gender at Work}

Although children in Ethiopia can be interpreted as being "burdened with adult-like duties and responsibilities" (Kefyalew 1996, 209), childhood is seen as a period of life in which work must be contributed to the household. Local constructions of Gedeo childhood emphasise the mutuality of a collective life, which steadily draws one from the social periphery of childhood to the central stage of adulthood, and eventually eldership in the community. It upholds the centrality of work in the socialisation of children for later life. In this respect, childhood is understood in relation to adulthood. Although many Gedeo children do not know their true chronological age, they realize their relative age and social position with respect to who the eldest in the community is, and what is expected of their age group (stage of childhood) in terms of different household chores. These relative social positions also dictate how some privileges and responsibilities are allocated to children, and may be different for boys and girls. For girls, they include family and/or household management (including the ability to carry out domestic activities, as well as acquiring cleanliness, sanitation and hygiene skills), honesty, politeness, respect and good manners, and the ability to process enset, and make the best meal possible from it. These skills are very crucial for girls when they marry, become mothers and assume responsibility for the health and well-being of their families. On the other hand, family socialisation for boys emphasises self-sufficiency, land 
management, respect for and working with the elderly, physical fitness, leadership skills, and the ability to be orally argumentative (see Bevan \& Pankhurst 1996).

In an essay she composed about her daily routines, Beletu ${ }^{3}$ (13 years old) documents the numerous reproductive tasks she performs on daily basis, such as running errands, feeding the cattle at home, collecting and splitting firewood, harvesting grass, weeding, chopping enset, fetching water, milking, cooking, sweeping floors, washing, making and serving coffee, in addition to schooling and playing. Most of these activities may be performed by both boys and girls. However, some activities are structured strictly along traditional gender roles and may not be looked upon favourably by boys. As Ayelech, a girl of 15 years, explained, "men and boys are not allowed to scrape and chop enset, because it is considered to be a woman's crop." Although boys may assist their elders in the laborious task of digging land, preparing nurseries, transferring seedlings and planting enset, the activity of processing this plant as food is largely left to women and/or girls. In other words, the association of men and boys with enset-once it leaves the farm to be either chopped up for sale or consumed as a staple inside the home-is seen, in Ayelech's own words, as "intruding into the women's guadda" (literally meaning women's space inside home), which is their private sphere.

However, the analysis of gender variations in children's work as 'differentiations' in the nature of the contributions they make to their families rather than as 'interdependence' conceals how the household division of labour reflects what Hamer and Hamer (1994: 4) call 'gender complimentarity'. The authors discuss how the ideology of child training practices among the Sidama, a neighbouring ethnic group to the Gedeo with whom inter-marriages are common, supports interdependent relations that are witnessed in everyday life between men and women who are engaged in various forms of household production and reproduction. They argue that, even though men control the cattle that provide milk, it is the women who prepare butter, which both historically and in the contemporary world is a scarce commodity. Complementarity

${ }^{3}$ Pseudonyms have been used to protect the anonymity of research participants.

This is a digital offprint for restricted use only | ( 2011 Koninklijke Brill NV 
is symbolized by women producing a precious commodity, which is also a sign of prestige for men.

Butter for women is a sign of invoking their rights to protection from harassment by men. It is also symbolic of their power in that by refusing to produce butter they can withhold prestige for men. Men in turn have to live up to their obligations of respecting and protecting women if they are to be honored with the presentation of a symbol which gives them renown among other men. (Hamer \& Hamer 1994, 4-5)

The complimentarity of gendered work in Gedeo should be seen against the backdrop of how young people and their families respond to the uneven social and spatial impacts of development prompted by cash cropping. The expansion of export-oriented agriculture has intensified economic differentiation and social inequalities (Grier 1994; Lange 2000). It has also led to the entrenchment of new forms of patriarchy in which economic control of household assets (coffee) by men is resulting in the increased subordination of women (Hamer \& Hamer 1994). In addition, in circumstances in which the returns from the sale of coffee have been declining, children's work has come to be characterized by an intensification of the jobs they normally do in order to maximize their households' capacity to earn a living. In Gedeo, the failure of the cash economy not only disrupted household livelihood systems by disempowering women through taking land away from the production of enset (Abebe \& Kjørholt 2009), it also transferred the burden of social reproduction from adults on to young people. Due to the increasing involvement of women in labour outside the home, their domestic responsibilities are partly or wholly being transferred to girls. Fikre (girl, 13 years), whose eldest sister (with whom she has lived since she was six years old) works in a coffee-processing firm, explained:

I look after my sister's children, who are now three years and eight months old. My sister works for the coffee processing firm (washing, sorting and drying beans), so after I return from school, I am in charge of them. I get them meals, and wash their clothes and bodies.

Although Gedeo District is considered to be the 'basket' of Yirgacheffe coffee, one of the high-quality, sun-dried organic Arabica beans favoured by consumers across the world, small-scale coffee producers like Debashu (man, 
about 45 years old) earn very little in return from the exploitative niche market:

I have given up the idea of picking the coffee berries because the income barely covers the labour of the children engaged in the production. Some farmers have even ripped up the thriving bushes laden with beans to plant maize, simply to survive. Why should I grow coffee when all it does is ruin my life?

As a result of these changes in rural livelihoods and the collapse in the price of coffee on the world market, many men have begun to migrate in search of employment beyond their immediate local environments. This leaves girls and women in their rural villages struggling to maintain the household. Accordingly, traditional and local gender roles are being reworked in particular ways. One consequence of the shift towards commercial agriculture in this respect is that it has accelerated the household division of labour, with more boys than girls increasingly drawn into the production and sale of cash-generating crops of coffee and khat. In order to augment family income in the context of poverty, boys have become involved in the rural informal economic sector through their participation in the circulation of commodities in the weekly and daily markets. In these markets, many boys work as delala-child brokers-as Negara (boy, 15 years) explained:

I help people who come from the towns to buy fruit in large quantities. I also work as a delala between the sellers and the buyers in the price-negotiation process. In doing so, I make both parties happy and get a commission.

The brokerage service provided by these boys is not restricted to finding the right product and trading partners, but also includes taking goods to the market, securing the means of transport and delivering the products from the market place to the transport terminals. Negara added:

My friend has a rickshaw with which he transports items from the daily market to the roadside. He also takes to the market those items which cars cannot deliver to the market place (due to accessibility problems). So, whenever my dembegnas-customers-demand a service like this, I recommend him to do it for them.

Negara was one of the many typical business boys in the daily market in Gedeo whose involvement in trade and informal work reveals how they play a crucial 
role in the local economy and, in particular, in the various activities and stages of commodity circulation. Like Negara and his friend, many boys and girls working in markets and transport terminals value and benefit from each others' support, social networks and cooperation in a number of ways. The fact that many child brokers charge their dembegnas significantly less commission compared to 'adult brokers' and that they can easily run in different places as the opportunities for brokerage arise gives them the added advantage of appealing to many marketers. As Sibilu (boy, 13 years) explained:

Since I am not strong enough to work as a porter or day-labourer to load and unload items from cars, I find the work of assisting clients in buying items easy.... I have many customers, and I am careful to keep their interest when they want to buy or sell items. I don't favour my people (the wholesalers in his community where he lives) because I do not want my dembegnas from town to be disappointed. They are equal to me.

Physical strength and social maturity play very crucial roles in nurturing children's experiences and competencies in how they develop networks of relationships to enhance their opportunities to earn better livelihoods. Gashaw (boy, 16 years) told me about his sense of responsibility and how he covered much of his family budget by working as the farm-help of richer households in subsistence cultivation involving food crops (maize, ensete, potato, root crops) and cash crops (coffee, khat, sugar cane, fruit). Although he does not attend school himself, he explained how his work as a daily labourer benefits his siblings' education: "I save up for brother and sisters' school expenses and clothing," and that without his financial contributions, "the household would not be viable economically." Despite the arduous nature of the jobs they perform, many children working in the informal economic sector alluded to the moral imperatives of not being dependent on their weak parents and the importance of bringing life-sustaining resources to their families and sharing them with them. Bedasso, a boy of 14 years old, who occasionally works as shoe-shiner in Dilla, a multi-ethnic town of about ninety thousand inhabitants and the district capital of Gedeo, explained:

During weekends and school holidays, I go out and find some work and earn money. I do not like going back home without having some money to provide. For me, to simply sit and wait for my weak parent to feed me is unacceptable.

This is a digital offprint for restricted use only | ( 2011 Koninklijke Brill NV 
Children's work needs to be seen as an integral part of a household's livelihood strategy, as well as in relation to adults who control most of the resources they earn. In this interdependent strategy, children buy and sell various commodities on a wholesale and retail basis and thus generate an income to meet personal and family needs. As opposed to boys who may be engaged in the wholesale trade, the retailing of commodities in the daily market is an important aspect of girl's 'trading careers', as Digafe (age 13), explained:

I buy and sell fruit-papaya, mangoes, bananas and pineapples-during different periods of the year. Now it is the season for mangoes. I buy twenty mangoes for one birr and retail each at ten cents ( 2 birr $=$ USD 0.25 ). On a good day, I can make two to three birr in profit, but nowadays, there's a lot of competition. Besides, fruit is getting cheaper. I am now considering buying cane sugar from the kola (lowland areas) (TA: Where her uncle resides and supports her in buying) and retailing it here. It is much more profitable than fruit (TA: Which also quickly becomes perishable, due to the hot and humid nature of the area) and is in high demand during drier seasons.

The implication of children's participation in the collective livelihood strategies of rural households, and of the conceptualisation of their 'agency as interdependence', is elaborated in another publication (Abebe forthcoming). Although young people's capacities in deriving livelihoods clearly demonstrate a great deal of personal agency, their individual actions are grounded in their obligation to reciprocate to their families. Due to their abilities to provide substantial incomes, entrepreneur boys, for example, invest their economic power in ways that situate them at the centre of the household economy. However, they also draw on familial resources such as land, animals and social networks of support to establish a more independent livelihood as they come of age (see Punch 2004). In these ways, relationships between children and families manifest interdependence, highlighting that-whereas relative autonomy is not a counterpart to dependency-relative dependence is not necessarily associated with a complete lack of individual agency. In the following section, I will explore children's participation in work during different agricultural seasons, and the implications that their involvement in off-farm work for cash payments has for their schooling. 


\section{Agricultural Work Cycles and Schooling}

Agricultural activities in Gedeo centre on rain-fed, non-mechanised cultivation and follow four predominant seasons. These are Ba'leessa (January-March), the season for land preparation, during which boys and men are engaged in harnessing the land by digging and making it ready for the spring rains; Haarsso (April-May), the major planting season, especially for crops like maize, which is planted mainly by women; Adoolessasa (June-July), the major rainy season involving activities like tending coffee trees and planting cereals, especially in highland areas; and Bonno (August-December), the harvesting season for most cereals and cash crops.

Children's schooling is closely interlinked not only with these agricultural work cycles, but also with the livelihood trajectories of their families and local communities. These four seasons greatly determine how the labour reserves of extended families are discharged and the ways in which children's contributions are organized. For instance, during Adoolessasa, when school is officially closed, many boys and men migrate outside their rural villages in order to be engaged in off-farm employment. Many stay in Dilla, working in the urban informal economic sector. Since Dilla is a centre of commerce and transportation hub for Ethiopia's far south, it provides young people with numerous opportunities compared to what they would expect to earn by farming or trading in their rural villages. For many children, such ruralurban links in livelihood strategies also enhance what they commonly refer to as 'social satisfaction'-from the information they acquire to improve their future life chances-as well as offer them a certain level of independence. Tsega (girl, 14 years) explained how work during school holidays in Dilla was instrumental to her education and that, although she did not have money to buy items such as stationary and was still wearing a uniform she bought five years earlier, she did not want to interrupt her school attendance:

At home, we don't have enough money to cover all our expenses. So I buy my exercise book and pens from the profits I get from retailing the sweet potato my mother prepares.

Like Tsega, the value of child labour for many children is closely tied to its potential for securing an income necessary to cover the expenses associated 
with schooling. This means that, instead of being an obstacle to her education, the money she earns from selling sweet potato is vital to pay for exercise books, pens and uniforms, and to continue education, which is indispensable for later entry into the formal labour market, as well as upward social mobility.

Many pupils in Gedeo consider education to be a key to success and a means by which to secure employment. However, they realise that prolonged schooling leading to paid jobs is restricted to only a very few elite members of the community. Most parents and educationalists are also pragmatic about the significance of formal schooling and believe that children should learn life skills which, to date, schools do not seem to be providing. Families that are hardpressed in terms of resources find it especially difficult to keep their children in school. In most instances, the returns from education will not be sufficient to justify the sacrifice that has to be made, especially in the context of deepening rural poverty. Instead, it is the labour contribution of children who earn money from employment in agriculture or in the informal sector that results in immediate rewards. The life of Abebayehu (girl, aged 14 years), who sells areke (local liquor) in the daily market, shows that children's ability to make decisions about school and work is highly circumscribed in structural terms: "I left school when I was in Grade 3 because my grandmother could not afford to keep me there."

Abebayehu began living in her grandparent's household shortly after the death of her biological parents. Although her brothers had been in charge of the rural farms for some time, what it produced was not sufficient for all of them to get by. Subsequently, the eldest brother decided to migrate to Moyale (bordering on Kenya), while the remaining two boys joined a non-related household (that of a friend of their deceased father). Abebayehu thought it was in her best interest to live with her close relative: "I chop enset for cash; I also help my sick grandma in brewing liquor because she is weak."

What the childhood experiences of Abebayehu and her siblings highlight are the ways in which poverty and gender intersect to shape children's livelihood trajectories and the implications of this for their life chances. Rural livelihood strategies in Gedeo reinforce the value of work and of earning an income on a regular basis, but they also reduce the value of formal schooling as a way of improving livelihoods, as well as the potential of families to look to the benefits 
of education in the long term. Moreover, the potential of the cash economy has been bleak due to the restructuring of the global coffee market, rising land taxes, the costs of agricultural inputs, population growth, the shortage of farmland, and infrastructural and transportation problems, with negative implications for sustainable livelihoods (Abebe 2007).

Part of the problem of school attendance relates to the school calendar, which does not fit in with children's productive and domestic tasks. In Ethiopia, school holidays are taken uniformly throughout the country (in July and August), but this is only compatible with the agricultural work and demand for child labour in the grain-producing regions of the north. In contrast, in the cash crop-producing region of Gedeo, the work calendar for farmers and their families is structured differently. As noted already, Bonno (August-December) is the busiest season of the year, in which the demand for child labour peaks as peasants and members of their households collect and process coffee beans. Since coffee production is a tedious activity, involving the selective picking of coffee berries which mature irregularly on the tree tops, children are considered to be more adept at it than adult men and women. During fieldwork, I also observed a substantial number of children working for coffee-processing firms on a long-term basis. However, Bonno is when children's education suffers most because then they are required to resume school attendance and also sit the first semester examinations. The rate of school absenteeism during the peak of the coffee-harvesting season was observed to be higher among boys (between one-third and two-thirds) than girls.

Although Admassie (2003) has proposed educational policies that make the school calendar compatible with children's agricultural work-cycle, especially with respect to activities related to coffee production, the challenges that rural children face are far more complex than this. Schools have very high pupilteacher and pupil-classroom ratios. In the classes in which I conducted lessons, four pupils sat on a bench meant for two, and many others simply sat on the floor. Classrooms of which windows had not been constructed properly let the rain come in, and students had to move their seats elsewhere when it rained. The situation became more complicated when some pupils came to school without any basic stationary materials (chapters, pens, pencils). If text books were available for rent from the school, pupils shared one textbook in groups of 
four to six in order to minimize the cost of renting. They also used one exercise book for two or three subjects. In a few cases, children were observed sharing notebooks with each other.

Distance is another main constraint in children's access to education. For many children in the peasant associations I studied, the nearest secondary schools were, on average, 10-15 km away. Some of the children I did research with also arrived late in school, physically exhausted, overworked or finding it extremely hard to find the time and resources to cope properly with both activities. In addition, children's education is influenced by complex and interconnected economic, social, livelihood, and cultural factors. Within households, birth order, the composition of siblings and social maturity influence the nature and type of work children are involved in. They also influence opportunities and constraints regarding access to resources and the potential for schooling. On my return visits, I noted that, when families were faced with the dilemma of making decisions as to who should attend school, they prioritised sending a child whose physical strength for agricultural work was weak, and/or one who they thought was academically bright. First-born children and/or physically stronger boys may be kept at home to help their parents with agricultural work. Boys may also be engaged to sell farm produce, and may be in charge of managing household assets from an early age, particularly if the parents believe that they are 'wise'. On the other hand, girls may be encouraged to learn social skills at home rather than attending school, especially if they are of a marriageable age and are the only daughters in the family. They are also responsible for most of the household domestic chores, may not receive an inheritance and will tend to have less invested in their education. This is because, as clan exogamy is the rule, they are treated as part of family collective only until adolescence and are considered as acquiring a 'new citizenship' after marriage. Although the heaviest tasks are carried out by boys, girls tend to be given less time to study as the most time-consuming work are carried out by them.

Moreover, the challenges to rural children's education have important resonance with Cindi Katz's (2004) longitudinal research in rural Sudan on the ways in which the knowledge children acquire from school is inferior to the knowledge they receive through apprenticeship and from participation in work and everyday life. Katz argues that, due to the entrenchment of global capital 
that has transformed the local politico-economic system and processes of social reproduction, what and how children learn and what they use knowledge for showed discontinuities through time, a disjuncture she calls 'deskilling' (2004, 250). In Gedeo, deskilling is manifested in the erosion of livelihoods, as well as in the altered trajectories of traditional pathways to adulthood. Although Gedeo livelihoods had for generations been based on an intricate interdependence between the 'food crop-cash crop complex', people's material desires have altered and, paradoxically, poverty has deepened following the intensification of 'cash-cropping'. As a result, like the children in Sudan, Gedeo children learn the agricultural skills of coffee and enset production but do not have enough land on which to practice them as they come of age. They also learn to work with and to use local resources, most of which are fast disappearing. Increasing population pressure, coupled with (unsustainable) livelihood strategies that have promoted cash-crop production at the expense of local subsistence production have not only made children economically redundant but also forced them to seek alternative non-rural livelihoods for which they are unprepared. This means compulsory education, which brings children to schools alone, is not enough. What are needed are proper educational policies based on children's gendered needs and realities (Ansell, 2002), their protection from exploitation and from being harmed by working, the provision of better opportunities, and adequate welfare for rural families who cannot send their children to school.

\section{Concluding Discussion}

This chapter has examined the interface between children's work, gender and schooling in rural Ethiopia, where for generations subsistence agriculture has met basic household needs. As transformations in the rural livelihood strategies of households affect children's engagements in different types of reproductive work, it is important to emphasize the ways in which contextualized perspectives reveal how child labour is intricately entwined with both the livelihoods of their families and communities, and regional and national priorities related to development. Children in Gedeo combine paid or unpaid work in subsis- 
tence production, on coffee farms and in coffee-processing firms. These activities may overlap with attending school and performing a number of activities in the informal rural economic sector. Also, although children's work reflects traditional apprenticeship, socialization and skills acquisition, it is simultaneously an integral part of the global system of economic production.

This chapter has used child labour as a lens to look at how childhood, as a relative social category, varies according to socio-cultural contexts, and childadult relations, as well as the spatial contexts in which children's livelihoods are envisaged. As the quotes from boys and girls demonstrate, children perform a range of domestic duties and income-generating activities as part of their social responsibilities, either independently and/or in support of adults. Family context and gendered expectations are crucial factors shaping the possibilities for attending school and the work experiences of children. Since Gedeo children form an integral part of their families, the view of their childhood as a carereceiving phase of the life overlooks not only the wider socio-cultural contexts, but also how interdependence is vital for everyday survival and to earn sustainable livelihoods. In addition, because children's lives in the peasant associations I studied are moderated by different forms of inter- and intra-household relationships, they perceive their needs as interdependent with those of their siblings, parents and other members of their extended families. While this does not contradict the principle that children should be taken seriously, it highlights the fact that the lives, agency and capacities of children are an integral part of, and are shaped by, the capability of households, and that to single them out 'in their own right' ignores the extent to which their work is circumscribed by intergenerational relationships and structural constraints of poverty.

The role of children in social reproduction takes place in the context of material poverty, but it involves a considerable degree of self-initiative. The chapter highlights how 'contributing children' occupy multiple positions in mustering resources for livelihoods in their household. It demonstrates children's involvement as producers of agricultural items, entrepreneurs of farm proceeds, carers of younger siblings and sick members of the family, as well as decision-makers in the allocation of who performs what kinds of work (even in the absence of adults). These childhoods represent the lives of millions of boys and girls in Ethiopia and beyond, who view themselves, and are viewed by their families, as 
having the potential and even the responsibility to be competent contributors to daily and generational reproduction.

As opposed to international organisations which, through global legislations like the UN Convention on the Rights of the Child (UNCRC), emphasize the right of children to be kept from work that interferes with schooling, ${ }^{4}$ many Gedeo children realize that the relationship between work and schooling is rather complex, and that they do not see their choices only in either/or terms. In most cases, culturally bounded notions of responsibility are linked to how children perceive the opportunities and constraints facing them and to their making decisions about if and how they should combine work with formal education (Punch 2004). In addition, although the social meanings that children attribute to work are shaped by local cultural norms and circumstances of deepening poverty, the value of child labour is multi-layered and goes beyond mere material advantages. Many children express their labour and economic contributions to their families very positively. Work not only gives them a sense of renewed identity and self-worth, but also enables them to redefine their social positions within households. Paternalistic approaches that view working children simply as victims are therefore not only problematic analytically, but also from a policy point of view. They offer a partial picture of the negative impacts of work on children's development. In doing so, they denigrate the capacities and meaningful contributions children make in their families, while simultaneously ignoring how, through work, children can improve their social and economic independence, attend school, gain self-esteem and increase their potential for upward social mobility.

The empirical material in this research further indicates that, whereas there is an overlap between children's work, exploitation and the generational contexts in which it takes place, drawing a boundary between what constitutes 'children's work' and 'adult work' or viewing the former separately from the latter can be elusive. This underscores the importance of locating children's subordination in the wider context of incorporating generational hierarchies and social structures locally, as well as of global processes that keep them mar-

\footnotetext{
${ }^{4}$ Article 28 of the UNCRC states the rights of children to education and urges governments to expand free and compulsory education, particularly at the primary level.
}

This is a digital offprint for restricted use only | (c) 2011 Koninklijke Brill NV 
ginalized in multiple ways. While agreeing with Nieuwenhuys (1998), who argues that children's material exploitation is the outcome of unequal relations of power with adults and market forces, it is also important to point out that this exploitation has multiple and interconnected geographical scales and contexts. The shift from local subsistence production towards export-oriented agriculture, accompanied by unfair terms of trade, suggests the increasingly deep exploitative system of international trade. However, although children's work is highly circumscribed in terms of how neoliberal economic policies and contexts of unfair trade disadvantage them, their exploitation has also its own history within the local political economy of Gedeo. This is because, both historically and in the present time, the interest of the state to extract resources for national development has been characterised by power asymmetry wherein the local inhabitants benefited very little in return.

A holistic approach to child labour is necessary to understand what it means to be a working child in rural agricultural contexts. It encapsulates how work is intertwined with processes of development and socio-cultural change, how it is constructed differently geographically and how children benefit from it. I have argued that situating the livelihood strategies of children at the heart of family livelihoods, and in relation to local, regional and global economic transformations, is vital if we are to make sense of working children's childhoods. This in turn invokes the significance of place-specific interdependence and relations with other spatial scales, thus highlighting the need for an analysis of both the immediate and the broader politico-economic contexts and the ways in which children's livelihoods are transformed in these contexts. In other words, although from the methodological and ethical points of view it is imperative to 'listen to what children say' about work (Woodhead 1999, 27), it is necessary to move beyond these 'voices' and reinterpret whether children themselves benefit from working or not, and to ground their opinions within the complex material social practices of interconnected histories and geographies in which their livelihoods continue to unfold. 


\section{References}

Abebe, T. (2007), Changing livelihoods, changing childhoods: Patterns of children's work in rural southern Ethiopia. Children's Geographies 5(1-2): 77-93.

- (2008), Ethiopian childhoods: A case study of the lives of orphans and working children. Doctoral Thesis, No. 48. Trondheim: NTNU.

- (Forthcoming). Interdependent rights and agency: Children's role in collective livelihood strategies in rural Ethiopia. In: O. Nieuwehuys \& K. Hanson, eds, Living rights: Theorizing children's rights in international development. Oxford: Oxford University Press.

Abebe, T. \& A.T. KJoRHolt (2009), Social actors and victims of exploitation: Working children in the cash economy of Ethiopia's south. Childhood 16(3): 175-194.

Admassie, A. (2003), Child labour and schooling in the context of a subsistence rural economy: Can they be compatible? International Journal of Educational Development 23: 167-185.

Aitken, S., S.L. Estrada, J. Jennings \& L.M. Aguirre (2006), Reproducing life and labor: Global processes and working children in Tijuana, Mexico. Childhood 13(3): 365-387.

Ansell, N. (2001), Producing knowledge about 'Third World Women': The politics of fieldwork in Zimbabwean secondary school. Ethics, Place and Environment 4(2): 101-116.

- (2002), Secondary education reform in Lesotho and Zimbabwe and the needs of rural girls: Pronouncements, policy and practice. Comparative Education 38(1): 91-112.

-. (2005), Children, youth and development. London: Routledge.

BAss, L. (2004), Child labor in sub-Saharan Africa. Colorado: Lynne Riemer.

Bevan, P. \& A. Pankhurst (1996), Ethiopian villages studies: Adado, Gedeo. URL: http://www .csae.ox.ac.uk/evstudies/pdfs/adado/adado-hiphotos.pdf (accessed 12 March 2005).

Brogger, J. (1984), Belief and experience among the Sidamo. A case study towards anthropology of knowledge. Trondheim: Norwegian University Press.

Bourdillon, M. (2006), Children and work: A review of current literature and debates. Development and Change 37(6): 1201-1226.

Boyden, J. (1994), The relationship between education and child work. Innocenti Occasional Chapters (Child Rights Series No. 9). Florence: UNICEF.

BOYDEN, J. \& D. LEvison (2000), Children as economic and social actors in the development process. Ministry of Foreign Affairs Working Paper. Stockholm: Ministry of Foreign Affairs.

Burman, E. (2006), Engendering development: Some methodological perspectives on child labor Forum: Qualitative Social Research 7(1): (online) URL: Www.qualitative-research.net/fqs/.

CSA (2005). Ethiopia child labour survey report. Statistical Bulletin 262. Addis Ababa: Central Statistics Authority.

Ennew, J., W.E. Myers \& D.P. Plateau (2005), Defining child labor as if human right really matter. In: B.H. Weston, ed., Child labor and human rights: Making children matter. Lynne Rienner Publishers. London.

Ennew, J. \& D.P. Plateau (2004), How to research the physical and emotional punishment of children. Bangkok: Save the Children.

Grier, B. (1994), Invisible hands: The political economy of child labor in colonial Zimbabwe 1890-1930. Journal of Southern African Studies 20: 27-52.

HAMER, J. \& I. HAMER (1994), Impacts of a cash economy on complementary gender relations among the Sadama of Ethiopia. Anthropological Quarterly 67(4): 187-202.

Holloway, S.L. \& G. Valentine (2000), Children's geographies: Playing, living and learning. London: Routledge.

InVERNIZZI, A. (2003), Street-working children and adolescents in Lima: Work as an agent of socialization. Childhood, 10(3): 319-341.

James, A., C. Jenks \& A. Prout (1998), Theorizing childhood. New York: Teachers College Press.

Jenks, C. (1996), Childhood London: Routledge.

Katz, C. (1991), Sow what you know: The struggle for social reproduction in rural Sudan. Annals of the Association of American Geographers 81: 488-514. 
-. (2004), Growing up global: Economic restructuring and children's everyday lives. Minneapolis: University of Minnesota Press.

LAnge, M. (2000), The demand for labor within the household: Child labor in Togo. In: S. Bernard, ed., The Exploited Child, pp. 268-77. London and New York: ZED.

Merera, G. (2003), Ethiopia: Competing ethnic nationalism and the quest for democracy, 1960200o. Ethiopia: Chamber Printing Press.

Nieuwenhuys, O. (1994), Children's life worlds: Gender, welfare and labor in the developing World. London: Routledge.

—. (1998), The paradox of child labor and anthropology. Annual Review of Anthropology 25: 237-51.

Panelli, R., S. Punch \& E. Robson, EDS, (2007), Global perspectives on rural children and youth: Young rural lives. London: Routledge.

Panter-Brick, C. (2000), Nobody's children? A reconsideration of child abandonment. In: C. Panter-Brick \& T.S. Malcolm, eds, Abandoned Children, pp. 1-26. Cambridge: Cambridge University Press.

Porter, K.A. (1996), The agency of children, work and social change in the south Pare mountains, Tanzania. Anthropology of Work Review 16(1-2): 8-19.

Punch, S. (2003), Childhood in the majority South: Miniature adults or tribal children. Sociology 37(2): $277-295$.

- (2004), The impact of primary education on school-to-work transitions for young people in rural Bolivia. Youth and Society 36(2): 163-182.

Reynolds, P. (1991), Dance civet cat: Child labour in the Zambezi valley. London: ZED books. Robson, E. (2004), Hidden child workers: Young carers in Zimbabwe. Antipode 36(2): 227248.

Robson, E. \& N. ANSELl (2000), Young carers in southern Africa: Exploring stories from Zimbabwean secondary school students. In: S.L. Holloway \& G. Valentine, eds, Children geographies: Playing, living, learning, pp. 174-193. London: Routledge.

Schildkrout, E. (2002), Age and gender in Hausa society: Socio-economic roles of children in urban Kano. Childhood 9(3): 344-368.

TAdesse, K. (2002), Five Hundred Years of Sustainability? A Case Study of Gedeo Land Use (Southern Ethiopia). Heelsum: Treemail Publishers.

UNICEF (2004), The State of World's Children-Annual Report. New York: UNICEF.

Woodhead, M. (1999), Combating child labour: Listen to what the children say. Childhood 6(1): 27-49. 



\section{In Between the Netherlands and Morocco: 'Home' and Belonging of Dutch Moroccan Return Migrant and Abandoned Children in Northeast Morocco}

June de Bree, Oka Storms \& Edien Bartels

\section{Introduction}

In recent years the study of children has become a sub-discipline within anthropological research (cf. Meurs et al. 1999; Reis and Dedding 2004; Toren 1999). In particular, applying adult-centred theory and methodology on children is considered as problematic. Children are increasingly regarded as "people to be studied in their own right, and not just as receptacles of adult teaching" (Hardman 2001, 504). Bucholtz (2002, 529) also criticizes such developmental perspectives which portray children as "not-yet-finished human beings" in transition towards adulthood. Children, instead, should be seen as a cultural category that has its own cultural practices. Many studies now emphasize that 
children can be seen as active agents in constructing meanings and symbolic forms which make up their cultures (Montgomery 2005). However, there is much that remains unclear about children's agency, such as its degree, nature and precise impact (Bluebond-Langner \& Korbin 2007). To what extent do children express agency? How is agency related to age? And which methods can be used to investigate children's agency?

In this chapter we will elaborate on children's agency by discussing how Dutch Moroccan return migrant and abandoned children express, and reflect on, feelings of belonging and 'home' in Morocco. During the 1960s and 1970s, these children's parents emigrated from Morocco to the Netherlands as labour migrants. Later on, they either brought their children from Morocco to the Netherlands at a very young age or they had children who were born in the Netherlands. Importantly, these children partly grew up in the Netherlands, which challenges adjustment to a Moroccan way of life after 'return' or abandonment in Morocco. For example, these children possibly do not feel understood by the local population who have never migrated to Europe. In Morocco, migration to Europe is generally perceived as one of the most preferred ideals towards an economic successful future. Leaving this place of 'milk and honey' for Morocco can therefore be difficult to understand. How do these children negotiate their 'place' in Moroccan society? In other words: How do these children express agency in this process of 'home making'?

In exploring how the concepts of agency and home/belonging are related to one another and which research methods are appropriate in the study of children, we chose to compare children of different age categories. We focus on two main categories: return migrant children (children who returned with their parents at the age of 12 to 14 years) and abandoned children (younger children who were abandoned by at least one of their parents). The group of abandoned children consists of three categories: children who were born in the Netherlands and then abandoned in Morocco, children who were born after their mothers were abandoned in Morocco and formerly abandoned children who have returned to the Netherlands. These different categories of children will provide a better understanding of different forms of belonging and the role of agency herein. We will first elaborate on how children are conceptualised in anthropological research, and discuss the concepts of agency and home/ 
belonging. The remainder of this chapter includes reflections on our methodology and results of fieldwork in Morocco. ${ }^{1}$

\section{Who Form the Category of 'Children'?}

A universal and single definition of 'the child' is hard to give. In the West, children are generally perceived as human beings under 12 to 14 years old, who shift to the category of 'adolescents' after that, and become 'young adults' after the age of 18. The UN Convention on the Rights of the Child defines children as all human beings under the age of 18 (Bluebond-Langner \& Korbin 2007, 244). However, there is much reason to assume that age is not the only distinguishing factor. The category of children seems to be flexible and can shift according to context. For instance, in the Netherlands it is possible to vote at the age of 18 , but sexual contact is allowed at the age of 16 (Reis \& Dedding 2004, 81). In Dutch law, children thus become 'adults' at different ages depending on the specific situation or context.

Besides these types of contextual differences within a country, many authors state that perceptions of 'childhood', 'adolescence' and 'adulthood' can also strongly differ between cultures (Levine 2007; Lancy 2007; Davis 1998). For instance, in the past, adolescence as a phase of life between childhood and adulthood did not exist in North Africa. Children were expected to become adults at the age of 12 or 14 years, when they married and/or started working (Schaefer Davis 1989). However, since the 1960s, there are more possibilities to experience adolescence in Morocco. For example, children are going to school for a longer period of time; accordingly, 'adult' responsibilities, such as work and marriage, start at a later age. So, also currently in Morocco 'adolescence' has become a relevant phase of life.

\footnotetext{
1 This chapter is based on research by Bartels (2005) on abandoned return migrant women and their children in Morocco in 2005, on research by de Bree (2007) on return migrants in Northeast Morocco in 2007 and on research by Bartels \& Storms on return migrant and abandoned children in Morocco in 2008. All three research projects were possible thanks to our research assistant Carolien Beilsma and to the SSR (Foundation to Support Return migrants) staff members Cynthia Plette, Joke Verkuijlen, Mohammed and Fatima Zahra Sayem \& Ellie van den Brom.
} 
During our research it appeared to be difficult to strictly follow the definition of the UN Convention of the Rights of the Child: 'the child' as a human being under 18. We found several examples of children whose childhood was more determined by the specific circumstances they were in than by strict age boundaries alone. In this chapter, two groups are discussed: 1) abandoned children who are younger than 14 years old, and 2) young adults, now in their twenties, who initially returned to Morocco with their parents when they were between the ages of 12 to 14 , thus remembering their return migration experience as adolescents. Although the children in this last category are actually adults now in terms of age, we will refer to them as return migrant children, because the fact that they (involuntary) returned as teenagers and as children of return migrants is essential here. We argue that it was indeed this involuntary return to Morocco that impacted on their real and experienced possibilities as adults both in terms of their livelihoods and existential sense of belonging. We used life histories to research return migrant children, and the drawing method and the word association method to investigate younger abandoned children.

\section{Do Children have Agency?}

Ahearn $(2001,112)$ comes to a provisional definition of the concept of agency: 'agency refers to the socio-culturally mediated capacity to act.' Agency should not be understood as 'free will', which is totally disconnected from socio-cultural context. Such a view would deny the influence of cultural background on human intentions, beliefs and actions (Ahearn 2001, 114). In this respect, Mahmood (2001) suggests that we should not think of agency in binary terms of resistance versus subordination. She illustrates how women in Egyptian mosque movements teach each other virtues, such as shyness, modesty and humility. From a Western perspective, it easily seems as if these women reproduce their own 'oppression'. However, their teaching enables them to participate in public spheres which were traditionally only confined to men. Therefore, these women are not just simply showing resistance or being subordinated, but they negotiate their place in society within the boundaries of their culture.

The question now arises to what extent this negotiation power applies to children. In the debate on children and agency, it is important to see that 
children form a social and cultural category which is often constructed around notions of 'innocence'. As Hall \& Montgomery (2000, 13) state: 'Whatever the reality of the lives of individual children, childhood figures in our imaginations as an idealized otherness, the purity and innocence of which is to be celebrated and protected.' In this way, children are often portrayed as devoid of agency, in contrast to adults (Panter-Brick 2000, 11). However, there are now numerous studies which show that both young people (cf. Bucholtz 2002; Valentine et al. 1998; Wulff 1995) and small children (cf. Reis \& Dedding 2004; Hardman 2001) exert agency by giving meaning to the world around them or by influencing people in a conscious way. However, the question remains how agency is related to age, and therefore we will explore how agency differs between young abandoned children and return migrant children who were elder when they came to Morocco.

\section{Home and Belonging of Return Migrant and Abandoned Children}

Belonging refers to emotional attachment, about feeling at home and feeling safe (Lovell 1998; Yval-Davis et al. 2006). In case of migrants, 'home' and 'belonging' often become contested issues. In political and public discourses, first and second generation migrants are often assumed to 'naturally' belong to their country of origin or descent (Pedersen 2003). From this perspective, the process of migration is easily understood as temporary settlement in the host country followed by permanent settlement in the country of origin or descent. This implicates that migrants who return or are abandoned to their country of origin or descent are seen as going back 'home'. However, this link between return migration/abandonment and 'home' can be questioned (Al-Rasheed in Ghorashi 2003, 188), especially in case of children who partly grew up in their parents' host country.

Belonging is not necessarily confined to one place alone. Werbner (1999) shows that Pakistani in Britain can feel they belong to two ethnic or cultural localities simultaneously. Also Hannerz (2002, 218-219), who defines 'home' in contrast to what is 'away', states that a sense of home can be constructed in biterritorialized or multiterritorialized contexts. Feelings of home can coincide with the physical space one inhabits, but can also refer to a more symbolic 
conceptualisation of where one 'belongs', implying that feelings of belonging can be 'dual' or 'multiple' too (Salih 2003, 70).

Many studies underline that belonging to a place is created through maintaining a diverse set of socio-economic activities. According to Ter Maat (2002, 149) belonging signifies 'a feeling of satisfaction and fulfilment with respect to work, study, family, friends and the extent of belonging to a group.' The feeling of being accepted is an important aspect here (Flores-Bórquez 2000). However, in this chapter we will also discuss a type of belonging which is not based on participation in socio-economic activities. Belonging to a place can be 'imaginary' as certain informants have never even been to the place they feel they belong to. We will now introduce the research population and discuss methodology and empirical findings.

\section{Research Population}

\section{Return Migrant Children}

The return migrant children described in this section returned together with their parents. Table 7.1 shows five typical examples of this category of children $^{2}$. They were born in Morocco. When they were o to 5 years old they were brought to the Netherlands. On average, they remained in the Netherlands for ten years. When these children were 11 to 14 year old adolescents, their fathers decided to return to Morocco, because they suffered from difficulties such as unemployment, weak health and psychological problems. Most wives opposed, but faced the threat of divorce and removal of their children. Therefore, they followed their husbands. As these children were under the age of 18 at that moment, they were too young to stay in the Netherlands independently. At the time of research, these youngsters had been back in Morocco for 12 to 25 years and they were between 25 and 40 years old.

${ }^{2}$ Both groups of children cannot be considered as representative due to small sample sizes. Instead of conducting a large scale quantitative study, we investigated concepts such as belonging and agency in an in depth way by exploring a limited number of cases, 5 return migrant and 17 abandoned children.

This is a digital offprint for restricted use only | ( 2011 Koninklijke Brill NV 
Table 7.1 Characteristics of Return Migrant Children

\begin{tabular}{lccccccc}
\hline Informants $^{3}$ & Sex & $\begin{array}{c}\text { Age at } \\
\text { time of } \\
\text { interview }\end{array}$ & $\begin{array}{c}\text { Left Morocco } \\
\text { for the } \\
\text { Netherlands }\end{array}$ & $\begin{array}{c}\text { Motives for } \\
\text { leaving }\end{array}$ & $\begin{array}{c}\text { Back to } \\
\text { Morocco }\end{array}$ & $\begin{array}{c}\text { Motives for } \\
\text { returning to } \\
\text { Morocco }\end{array}$ & $\begin{array}{c}\text { Dutch } \\
\text { Passport/ } \\
\text { permit of } \\
\text { residence }\end{array}$ \\
\hline Hind & F & 27 & 1982 & Reunification & 1993 & Joined parents & No \\
Hayat & F & 25 & 1986 & Reunification & 1996 & Joined parents & No \\
Souad & F & 39 & 1974 & Reunification & 1983 & Joined parents & No \\
Bouchra & F & 23 & 1988 & Reunification & 1995 & Joined parents & No \\
Amine & M & 24 & 1983 & Reunification & 1994 & Joined parents & No \\
\hline
\end{tabular}

Source: fieldwork 2007 and 2008 De Bree, Storms and Bartels.

Return had consequences for the right to Dutch citizenship. These children's fathers made use of the Dutch 'Remigration Act' (Remigratiewet 2009). This arrangement facilitated return of these $45+$ immigrants by providing a postreturn monthly allowance. However, they also had to give up their Dutch residence permit. As their children had a dependent residence permit, the children could not easily return to the Netherlands legally, despite the fact that they could experience difficulties in accustoming themselves to Moroccan society. The children were also likely to be affected by the 'culture of migration' in Morocco. Due to massive emigration to Europe, migration has generally become 'the norm' for many Moroccan youngsters, who perceive migration as the best strategy for having a successful future (De Haas 2003, 351).

For this reason, Dutch law (section 3.92, Aliens Decree) provides two possibilities for return migrant children who feel uprooted in Moroccan society. First, a child has the right to return to the Netherlands immediately if he/ she lived in the Netherlands for ten years continuously between the ages of four and nineteen. Second, if a child lived in the Netherlands for five to ten years continuously between the fourth and 19th year, Dutch court needs to be convinced that the Netherlands is the most suitable place to live before legal return can take place (Vreemdelingencirculaire 1994, 11). The administrative procedure of the second possibility can last for years.

\footnotetext{
3 The names used in this article are fictive as to protect the anonymity of the respondents.
} 


\section{Children and Abandonment}

Every year, mainly during summer holidays, migrant women and children are left behind in Morocco by, respectively, their husbands and their fathers. These men withhold passports and residence permits of their spouses and children whilst in Morocco and return to the Netherlands alone. Reasons for abandonment can vary between conjugal problems between the parents, problems concerning the upbringing of the children, or parents' fears that their children are 'becoming too Dutch' and forget their own cultural background and religion (Bartels 2005). Table 2 shows 8 of the 17 researched children. ${ }^{4}$

Table 7.2 Characteristics of Abandoned Children

\begin{tabular}{|c|c|c|c|c|c|c|c|}
\hline Informants & Sex & $\begin{array}{l}\text { Age at } \\
\text { time of } \\
\text { interview }\end{array}$ & Place of birth & $\begin{array}{l}\text { Motives } \\
\text { for leaving } \\
\text { Morocco }\end{array}$ & $\begin{array}{l}\text { Back in } \\
\text { Morocco }\end{array}$ & $\begin{array}{l}\text { Motives for } \\
\text { returning to } \\
\text { Morocco }\end{array}$ & $\begin{array}{l}\text { Dutch } \\
\text { pass- } \\
\text { port }\end{array}$ \\
\hline Naima & $\mathrm{F}$ & 12 & The Netherlands & $\mathrm{n} / \mathrm{a}$ & 1998 & Abandoned & No \\
\hline Siham & $\mathrm{F}$ & 6 & Morocco & $\begin{array}{l}\text { Stayed in } \\
\text { Morocco }\end{array}$ & $\mathrm{n} / \mathrm{a}$ & $\begin{array}{l}\mathrm{n} / \mathrm{a} \\
\text { (mother was } \\
\text { abandoned } \\
\text { before) }\end{array}$ & Yes \\
\hline Karim & M & 11 & Morocco & $\begin{array}{l}\text { Stayed in } \\
\text { Morocco }\end{array}$ & $\mathrm{n} / \mathrm{a}$ & $\begin{array}{l}\mathrm{n} / \mathrm{a} \\
\text { (mother was } \\
\text { abandoned } \\
\text { before) }\end{array}$ & No \\
\hline Loubna & $\mathrm{F}$ & 8 & Morocco & $\begin{array}{l}\text { Stayed in } \\
\text { Morocco }\end{array}$ & $\mathrm{n} / \mathrm{a}$ & $\begin{array}{l}\mathrm{n} / \mathrm{a} \\
\text { (mother was } \\
\text { abandoned } \\
\text { before) }\end{array}$ & Yes \\
\hline Said & M & 15 & The Netherlands & $\mathrm{n} / \mathrm{a}$ & 1995 & Abandoned & No \\
\hline Najat & $\mathrm{F}$ & 18 & Morocco & Re-unification & 2000 & Abandoned & Yes \\
\hline Abdel & M & 9 & The Netherlands & $\mathrm{n} / \mathrm{a}$ & 2003 & Abandoned $^{5}$ & Yes \\
\hline Aziza & $\mathrm{F}$ & 8 & The Netherlands & $\mathrm{n} / \mathrm{a}$ & 2003 & Abandoned $^{6}$ & Yes \\
\hline
\end{tabular}

Source: fieldwork 2007 and 2008 De Bree, Storms and Bartels

${ }^{4}$ For the purpose of this chapter we only discuss 8 children in this chapter. These 8 are characteristic for all three categories (see Introduction).

5 After the father of Abdel and Aziza abandoned them and their mother in 2003, the children spent four years in Morocco. Since 2007 they have been back in the Netherlands.

${ }^{6}$ See footnote 5 .

This is a digital offprint for restricted use only | ( 2011 Koninklijke Brill NV 
Table 7.2 shows three categories of abandoned children. First, children who lived in the Netherlands and were abandoned in Morocco (Najat, Naima, Said). Second, children who were born in Morocco after their mother was abandoned by their father who lived in the Netherlands (Siham, Karim, Loubna) and third, children who were born in the Netherlands, abandoned in Morocco and returned to the Netherlands again (Abdel, Aziza). The children of category 1 and 3 migrated to Morocco (were abandoned) at a young age and hardly had any memories of the Netherlands. Only Najat, who migrated to the Netherlands at six and returned to Morocco at ten years old, had vivid memories and spoke Dutch. Abdel and Aziza, who returned to the Netherlands after their abandonment in Morocco, spoke Dutch and attended a Dutch school.

The children in category 2 had never been to the Netherlands at all. Importantly, the table shows that residency or birth in the Netherlands did not automatically lead to a Dutch passport. Some of the children who were born in the Netherlands never had a Dutch passport (Naima, Said), whereas others who had never even been to the Netherlands had one (Siham, Loubna). This is explained by the fact that Dutch law allows parents to assign their Dutch nationality to their children whether their children are living in the Netherlands or not. This is illustrated by the case of Karim (no Dutch passport) and Loubna (Dutch passport), who are brother and sister. Their father was not yet naturalized when Karim was born, but he was when Loubna was born.

In our sample, abandoned children were generally much younger than return migrant children, which can be explained as follows. For migrants, Dutch policy prescribes a period of five years residency in the Netherlands before Dutch nationality can be obtained. The mothers of abandoned children who came to the Netherlands to join their spouse who already lived in the Netherlands, initially obtained a dependent residency permit for three years. If these women (and their children) stay less than three years in the Netherlands, they cannot return to the Netherlands legally after abandonment. In our sample, most abandonments took place before these three years ended, when these women were pregnant or had young children. This explains why children tended to be young at the point of abandonment to Morocco. 


\section{Methodology}

\section{Life Histories}

The oral life history research method was particularly relevant for investigating post-return 'belonging' of returning adolescents. Compared to abandoned children, they were relatively older at the point of return, spent a longer period in the Netherlands and generally had been back in Morocco for a longer time. They were thus more conscious of their lives in the Netherlands. Their memories were an influence on how they constructed their current sense of belonging in Morocco.

Life histories or narratives should not be understood as presentations of truth or facts, as the accuracy of a person's memory cannot be taken for granted (Pratt \& Loizos 1992). Life histories are constructions of the past; certain events are emphasized and others are omitted. According to Riessman (2001, 701), life histories have a 'performative function'. As the act of telling stories always takes place in social contexts, life histories potentially become representations of 'the preferred self', or how the person sees him or herself and wishes to present this image to his or her audience, rather than an accurate representation of the past. An edited representation of the past arises, which functions as giving meaning to the present (Henning et al. 2004).

Life histories are all about the positioning of individuals in relation to the audience, other people and themselves (Riessman 2001). They can position themselves as victims or as active agents controlling the past circumstances they were in. The way other people are perceived is also an important aspect of positioning the self, as 'narratives (...) are clustered around some hegemonic constructions of boundaries between "self" and "other" and between "us" and "them"' (Yval-Davis et al. 2006, 2). Life histories can thus provide information about the characteristics of people perceived as belonging to the same group and people defined as 'others'.

Life histories with return migrant children were conducted in their homes and held in Dutch. The conversation generally started off with open questions on past experiences related to life in the Netherlands and return to Morocco, so that respondents could raise the topics that were most important to them. 
Additionally, some questions were asked about past behaviour, such as form and frequency of economic and socio-cultural participation in Dutch society. Although such 'memories' were most probably coloured, they still provided valuable insights on how return migrant children gave meaning to their current sense of belonging.

\section{Drawing Elicitation Method and Word Association Elicitation Method}

This section discusses the research methods that were used for the younger abandoned children. In comparison to adults, children ask for an altered research approach. Although children are increasingly considered as active participants and culture makers, child focused research methods are still in their infancy in anthropological methodology. Quantitative data gathering such as questionnaire surveys with children is difficult (Young \& Barett 2000, 142). However, qualitative data gathering methods such as semi-structured interviews are also difficult. Children's verbal expression is often not developed enough for answering questions in an interview setting (Clark-Ibáñez 2004, 1512). Participant observation is a research method that goes beyond age categories, but is only partly suitable for researching belonging, as this topic requires verbal expression to some extent.

During our research, we tried to develop two research methods in order to communicate with children in a child-friendly way: the drawing elicitation method (DEM) and the word association elicitation method (WAEM). DEM was derived from the photo elicitation method (PEM). PEM is a qualitative methodological approach; photographs are used as an interview technique (Clark-Ibáñez 2004, 1507). Informants are given a photo camera and are asked to take photographs of a certain topic. After that, the contents of the pictures are discussed. The photographs serve as 'a medium of communication between researcher and participant' (Clark-Ibáñez 2004, 1512).

However, for this particular research we needed to know children's sense of belonging with regard to both the Netherlands and Morocco. As taking photos of the Netherlands was not possible, we chose to work with drawings instead. Another advantage of children's drawings is that these present what children know. Children tend to draw what they know and not what they see, as adults 
do (Willats 2005). We handed a piece of paper to the children and asked them to make a drawing of Morocco and the Netherlands. After finishing, we discussed the drawing together with the child and often the mother. In this way, drawings are a medium for elicitation of thoughts and a means to discuss in children's terms what they think and imagine.

Secondly, we used the word association elicitation method. We asked the children to tell us what first popped in their head when we said a certain word. To become accustomed to the game, we first tried words such as couscous, kitchen and TV. Later on, we presented words such as the Netherlands, Morocco, mother and father. Their answers often elicited more information and gave insight into their perspectives of the situation they, their siblings, and mother were in.

The methods mentioned above supplemented main stream methodological approaches such as life histories and participant observation. Additionally, it was crucial to collect life histories from the mothers. These served as a context to talk with the children and to elicit their view. The use of various methods enhanced the validity of the research material concerning children who were often not fully able to express themselves verbally. At the same time these methods gave children a chance of free expression.

\section{Empirical Results}

\section{Return Migrant Children}

This section will describe the experiences of return migrant children. They grew up in the Netherlands, returned to Morocco as adolescents and are now adults. They experienced many post-return problems in economic and socio-cultural participation in Morocco, as the story of Hayat (25 years old) showed:

Hayat was three years old when she went together with her mother and younger brother to the Netherlands. Her father had already been living there for twenty years. She went to a Catholic primary school. After one year of secondary school her father decided to return together with his family. He had been unemployed and was suffering from psychological problems. Upon return, they lived for more than a year with family and then started to live 
in their own house in Oujda. Hayat did not realize what was happening. She thought she was just on holiday in Morocco. She could not continue her school in Morocco due to language barriers and remained at home. Her life made her feel very depressed and she had many fights with her father about his decision to return. At the age of twenty a Dutch Moroccan asked her to marry and she agreed. She moved back to the Netherlands. She was treated badly and told her father she needed to come back to Morocco. Back in Morocco she became depressed. She tried to look for work without success. She has been back in Morocco for ten years now and wishes to return to the Netherlands. Since 2 years she has been involved in the legal procedure to obtain access to the Netherlands again.

All return migrant children discussed in this chapter grew up in Dutch society, which made them internalize a Dutch way of life. They all attended Dutch schools and spoke Dutch fluently. Interestingly, all, except for one, were unable to understand or speak Moroccan (Arabic Deriya) or Berber (Tamazigh). They knew little about Islamic or Moroccan practices, as Amine illustrated: 'I had never even heard of Mohammed, only about Jesus. I was just like a Dutch person!' They had been on holiday to Morocco only once or twice in ten years time. All these children almost exclusively lived in Dutch contexts, which made their fathers' decision to return to Morocco a shocking turning point in their lives.

Upon return, all five of them were confronted with a different way of life. This caused many difficulties, which were different for the two genders. Three girls were not able to continue school. They blamed this on language barriers, but gender hierarchies also played a role. Except for Bouchra who studied English literature at University, the other girls were not stimulated to go to school. Most girls remained indoors, which strongly contrasted to their lives in the Netherlands. This negatively affected their self-worth and well being, as illustrated by Hayat:

I felt like I was nothing, like I was no human being. This is how you start feeling when you do nothing. I know that I am intelligent, but I cannot prove it. If you start doing something, you start feeling like you are something, like you are alive. I felt more dead than alive. At some point I was thinking it would be better to be dead, because then I could finally stop doing nothing. 
Although Bouchra went to school, she was negatively affected by gender expectations too. Freedom of movement and being outdoors can be limited for girls and women in some parts of Morocco, as Bouchra complained:

As a woman, you cannot even do groceries without people staring at you. You cannot do anything without hearing comments.

As a boy, Amine did have the possibility to go to school, but he initially suffered from language barriers and had problems with teachers who beat pupils. As a result, he never obtained his certificate. Although boys and girls thus experienced different difficulties, they all had to deal with a post-return context in which their 'Dutch' way of life did not fit.

Furthermore, work was difficult to find due to high unemployment rates, lack of certificates and contacts. Scarcity of work opportunities was even the most important reason for wishing to return to the Netherlands, as Souad expressed:

If I was in the Netherlands now, I would be able to work. I just want to work and make money, so I can take care of my children by myself. I do not want my husband to earn all the money. Here in Morocco even if people have a certificate they still do not find work.

These returnees were not suffering from a lack of income. Financially, return migrant children were much better off than abandoned children. However, their ideas and norms about being able to work and being financially independent made them wish to return to the Netherlands.

Although these return migrants tended to describe themselves as victims of constraining circumstances, they also possessed agency to refuse the options that came on their path. They were not willing to do every kind of work. Amine worked one week for his cousin's illegal taxi company. He did not want to continue because he thought he did not earn enough. Hayat did a course to become a hairdresser, but she never intended to do the work. The salary would be very low and she would have to work in authoritarian circumstances. She only did the course to be able to leave the house during the day. Thus, also their views of 'normal' working conditions were in conflict with post-return reality.

Within the socio-cultural domain, these returnees showed agency by expressing great anger towards the person who decided to return, predominantly their father. Hayat had many fights with her father; she blamed him for taking away 
both her life in the Netherlands and her future. She usually isolated herself from her family, e.g. by watching German television in her own room, as the German language resembled Dutch. This showed how return can worsen family relations within the household, and how return migrant children actively contributed to that.

Besides problematic family relations, these return migrants also had difficulties in dealing with people who were their own age. Except for Souad, they all did not want to marry in Morocco for this reason, as Amine explained:

If I stay here in Morocco, I will never marry. I cannot marry a girl from the Rif mountains. I do not think they have a normal life. They only stay at home since the day they were born, they do not know anything about the world, they never went to school. Moroccan girls only think about marriage and children. They think they have no future without a husband. They are very different, I cannot talk to them.

All five return migrant children tended to perceive non-migrants as 'others', sometimes in very negative terms. Hayat did not get along with Moroccan girls and described them as 'jealous' and 'unreliable'. Return migrant children also tended to describe non-migrants as more 'backward', as the quote of Amine illustrated. This was also the case for Hind, who explained how she found other youngsters 'incredibly strange', that she 'could not deal with those people' and that she 'was just like a foreigner there'. Hayat and Hind were very limited in their social life, as they only had one close friend. Amine was better off; he had the chance to go to school and establish friendships there. He did not feel treated as much as an outsider as Hind and Hayat did. This was also the case for Souad, who knew all people in her neighbourhood. However, she considered none of them as friends, even after 25 years of return. Bouchra also kept a distance towards her fellow students as she felt different from them.

As a result of all these post-return problems, these return migrant children preferred to return to the Netherlands. They strongly identified themselves with the country they grew up in, which is expressed by the importance they attached to the Dutch language. They had learnt to speak Moroccan and/or Berber dialects, but they still considered Dutch as their mother tongue. They all identified themselves as Dutch instead of Moroccan. Language played an important role in this, as Hayat showed: 
My nationality is Moroccan, but in my heart I feel like a Dutch person. I am different. I try to live like a Dutch person here, I also took my habits with me from the Netherlands. I still think in Dutch. If I have to translate a recipe, I always translate it in Dutch. My mobile phone is also still programmed in Dutch. Because the Dutch language is in my blood. If I make a wish for myself, I always wish in Dutch. But if I have to speak up: always in Moroccan.

This quote of Hayat demonstrated her agency, as she actively held on to the Dutch language, even after ten years of return. She also followed some Dutch language classes; not to learn anything (as Dutch was her mother tongue) but only to hear the language. In contrast, she never developed much interest in learning French, the second language in Morocco. Instead, she taught herself German from television channels, because German served as a substitute to Dutch channels which she could not receive on her satellite. All this showed how Hayat resisted integration in Moroccan society by actively holding on to the Dutch language.

\section{Abandoned Children}

The case of Naima (12) and Siham (6) illustrated the circumstances of abandonment. Both sisters lived with their mother Mounia in the outskirts of a large city in Morocco.

Mounia married at the age of 21 with a Moroccan man who lived in the Netherlands. A year later, Mounia migrated to the Netherlands where she started to live with her in-laws. During this period Naima was born. After five years, Mounia's husband took her and Naima to Morocco, under the pretences that they could stay in his house there while he sought after a house in the Netherlands. During this time, he commuted between Morocco and the Netherlands. Siham was born in 2005. Mounia started questioning whether her husband would take Naima to the Netherlands in order to go to school-as he had promised. However, a letter arrived from court in which he applied for divorce. After the divorce the police evicted Mounia and her two daughters from the house. At the point of the interview she lived in her parental house with her daughters, mother and sister. Mounia applied for alimentation in court. 'It is no use, every time my husband is ordered to come to court; he leaves for the Netherlands. He pays nothing, I'm tired, I've had it', said Mounia, who started working as a housekeeper. Siham had never seen her father. Mounia and her daughters wanted to return to the Netherlands. After her divorce she started informing about return to the 
Netherlands. Mounia visited the $\operatorname{SSR}^{7}$ once; went to the Dutch Embassy in Rabat several times; bid for return more than once, but wrongly submitted the application. Thus, the request was never granted.

We asked Mounia why she wanted to return to the Netherlands. 'My future is gone, I want my children to go to school and have a better future. It is my responsibility', Mounia answered. Her chances of returning are minimal. Too much time had passed since her return. However, Siham, who never went to the Netherlands, had the passport to go overseas. Naima, who was the eldest and was born in the Netherlands, did not obtain a Dutch passport. Their father was not yet naturalized when Naima was born, but when Siham was born he was.

After abandonment, children and their mothers were mainly confronted with economic problems. Often, the father refused to pay alimony. At the same time these children were confronted with a broken family, because abandonment often led to divorce. As a consequence, these children often formed a front with their mother against their father. Because of such problems all children considered the Netherlands as the country they belonged to and wanted to live in, although they also had warm feelings towards Morocco, mainly because their relatives were living there.

The drawing elicitation method provided us with information on feelings of belonging of these children. For example, we asked eight year old Aziza, who returned to the Netherlands in 2007 and lived in a shelter, to draw two pictures: one about Morocco and one about the Netherlands. She drew a house, a sun and birds flying in the sky on the 'Moroccan' picture, and a sea and a sun on the 'Dutch' picture. 'To whom does the house belong?' we asked her. 'To my mother,' Aziza answered. 'And why did you draw a house in Morocco and a sea in the Netherlands?' Aziza responded, staring at her drawing: 'I don't know. It should be the other way around.' 'Why?' We asked. 'The house should be in the Netherlands and the sea in Morocco.' 'Why is that?' 'Because I want a house in the Netherlands,' she continued, 'I want a room of my own, with a computer and television. My friend's house is very beautiful. She has a big TV

7 The SSR (Foundation to Support Return migrants) is located in Berkane. This foundation facilitates Dutch Moroccan returnees in their contacts with Dutch government and social security institutions. Assisting youngsters and abandoned women and children wishing to return to the Netherlands is one of its activities.

This is a digital offprint for restricted use only | ( 2011 Koninklijke Brill NV 
and computer in her room, and little hearts painted on the walls.' This story, which was elicited while discussing Aziza's drawing, showed that Aziza felt she belonged to the Netherlands.

The word association game also provided us with some interesting insights. We asked Naima what first came to her mind when she heard the word 'the Netherlands'. She answered:

There is much in Holland. Morocco is not fun. In the Netherlands, there is work, schooling and rights. Here (in Morocco) you are not valued as an individual (...) There are no rights in Morocco.

The words chosen by Naima seemed very mature and appeared to stem directly from her mother, who used similar words to express her feelings. It was clear that the mothers transmitted feelings of non-belonging in Morocco and longing for the Netherlands. The children internalized and expressed this discourse. These children developed 'imaginary belonging' which resulted from intergenerational transmission of identity (Moen et al. 1997; Schönpflug 2001; Nauck 2001).

Respondents mainly wished to migrate to the Netherlands because of economic constraints in Morocco, such as limited possibilities with regard to schooling, lack of work, and 'getting your rights'. Low financial resources could constrain children to go to school in Morocco. However, mothers mainly emphasized the low standard education in Morocco. Even with having successfully completed education, chances of work are very limited due to high unemployment rates in Morocco. Contrary to return migrant children, language barriers and adaptation to Moroccan life did not form problems. Because abandoned children were young, they could better accustom themselves to Morocco, especially because they had no other reference. 'Having rights in the Netherlands' was mentioned repeatedly. The mothers felt their rights were violated in Morocco, and injustice was done to them through abandonment. The mothers' drive to provide their children with a better future was remarkable. They were determined to return to the Netherlands and give their children a good education and financial resources.

Post-return problems were mainly communicated by mothers. While some children copied their mother's words, others did not communicate explicitly about home and belonging. It was difficult to describe the agency of these 
children, especially the young ones. They often expressed anger towards their father for abandoning them, but the consequences were not fully understood. As explained above, their feelings of belonging could possibly develop in favour of the Netherlands. Children who obtained a Dutch passport could possibly migrate to the Netherlands at the age of eighteen. Although 'home' could be in Morocco, as they spent most of their life there, they could also feel they belong to the Netherlands. On the question, 'you have two passports, which one is you?' Najat (18) answered: 'The Dutch one, because I want to go back. In the Netherlands you can study, do everything, it is not like here. You can find work easier, it is not like here.' On the question, 'if you had good education and work in Morocco, would you stay here?' Najat replied: 'Maybe, not really. I want to go back to the Netherlands, despite of everything here. I want to see the Netherlands.'

Najat thus expressed agency, also at a younger age:

\begin{abstract}
Najat had good memories of her primary school period. Unfortunately, her memories of living with her father and her stepmother were not good. They had molested her severely. One day Najat went to the police who brought her to Child protection. Eventually the police sent her home with her father. Back home, her father brought her to South Morocco while her mother lived in the North. After many months Najat's father took her to her mother. Najat never had any contact with her father again.
\end{abstract}

At a very young age (10 years old) Najat stood up for herself and tried to escape the abusive situation she was in. This shows that children can have agency at a young age. Possibly, agency develops at a younger age when children are in pressured situations. The case of Najat was a very extreme one; she had no one but the police to turn to. Generally, abandoned children were supported by their mothers, who did everything to provide them with a secure future.

\title{
Conclusion
}

This chapter argued that Dutch Moroccan children in Morocco did not exclusively construct feelings of home in the physical place they inhabited. However, some remarkable variations existed between the different children discussed in this chapter. Firstly, children who returned as young adolescents with their 
parents tended to claim mono-belonging to the Netherlands. They grew up in this country. Particularly through school, they internalized a Dutch way of life, which made the confrontation with the Moroccan way of life an overwhelming one. Participation in Moroccan society was a very important factor here, as those who had more possibilities to participate seemed to entertain feelings of belonging towards both the Netherlands and Morocco. However, all felt uprooted in Morocco to some extent and wished to return to the Netherlands.

This chapter also discussed different types of (younger) abandoned children, who were more likely to claim dual belonging. They grew up in Morocco, but they also expressed feelings of belonging towards the Netherlands. Interestingly, some children showed imaginary belonging, such as the ones who had never been to the Netherlands, as they were born in Morocco after their mothers were abandoned. These feelings of belonging were mainly transferred from mother to child. Imaginary belonging or not, all children longed for the Netherlands. This was mainly explained in terms of good education and better chances of work later on. These children also mentioned 'having rights' in the Netherlands. This was explained by the fact that they, and/or their mothers, had to deal with feelings of force and injustice by being abandoned in Morocco.

The different constructions of belonging revealed children's agency, which is largely affected by age at the point of return. Elder return migration children expressed agency most strongly, as they tended to refuse participation and belonging to Moroccan society. However, these expressions of agency were not isolated from local Moroccan discourse, or the 'culture of migration'. In Morocco, migration to Europe is generally considered as the ideal way to achieve a successful future. Within this context, return migrant children had to negotiate their own position in society. This was done by refusing to accept both the fact that they returned and participation in Moroccan society. Blaming their fathers and being negative about living conditions and life in Morocco in general, exempted them from responsibility and from being 'losers'. Feeling not at home in Morocco was a way of negotiating a symbol of 'otherness', of dealing with feelings of force, injustice and stigma as a 'loser', which was a consequence of being relocated from one country to another and of giving up a future and life in the Netherlands. 
For younger abandoned children, agency played a different role in the process of constructing post-return belonging. Intergenerational transmission was an important factor here. Abandoned children predominantly wished to return to the Netherlands because their mothers told them to. Apparently, younger children's agency mainly consisted of reproducing perceptions of their mother, whose views were not isolated from the 'culture of migration' either. In this sense, it was arguable that younger children expressed free will to a lesser extent than the elder ones. However, this might change at a later age. When the children grow older, they may internalize their mother's wish to return to the Netherlands and express it as their 'own' free will as a consequence of intergenerational transmission and growing up in a 'culture of migration'.

The three methods described in this chapter, life histories, the drawing elicitation method and word association elicitation method, seemed to be relevant tools for researching different age categories in this chapter. Life histories provided the meanings returnees attached to the past, to themselves and others. This was an act of agency in itself. The drawing elicitation and word association elicitation methods seemed to be suitable in case of younger children. In this way children had a chance to express themselves while they were simultaneously included as an active research group rather than passive actors. It would be interesting to conduct longitudinal research on younger children. This could clarify the query in what way their sense of belonging and agency will develop over the years. For example, drawing elicitation and word association elicitation could be used when they are young, whereas life histories could be conducted when they are older. This would provide a better understanding of the links between age and children's agency in the context of return migration and abandonment.

\section{References}

Ahearn, L.M. (2001), Language and agency. Annual Review of Anthropology 30: 109-137. BARTELS, E. (2005), Onderzoeksnotitie over migrantenvrouwen en kinderen die gedwongen zijn achtergelaten in landen van herkomst. Voorstudie voor Adviescommissie van Vreemdelingenzaken, Den Haag. (Research report concerning migrant women and children who have been left behind in their country of origin, a pre advice for the Advisory Committee for Foreign Affairs of the Ministry of Justice in the Netherlands). 
Bluebond-Langner, M. \& J.E. Korbin (2007), Challenges and opportunities in the anthropology of childhoods: An introduction to children, childhoods and childhood studies. American Anthropologist 109(2): 241-246.

Bucholtz, M. (2002), Youth and cultural practice. Annual Review of Anthropology 31: $523-552$.

Clark-IBÁŇEz, M. (2004), Framing the social world with photo-elicitation interviews. American Behavioral Scientist 47(12): 1507-1527.

DAvis, J.M. (1998), Understanding the meanings of children: A reflexive process. Children and Society 12: 325-335.

DE BREE, J. (2007), Belonging, transnationalism and embedding: Dutch Moroccan return migrants in Northeast Morocco. Master thesis Development Studies, Radboud University Nijmegen.

De Haas, H. (2003), Migration and development in southern Morocco: The disparate socioeconomic impacts of out-migration on the todgha oasis valley. Amsterdam: De Haas.

Flores-Bórquez, M. (2000), Children of protracted exile: Where do we belong? In: C. PanterBrick \& M.T. Smith, eds, Abandoned children, pp. 213-223. Cambridge: University Press.

Ghorashi, H. (2003), Ways to survive, battles to win. Iranian women exiles in the Netherlands and the United States. New York. Nova Science Publishers, Inc.

Hall, T. \& H. Montgomery (2000), Home and away: 'Childhood', 'youth' and young people. Anthropology today 16(3): 13-15.

Hannerz, U. (2002), Where we are and who we want to be. In: U. Hedetoft \& M. Hjort, eds, The postnational self: Belonging and identity, pp. 217-233. Public World Series, Vol. 10. Minneapolis: University of Minnesota Press.

Hardman, C. (2001), Can there be an anthropology of children? Childhood 8 (4): 501-517.

Henning, E., W. VAn Rensburg \& B. Smit (2004), Finding your way in qualitative research. Pretoria: Van Schaik.

LANCY, D.F. (2007), Accounting for variability in mother-child play. American Anthropologist 109(2): 273-284.

Levine, R.A. (2007), Ethnographic studies of childhood: A historical overview. American Anthropologist 109(2): 247-260.

LOVELL, N. (1998), Locality and belonging. London: Routledge.

Mahmood, S. (2001), Feminist theory, embodiment and the docile agent: Some reflections on the Egyptian Islamic revival. Cultural Anthropology 16(2): 202-236.

Meurs, P., S. Van Wolputte, F. De Boeck, G. Cluckers \& R. Devisch (1999), Kinderen, gezondheid en welzijn: Naar een medische antropologie van kinderen (Children, health and well being: Towards a medical anthropology of children). Medische Antropologie 11(1): 199229.

Moen, Ph., M.A. Erikson \& D. Dempster Mcclain (1997), Their mother's daughters? The intergenerational Transmission of gender Attitudes in a World of Changing Roles. Journal of Marriage and the Family 59: 281-293.

Montgomery, H. (2005), Gendered childhoods: A cross disciplinary overview, Gender and Education 17(5): 471-482.

NAUCK, B. (2001), Intercultural contact and intergenerational transmission in immigrant families. Journal of Cross Cultural Psychology 32(1): 159-173.

PANTER-Brick, C. (2000), Nobody's children: A reconsideration of child abandonment. In: C. Panter-Brick \& M.T. Smith, eds, Abandoned children, pp. 1-26. Cambridge: Cambridge University Press.

Pedersen, M.H. (2003), Between homes: Post-war return, emplacement and the negotiation of belonging in Lebanon. New issues in refugee research. Working paper no. 79. Denmark: United Nations High Commissioner for Refugees.

Pratt, B. \& P. Loizos (1992), Choosing research methods: Data collection for development workers. Oxford: Oxfam Great Britain.

Reis, R. \& C. Dedding (2004), Kinderen als mede-onderzoekers: Mogelijkheden en problemen van kind-gestuurd onderzoek (Children as fellow-researchers: Possibilities and problems of child-centred research). Medische Antropologie 16(1): 79-92. 
RemigRATIEWET (2009), Wet van 22 april 1999, houdende regels inzake het treffen van voorzieningen ten behoeve van remigratie (Remigration Act). URL: http://www.st-ab.nl/wetten/o250_ Remigratiewet_Rw.htm (accessed 2 February 2010).

Riessman, C.K. (2001), Analysis of personal narratives. In: J.F. Gubrium \& J.A. Holstein, eds, Handbook of interview research: context \& method, pp. 695-710. Thousand Oaks: Sage.

SALIH, R. (2003), Gender and transnationalism. home and belonging among Moroccan migrant women. London and New York: Routledge.

Schaefer Davis, S., D.A. Davis \& J.W.M. Whiting (1989), Adolescence in a Moroccan town. New Jersey: Rutgers University Press New Jersey.

SchöNpFLUG, U. (2001), Introduction: cultural transmission-A multidisciplinary research field. Journal of Cross Cultural Psychology 32(2): 131-134.

Ter MaAt, I. (2002), I'm a tree, with roots in Chile and branches and fruits in the Netherlands: Chileans in the Netherlands: Changes in gender identity and processes of embedding. Nijmegen: Vrouwen Alliantie Media Producties.

Toren, C. (1999), Why children should be central to anthropological research. Etnofoor, Kids and Culture 12(1): 27-39.

Valentine, G., T. Skelton \& D. Chambers (1998), Cool places: An introduction to youth and youth cultures. In: T. Skelton \& G. Valentine, eds, Cool places: Geographies of youth cultures, pp. 1-31. London/New York: Routledge.

VREemdelingenCirCulaire (1994), Vc94 B 21 Verblijfsrechtelijke gevolgen van (tijdelijk) verblijf buiten Nederland. Retrieved from: http://cmr.jur.ru.nl/cmr/vc/vc94/DeelB/B21.pdf (accessed on 2 February 2010).

Werbner, P. (1999), Gobal pathways. Working class cosmopolitans and the creation of transnational ethnic worlds. Social Anthropology 7(1) 17-35.

Willats, J. (2005), Making sense of children's drawings. New Jersey: Erlbaum.

WulfF, H. (1995), Introduction: Introducing youth culture in its own right: The state of the art and new possibilities. In: V. Amit-Talai \& H. Wulff, eds, Youth Cultures: A Cross-cultural Perspective, pp. 1-18. London/New York: Routledge.

Young, L. \& H. BARrett (2001), Adapting visual methods: Action research with Kampala street children. Area 33(2): 141-152.

Yval-Davis, N., K. Kannabiran \& U.M. Vieten (2006), The situated politics of belonging. London: Sage. 



\title{
8
}

\section{The Learning Experiences of Refugee and Asylum-Seeker Children: A Model for Meaningful Learning}

\author{
Cilel Smith
}

\section{Introduction}

This chapter focuses on the learning experiences of refugee and asylum-seeking children within the context of English schools. It explores children's learning experiences pre-, during and post-migration, and examines both circumstantial and consequential influences. Special attention is given to the way in which educators and children perceive of education and learning. Further consideration is given to the methodological approaches and challenges faced in researching the learning experiences of new students and, in particular, refugee and asylum-seeking children.

This chapter aims to provide a deeper understanding of the complexities involved in carrying out research on refugee and asylum-seeking children. Developing a clear understanding of what a 'refugee' is provides important 
insights into how children's learning experiences are influenced by a variety of factors. Consideration is thus given to the unique, individually diverse and complex qualities of each child involved in this study. While empirical research for this study was undertaken in London schools, it is hoped that the use of board games in research, as explored further in this chapter, will offer a wider range of methodological options for doing research on refugee children. In turn, it was found that focusing on the individual child's experiences, agency and interdependencies is a necessary approach to such research.

\section{Conceptualising 'Refugeeism' and the 'Illuminative Approach'}

The concept of Refugeeism is here constructed, rather than defined or described, through the 'illuminative approach' in order to consider the complexities of forced migration. The significance of the 'illuminative approach' is that information and analysis are facilitated through a flexible methodology that draws from different techniques, thereby approximating the experiences of each individual refugee child. The 'illuminative approach' therefore permits the exploration and conceptualisation of refugee children's learning experiences through geographical and circumstantial influences, thus reflecting on consequences and perceptions of learning experiences. Therefore conceptualising 'Refugeeism' and understanding the 'illuminative approach' in this research are essential tools to make sense of the learning experiences of each individual child.

Against a backdrop of both shared understandings and experiences of forced migration as well as specific life circumstances, the twin concepts of 'Refugeeism' and the 'illuminative approach' are particularly useful. Parlet $(1977,17)$ states that "the researcher is concerned to familiarise with the day to day reality of the setting and in this he is similar to social anthropologists or to natural historians." Refugeeism thus aims to describe the environment, experiences and life-worlds of refugees and asylum-seekers. While using the illuminative approach' a day to day account of their environment, life and experiences can be recorded. These factors are positioned within a conceptual framework, through which their world is described and explained. 
As there is a danger of generalizing the refugee experience, an historical perspective is needed in order to identify the heterogeneity of refugee conceptualisations. In its definition and description of refugees, the United Nations High Commission for Refugees (UNHCR) states the following:

Behind the phenomena of moving lie deeper and often interrelated patterns of political, economic, ethnic, environmental, or human rights pressures which are further complicated by the interplay between domestic and international factors, there are as many reasons for moving as there are migrants.

(UNHCR 1993, 13)

The word 'refugee' (or in French, 'refugier') may be traced back as far as the seventeenth century; it was introduced by Huguenots seeking sanctuary in the United Kingdom. Rutter $(2006,16)$ suggests that the term was an internal socio-political construction: "it was based on the obligation of the government to give sanctuary to those fleeing danger and in legal terms, being a refugee is a condition afforded by the state of sanctuary and therefore a bureaucratic identity."

Rutter $(1994,4)$ argues that the term, 'refugee' does have a legal meaning; drawing upon the 1951 United Nations (UN) Convention and 1967 UN Protocol Relating to the Status of Refugees and states, "it is someone who has a well founded fear of being prosecuted for reasons of race, religion, nationality, membership of a particular social group or political opinion and an asylumseeker is a person who has crossed international borders in search of safety and refugee status."

From an historical perspective, a refugee's experience might include forced migration, the chaos of conflict-driving millions of people from their homes, leaving them exposed to multiple dangers and overwhelmed by their anguish, suffering the loss of homeland, family, property, friends, familiar surroundings, and established social networks. One may argue that losing a sense of social and national identity can lead to generalizing conceptions of refugees, due to their shared, yet diverse life-worlds.

However, there is danger of refugees being perceived as a homogeneous group, all with the same experiences and needs. As Soguk (1999) suggests, this is an over simplification of the situation: 
There is no intrinsic paradigmatic refugee figure to be at once recognised and registered regardless of historical contingencies. Instead there are a thousand multifarious refugee experiences and a thousand refugee figures whose meanings and identities are negotiated in the process of displacement in time and place. (Soguk, 1999, 4)

Refugeeism is a term used to envelop the circumstances of people who have experienced forced migration. Refugees account for approximately 40 million people in the world. Alarmingly, Machel $(2001,26)$ states that " 20 million of them are children, deprived of the security of their communities and exposed to multiple dangers of armed conflict or human rights violations." While there is a tendency to generalise refugees into one, homogenous category, Soguk (1999) recognises that refugees have shared experiences, and that the diversity is within actual individual experiences.

Developing a definition for 'refugeeism' involves exploring the processes and concept of 'shared experiences' during forced migration, whilst recognising the various units of unique life-worlds of each individual refugee. Therefore, how does one begin to conceptualise refugee children arriving in an English school, ready to enter the 'learning environment' for the first time, with no previous educational experience? How do we understand the world of this child accurately, when we have not observed, examined, or assessed his/her past learning experiences? Refugee or asylum-seeking children often arrive unaccompanied, or with parents, guardians and care-givers who do not speak English and have limited educational experiences. Thus, in order to conceptualise 'refugeeism', it is necessary to consider the ways refugee children learn and their environment. Also how these issues can be investigated and constructed in such a way as to understand their learning experiences within the 'natural setting'. The 'natural setting', or 'milieu', herewith referred to as 'environment', refers to the three stages of the migration process: These include learning experiences in the country of origin, during migration and within the final stage-on arrival in English schools. These settings are explored in order to evaluate and investigate how learning either did or did not occur. Bronfenbrenner (1992) argues the importance of context and the influence of the environment on child development and learning. He states that "development occurs in context and therefore can only be properly understood in context and is the progressive, mutual 
accommodation throughout life course between active, growing human being, and the changing properties of the immediate settings in which the developing person lives" (Bronfenbrenner 1992, 187-249). The way in which children learn and acquire knowledge will be further explored in this chapter.

\section{Understanding the 'Illuminative Approach'}

The basic emphasis of this study on the 'illuminative approach' is based on a previous investigation of participants' experiences of being refugees. The approach provides a means of analysis designed to increase knowledge, and in this instance understanding, of the learning experiences of refugee and asylum-seeking children. The 'illuminative approach' is primarily concerned with description and interpretation rather than measurement and prediction. It is aimed at exploring situational influences and concerns of participants' experiences. In this study, the 'illuminative approach' reveals how the particular learning experiences of child refugees are implicated in their education within English schools. This is achieved using a pattern analysis, as explored in the methodological section of this chapter.

Methodologically, this approach aims to be both adaptable and eclectic, facilitating the process of data cross checking derived from a broad range of sources and findings from the children interviewed. In adopting this approach, I familiarized myself thoroughly with the day-to-day reality of the settings, documentation and learning experiences of the refugee children. I made no attempt to manipulate, control or eliminate situational variables, but rather took them as "givens" within the complex situations I encountered. In doing this, the chief task was to unravel the data, isolate the findings, delineate and outline the cause, effect and consequences, and to study relationships between patterns and the responses of individuals. This study thus emphasised observation and progressive interviews. 


\section{The 'Instructional System' and the 'Milieu'}

Two elements remain central to the 'illuminative approach': 'The instruction system' and the 'learning milieu'. These factors take into account the wider contexts in which education, and in this instance learning, functions as explored in this chapter.

An 'instructional system', or programme for learning in the 'illuminative approach', refers to an educational plan, with goals or objectives and desired outcomes. Furthermore, it relate to formalised plans and particular teaching arrangements. Partlett \& Dearden (1977) argue:

The instructional system may remain as a shared idea, abstract model. But it assumes a different form in every situation or milieu and acknowledging the diversity and complexity of learning milieux is an essential pre-requisite for the study of educational programmes and necessary for analysing the interdependence of learning and teaching (Parlett \& Dearden 1977, 15).

However, one of the main concerns of the 'illuminative approach' is to 'connect' changes in the learning milieu. Refugee children live in constantly shifting settings, a phenomenon caused by war, poverty, displacement, and ultimately migration. Machel (2001) states that "education is difficult to sustain amid political instability" $(2001,93)$. Schools and teachers are important members of the community and often targets vulnerable to attacks. Fear and disruption often make it difficult to maintain education, schooling and learning; this creates changes in the community and family structures. As a result of the changes, parents and community members may take over the responsibility of educating their children and be the reinforcement agents for learning, thus supplementing teachers and education structures. However, there may be further disruption when family members become absent through war and the consequences of trauma and other psychological influences.

Much learning takes place within the environmental context of socialisation and enculturation. Children learn through the environment and socialisation and are also active agents in the learning process: Green and Hogan state that "children therefore can be seen as much more active in the process of cultural learning as interpreters and creators of meaning rather than simply absorbing the meaning of adults" $(2005,49)$. This might suggest a paradigm shift in how 
children learn; Green \& Hogan (2005) thus question children's interdependencies within or independence from society, adults and formal learning. Children from Somalia have not been to school for many years due to conflict and war. Are we then to assume that they have not learned, because of the lack of formal educational systems and programmes? The process of learning through enculturation is typified as learning without deliberate teaching, but can take place through observation and learning from other family members. Refugee children can therefore be seen as active social actors in the construction and determination of their social lives and the societies that they live in. Interaction with adults or other societal members and peers results in the shaping of socially approved behaviours and learning, a socialisation process which might consist "primarily of deliberate tutelage" (Segall et al. 1990, 24).

Particular ideas, concepts and values are thus learned; they are determined by exposure to different places. This may provide an understanding of the refugee children's learning processes, as they find themselves regularly in different environments. Socialisation commences when we begin life in a particular social context, within which we learn and develop. With regard to both biological and cultural developmental processes, I argue, along with Child (1954, 665), that an individual is born with a wide range of "potentialities"; however, the standards of his/her group, environment and culture determine the range of development. Child (1954) defines this narrow range, as well as the process of socialisation, as:

The whole process by which an individual, born with behaviour potentialities of enormously wide range, is led to develop actual behaviour, which is confined within a much narrower range of what is customary and acceptable for him according to the standards of his group (Child 1954, 655).

We may conclude from Child's definition that each society determines what a person knows and learns; this changes when a society disappears and an individual moves into different societies and environments. Learning then takes place without deliberate teaching; people must conform to the instructional systems of new societies in host countries and refugee settlements.

Educational provision in certain countries and cultures often consisted of teaching religious materials, which is not universal or national, but confined to a small urban minority. In many parts of the world, written language is not

This is a digital offprint for restricted use only | ( 2011 Koninklijke Brill NV 
developed and the spoken word remains the main medium of transmitting cultural norms and moral values. Kahin $(1997,19)$ explains that "habits and skills were acquired through parental stewardship and exposure to adult life."

Moving from the 'instructional system' to the role of the 'milieu', the second concept of the 'illuminative approach' in this study acknowledges the diversity and complexity of the learning milieu as an essential prerequisite for the study of educational programmes and learning experiences of refugee children. Establishing the learning experiences of refugee learners is essential for evaluating the impact of their experiences on their future learning. This evaluation provides a means of contributing to the knowledge of educators in English schools. Hamilton et al. $(1977,22)$ argues that "the investigator contributes to a field that has received only minimal attention from social scientists and has not only short term goals but also the long term goal of contributing to a developing and urgently required new field of study." In this study, the policies and backgrounds of each refugee learner are explored through interviews, revealing what the learner already knows and the perceptions of educators concerning refugee education in England.

\section{The Learning Milieu}

Parlett and Hamilton $(1977,11)$ argue that "the learning milieu represents a network or nexus of cultural, social, institutional and psychological variables." This "nexus"-or connected group of variables-is the crux of Refugeeism, wherein the notion of identity is the most significant aspect of being a refugee. Refugees are often faced with the task of both confronting their own identities and constructing new, accumulative identities within the host country. The change in identity may mean that refugees become classless or Stateless because of laws, polices and asylum procedures within host countries; however, ultimately refugees still belong to a nationality, culture and language group. It is within the exploration of their context and milieu that refugee identities are established; through geographical, cultural, religious, social structures, including their previous economic power and learning experiences. This chapter explores primarily these geographical and cultural identities or backgrounds 
to establish milieus of previous refugee learning experiences and the consequences and implications of such experiences for their future education in England. This learning milieu approach is combined with a form of a 'naturalistic' or constructivist approach, thus providing a holistic view, endeavouring to construct a complete picture of refugee children and their learning experiences. What these approaches have in common with the illuminative approach is a commitment to study human action in some setting that is not contrived, manipulated or artificially produced or set up by the researcher.

Schwandt emphasises that the naturalistic or constructivist approach aims at "faithful, authentic reproduction or representation of others ways of life" $(2001,31)$. Parlett \& Hamilton (1977) argue that these approaches share many common elements in that they all tend to be holistic; they are processes rather than products oriented and carried out under naturalistic or field conditions (as opposed to contrived, laboratory-type experimental conditions). They further argue that these approaches give less prominence to quantitative measurement procedures, using instead extensive observational and participatory techniques, such as interviews. Most significantly, according to Parlett and Hamilton, such an approach is "concerned with the way in which educational phenomena, practices and policies are influenced by the wider social and institutional contexts" $(1977,11)$. The concept of a 'learning milieu' enables us to explore the wider social and institutional contexts of learning and teaching. It is useful for relating the organization, practices and policies of instruction with the immediate and long-term consequences of the learning experiences that cannot be understood in isolation, but rather within a particular setting or milieu for their future education.

The learning milieu depends on the style of education and influences of the wider social and community context. These influences may be attributed to the uniqueness and diversity of each individual refugee learner who adapts to and works within the learning milieu of each host country during or after migration. They acquire particular habits of studying and learning and assimilate the conventions, beliefs and policies that are transmitted through the teaching process in each country, school and social context.

The research design informing this chapter involved a continuous dialogue between conceptual frameworks (i.e. 'learning milieu'; 'illuminative approach') 
and empirical work. The 'illuminative approach' is flexible in that it can accommodate changes in the learning milieu. Parlett \& Hamilton suggest that "acknowledging the diversity and complexity of learning milieux is an essential pre-requisite for the serious study of educational programmes" $(1977,11)$. Educational policies, practices, guidelines and other primary sources from different countries provide an historical perspective and background to the education of refugee learners. Furthermore, these factors may point to topics for intense discussions that may expose aspects of a policy that may be otherwise missed. Therefore, an understanding and comprehension of refugee education and learning, take into account the type of learning experienced or not experienced with regard to past schooling experiences, impacts of migration, pupil mobility, no educational experiences, alternative schooling, religious schools, homebased learning, and traditional learning styles and strategies. The variables and ranges of experience and educational levels may be vast and diverse.

The 'illuminative approach' is used to highlight the above points: That child refugee learning strategies are complex; the concept goes further to unravel such complexity by isolating significant features of and comprehend relationships between organizational patterns of learning and the responses of individuals. Hamilton et al. (1977) argue that:

...illuminative evaluation is not a standard methodological package, but a general research strategy and that the choice of research tactics follow not from research doctrine, but from decisions in each case as to the best available techniques and that the researcher familiarise herself with the day to day reality of the settings that is being studied (Hamilton et al. 1977, 13).

Although this approach seeks a wider understanding of the entire situation, progressive interviews with forty refugee children in three London schools reveal the context, or natural setting, of the variables under consideration. This understanding is based on three interviews with each child, paying special attention to the child's perceptions of learning.

In this study, it was found that the learning milieu often changes for refugee children; these results demand new investigations of pedagogy experienced by children during each change, with each host country before arriving in England. The biggest and most demanding change is when refugee children arrive in England and in English schools for the first time. These changes have impli- 
cations related to the resilience of the child, his/her ability to adapt to multiple changes and experiences of new and different teaching styles, languages and cultural diversity.

Parlett \& Hamilton argue that "within the learning milieu diversity and complexity is recognised" $(1977,11)$. In order to recognize this complexity and diversity, progressive focusing is used. This involves the researcher becoming engaged with the data, wherein new issues emerge with some assuming greater importance than others. Use is made of historical documents, histories, policies, and information related to each educational system, learning experiences, individual identities and descriptions of lifestyles in each country of origin and host countries travelled through. However, there is an emphasis on interviewing and observation as research tools, and both qualitative and quantitative methods are used to analyse the data. This allows for relationships and patterns from the responses of individuals to be illuminated.

\section{Methodology: Characteristic Stages of the 'Illuminative Approach'}

The difficulty involved in such research is in capturing the immediacy and vividness of the participants' learning experiences. According to Parlett \& Dearden the concern is "to do them justice, to summarise and select in a way that does not seriously degrade them" $(1977,145)$. Therefore, there is a need to portray a 'textured' description which is determined by the nature and complexity of the context in which the experiences arise. It is also necessary to validate the data and outcomes. By using interviews, engaging in dialogue and playing board games, much more could be discovered about the learning experiences of refugee children whilst focusing on the conceptual framework and research questions.

\section{The Board Games}

Two board games were designed in two levels with five focus boards, handbooks, activity, observation, analysis and assessment sheets to monitor and observe the children in their levels of competence, schooling and learning experience 
during the migration stages. Forty-eight reading and graphic picture cards in the child's own language and in English were used in order to observe and profile prior learning experiences. Each child received a workbook with activity sheets, which were used for progressive focusing, observation and data gathering on writing skills. These tools were also used to help profile and monitor the learning experience of the refugee children: Such as how they understood concepts and adapted to teaching styles. Most importantly, this allowed for the cross checking of data from the interviews.

\section{The Use of Board Games in this Study}

Board games in this study are seen as ways of understanding major aspects of a refugee child's world: His/her learning history and their perception of their learning experiences. Interpretations of these issues, as well as the child's reaction to either participating or not, resulted in a triangulation process that reinforced, justified and added validity to the findings of observations and interviews. Data from the interviews and observations shaped conditions for the participant to 'play and participate' in the learning process of a board game and to reinforce and cross check learning experiences. Refugee children in this study familiarised themselves with a schools, the systems, subjects, rules, expectations for progress, pastoral care and general cultural differences such as dress, food and social inclusion. This process included the continuous observation and 'indwelling' into their learning experiences. The process for induction, inclusion and assessment were built into the game, recording specific observational and individual experiences, therefore profiling the child and providing 'snapshots' of their learning through self reflection. Through play, progressive focusing, individual differences, knowledge, and gaps in children's learning experiences were explored and recorded.

\section{Example of Using the Board Games}

The board game was also used to track their journeys through a world map activity, recording the number of host countries visited, which provided insights into the frequency of migration, resilience and adaptation. Four chil- 
dren played this learning game at a time, which had an element of winning, competition and chance, providing an opportunity for observing instructions, personal attitudes, school readiness, preparedness and interactions. Assessments were made based on their understanding of instruction as well as numerical, social and educational knowledge, and writing skill. Children used the reading cards to navigate their way through the green pathway, while rolling a dice and using 'play movers' to identify their place on the board. As children land on a number, they match it to the number on the reading card, which gives them instructions or information about the school and the activity in their individual board game workbook. Children then have to set out the cards, which are numbered, and they follow the number of paces as indicated on the dice when they have rolled it. Observation was taken on their knowledge of counting, the concepts of living things, colour and vocabulary in their mother tongue as well as in English.

The application form on the second page related general knowledge of refugee children's lives, their country of origin and number of family members before and after migration. This data was reinforced with art interpretation and probing into their family structure and support for learning. The use of colour or mono-colour art activities, name-writing, reading ability and knowledge transfers were cross-checked with data from the interviews. Profiling the children's experiences recorded incidents remembered and slowly, patterns were formed. Sugerman et al. state that "learning theories suggest that recognising patterns and making those connections between new material and previous experiences is key to learning" $(2000,3)$.

Thus, the use of our board games linked findings concerning the conceptual framework of this study to the research questions and pattern analysis. Games, as designed and used in this research, are a type of "culture" shaping human activity. According to Klabbers $(2006,38)$ "games as a form of play is the expression of human and social systems that generate culture and can intrinsically be valued- games are social systems as well as models of social systems." Klabbers (ibid., 37) defines games as "artefacts, human constructions developed with clear intentions in mind that only receive their meaning while being played and includes forms of knowledge that can make knowledge content meaningful while playing." The author further expresses that "models and 
games have become part and parcel of advanced learning environments and knowledge management systems" (ibid., 37).

\section{The Research Design and Refugee Sample}

Consideration was given to participants' proficiency in English in order to ensure that their perspectives through 'indwelling' were captured during the interviews. The notion of 'indwelling' is used to understand the children's points of view; it assists the researcher in better understanding their experiences, almost 'walking in another persons shoes' - reflecting, pausing and thinking about what has led to the child's perception of reality. Maykut and Morehouse $(2000,25)$ state that in "doing qualitative research one understands the person's point of view from an empathic rather from a sympathetic point of view and that indwelling is reflective." The research design therefore considered the interviews, research questions, case studies and in particular, the quality, reliability and 'accuracy' of the data.

In order to collect data from forty refugee children in three English secondary schools, interviews required explicit, clearly expressed and easily understandable questions. Tacit knowledge, however, was not completely ignored as it constitutes the general understanding of phenomena researched and in this study, the research and interviews with refugee children. It was only after the progressive interviews had been conducted that I could reflect on each interview and began to uncover the tacit knowledge and meaning of the data. Indwelling, in this sense, are not just the pieces of data, but the whole: What Polanyi $(1967,18)$ calls "joint meaning". It is imperative to let the whole emerge from the experience in order to understand that explicit knowledge derives from tacit knowledge. Gaining access to new meanings of refugeeism was carried out through indwelling or progressive focusing. Furthermore, piloting both the interview questions and board games as a reinforcement of the findings and further indwelling ironed out the consideration of issues of validity and trustworthiness in the research design and established a purposeful sample. 
Problems and Possibilities of Doing Research, Using the 'Illuminative Approach'

One of the main problems associated with the 'illuminative approach' lies in the issue of subjectivity. It may be argued that (purely by definition) the study of children, refugees and asylum-seekers presents a number of problems and questions emerging from personal feelings and political opinions, potentially leading to a biased report. Therefore, one may question if 'personal interpretation' can be scientific and whether the collection, analysis and the reporting of the data can be seen as entirely at the discretion of the researcher. Parlett \& Hamilton $(1977,18)$ underline this problem and argue that "there is no research study, which is immune to subjectivity." Researching sensitive issues may be more problematic as far as subjectivity is concerned, arising from social issues, past, traumatic and situational experiences, social exclusion and the assumptions and public opinions about refugees and asylum-seekers in England. Central to this sensitivity is the ethical responsibility to produce sound research. Esterhuizen (2004) argues:

For the sake of the credibility of the research and information we generate, we need to ground all the statements we make in evidence rather than make assumptions that immediately locate our organisations and our work on an unforgiving political spectrum (Esterhuizen 2004, 8).

In order to ground the statements made about data collected, judgement and reflection is necessary at every stage of the research. Further preliminary precautions were taken by piloting the study, endeavouring to exclude all possible situations and elements of subjectivity, thus focusing on my position as the investigator. Partiality may still be possible through the 'illuminative approach' through the open-ended techniques, progressive focusing and the nature of the interpretation of the qualitative data and cross checking the most important findings. Tact, a sense of responsibility and cooperation were employed. The guidelines as provided by the 'illuminative approach' —on retaining trust, being open about the aims of the study in order to ensure there is no ambiguity were adhered to. While considering issues of hostility and nervousness, parents of the participants were reassured of their children's confidentiality and anonymity at all times, and that they could withdraw at any time. In order to obtain informed consent, parents were invited to discussions, to observe the research 
and interview questions in order to obtain informed consent. This is a complicated issue as many children arrive in England unaccompanied or without parents.

Informed consent was often difficult to obtain, due to both protective legislation and the often absence of a guardian. Support from the community liaison officers resulted in gaining informed consent from a responsible guardian and the children. A summary of all key aspects of confidentiality, overall purpose of the investigation and any possible risks and benefits from the participant and the research study was given to them.

Therefore, consideration was given to the method of inquiry and case studies were used as the basis for empirical research. The investigation was carried out under 'naturalistic' or 'field' conditions in order to explore the 'case' of each school and maintain the aims, as set out in the 'illuminative approach'. This sample of forty children represented the refugee and asylum population insofar as their characteristics and experiences matched those of other refugees. According to Robson $(1999,136)$ "lower the likely error in generalisation and the more variables there is in the population, the larger sample size is needed." Furthermore, the method of analysis influenced the sample size, as did the categories into which the data was subdivided, reinforcing the need to consider what to do with the data analysis.

This large sample made provision for the inclusion of refugee children from different countries, representing a global population and providing more variability in the refugee population analysis. Once the schools agreed on the investigation and research design, the process of selecting the sample participants in the research and interviews had to be determined. The problems and complexities of Refugeeism and possible barriers to participation made this a difficult task. However, all the sample schools had at least 75 to 95 different languages spoken in their schools, which proved to be positive in terms of the numbers of children available to sample from. It was important to work through the 'new arrivals' list and determine or identify from the records. The refugee co-ordinator or teachers had no influence on the list of children selected and did not give any preference on the suitability of the participant, their abilities, backgrounds and experiences. Their role was to confirm if the child would be able to respond to questions. 
The children represented different countries of origin, who have either been in England for at least 6 months or who could converse and communicate with me, understand the questions and also respond to them. This was often a lengthy task, but in order to not confuse a refugee with an economic migrant or a new arrival, a further list was drawn up from the names of the new arrivals. Investigating admission forms and matching their geographical origin often identified and confirmed their status as refugees, which was reaffirmed by the refugee co-ordinators in the schools. I considered the geographical and circumstantial influences for determining the classification and possible identification of the child. The 'stigma' and often negative portrayal of refugees in the media made them reluctant to confirm their status as refugees.

Cohen, Manion \& Morrison (2000, 104) insist that "purposive sampling is unashamedly selective and biased and does not represent the wider population." It may be perceived as such, but in this instance preference was given to communicative ability and English language proficiency due to the time scale of the research and the decision to not use an interpreter. In support of purposive sampling, Robson $(1999,142)$ states, "it is an approach commonly used in case studies." The children selected were representative insofar as their learning experiences, pre-, during and post-migration, allowed.

\section{Stage 1-The Observational Investigation and Case Studies}

Observational investigation and case studies began by visiting three secondary schools, analysing their admissions lists, policies and organisational structures with refugee children, building up a continuous record of on-going events in the school and day-to-day activities for a period of 12 months. Discussions between refugee children, their peers and teachers were recorded. These recordings and observations were used to provide data and information on the perceptions of the educators of refugee children. Patterns of attendance, school admission forms, achievement records, support and the implementation of policies and the perceptions of educators on refugee children in the three schools were investigated, providing an opportunity to discover, explore and share the individual needs of refugee children as an innovation for policymakers and educators through profiling and case studies. This data was used 
in designing the interview questions, board games and profiles of the refugee children.

\section{Stage 2-The Three Progressive Interviews}

The second stage, involving progressive interviews, was crucial as it provided an understanding and snapshot of how refugee children have experienced learning, during all migration stages and in English schools. Open-ended questions were suitable for this study, enabling me to probe, explore and progressively investigate children's learning experiences and how these experiences may or may not be implicated in their education in English schools. Three interviews were designed, each to provide data on specific stages of their learning experiences.

- This first interview focused on personal details about the children themselves: Their families, schools, friends, neighbourhood, parents' occupations, religious, cultural and learning experiences, specifically before migration.

- The second interview concentrated on the concrete details of their actual learning experiences in their country of origin, during migration and when they arrived in England-or more concisely, within the period before and after they entered English schools.

- In the third interview, pupils were asked to reflect on the meaning, consequences and implications of their past learning experiences. They were also asked to evaluate differences in their learning experiences during the various stages of migration.

Consideration was given to the advantages of discussions or interviews in researching refugee children. Questions may not have been answered or accurately captured in a questionnaire with structured or closed-ended questions Interviews allowed for the capturing of the day-to-day, real life experience, tensions, conflicts, and pleasures of the participants, while drawing upon and reporting their points of view. During discussions, dialogue and progressive focusing understanding of their individual experiences, their perceptions and reflections unfolded as Parlett \& Dearden $(1977,145)$ explain, "what held them 
back from understanding sooner, when they got lost and when they begin to get the feel for it or catch on to it." Progressive focusing started with establishing a general overview of the child and their geographical background, circumstances of migration and preliminary discussions on the consequences of migration. These overviews formed the basis of the conceptual framework of the research.

Furthermore, progressive focusing allows for reflection, sifting, sorting, and reviewing the data gathered in the first and second interviews. This acted as a foundation for the third interview, which was chiefly focused on the child's perceptions and perspectives of their learning experiences. Probing and clarification of issues was possible, thus providing a more holistic approach to the child as a coherent whole. Early analysis may also, according to Cohen (2000, 147) "reduce the problem of data overload by selecting out significant features for future focus."

Therefore an advantage of using interviews is that they provide flexibility which, in the case of this research, was essential due to the various responses and individual differences specific to each student. The interviews were conducted in English, as interpreters and the presence of a third person may not have given the results and open discussions desired. Language, class and cultural differences may also impact upon the reliability of translations. Temple \& Moran $(2006,49)$ argue that "it is not possible to choose one person to represent a particular language group and assume that words and concepts move across language in a neutral way." The presence of a 'stranger' during the interviews and often-sensitive questions had to be considered. Hamilton $(1977,19)$ suggests that "illuminative researchers recognise this and attempt to be non-doctrinaire without appearing to be unsympathetic."

The flexibility of the 'illuminative approach' allows for questions to be rephrased in order for the participant to understand the questions and respond accordingly. This adaptability and flexibility is captured in the research design. Interpretation was also made of unspoken language: Behaviour and silent moments during the dialogue. Therefore, face-to-face interviews made it possible to modify the line of enquiry, following interesting responses and, according to Robson $(1999,229)$ "investigate underlying motives in a way that postal and other self-administered questionnaires cannot." The preparation of the 
interviews was time consuming but essential in that it provided access to children's perceptions of learning, guaranteed complete confidentiality, and generated good, valid, unbiased case studies.

According to Judd, Smith \& Kidder $(1991,253)$, in order to capture the details of the learning experiences of refugee children, the comprehension and accessibility of information depends on the design and research sample, thus "avoiding the creation of motives to give socially desirable, conforming or other biased responses." An overall framework for thinking about interviewing, the audience and the position of the researcher was essential in designing the research schedule. Consideration and reflection were given to the conceptual framework and research questions, which provided a thread for thinking about refugee children and their experiences of migration and learning.

According to Cohen et al. $(2000,269)$ further advantages and disadvantages for carrying out progressive interviews with refugee children include "literacy and writing skills of refugee children who may not be competent to answer and complete a questionnaire; allows for greater depth; has the potential to provide rich highly illuminating material and expansion of further dialogue." Interviewing therefore in this study, is a progressive way in which we try to capture the data.

Consideration had to be given to the fact that children might provide answers to questions with the desire to please, rather than being truthful. One might question, when researching the experiences of children, how the recounting of an experience or an imaginative tale was told, to amuse, fascinate or mislead the researcher. It was imperative that I successfully negotiate a space between myself as the adult figure of authority and the children themselves. In this chapter, I explain how I negotiated this space and built a foundation for trust and understanding of the study, starting with the sampling of the group, piloting the interview questions, and conducting the main interviews for the final research and case study. In this sense Green \& Hogan (2005) suggest that:

It is always appropriate to see children as participants in the research process and that checking back with child participants that the researcher's attempts to understanding make sense to them and is in line with the goal of keeping faith with children's own perspective and voice (Green \& Hogan 2005, 12). 
This perspective that Greene \& Hogan (2005) offer, of checking back with child participants, is essential when carrying out research on Refugeeism. Checking back, and considering the participants' views and understandings, was reflected in the design and implementation of progressive focusing techniques. These included examining the role of 'indwelling' during interviews, designing and using board games, piloting, profiling the countries of origin, and positioning each child within the conceptual framework of the geographical, circumstantial, consequential, and perceptional contexts ('milieus'). While checking back, consideration was given firstly to the learning experiences of the children, secondly the process and validity of the 'illuminative approach' and thirdly, to the usefulness of data from the interviews in providing opportunities to design the board games.

\section{Stage 3-Pattern Analysis}

The third stage of the 'illuminative approach' seeks to find patterns in responses and places individual findings from a broader explanatory context within the conceptual framework of Refugeeism. Due to the extensive data of forty refugee children (interviewed three times) I systematically reduced the breadth of the inquiry to give a more concentrated response to the emerging issues. Parlett \& Hamilton calls this 'progressive focusing' $(1977,15)$ and Cohen et al. (2000, 147) argue that "making sense of the data in terms of the participant's definitions of the situation, noting, patterns, themes, categories and regularities from the data analysis starting during data collection."

Data collection started from a wide angle and, through progressive sifting and sorting, funnelled to a narrow corridor in order for theory to be generated. It is therefore portrayed in a series of seven steps, as stated by Cohen $e t$ al. $(2000,148)$ to "establish units of analysis, create a domain analysis, establish relationships and linkages, making speculative inferences, summarising, seeking negative and discrepant cases and generating theory." An important element of data reduction and selection was displaying the data. I therefore developed a series of grids to capture data from the interviews, allowing for both qualitative and quantitative analysis. According to Miles \& Huberman $(1994,11)$ data displays help us to understand what is "happening." 
Displays were developed through, firstly, profiling the schools, and secondly, identifying categories of influence as defined in the conceptual framework. These categories were geographical, circumstantial, consequential, and perceptual, and together became the domain analysis grid. Data extracted from the interviews were placed in these categories to form patterns, permitting the cross-checking between schools, children, and the data captured during the pilot studies, activities, and the use of the game boards and admission forms.

Findings were captured and recorded on grids from the data focusing on learning or non-educational experience. This method of analysis enables gaps in learning to be evaluated, and reveals how and what they learned during various periods of migration. It also identifies the cognitive skills required to close the gaps in learning for future education in English schools.

Thus, this methods used in this analysis allow for the mapping of previous learning experiences, finding and closing the gaps in progress at English schools. A progression grid, similar to the "Thurnstone Scales", of Nachmias \& Nachmias (1981, 275-277) mapped out the educational category scales on vertical and horizontal axes, thus representing experiences achieved in schooling and education as expected in England. Nachmias \& Nachmias (ibid.) states that "the researcher selects the number of categories to form the scale to present the views from the population scaled." A clear picture of the learning experiences of all the children interviewed can be viewed using this method of recording and the capturing of data. However, it must be understood that it is progressive focusing, 'indwelling', reducing, patterning, and establishing relationships and linkages will evidently provide the data. The data were used in the pilot study in order to evaluate the validity and process of analysis.

\section{The Pilot Study and the Use of the Board Games and Analysis}

The findings of the pilot studies, as described, provided further evidence and analysis of children's learning experiences in all their settings and environments. Data captured on the grids were analysed and patterns were formed from the interview and observation data; this data was cross-checked while refugee children played the board game and completed the activities in their workbooks. 
Observation and discussions with the children during the board game exercise were recorded. This was entered onto new analysis grids for each child and cross-checked with the grids from the interviews. This process was also used with other refugee children, who were not interviewed and analysed against the conceptual framework of refugees learning experiences. This process provided an opportunity to build and construct further conceptual knowledge and understanding in the learning experiences of refugee children. Using the board games provided the opportunity for a wider sample to be observed and analysed.

\section{Conclusion}

Diverse backgrounds, socio-economic contexts, classes, religions, cultures, and experiences influence individual differences in learning. This uniqueness and individuality is embedded in children's cultures, environments, religious values, and ultimately in their experiences, which may or may not have influenced their development and learning experiences as perceived in the "Westernised" world.

'Out of date' pedagogical methods still often used in a number of countries, in contrast to reformed teaching informed by modern pedagogy common in Westernised countries. Various factors, such as high school fees, geographical difficulties in accessing schools and conflict may prevent children from attending schools. These factors often highlight the tragedy of the unschooled and those rejected by the system. This was evident in the 'snapshots' provided by children from Africa where their gaps in learning were also from poverty or 'outdated' school systems. The value or lack of concern, of education for girls often revealed their gaps in learning. Whilst playing the board game their eagerness to learn was highlighted. The game made learning easy, exciting and fun and gave them a sense of competence in being able to achieve and follow the instructions given. For many children, this was their first time in formal schooling. While the children had these feelings of accomplishment, I had an opportunity to observe them and analyse the findings against the interviews and discover patterns in the analysis. 
Refugee children interviewed experienced various forms and systems of education and learning. Some have never been to school; often the knowledge transferred from parents to children is both valued and limited, depending on the milieu and environment where children find themselves through forced migration. However, during migration parents may remain outside the activities of the school and often play little part in the educational activities of their children. Parent and child may be excluded through the foreign languages used in schools.

However, the crucial element needed to capture the learning experience of every refugee child is based on the conceptual framework of Refugeeism. This is explored through the 'illuminative approach' and the use of board games, which takes consideration of the environment and milieu-providing snapshots of the world of learning for Refugee children.

\section{References}

Bronfenbrenner, U. (1992), Ecological systems theory. In: R. Vasta, eds, Six theories of child development: Revised formulations and current issues, pp. 187-249. London: Jessica Kingsley Publishers.

Child, I.L. (1954), Socialization. In: G. Lindzey, ed., Handbook of Social Psychology, pp. 655692. Cambridge: Addison-Wesley.

Cohen, L., L. MAnion \& K. Morrison (2000), Research methods in education. London: Routledge Falmer.

Esterhuizen, L. (2004), Doing case studies for the refugee sector. A DIY handbook for agencies and practitioners. London: ICAR King's College London.

Green, S. \& D. Hogan (2005), Researching children's experience. Approaches and Methods. London: SAGE Publications.

Hamilton, D., D. Jenkins, C. King, B. MacDonald \& M. Parlett (1977), Beyond the numbers game a reader in educational evaluation. Houndmills Basingstoke: Macmillan Education LTD.

Judd, C.M., Smith, E.R. \& L.H. Kidder (1991), Research methods in social relations. Fort Worth: Harcourt Brace Jovanovich College Publishers.

Kahin, M. (1997), Educating Somali children in Britain. Stoke on Trent: Trentham Books Limited.

KLAbbers, J.H.G. (2006), The magic circle: Principles of gaming and simulation. Rotterdam: Sense Publishers.

Machel, G. (2001), The impact of war on children. London: C. Hurst \& Company Ltd.

MAYкut, P. \& R. MoRehouse (2000), Beginning qualitative research. A philosophical and practical guide. London: Routledge Falmer.

Miles, M. \& M. Huberman (1994), Qualitative data analysis. Thousand Oaks: SAGE Publications Inc.

Nachmias, C. \& D. Nachmias (1981), Research methods in the social sciences. New York: St. Martin's Press Inc.

This is a digital offprint for restricted use only | (c) 2011 Koninklijke Brill NV 
Parlett, M. \& G. Dearden (1977), Introduction to illuminative evaluation: Studies in higher education. Cardiff-by-the-Sea, California: Pacific Soundings Press.

Parlett, M. \& D. Hamilton (1977), Evaluation as illumination: A new approach to the study of innovatory programmes cited in Beyond the numbers game. London: Macmillan.

Polanyi, M. (1967), The tacit dimension. Chicago, IL: The University of Chicago.

Robson, C. (1999), Real world research. Oxford: Blackwell Publishers Ltd.

RutTer, J. (1994), Refugee children in the classroom. Stoke-on-Trent: Trentham Books Limited. -. (2006), Refugee children in the UK. Maidenhead: Open University Press.

Schwandt, T.A. (2001), Dictionary of qualitative inquiry. Thousand Oaks: Sage Publications Inc.

Segall, M.H., P.R. Dasen, J.W. Berry, \& Y.H. Poortinga (1990), Human behaviour in global perspective. An introduction to cross-cultural psychology. New York: Maxwell Macmillan Pergamon Publishing Corporation.

SoGuK, N. (1999), States and strangers: Refugees and displacements of statecraft. Minnesota: University of Minnesota Press.

Sugerman, D.A., K.L. Doherty, D. Garvey \& M.A. Gass (2000), Reflective learning: Theory and practice. Dubuque, Iowa: Kendall/Hunt.

Temple, B. \& R. Moran (2006), Doing research with refugees: Issues and guidelines. Bristol: The Policy Press.

UNHCR (1993), Information paper Geneva. March 1993. Geneva: UNHCR. 



\title{
Reconceptualising Child
}

Protection Interventions

\section{in Situations of Chronic Conflict: North Kivu, DRC}

\author{
Claudia Seymour
}

\section{Introduction}

The lives of young people in many parts of sub-Saharan Africa have been dramatically affected by the experience of violent conflict, with repeated displacement, threats to physical security and lack of access to even the most basic social services only some of conflict's immediate negative consequences. The focus on children and their experience of war was galvanised with the publication of a 1996 study led by Graça Machel on the impact of war on children. This study helped to provide renewed attention to children's experiences of conflict throughout the world, showing how children are especially vulnerable to the negative consequences of modern warfare. ${ }^{1}$ Concurrently, ongoing efforts to

${ }^{1}$ Research into children's experience of conflict is not new; as early as the Second World War, child psychologists conducted studies of how children cope with destruction and loss (Freud \& Burlingham 1943). 
institutionalise the concept of universal child rights were making progress; the Convention on the Rights of the Child (CRC) which had been adopted by the United Nations General Assembly in November 1989, was further strengthened by instruments such as the African Charter on the Rights and Welfare of the Child, ${ }^{2}$ the Optional Protocols to the CRC, ${ }^{3}$ and the International Labour Organisation Convention 182 against the worst forms of child labour 4 -each including provisions guarding against the exploitation and abuse of children living in situations of conflict.

In the two decades since then, significant amounts of political, financial and practical energy have been channelled towards the protection of children in war environments. A large number of actors now focus their efforts on protecting children in armed conflicts, including, inter-alia, the United Nations Children's Fund (UNICEF) and other offices of the United Nations, childfocused international non-governmental organisations, as well as national and local actors. What could be considered as an emergent international child protection regime-i.e. actors and actions buttressed by established international legal norms-the focus of these actors is to support national governments in fulfilling the basic protection needs of children. In situations of violent conflict, especially when the state has either collapsed or is not effectively functioning, these actors play a dominant role in supporting the provision of children's basic needs, including access to healthcare, hygiene and education. Beyond basic survival and development, these actors also respond to other protection concerns, including the use of children by armed groups, the sexual exploitation of girls, or children separated from their families or orphaned by war.

On the other side of practice is the burgeoning field of academic research into children's experiences of war. Two separate fields of literature have notably emerged, the first within the field of psychology, from which exten-

\footnotetext{
2 African Charter on the Rights and Welfare of the Child, OAU Doc. CAB/LEG/24.9/49 (1990), entered into force 29 November 1999.

${ }^{3}$ Optional Protocol to the Convention on the Rights of the Child on the involvement of children in armed conflict A/RES/54/263 May 2000.

${ }^{4}$ ILO Convention 182 of 1999: Convention concerning the Prohibition and Immediate Action for the Elimination of the Worst Forms of Child Labour.
} 
sive quantitative studies of children's experiences of violence and adversity have raised important discussions on vulnerability and resilience. Since the mid-1990s, such studies have been conducted in Palestine and Israel (Punamaki 1996; Garbarino \& Kostenly 1996), Northern Ireland (Cairns 1987; Muldoon 2004), South Africa (Dawes \& Donald 1994), and Uganda (Annan, Blattman \& Horton 2006), leading to further development of Western psychological concepts in non-Western contexts. Anthropologists have also dedicated attention to children's experiences of war, conducting in-depth ethnographies that have revealed new understandings of the ways in which children interpret and cope with adversity (Boyden \& de Berry 2004; Scheper-Hughes \& Sargent 1998; Whitehead 2004; Riches 1986; Leopold 2005). Both of these disciplines offer important insights for the field of child protection, but remain separate from each other, thus missing opportunities for cross-disciplinary learning and deeper knowledge of children's war experiences.

This chapter takes as its frame of reference child protection interventions in North Kivu, Democratic Republic of Congo (DRC), specifically as they relate to the recruitment and demobilisation of children associated with armed groups. It is hoped that, through an analysis of recurrent concerns for child protection, the chapter will impart more responsive and reflexive child protection interventions. The aim is to highlight some of the ways in which theoretical insights emerging from anthropological and psychological studies of children and war might positively contribute to improving the effectiveness of the current international child protection regime.

This chapter also emphasises the importance of taking an interdisciplinary approach to understanding children's war experiences. It examines how the quantitatively-backed psychological theory of resilience may be linked with qualitative anthropological themes such as identity and meaning. By linking these two usually disparate theoretical approaches, possible entry-points for a deeper, interdisciplinary exploration of childhood in Africa are highlighted. This chapter assumes a perspective in which children are considered to be agents actively engaged in their own experience of conflict, arguing for a broader appreciation of the contributions and insights children themselves can offer towards a better understanding and deeper analysis of armed conflict. 
The material covered in this chapter is part of a larger interdisciplinary doctoral research project on children's experiences of violent conflict. ${ }^{5}$ This research was initiated following several years of professional work as a child protection advisor in conflict-affected countries, ${ }^{6}$ experiences which raised two persisting questions. The first was more esoteric, an attempt to make some sense of how children find ways of coping with their daily lived experience of war, often in conditions of extreme suffering and hardship. The second question emerged from this practitioner's troubled knowledge that, despite the massive mobilisation of resources and generally good intentions of child protection actors to improve children's lives, the aims of child protection interventions are rarely achieved. The first question led to a body of research on psychological resilience and children's adaptation to adversity, as well as to ethnographic literature on children's lived experiences of war. The second question remains at the foundation of an ongoing personal critique of dominant child protection practices in conflict situations.

This chapter now turns to an overview of the child recruitment phenomenon in North Kivu, Democratic Republic of Congo (DRC) where the mobilisation of children by multiple armed groups has occured in all iterations of the war. This phenomenon is discussed in order to highlight how current approaches to child protection in conflict environments can be ill-adapted to realities on the ground. Qualitative understandings of the North Kivu conflict, and children's perceptions and roles in it, are needed. Such analyses must commence with an appreciation of the historic rootedness of the conflict and give attention to key concepts, such as meaning and identity, which are relevant to children's lived experiences.

\footnotetext{
${ }^{5}$ Doctoral research being conducted with the Department of Development Studies at the School of Oriental and African Studies, University of London.

${ }^{6}$ Serving with the United Nations Children's Fund in Liberia and the Central African Republic, and with the UN Department of Peacekeeping Operations in the Democratic Republic of Congo.
}

This is a digital offprint for restricted use only | (c) 2011 Koninklijke Brill NV 


\section{How the Child Protection Regime Addresses Child Recruitment in North Kivu}

The practice of using children has been systematic among most of the fighting forces in the DRC at least since 1996, at the start of the 'first war' to topple former president Mobutu Sese Seko. The emerging leader from that war, Laurent Kabila, was widely reputed for his mobilisation and use of 'kadogos' (Kiswahili word meaning 'little ones') in leading the march across then-Zaire and eventually taking control of Kinshasa. ${ }^{7}$ For purposes of definition, children who are considered to be associated with armed groups include "any person below 18 years of age who is or who has been recruited or used by an armed force or armed group in any capacity, including but not limited to children, boys and girls, used as fighters, cooks, porters, messengers, spies or for sexual purposes. It does not only refer to a child who is taking or has taken a direct part in hostilities." "Since the beginning of the 1996 war, child protection actors estimate that a total of 33,000 children served in the armed groups in the DRC. ${ }^{9}$ The first national disarmament, demobilisation and reintegration programme (DDR) for children was initiated in 1999, and since then an estimated 31,200 children have been formally demobilised by child protection actors. ${ }^{10}$ These figures tend to inspire a spectrum of responses ranging from outrage, to donor largesse to fascination with what armed children are capable of doing. ${ }^{11}$ Surprisingly, however, they do not tend to inspire reflection on why, after ten years of international child protection efforts to separate children from armed groups,

\footnotetext{
${ }^{7}$ For an in-depth analysis of the eastern DRC war, see Prunier, G. (2008) Africa's World War: Congo, the Rwandan Genocide, and the Making of a Continental Catastrophe.

${ }^{8}$ Paris Principles, http://www.un.org/children/conflict/_documents/parisprinciples /ParisPrinciples_EN.pdf (accessed 19 April 2009).

9 Figure quoted by UNICEF In Brief: DRC child recruitment a "tragic consequence" of war: http://www.reliefweb.int/rw/rwb.nsf/db9ooSID/ACIO-7VGD 3 G?Open Document (accessed 3 September 2009).

$10 \mathrm{http} / / /$ www.unicef.org/infobycountry/files/DRC_HAU_22_June_2009.pdf (accessed 6 September 2009).

${ }^{11}$ In the same press release quoted above, UNICEF's Executive Director on a recent visit to the DRC also portrays this sense of fascination, being quoted as saying a '14-year-old boy whose name translated from Swahili to Innocent, told me he was forced to commit acts of sexual violence against women", while another child interviewed "still believed that he was invincible against bullets, a common belief among the Mayi-Mayi traditional armed groups.'
}

This is a digital offprint for restricted use only | (c) 2011 Koninklijke Brill NV 
child recruitment remains such a significant phenomenon today. Assuming the genuine will of child protection actors and policy makers is to protect children's best interests, it can be argued that there is insufficient understanding of the child recruitment phenomenon in Eastern DRC.

There are many problems with the approach taken by child protection actors in addressing the recruitment of children, but one generalised critique is the lack of conceptualising child recruitment as a socio-economic, historic and cultural phenomenon. The child protection regime considers recruitment primarily as a violation of established child rights norms, a problem which can be addressed logistically and absolutely. The international child protection regime applies a universal definition of a child: Anyone under the age of 18. This normative framework holds that children cannot be associated with the armed forces, and thus anyone under the age of 18 should simply be removed from their ranks.

A brief summary of this approach to child recruitment could be provided; in generalised terms, the nationally conceived disarmament, demobilisation and reintegration (DDR) programme for children begins when a presumed child is identified among the ranks of an armed group. Upon identification, child protection actors negotiate with military commanders to try to gain access to the child and advocate for his or her eventual release. The presumed child is interviewed by age-verification agents, and if verified to be under the age of 18 , should be released by his or her commander and handed over to child protection actors.

This begins the demobilisation process, in which the child is taken either to a transit centre or placed with a host family. Children are closely supervised during this period, and are engaged in social and psychosocial activities, basic education, and recreation, with the aim of supporting their eventual re-adjustment to civilian life. This transition period should take approximately three months, though the period can be longer or shorter depending on the circumstances. For example, if the situation remains insecure in the child's home community, it may be considered safer for the child to stay in the centre longer; if there is insufficient transitional care capacity, the child may be returned home much sooner.

During the transitional demobilisation period, child protection agents undertake family tracing, a process which involves consultation with the family to 
prepare for their child's return. A child protection agent then accompanies the child back home where, ideally, he or she is welcomed back by their family and community. The child is given a reunification kit which includes little more than a few material goods such as soap and a new set of clothing. The child also receives an attestation de sortie, or a certificate issued by the government serving as proof of formal demobilisation; this piece of paper is meant to protect the child from any future threats, accusations or attempts at re-recruitment. In ideal circumstances, the child then begins reintegration activities, which could be formal education, vocational skills training, or an income generation project. The child should continue to receive periodic visits from the child protection agent to support his or her transition back home; the follow-up visits should become less frequent, until the child is fully reintegrated back in his or her family and community.

This outline is overly simplified, but it does provide the general framework for children's DDR programming in the DRC today. Any child protection practitioner would confirm that the practice of children's DDR is enormously more complicated. Firstly, it is often difficult to separate children from their commanders; despite years of concerted advocacy and sensitisation efforts to stop military elements from using children, children are often still considered to be military assets. In North Kivu, government army officers and other rebel leaders are virtually all aware that it is against Congolese and international law to recruit or use anyone in their forces under the age of eighteen. ${ }^{12}$ However, in a continuing conflict where additional elements can provide increased power both on the front lines and at the negotiating table, upsurges in child recruitment in North Kivu continue to be seen during periods of heavy fighting and at the beginning of peace negotiations. For the government forces, children also represent potential financial gain, as a portion of each soldier's monthly

12 The Government of the DRC has signed and ratified the Convention on the Rights of the Child and its Optional Protocols (including the protocol against the use and recruitment of children), the African Charter on the Rights and Welfare of Children, the International Labour Organisation law Number 182 against the worst forms of child labour, and the Rome Statute of the International Criminal court. In January 2009 a national Child Protection Code was passed, specifically outlawing the use and recruitment of anyone under the age of eighteen. It should also be noted that the ICC's first prosecution of the Congolese former warlord Thomas Lubanga is for crimes against humanity including the forced conscription of children.

This is a digital offprint for restricted use only | (c) 2011 Koninklijke Brill NV 
salary is usually siphoned off by those along the chain of command. As will be discussed in more detail below, various rebel commanders would consider notions of identity and community responsibility to be sufficient justification for the continued use of children. When interviewed, military commanders also listed the loyalty offered by children, the ease with which they follow orders, their bravery on the front lines, and their lack of family responsibilities as reasons for their strategic battle utility. ${ }^{13}$ These motivations are further facilitated by the pervasive impunity that known recruiters of children continue to enjoy in the DRC. ${ }^{14}$

Once children are released from armed groups, problems during the demobilisation period and reintegration period are common. For example, transitional care is usually provided in urban centres, far away from the child's community of origin. As will be discussed below, sensitivities relating to identity are particularly relevant to the conflict in North Kivu, and yet at the centres, few adaptations are made to address these often explosive issues. For example, children of one identity group who would have been associated with an identity-based military movement may be placed in a centre where he or she will feel ostracised, or where social workers do not even speak their language. The tendency of child protection actors to disregard these issues obscures the realities of children's lived experiences in North Kivu.

A much longer critique could be offered on the failures of what the child protection regime terms the 'reintegration' of demobilised children. In briefand given the context of poverty, the absence of basic services such as education, as well as the chronic condition of insecurity-the predominant approach to children's reintegration is ill-suited to the realities of North Kivu. When it is actually provided, the focus on short-term assistance to individual children tends to ignore the root socio-economic causes of recruitment and the broader importance of family and community-based support. As the conflict continues in North Kivu, re-recruitment of children who have already passed through the DDR programme is common.

\footnotetext{
${ }^{13}$ Based on discussions held by author with former army and rebel commanders in 2009.

${ }_{14}$ The continued presence of General Bosco Ntaganda, indicted by the ICC for child recruitment, in the DRC's national armed forces is only one of many possible cases in point.
} 


\section{Qualitative Approaches to Understanding Child Recruitment}

Much deeper appreciation of the complexity and historical rootedness of North Kivu's conflict is required, and could be approached through the qualitative exploration of themes typically dealt with in anthropological literature, such as meaning and identity. In North Kivu, the interlinking themes of history and identity require careful exploration if there is to be hope of understanding chronic iterations of violence and children's experiences of it. One analytical perspective would consider the proprietary contestation for North Kivu's land, its massive natural resource wealth and the historic manipulation of these material contests into conflicts over identity. Late nineteenth century accounts document the first waves of violence and migration in the Kivu region as people moved from what was then the Kingdom of Rwanda to what is now the province of North Kivu (Mamdani 2001). Between the 1920 s and 1950s, tens of thousands of Rwandans were forcibly displaced into the Congo in order to relieve the pressures of drought and scarcity, or to work the fertile North Kivu land. The 'native' and 'non-native' dichotomy imposed by the colonial administration became a legacy of the conflict, as the displaced Rwandan civilians were formally labelled as non-native and thus prevented from gaining legal access to land; moreover, they were refused political representation. This marginalising treatment, which transformed conceptions of identity and belonging among both 'native' and 'non-native', lies at the root of the current conflict discourse in North Kivu.

In the late 1950 s and early 1960s, regional conflicts in Burundi and Rwanda led to massive refugee flows into eastern Congo, contributing further to identity-based conceptions of belonging and exclusion. The foundations of “ethnic self-consciousness" (Pottier 2002, 112) became increasingly entrenched during the DRC's process of democratisation in the early 1990s, with the politics of exclusion eventually leading to ethnically-based massacres in 1993 (Jackson 2007). The 1994 Rwandan genocide and its massive population flows into eastern DRC further polarised the identity-based conflict, leading to the wars between 1996-2003 (Prunier 2008), the vestiges of which continue to be fought in North Kivu today.

This is a digital offprint for restricted use only | (c) 2011 Koninklijke Brill NV 
This play of history is transferred across generations, as evidenced in discussions with children who had been associated with identity-based military groups in North Kivu. When asked about why they joined one group or another, some of the children would respond that it was to avenge the killing of their father, or of another family member, thus assuming their role in the next generation of North Kivu's conflict. ${ }^{15}$ As seen in other contexts of violent conflict, socially-transferred memories can play a key role in perpetuating violence (Malkki 1995). As social memories become "institutionalized and transmitted across generations, children's perceptions are important. These memories in turn contribute to conflict's intractability, resulting in a self-perpetuating cycle. Ultimately such social memories fill determinative roles in the formation of 'cultures of violence'” (Cairns \& Roe 2003, 7). In North Kivu, historic injuries continue to reinforce distrust and lead to new mobilisations of violence against perceived future threats.

It is important to consider that anyone 16 years of age or younger in North Kivu has only ever known a situation of violent conflict, if one considers the pogroms of 1993 as the starting point for the current North Kivu conflict. One 17-year-old who had been repeatedly recruited to North Kivu's armed forces asked, rhetorically: "this conflict, will it really ever end?"16 In a reality of "quotidian war, war as an everyday possibility" (Appadurai 2006, 31), children's perspectives of violence are salient bases for any prospective for eventual peace.

A brief mention of methodological issues should be made, particularly as children are the main interlocutors in these discussions. Standard practice on appropriate interviewing techniques with children always needs to be applied, ${ }^{17}$ while knowledge of the historical, political, social and cultural nuances relevant in North Kivu is important prior to convening discussions. Researchers must practice utmost sensitivity when engaging in discussions with children related to the often difficult subject-matter of war and violence. For example, in Eastern DRC it would be considered extremely inappropriate for a girl to discuss

\footnotetext{
15 Interviews with boys in Goma in 2007 and 2009.

1617 year old boy interviewed in a Goma DDR transit centre, February 2009.

17 For example, see Guidelines for interviewing children. Save the Children UK. www.savethechildren.org.uk/en/docs/guidelines_interview_children.pdf (accessed 18 May 2009).
} 
any sexual experience except with those closest to her; girls used by soldiers or officers as sexual slaves would thus rarely make mention of their experiences whilst enrolled in the armed forces. ${ }^{18}$ To overcome this methodological obstacle, interviews and discussions elaborated in this chapter were always conducted with the help of social workers known and accepted by the children; interviews with child informants occurred either one-on-one or as part of a group discussion among several children, in the language most comfortable to the child.

Despite the best efforts on part of the researchers, the dilemma of working with children on such sensitive topics remains relevant, especially within the context of ongoing conflict and when such discussions themselves could contribute to further contestation. However, these sensitivities should not preclude children's participation in such research; indeed, this chapter urges for greater involvement of children in conflict research. Their insights into and interpretations of the 'meanings in use' (Finnstrom 2005) of violence offer new understandings of the conflict in North Kivu, contributing more generally to the conflict analysis literature. For example, non-Kinyarwandan speaking children would often state that they consider members of the Tutsi ethnic group to be their biggest threat. They would suggest that Tutsi people were sent to the DRC by Rwanda in order to lead Rwanda's eventual occupation of Eastern DRC, echoing the historic roots of the conflict mentioned above. On the other side of the identity discourse, Tutsi children interviewed stated that they were fighting on behalf of their community, a community depicted by political and military leaders as a marginalised minority fighting to protect themselves and the 40,000 Congolese Tutsi refugees who have been living in camps in Rwanda since the early 1990s. These opposing sentiments form a common discourse of distrust in North Kivu, used at the convenience of political leaders who do little to move the public beyond these polemics. Identity politics have often been militarised in North Kivu the most recent manifestation placed the Congrès National pour la Défense du Peuple (CNDP), national government forces and various Mayi-mayi militia in shifting opposition to each other. Negotiations

\footnotetext{
${ }^{18}$ Beth Verhey (2004), Reaching the Girls: A study on girls associated with armed forces and groups in the Democratic Republic of Congo. London: Save the Children UK.
}

This is a digital offprint for restricted use only | (c) 2011 Koninklijke Brill NV 
in 2008 eventually led to the 2009 integration of the CNDP and Mayi-mayi groups into the national Congolese army. Both the CNDP and Mayi-mayi groups recruited large numbers of children to their ranks, and current DDR efforts are focused on the separation of children from what is now the national army. As argued above, the DDR approach currently taken by child protection actors is unlikely to lead to sustainable success in keeping children out of the armed groups should violence re-erupt. Instead of continuing the logistical operations of getting children out of the armed forces, child protection actors need to focus on understanding why it is that children were first recruited. For example, the recruitment methods for the CNDP and the Mayi-mayi are often vastly different, rooted in different historic and socio-cultural perspectives.

\section{Voluntary Recruitment to the CNDP}

Between 2006-2008, the CNDP systematically recruited children into its forces, with multiple reported cases of violent attacks on children in their schools and communities. ${ }^{19}$ Some children, however, primarily those of Tutsi identity, joined the CNDP voluntarily, or were sent by their families to fulfil their perceived social, cultural and political responsibilities. The problem of conceiving volition and choice in a context of conflict will be discussed further below, but these 'voluntary' recruits reported a very different experience from those who would have been forcibly recruited. When interviewed, these children stated that they tended to be better cared for by their commanders, and generally believed in the cause for which they were fighting.

The ill-adaptability of the child protection response for a child who would have voluntarily joined the CNDP became evident to me when I was working as a child protection advisor in North Kivu in 2007. At that time, there had been another peace agreement (that would subsequently fail) in which the CNDP forces were being integrated into the national army. My job at that time was to ensure the separation of all children present in the newly integrated army and to facilitate their entry into the national DDR programme for children.

\footnotetext{
19 Based on interviews with children conducted during my time as a UN DPKO Child Protection Advisor in Goma, 2006-2007.
}

This is a digital offprint for restricted use only | ( 2011 Koninklijke Brill NV 
There were many examples to chose from, but one case in particular stands out in my memory: It was of a 17-year-old Tutsi boy who volunteered to serve in the CNDP after his parents had been killed by an element of a Hutu militia active in his region. Having served as the escort to his commander for several years, all of his basic needs had been provided for. He believed he was fighting on behalf of his people and in the memory of his parents. During a screening of CNDP troops, he was identified by child protection age-verification agents as a child, and following an age-verification interview was confirmed to be approximately 17 years old. Brandishing the laws criminalising the use of children and with loud denunciation capacities, I advocated strongly for the child's release. Afraid of a possible, eventual sanction by the International Criminal Court in The Hague-at that time beginning its first pre-trial hearings of the formal Congolese warlord Thomas Lubanga ${ }^{20}$-the CNDP commander agreed to release the child.

Convincing the commander turned out to be the lesser challenge; it was the child who insisted that he not be separated. Despite my efforts to describe all the potential benefits of the children's DDR and the possibilities of a future with schooling and skills-training, he refused. Unfortunately for him-because he was considered to be a child, and because I represented the force of the international child protection regime-we proceeded with his separation despite his protestations and clear desire to remain with his commander. It was when he realised that he no longer had a choice in the matter that this 17-yearold, in his sharp military fatigues and in front of several officers, international actors and other children, succumbed to the culturally and socially impossible: He began to cry. Moments after this difficult moment ended, he was put in a United Nations vehicle with the other children separated that day and driven to Goma, the provincial capital, a place where he had never before visited. He was then placed in the transit care centre, where he would have begun the demobilisation process described above. However, at the centre he found it difficult to adapt; within a few days, he ran away, not to be heard from again.

\footnotetext{
${ }^{20}$ See the website of the International Criminal Court: http://www.icc-cpi.int/NR/exeres/ E10A622B-3115-4Co5-B8A2-EA83DC2827D8.htm (accessed 20 September 2009).
}

This is a digital offprint for restricted use only | (c) 2011 Koninklijke Brill NV 


\section{Voluntary Recruitment to the Mayi-Mayi Groups}

On the other side of the North Kivu battle lines are the children who voluntarily join the Mayi-mayi forces. Mayi-mayi militia groups in the DRC have historically mobilised to protect their communities from outside aggression. As community-based movements, Mayi-mayi groups are usually mono-ethnic and mono-lingual. Considering the dialectic absence of and predation by the state in many parts of the DRC, as well as the continued presence of foreign armed groups in the mineral-rich border provinces of the Kivus, the presence of Mayi-mayi forces are often locally appreciated as a necessary force for communal self-defence. Men are often mobilised to protect their community's interests; this mobilisation would include adolescent boys who are socially and culturally considered to be of an appropriate age to support the armed defence of their community.

During the same child protection DDR work mentioned in the section above, I would also conduct active advocacy efforts to separate children from the Mayi-mayi groups. I found that it was generally easier to secure the release of children from Mayi-mayi commanders, who tended to be more accepting of the idea of their children travelling to Goma to benefit from demobilisation and eventually reintegration programmes. The difficulty with DDR for children from Mayi-mayi groups would be that once they were reunited with their families in their home communities, they would eventually remobilise. ${ }^{21}$ Coupling the continuing violence in North Kivu with young people's social responsibilities, it was often considered appropriate for children to be a part of the local Mayi-mayi force.

When interviewed, children separated from the Mayi-mayi groups would state that it was under the influence of their friends or older family members that they decided to join. They fought to defend their identity, territory and community. Interviews conducted with three sixteen-year-old boys who had been separated from Mayi-mayi groups in July, 2009 revealed their conviction to protect what they considered as their communal interests. One child claimed to have joined in order "to defend my territory from being invaded by those

\footnotetext{
${ }^{21}$ This tendency towards remobilisation is facilitated by the above-mentioned weaknesses of the existing 'reintegration' programmes promised by child protection actors.
}

This is a digital offprint for restricted use only | (c) 2011 Koninklijke Brill NV 
unknown", "to fight on behalf of my ethnic group," and to "liberate my country from the influence of Rwanda."

\section{Disparate Experiences of Recruitment}

Given the disparate recruitment experiences of these children, it is strikingly clear that any generic approach to DDR will not work. As seen above, some children join voluntarily for socio-cultural reasons, others for practical reasons of survival, while still others have been taken by force. In North Kivu, a child used as a cook experiences a different side of the war than a child deployed on the front lines; similarly, a girl will usually be used differently than a boy. Ages of recruitment also vary considerably, and it can be expected that a 12 year old will interpret his/her experiences differently than a 17 year old. Despite the vast array of possible experiences of children in war, child protection actors continue to implement standardised, generic programming.

The top-down approach to separating children from armed groups is often ineffective, as seen in the case of the Mayi-mayi children who would likely be rerecruited as soon as they returned home. As it was in the case described above (the child who did not want to be separated from his CNDP commander-the one father figure he had following the death of his parents) the forced separation of some children by child protection actors may be potentially damaging in the long-term, particularly if approaches are not effectively adapted to the context and to children's actual needs. Focus on the fixed construct of age-18 years old as enshrined in Article 1 of the Convention on the Rights of the Child-ignores disparate understandings and interpretations of childhood over time and geographical space (Ariès 1962), ${ }^{22}$ while it also fails to acknowledge children's historic involvement in wars throughout the world (Rosen 2005). Instead, by considering childhood to be the socially constructed and negotiated concept it is (Prout \& James 1990), child protection interventions might become more appropriately adapted to local contexts. These examples also show that

${ }^{22}$ Ariès' historical review shows that the concept of childhood only emerged in Europe with the Industrial Revolution and its consequent differentiations in economic and social structures. Children came to be seen as needing protection, nurturing and preparation for adulthood through longer periods of formal education.

This is a digital offprint for restricted use only | ( 2011 Koninklijke Brill NV 
having nuanced appreciations of the underlying historical and socio-economic factors that shape processes of identity formation and cultural understandings of conflict are necessary in order to better analyse why young people may be motivated to join armed groups.

\section{Agency and Resilience of Children}

Children's perceived 'vulnerability' to violence remains a common theme within the child protection discourse, a justification perhaps for its own existence. Child protection interventions tend to focus on specific categories of 'vulnerable' children, including 'victims' of abuse, such as children recruited to the fighting forces, children living in the streets, sex workers or orphans. These categories are usually attributed to children without considering the unique circumstances which may have led to each child's position of 'vulnerability.' The resulting portrayal of the 'generic child' (Mann 2004) obscures the deeper complexities and unique experiences of each child. What might instead be considered is that outward expressions of vulnerability, such as recruitment or another form of perceived exploitation, may actually be the child's best means of protecting him or herself.

Contrary to the dominant child protection assumption of vulnerability, children are resourceful and develop the necessary competencies to deal with their environment, "interpreting the world around them, making choices, defining their own roles and identities, managing crises, reaching decisions and working collaboratively with others" (Boyden 2000). In the DRC as in much of sub-Saharan Africa, children from a young age assume important individual and familial responsibilities, contributing in important ways to the running of the household and to the rearing of younger siblings. In a war environment, survival takes on new dimensions, and children are also expected to adapt; in North Kivu's zones of active conflict, this means learning how to engage with conflict dynamics.

Data collected from a limited sample of children recently separated from armed groups in North Kivu show that a significant proportion of children who joined the fighting forces did so voluntarily. Of a sample of recruitment 
cases, almost half were reported to be voluntarily recruited. ${ }^{23}$ Voluntary mobilisation of this kind is one "expression of young people's determination to survive against considerable odds in a setting where adults have failed in their duty to protect" (Hart 2008, 278).

Because notions of 'voluntary' are questionable in the adverse circumstances of protracted conflict, it would be more useful to think in terms of rationaldecision making processes. Young people often engage in violence for rational reasons when alternatives are scarce and survival is at stake (Richards 1996). Some children's choices for joining the armed groups were linked to survival, following the destruction of their village or the death of their parents. Many children who joined armed groups in North Kivu stated that it was their inability to pay school fees which led to them joining the armed group..$^{24}$ A general lack of socio-economic alternatives served as a practical motivation for a large number of these children-children who had learnt through their own experience that looting and pillage may be the most certain way to earn a livelihood in North Kivu.

Often choices that children may have to make in conflict contexts can only be chosen from a series of harsh possibilities. For example, a 15 year old spoke about her choice to join one of the Mayi-mayi groups in North Kivu. When the battlefront reached her village, she knew already at least one of the likely outcomes, and reported: "I knew I would be raped by soldiers on both sides, so I decided to join one voluntarily hoping that I'd be raped less." Knowing her context, she made a rational decision based on the alternatives available to her. ${ }^{25}$

Psychological resilience theory may provide useful insights into how children engage with the complexities of North Kivu's war. As early as the Second World War, child psychologists conducted studies which explored how children cope with destruction and loss (Freud \& Burlingham 1943). In the following decades, research addressing children's capacity to cope with stressful

${ }^{23}$ The empirical data upon which this analysis is made emerges from work by the author within the mandate of the United Nations Security Council Resolution 1857 (2008) arms embargo.

${ }^{24}$ Interviews conducted in Goma, February-July 2009.

${ }^{25}$ Interviewed in Goma, February 2009.

This is a digital offprint for restricted use only | ( 2011 Koninklijke Brill NV 
life events, such as death, mental illness or alcoholism in parents (Haggerty et al. 1994) emerged. Studies of how children grow up within conditions of economic adversity (Elder 1974) led to the evolution of concepts such as 'invulnerability' (Anthony 1974) and 'resilience' (Rutter 1990; Garmezy 1985). Despite being characterized by conditions of risk that would otherwise lead to psychopathology or other serious secondary effects, 'psychological resilience' may be understood as a dynamic process of adjustment that produces relatively good outcomes (Rutter 2007). Although primarily quantitative and premised upon Western-based understandings of psychological development, resilience theory can provide insightful avenues of exploration towards understanding how children cope with adversity.

Adapting the theory to conflict situations, resilience could be considered as the capacity to cope with an insecure and violent situation without significantly adverse effects on child development. For example, a primary assertion of resilience theory is that children's capacity to cope is neither a static nor an individual trait, but a process of adaptation that occurs over time and varies depending on the situation (Luthar 1991). As a process, variations in resilience are related to and impact upon previous and subsequent experiences, with the possibility of risk accumulation having an impact on children's coping capacities (Rutter 1999). Children who experience multiple risks-including chronic poverty, parents with little formal education, and disorganised family environments-may either become more vulnerable (Werner \& Smith 1992) or, conversely, experience 'steeling' effects which help to strengthen their capacity to cope (Rutter 2007).

Resilience theory also emphasises the importance of social support in strengthening children's coping mechanisms. Local family and social networks are considered necessary in creating the foundations upon which children are able to explore and test the world around them (Rutter \& Madge 1976). The family environment provides moral guidance for the child, while encouragement and discipline set the guidelines for appropriate behaviour (Bandura 1977). Resilience is considered to be reinforced by external support provided to the child by the community (Garmezy 1985), while social belonging can help children learn how to cope with situations of adversity. Social frameworks help children understand the experience of violence and adapt appropriately. 
Depending on the circumstances, ascribing meaning to conflict and violence can either be a protective factor or it can increase a child's vulnerability. Some studies have shown that resilience is strengthened when children feel a sense of coherence and predictability between their internal and external environments (Werner \& Smith 1992); however, in conflict realities, predictability can rarely be assumed. As described in the anthropological literature on meanings and interpretations of violence, “...violent scripts are uncertain and ambiguous, subject to the poesis of individual actors-a roadblock passed without trouble in the morning may become the scene of killing in the afternoon" (Whitehead, 2004,15). Despite these external uncertainties, researchers have shown that children are still able to establish understandings of the self, society and their interrelationship, even in a context of pervasive insecurity (Ager 1996). This cognitive appraisal of events is an important coping mechanism for children (Lazarus \& Launier 1978), especially if their ability to derive meaning from the situation can help them deal with insecurity and violence.

Initial studies on the impact of violent conflict and situations of chronic danger on children were based on the trope of vulnerability; in short, earlier work hypothesised that experience of conflict leads to significantly negative impacts on children (Garbarino, Kostelny \& Dubrow 1991). Theorists assumed that "repeated and chronic stresses may lead to anger, despair, and severe psychic numbing...Permanent developmental damage is more likely to occur when multiple risks are present in a child's environment and when stressful settings endure as a feature of the child's life" (Garbarino \& Kostelny 1996, 33-34). Others posited that children "exposed to ethnic and political violence are more likely to develop a variety of difficulties, including mental health disorders, behavior problems, sleep disturbances, somatic complaints, and altered levels of cognitive functioning and moral reasoning" (Ladd and Cairns 1996, 14).

However, when theories of trauma and vulnerability were tested empirically in places such as Palestine and Israel (Punamaki 1996), Northern Ireland (Muldoon 2004), and South Africa (Dawes \& Donald 1994) the emerging results were contrary to expectations. These studies showed that children were not only far from traumatised, they were also generally able to adapt to and cope with the daily risks and adversities of conflict. Only a small minority of children growing up during war were found to express any form of mental pathology (Killian 2002) or long-term emotional reactions (Dawes and Donald 1994). 
As shown by resilience studies, most children are resourceful and develop the necessary competencies to interpret and deal with their world. While it should be noted that some children do experience negative developmental, emotional and mental effects as a consequence of their war experience-usually termed as 'trauma' in the psychological literature-the majority of children are able to cope with their experiences, effectively negotiating their roles and making decisions on how they choose to engage with their world (Boyden 2000).

\section{Way Forward}

The need for new approaches to child protection in situations of violent conflict is clear. As shown in this chapter, understanding the historic, cultural and socio-economic context of violent conflict is the essential starting point for any child protection actor hoping to improve the lives of children living through war. As described above, children's experiences of conflict are deeply nuanced, and cannot be classified into generic, Western-based notions of violence or childhood. The themes of identity and 'meaning-giving', in particular, remain under-explored by researchers, and would likely contribute new and important insights both to resilience studies and conflict analysis.

The academic literature currently available in the fields of anthropology and psychology provides rich material for child protection practitioners. This literature is also important for understanding how children cope with war and adversity, providing greater emphasis on qualitative, culturally-appropriate methodologies. For example, constructivist conceptions of childhood favoured by anthropologists would be more relevant to the realities of the DRC, while the rich ethnographic literature on children's war experiences would provide the necessary nuance currently missing from child protection interventions. At the same time, psychological research on resilience and coping has expanded beyond its Western origins, and is finding useful applications within conflict zones in other parts of the world.

The international child protection regime should now prioritise learning from these theoretical and methodological advances. Continuing attempts to simplify interventions in situations of conflict do not help children if the 
root causes and contextual realities are not considered. The tendency for child protection actors to adhere strictly to the children's rights discourse is usually contrary to children's lived realities, where often even basic rights such as education or adequate health care are far from being realised. This is especially the case in a context like the DRC, where the State and justice system are functionally limited.

More reflection is needed on the inherent contradictions of the international rights framework, particularly in a situation of active conflict. Advancing the notion of 'inalienable rights' when such rights are systematically denied is strikingly incongruous, and the negative impact of learnt distrust from unrealised promises should not be overlooked. When more emphasis is placed on understanding children's lived experiences of the war, child protection actors might be more effective in helping children deal with the complexities of growing up amidst chronic, violent conflict.

\section{References}

AFRICAN UNION (1990), African charter on the rights and welfare of the child. OAU Doc. CAB/ LEG/24.9/49. URL: http://www.africa-union.org/official_documents/Treaties_\%2oConventions_\%2oProtocols/A.\%20C.\%2oON\%2oTHE\%2oRIGHT\%2oAND\%2oWELF\%20OF\%20 CHILD.pdf (accessed 2 February 2010).

Ager, A. (1996), Children, war, and psychological intervention. In: S.C. Carr \& J.F. Schumaker, eds, Psychology and the developing world, pp. 162-172. Westport, Connecticut: Praeger.

Allen, T. \& J. Seaton (1999), Perceiving contemporary wars. In: T. Allen \& J. Seaton, eds, The media of conflict: War reporting and representations of ethnic violence, pp. 11-42. London: Zed Books.

ANDERSON, B. (1983), Imagined communities: Reflections on the origin and spread of nationalism. London: Verso. (Revised edition 2006).

Appadurai, A. (2006), Fear of small numbers: An essay on the geography of anger. Durham: Duke University Press.

ARIÈs, P. (1962), Centuries of childhood: A social history of family life. New York: Vintage Books.

Bandura, A. (1977), Social learning theory. London: Prentice-Hall.

- (2001), Social cognitive theory: An agentic perspective. Annual Review of Psychology 52: $1-26$.

Boyden, J. (1990), Childhood and the policy makers: A comparative perspective on the globalization of childhood. In: A. James \& A. Prout, eds. Constructing and reconstructing childhood: Contemporary issues in the sociological study of childhood, pp. 184-215. London: The Falmer Press.

Boyden, J. (2000), Children and social healing. In: L. Carlson, M. Mackeson-Sandbach \& T. Allen, eds, Children in extreme situations. Proceedings from the 1998 Alistar Berkley Memorial Lecture, DESTIN working paper No o0-005. London: London School of Economics. 
Boyden, J., \& DE Berry, J. (2004), Introduction. In: J. Boyden \& J. de Berry, eds, Children and youth on the front Line: Ethnography, armed conflict and displacement, pp. xi-xxvii. Oxford: Berghahn Books.

CAIRns, E. \& M. RoE, EDS, (2003), The role of memory in ethnic conflict. Hampshire, UK: Palgrave Macmillan Ltd.

Chatтy, D., \& G.L. Hunt, EDS, (2005), Children of Palestine: Experiencing forced migration in the Middle East. New York: Berghahn Books.

Dawes, A. (1990), The effects of political violence on children: A consideration of South African and related studies. International Journal of Psychology 25(1): 13-31.

Dawes, A., \& D. Donald, Eds, (1994), Childhood \& adversity: Psychological perspectives from South African research. Cape Town: David Philip Publishers.

ELDER, G.H.J. (1974), Children of the great depression: Social change in life experience. Chicago: University of Chicago Press.

Finnstrom, S. (2005), 'For God \& My Life': War \& cosmology in Northern Uganda. In: P. Richards, ed., No war no peace: An anthropology of contemporary armed conflicts, pp. 98-116. Oxford: James Currey.

Freud, A. \& D. Burlingham (1943), War and children: Medical War Books.

Garbarino, J. \& K. Kostelny (1996), The effects of political violence on Palestinian children's behavior problems: A risk accumulation model. Child Development 67(1): 33-45.

Haggerty, R.J., L.R. Sherrod, N. Garmezy \& M. Rutter, EDS, (1994), Stress, risk, and resilience in children and adolescents: Processes, mechanisms, and interventions. Cambridge: Cambridge University Press.

HART, J. (2008), Displaced children's participation in political violence: Towards greater understanding of mobilization. Conflict, Security \& Development 8: 277-293.

Ladd, G.W. \& E. CaIrns (1996), Children: Ethnic and political violence. Child Development 67(1): 14-18.

Lazarus, R.S. \& R. Launier (1978), Stress-related transactions between person and environment. In: L.A. Pervin \& M. Lewis, eds, Perspectives in interactional psychology, pp. 287-327. New York: Plenum Press.

LEOPOLD, M. (2005), Review article: Violence in contemporary Africa reassessed. African Affairs 104/417: 685-695.

Luthar, S.S. (1991), Vulnerability and resilience: A study of high-risk adolescents. Child Development 62(3): 600-616.

MACHel, G. (1996), Impact of armed conflict on children. United Nations report A/51/306. URL: http://www.un.org/children/conflict/english/machel-reports.html.

Malkki, L.H. (1995), Purity and exile: Violence, memory, and national cosmology among Hutu refugees in Tanzania. Chicago: University of Chicago Press.

MAMDANI, M. (2001), When victims become killers: Colonialism, nativism, and the genocide in Rwanda. USA: Princeton University Press.

ManN, G. (2004), Separated children: Care and support in context. In: J. Boyden \& J. de Berry, eds, Children and youth on the front line: Ethnography, armed conflict and displacement, pp. 3-22. Oxford: Berghahn Books.

Muldoon, O.T. (2004), Children of the troubles: The impact of political violence in Northern Ireland. Journal of Social Issues 6o(3): 453-468.

Muldoon, O.T., K. Trew \& R. Kilpatrick (2000), The legacy of the troubles on the development of young people. Youth and Society 32(1): 6-28.

Nordstrom, C. (1997), A different kind of war story. Philadelphia: University of Pennsylvania Press.

The Paris Principles (2007), URL: http://www.un.org/children/conflict/_documents/ parisprinciples/ParisPrinciples_EN.pdf.

Pottier, J. (2002), Re-imagining Rwanda: Conflict, survival and disinformation in the late twentieth century. Cambridge: Cambridge University Press. 
- (2003), Modern information warfare versus empirical knowledge: Framing 'the crisis' in Eastern Zaire, 1996. In: J. Pottier, A. Bicker \& P. Sillitoe, eds, Negotiating local knowledge: Power and identity in development, pp. 215-240. London: Pluto Press.

Prout, A. \& A. James (1990), A new paradigm for the sociology of childhood? Provenance, promise and problems. In: A. Prout \& A. James, eds, Constructing and reconstructing childhood: Contemporary issues in the sociological study of childhood, pp. 7-34. London: The Falmer Press.

Prunier, G. (2008), Africa's world war: Congo, the Rwandan genocide, and the making of a continental catastrophe. Oxford: Oxford University Press.

PunAmaki, R.L. (1996), Can ideological commitment protect children's psychosocial well-being in situations of political violence? Child Development 67(1): 55-69.

Richards, P. (2005), New war: An ethnographic approach. In: P. Richards, ed., No peace no war: An anthropology of contemporary armed conflicts, pp. 1-21. Oxford: James Currey.

Riches, D. (1986), The phenomenon of violence. In: D. Riches, ed., The anthropology of violence, pp. 1-27. Oxford: Basil Blackwell Ltd.

Rosen, D.M. (2005), Armies of the young: Child soldiers in war and terrorism. Piscataway, N.J.: Rutgers University Press.

Rutter, M. (1990), Psychosocial resilience and protective mechanisms. In: J. Rolf, A. Masten, D. Cicchetti, K. Nuechterlein \& S. Weintraub, eds, Risk and protective factors in the development of psychopathology, pp. 181-214. New York: Cambridge University Press.

- (1999), Resilience concepts and findings: Implications for family therapy. Journal of Family Therapy 21: 119-144.

- (2000), Resilience reconsidered: Conceptual considerations, empirical findings, and policy implications. In: J.P. Shonkoff \& S.J. Meisels, eds, Handbook of early childhood intervention, pp. 651-682. Cambridge: Cambridge University Press. Second edition.

- (2007), Resilience, competence, and coping. Child Abuse \& Neglect 31: 205-209.

Rutter, M. \& N. Madge (1976), Cycles of disadvantage: A review of research. London: Heinemann.

Rutter, M. \& D. Quinton (1984), Parental psychiatric disorder: Effects on children. Psychological Medicine 14: 853-880.

Scheper-Hughes, N. \& P. Bourgois (2004), Introduction: Making sense of violence. In: N. Scheper-Hughes \& P. Bourgois, eds, Violence in war and peace: An anthology, pp. 1-32. Oxford: Blackwell Publishing Ltd.

Scheper-Hughes, N. \& C. SARgent (1998), Introduction: The cultural politics of childhood. In: N. Scheper-Hughes \& C. Sargent, eds, Small wars: The cultural politics of childhood, pp. 1-33. Berkeley: University of California Press.

United Nations (1989), Convention on the Rights of the Child. URL: http://www.unhchr.ch/ $\mathrm{html} / \mathrm{menu}_{3} / \mathrm{b} / \mathrm{k} 2 \mathrm{crc} . \mathrm{htm}$.

- (2000), Optional protocol to the Convention on the Rights of the Child on the involvement of children in armed conflict. A/RES/54/263. URL: http://www2.ohchr.org/english/law/ crc-conflict.htm.

United Nations ILO Convention 182 (1999), Convention concerning the prohibition and immediate action for the elimination of the worst forms of child labour. URL: http://www.ilo .org/ilolex/cgi-lex/convde.pl?C182.

VERHEY, B. (2004), Reaching the girls: A study on girls associated with armed forces and groups in the Democratic Republic of Congo. London: Save the Children UK.

WERNER, E. \& R. SMITH (1992), Overcoming the odds: High risk children from birth to adulthood. Ithica: Cornell University Press.

Whitehead, N.L. (2004), On the poetics of violence. In: N.L. Whitehead, ed., Violence, pp. 55-77. Oxford: James Currey. 



\section{Agency, Resilience and the Psychosocial Well-Being of Caregiving Children: Experiences from Western Kenya}

Morten Skovdal

\section{Introduction}

AIDS remains a leading cause of mortality worldwide and is the primary cause of death in sub-Saharan Africa (UNAIDS/WHO 2007). Experiencing this epidemic first-hand are the children of those infected by AIDS, many of whom provide care and support for their parents or guardians. Care is often provided in difficult circumstances with inadequate access to antiretroviral drugs and palliative care services. With many children witnessing the slow disintegration of their parents' health and taking the role as the primary caregiver and head of house, it is perhaps no surprise that the circumstances of children living in households affected by AIDS have alarmed many academics, policy makers and mental health professionals. This is reflected by the growing body of literature on young caregiving and children of child-headed households in Africa. Whilst some of 
this literature is reflective and provides a balanced account of the positive and negative outcomes of young caregiving, and acknowledges children as social actors, there is still a tendency to side with the dominant discourse in viewing caregiving children as victims in urgent need of psychological support.

It is the aim of this chapter to problematise any one-sided stereotype of caregiving children as passive and incompetent victims with solely detrimental experiences. To achieve this, I will first argue that this continued victimological focus on caregiving children is a result of dominant Western understandings of childhood and mental health. I will then give evidence to show how the psychosocial well-being of many caregiving children is rooted in a social context that draws on local understandings of childhood, which helps them participate in community life and build resilience.

My starting point is that children are social actors. I therefore locate this study within the 'new social studies of childhood', a paradigm which stands in contrast to the developmental psychology research that sees children as both dependent and 'becoming-adults' (James, Jenks \& Prout 1998). However, to avoid simplifying the complexity and interdependence of children's livelihoods, I extend the argument that children's abilities to exercise agency and cope are dependent on the facilitating or constraining nature of their social environment (Abebe \& Kjørholt 2009; Skovdal, Ogutu, Aoro \& Campbell 2009).

In seeking to understand the psychosocial well-being of caregiving children, I have used the salutogenic orientation of Antonovsky (1987). Salutogenesis is an approach that allows public health professionals and researchers to examine social structures that foster coping and successful adaptation (Antonovsky 1987). This allows for possible explanations of how people cope with difficult circumstances. As an approach, it does not guarantee solutions to situations of hardship and the complex dynamics of human existence, but it does lead to a more profound understanding and knowledge of coping and well-being (Antonovsky 1987). As I seek to report on children's perspectives on existing indigenous coping strategies, developed by the children themselves within their immediate communities, this chapter contributes directly to research in the salutogenic tradition. I also argue that the best way to gain child-centred perspectives and develop culturally appropriate interventions is to draw on participatory action research methods.

This is a digital offprint for restricted use only | @ 2011 Koninklijke Brill NV 


\section{Representations of Caregiving Children}

Being a young carer is portrayed in almost wholly negative terms in the literature (Olsen 1996, 44).

Research on caregiving children in the United Kingdom (UK) suggests that young caregiving can be a highly stressful situation. Experiences from the UK, for example, suggest that caregiving children often live in poverty and social exclusion (Dearden \& Becker 2000), have emotional difficulties (Dearden \& Becker 1995; 2004), and impaired mental health (Cree 2003). According to Aldridge and Becker (1993), caregiving children experience ill health and restricted opportunities for developing friendships and social networks, such as taking part in leisure activities, and have been identified to have limited visions of the future (Aldridge \& Becker 1993; Dearden \& Becker 2000) and difficulties with education (Dearden \& Becker 2004). According to Olsen (1996), such research suggests that academics and health professionals are keen on addressing the ways in which caregiving children live, and are guided by an ideology of childhood as a period of protection, vulnerability and incompetence.

These UK-based perspectives have encouraged both researchers and policy makers to explore the circumstances of caregiving children in Africa (Robson \& Ansell 2000). Development practitioners and policy specialists, for example, have already transferred UK-based representations of young caregiving to an African context. At an international symposium on 'young carers' in Nairobi (2006), practitioners, policy specialists and caregiving children from Africa and UK spent three days sharing knowledge on issues affecting caregiving children (Commonwealthtube 2007; TCSUK 2006). The conference was jointly organised by The Children's Society UK (TCSUK), who already facilitate a number of 'young carer' support activities and networks in the UK, and the Commonwealth Organisation for Social Work. The conference received much attention, including coverage on BBC World Service, covering the plight of caregiving children (Commonwealthtube 2007). In the BBC interview, Ruth Nesoba spoke of the problem of children taking on 'adult responsibilities' and of their 'lost childhoods'.

Literature searches on caregiving children and child-headed households in Africa yield only a small handful of papers and one book. These papers have 
usefully mapped out the circumstances and problems faced by children living in households affected by AIDS. These include disruption of schooling, loss of friends and isolation, difficulties looking after an ailing person and the wider household, and trauma as a result of caring and bereavement (Ayieko 1997; Bauman et al. 2006; Donald \& Clacherty 2005; Martin 2006; Robson, Ansell, Huber, Gould \& van Blerk 2006; Ruiz-Casares 2007).

Work on caregiving children in Africa was initiated by Robson and her colleagues (cf. Robson 2000; Robson \& Ansell 2000; Robson et al. 2006). In addition to looking at their circumstances and problems, Robson et al. (2006) also indicate the potential benefits of young caregiving, such as learning new skills, developing close and loving relationships with the person they care for, and growing up as a mature and responsible person. Donald and Clacherty (2005) have also helpfully noted the benefits and strengths of children living in childheaded households.

Guided by the initial observations of Robson and colleagues, Evans and Becker (2009) set out to compare the experiences of children caring for parents with HIV and AIDS in the UK and Tanzania. The authors draw on a resilience framework, providing a useful counterpart to a focus on risk and problems. Aside from identifying problems of stigma, poverty, poor physical and emotional health, social isolation and poor academic performance, Evans and Becker (2009) also identify the importance of supportive school environments, young people's friendships and supportive social networks. They conclude that researchers need to move away from a focus on the 'vulnerability' of caregiving children to one concerned with 'resilience' (ibid.). This is a good starting point to explore in greater detail the coping strategies, processes and resources that impact upon children's psychosocial well-being. Nevertheless, the perceived diversion away from 'normal childhood', which labels caregiving children as 'at risk', continues to give rise to psychopathological responses.

\section{Childhood, Caregiving and Mental Health}

The assumption that psychopathology is an appropriate framework for characterising African children with so-called 'adult responsibilities' as 'at risk' is 
apparent. Researchers have consistently noted the psychosocial fragilities of caregiving children, highlighting their vulnerability to abuse (Ruiz-Casares 2007), depression (Bauman et al. 2006; Bauman, Johnson Silver, Berman \& Gamble 2009; Boris et al. 2008), poor self-worth, unresolved grief, lack of longterm goals and poor internal locus of control (Donald \& Clacherty 2005; Martin 2006), and lack of social support (Thurman et al. 2008). Similarly, guardian illness has been associated with increased risk of poor mental health among AIDS-orphaned children (Cluver, Gardner \& Operario 2007).

In a comparative study of caregiving children in Zimbabwe and the United States (US), Bauman and colleagues (2006) investigated the psychological consequences of caring, measured in terms of depression. The very design of this study is permeated with victimological representations of caregiving children through its choice of a measure of 'depression' as the most appropriate tool to characterise their experiences. The study begins with the assumption that caring for an ill parent is an inherently traumatic experience, which automatically puts children at risk of mental health problems. Although the study found that $63 \%$ of Mutare children had clinically significant symptoms of depression, this was not correlated to caregiving (Bauman et al. 2006). Perhaps more importantly, they found the bond between child and parent to be an important predictor of child mental health. In fact, the study found that children may benefit from helping to make a parent feel better.

Whilst a minority of children undoubtedly suffer from mental ill health, it can be argued that the focus on children's poor mental health reflects Western discourses and representations of childhood as a period of innocence and psychological fragility in the absence of adult protection (cf. Summerfield 2000; Summerfield 2004). It is precisely such unproblematised associations and theoretical perspectives of caregiving children and child-headed-households that I seek to challenge in this chapter. Although attempts have been made to adapt and validate mental health measures in local contexts (Patel 1998; Pereira et al. 2007), the validity of diagnostic criteria for child disorders cross-culturally is still lacking (Canino \& Alegria 2008). And whilst one can not ignore the increasingly sophisticated studies that give evidence to worrying trends of psychosocial distress amongst AIDS orphaned children (Cluver \& Orkin 2009; Nyamukapa et al. 2008), it remains of concern that psychological frameworks 
for the study of AIDS-affected children (e.g. Li et al. 2008) are based primarily on Western experiences, ignoring the experiences and life-worlds of children in Africa. As highlighted by Summerfield (2004), one very practical danger of Western conceptualisations of mental health and childhood is that the more prevalent Western and adult-centred theories and technologies in therapeutic treatment become, the more children (in Africa for example) will realise that they are not expected to cope using their own resources and networks.

It is therefore imperative that children living in households affected by AIDS are not seen as 'at risk' because of their deviation from Western and adultcentred representations of childhood, which are posited as the universal norm and neglect the historical and geographical specificity of children's experiences (Jenks 1992). Rather, children's vulnerabilities should be understood within their own social contexts. As Hutchby \& Moran-Ellis argue (1998, 6), "Childhood is not a natural phenomenon or fixed stage of life, but a historically and culturally variable social construction." Psychosocial support is therefore best offered within a framework which seeks to recognise and boost social resources and existing coping strategies, with an understanding of the interplay between local representations of childhood and children's psychosocial well-being, rather than assuming that AIDS-affected children are automatically at risk of mental ill-health problems and typecasting them as 'helpless victims of Africa's problems'.

As a result of the developments described above, it seems sensible to focus future research on the psychosocial development and well-being of caregiving children. Euwema, de Graaff, de Jager and Kalksma-Van Lith (2008) note that such a focus automatically gives us an insight to their problems, but more importantly give us an insight to how the children, their extended families and communities cope with difficult circumstances. Equally important, a focus on well-being and coping also encourages us to move away from psychopathological measures (often developed by adults in the West) and explore, through participatory action research, the perspectives of the children on how they cope. Such a theoretical and methodological shift in focus could lead to the development of more meaningful interventions that could improve children's lives. This chapter presents a participatory action research project, in line with Freire (1996; 2005) and Lewin (1946), and gives an example of how a more dialogical 
approach to research can help us reconceptualise the needs and circumstances of caregiving children and encourage more culturally relevant psychosocial support. To broaden the concept of caregiving children, I refer to 'young carers' as children under the age of 18 who provide significant nursing care and support for their sick, disabled or elderly relatives or guardians on a regular basis and play a key role in sustaining their household.

\section{A Social Psychological Study of Caregiving Children in Western Kenya}

To develop our understanding of young caregiving and to provide a more nuanced perspective, I set out to explore children's experiences and the perceptions they attach to their circumstances. Echoing Roberts (2008), I believe children are the real experts on their own lives and therefore draw on multiple methods (Photovoice, draw-and-write exercises with written reflections, and interviews) in an effort to involve and consult the children in the data collection process. The participatory research tools used in this study served as a catalyst for change, with the children's observations and recommendations being immediately translated into action through cash grants from a local NGO (WVP Kenya) catering for their material as well as psychosocial needs.

The information presented in this chapter is based on my analysis of data gathered from the first two phases of a larger ethnomethodological action research study. The study was conducted in the Bondo district of Nyanza province in Western Kenya in 2007. Bondo district was chosen for its high HIV prevalence rate, which is estimated to be $13.7 \%$, still twice the national average (NACC 2005). Informants were sampled from two rural communities within Bondo district, both characterised by high HIV prevalence rates. With no known local definition of 'young carers', children who did more than 25 hours per week of work and care for an adult were purposefully recruited by local gatekeepers (committee members of a local community-based organisation) for this study. Forty-eight children aged between 12 and 17 years were selected from the two communities. 
In consultation with the children, two Youth Community Clubs were established, one club in each community. The clubs continue to be facilitated and supported by social workers from WVP Kenya. Sports facilities, creative arts material and small cash grants are made available to the children through the clubs, with children meeting regularly for creative activities and to work on income generating activities such as growing kale, keeping poultry and selling maize. Data were collected through these clubs.

I distributed disposable cameras to all 48 children, but only 45 children managed to return their cameras for developing. Photovoice has been identified as a method through which marginalised groups can communicate, identify, represent, and enhance their community and circumstances (Stack, Magill \& McDonagh 2004; Wang \& Burris 1997). The children were briefed on the aims and objectives of the exercise, trained on how to take photos and briefed on the ethical implications of research and photography, such as the need for them to seek consent of those featured on the photographs and not to take photos of people in situations they thought would make them uncomfortable. In a brainstorming session, the children shared situations they thought would be inappropriate (e.g. of an ailing and bed-ridden adult to take pictures of). They were also given the option of drawing pictures of situations they wanted to share, but felt unsure about the appropriateness of taking a photo.

The children were told to pick six photos that had a relevant or important story they wanted to share and were encouraged to write reflections prompted by the following questions: 1) 'I want to share this photo because...', 2) 'What's the real story this photo tells?', and 3) 'How does this story relate to your life and/or the lives of people in your neighbourhood?' At this stage, if the children wanted to write about a situation that they did not capture on camera, they were encouraged to draw the situation. This exercise generated a total of 184 photos and 56 drawings, each with an accompanying written reflection or story. The Photovoice exercise was complemented with a draw-and-write exercise, covering the theme 'Caring for an adult'. The children were encouraged to make a drawing and write a short story or essay on the topic. These written assignments were further supported by 39 individual interviews and four group discussions with children as well as adults from the two communities. 
To recognise and support the different ways in which children feel most able to share their experiences and perceptions of a phenomenon, a multi-method technique was used (O'Kane 2008). The use of multiple methods is a direct response to the hegemonic adult centredness of society and the disenfranchised position of children, which is often replicated in research involving children (Kirk 2007; Punch 2002).

All workshops and data collection were conducted in Dholuo language by two local research assistants and later translated into English. Interviews and written narratives were coded and analysed in Atlas.Ti using thematic networks analysis (cf. Attride-Stirling 2001; Skovdal et al. 2009). It is these thematic networks that will guide the remaining narrative of this chapter. The study was granted ethical approval by the Research Ethics Committee of the London School of Economics and permission to conduct the study was granted by the Department of Gender and Social Services in Kenya. Pseudonyms are used throughout to protect the identity the research participants.

To facilitate a re-conceptualisation of caregiving children, the findings presented in this chapter reflect the experiences of caregiving children and their perceptions of the impact of caregiving on their lives. I first provide some background to the social context in which caregiving children are located, which informs the possibilities and limitations on children's coping that are discussed later. I then explore the socioeconomic and psychosocial forces that determine a child's capacity to participate in social life. This is followed by an outline of what it means to be a caregiving child, including details of their roles and responsibilities and their needs and difficulties. The final section presents some of the strategies that caregiving children actively employ to cope with adversity, an engagement facilitated by local understandings of childhood and poverty.

\section{Childhood, Young Caregiving and Poverty}

To fully understand the caring experiences of these children, one must also develop an insight to the immediate context in which they are located. This 
section presents some of the local understandings of childhood that influence representations of young caregiving. In doing so, this section does not seek to enter into a binary discussion on traditional versus Western notions of childhood, but seeks to argue that local understandings of childhood are vibrant and changing, influenced by disease, poverty and contemporary notions of childhood (Kesby, Gwanzura-Ottemoller \& Chizororo 2006). It is within this framework that children derive meaning and access psychosocial support.

The sense people make of their surroundings often derives from social expectations and roles (Mead 1934). The traditional expectations of Luo children to contribute to the household economy, both formally through income generating activities and informally through their participation in home duties, is therefore an important observation. Luo children's contribution to livelihoods is part of every day life and language, with children being socialised from a very young age to take an active role in sustaining the household in which they live. One adult, for example, said, "a 10-year-old is old enough to know that he or she should help you with duties. The child can cook and arrange (working the farm) everything for the family to eat." However, this socialisation of 'working children' also reflects an adaptation to current problems of disease and poverty. One adult exemplifies this well, in her recognition of an increased likelihood that children will be left at an earlier age to fend for themselves due to death caused by AIDS and other tropical diseases.

Once it was against Luo culture for a male child to go to a fire place, to cook in the kitchen. Today it has changed; they cook and do these duties. Also, if you don't teach him to cook and his wife dies, his children may suffer. Today you cannot know who will die first. (Adult4, interview)

Although the majority of adults argued that children should contribute to their household livelihoods, a minority of adults drew on more contemporary and conflicting expectations of children and said that children should be cared for, be in nursery and prepare for going to school. Nevertheless, many children continue to take on caregiving responsibilities. Most of the children involved in this study generated food and income through cultivation of their gardens and selling of their produce at a nearby marketplace. Sixteen-year-old Zeddy said, "I think it is important to grow vegetables; if one is assisting a sick person and has a garden, you can grow vegetables and sell them to get drugs to the 
sick person, food and get money to buy clothes and shoes." In addition to contributing significantly to their households, caregiving children are also involved with much more intimate care such as bathing, massaging and feeding the sick. Reflecting on her experiences, one girl said.

I was always with my mother at the hospital to ensure that when she woke up, a doctor would come and see her. I was washing her, washed her clothes, bought and brought her the drugs needed for treating her. I was doing everything for her in the hospital. My uncle came to pay the hospital bill. She was discharged, felt well but had no strength. (Catherine, age 14, Photovoice).

Although AIDS is arguably the root cause of much young caregiving, the prevailing notion of childhood as a time of duty and service, and the representation of children as 'helpers', has encouraged many parents to send their children away to provide care and support for ageing grandparents. In a group discussion, one adult said that "children can help in various ways, they can assist a grandmother, prepare porridge and wash her clothes. If I know she needs help, I will send my child and tell him or her to help the grandmother."

Children in this context respect their guardians tremendously and appear to draw on a number of sayings. The Luo saying 'chakochon loyo dhi ajuoga' (a start in time saves nine), refers to how the destiny of a child is dependent on the teachings of its guardians. Reflecting such sayings, many caregiving children view their guardians as important and seek to live up to social expectations and responsibilities. One person who does that is 14-year-old Loyce, who in a Photovoice essay said, "I always help out my guardian and she always gives me food. My guardian gives good advice and is honest. I give her respect and live up to my responsibility all the time." By drawing on the representation of being a 'helper', many caregiving children see themselves as 'good children' and therefore often manage to see the positive side of caregiving. When reflecting upon her caregiving experiences, Everline, age 14, said, "people in the community love me, they are proud of me." Everline and many other young caregivers actively reflect on local representations and expectations of childhood, taking advantage of their responsibilities as 'helpers' and construct positive identities - a process that facilitates psychosocial coping and well-being. 
These findings give some background to how disease, poverty and culture influence local representations of childhood and young caregiving. I have also briefly exemplified some of the activities caregiving children engage in, echoing findings made by Robson and colleagues (Robson 2000; Robson et al. 2006). In drawing on local representations of childhood, many of the caregiving children describe their circumstances gracefully and with little reference to negative consequences. I argue that the children's participation in community life, coupled with local representations, enable the children in this context to build positive caring identities that facilitate their psychosocial well-being. However, the responsibilities and experiences of the caregiving children do not come without challenges.

\section{Needs and Difficulties Faced by Caregiving Children}

Caregiving children face a number of difficulties and challenges. The challenges identified by the children fall into three categories. Firstly, poverty and destitution, including issues of malnutrition, access to water, material needs and poor housing. Secondly, psychosocial challenges such as lack of support, stigma, fear, bullying and parental bereavement. Finally, managing their education alongside caregiving duties.

As all the caregiving children participating in this study live in absolute poverty, their diet and nutritional intake is often inadequate. Many children made note of their undiversified diet compared to that of other children and families. For example, fifteen-year-old Carolyn notes that while other children "eat chapatti and beans, we eat ugali (cooked maize flour, a staple food). The following day they may eat something else, such as tea with rice, whilst we have ugali again." While poverty is a generic problem in Bondo, caregiving children do represent a minority and often describe their levels of poverty relative to other children. For instance, twelve-year-old Mercy said in an interview that "the difference between me and other children is that I go barefoot whilst they wear shoes, they have good clothes, they pay school fees on time, whilst I have to go and look for that money." 
Other challenges faced by some of the children range from lacking social support, lack of time to play, experiencing parental bereavement, being worried about what the future might bring, and feelings of fear. Occasionally, caregiving children reported being bullied by other children and experienced abuse and neglect by adults, often as a result of the stigma attached to HIV/AIDS. Roseline, age 14, explained that she sometimes missed school, not because of her caregiving duties at home, but because "non-caring children talked badly about me. They joked about my mother's condition." Stigma attached to AIDS was also found to determine the level of social support available to some young caregivers. Whilst some children are without adequate support in their caring role, others, as I will show later, are much more successful in mobilising social support networks.

In general, all the participants attended school. Going to school served as an escape from their difficulties at home. Education takes up a large portion of their time and their commitment to education signifies the importance it plays in their lives. Education not only gives them a break from duties, but also provides them with an opportunity to spend time with friends. The children seemed generally satisfied with the quality of education and perceived education to be the only way out of poverty. However, managing their commitment to education with caring responsibilities was a challenge for many of the children. Some of the children therefore felt that their caring experience has negatively affected their school attendance and performance. As told by 15-year-old Debora, many children will, at some point, skip school to provide care for someone: "when my mother was sick I had to miss school, but had no permission to be out of school. The teachers did not understand my problem and caregiving duties. It was so painful for me to miss school." A number of children also mentioned their lack of concentration in school as a result of their worries and fears for their sick parents and what the future might bring. Although some caregiving children claim their school performance has persistently deteriorated since they took on caring responsibilities, many children go back to school and do exceptionally well.

When the school re-opened I missed school; my fellow children were going to school as I stayed at home caring for my sister. I returned to school with only four weeks left. I told the teacher of my sister's sickness. The teacher 
encouraged me to study hard since I had missed a lot. I studied and managed to be position 9 out of 48; I performed well despite the fact that I only studied for 4 weeks out of the 14 weeks in a term. (Austine, age 14, Photovoice)

The ability of many caregiving children to bounce back and improve their school performance rank is an indicator of their resilience. Dropping out of school for a year to provide care for ailing or ageing guardians does not have to be detrimental to the child's school performance in the long-term. Although caregiving may come with a high cost at a particular point in time, some of which are highlighted in this section, their situation often improves. The challenges presented in this section reiterate that the children do face difficult circumstances and that these challenges should be addressed. Though the underlying causes of poverty and disease can be addressed at geopolitical level (Robson 2004), the challenges outlined in this section should also be addressed at a local and community level. The next section presents the social coping strategies of caregiving children, illustrating how children can negotiate and navigate social support by drawing on local representations of childhood.

\section{Social Coping Strategies: Exercising Agency and Competence}

To gain a more nuanced understanding of the lives of caregiving children, the background and difficulties presented above must be understood with reference to the children's social coping strategies. These strategies are located within a social context that allows children to exercise agency as they navigate and actively negotiate support. This section presents some of these processes.

In addition to the importance of education more generally, school and teachers are also an important source of support for some children. Twelve-year-old John stated that, "children can go to school and ask the teachers for support, who will see what they can do for the child." John expresses a confidence in the approachability of teachers and their capacity to help, and more importantly, he notes the active role of children seeking support by simply asking. Schools were reported as important for the children in developing friendships and in giving them a sense of normality and stability amidst difficult circumstances. Although schools have the potential to be supportive, an earlier example showed 
how schools can also be a source of stress and unhappiness when caregiving and stigma impact on school performance and attendance.

Churches and faith-based groups were also mentioned by many children as a source of food and emotional support. A number of children took a photo of their local church, describing how their church had helped them with school materials, food and psychosocial support. The role of faith in helping these children cope is also noteworthy; many children believed that 'God gives answers and is always there' for them-providing them with tranquillity and hope. The faith and spiritual support from God was seen by some children to help them cope with bereavement and difficult circumstances.

Less fortunate and needy children also benefit more generally from community members. When asked about the potential sources of support for caregiving children, one adult answered, "If a child is living with an old person and struggling, I can buy him or her clothes because I know that s/he is suffering. It also means that if I do that, God will bless me." With many community members being willing to help vulnerable children, it is no surprise that many of the children reported neighbours and community members to be a source of support, particularly when it came to giving them food and school materials.

Accessing support from community members, however, rarely comes without some kind of negotiation. This negotiation ranges from the children giving generous community members an impression of their vulnerability in the hope this will gain them support, to them asking directly for support (with an awareness of whom to ask and when). Twelve-year-old Mercy drew on the former, describing the effect of wearing torn clothes, "some people buy you clothes because they see you wearing clothes which are torn. When they see you like this, the community/village can buy for you clothes with the money they have raised."

One of the dangers of this explicit negotiation is the victimological representation that the children contribute to. This is illustrated by 12-year-old Joyce who, in her negotiation for support, represented herself as a vulnerable child. She used clothes and physical appearance to project her vulnerability in order to receive support: "if we do not have clothes there may be others who can buy it for us. There are some parents who are very generous and when they see you hungry, they give you food." 
Children were also found to project their needs explicitly to community members by verbally sharing their circumstances in the hope of winning sympathy that would translate into support. For most children however, negotiating support required a degree of reciprocity. Twelve-year-old Kevin illustrates this well by describing how he gets food from his neighbour, in return for his labour in weeding and harvesting their shamba (piece of land used for subsistence farming). By working their land and giving them some of the harvest, Kevin gets access to land and food that he otherwise would not have had. Kevin stated, "If I have no food, I get it from the neighbours and I assist them in harvesting maize, sorghum and beans." A more implicit strategy used by most of the children in conjunction with the less direct negotiation of support (as seen above), is to simply ask for support, as 15-year-old Carolyne would do, "The photo reminds me of the kind of support and love we get from the community members. If I need anything, I tell them and if it is available, I will get it."

Another more direct type of support usually takes place through a "harambee'. This is a Kenyan tradition of community self-help events, and translates into 'working together for a common purpose' in which vulnerable children receive support from groups or networks of community members. Harambee forms the foundation for the many community and grassroots groups that fill the social landscape in Bondo and support many children, irrespective of the stigma associated with AIDS. The strong community ethic and harambee which often makes support available to children during times of hardship also shapes the way in which the children themselves articulate a strong ethic of responsibility to care for those in need of support. Some children even set up groups and clubs aimed at helping one another. Inspired by what can be achieved as a group, 15-year-old Millicent said,

I want to talk about this photo because these school children have formed a group which I am a part of. We help each other. I once had a problem and they helped me through a difficult time. They regularly came to visit my mother and they also helped me in fetching water and firewood. We should respect and assist one another. My fellow children help me. If a friend needs help we can always join hands and do fundraising to help someone through a difficult situation. (Millicent, age 15, Photovoice) 
Bonds of friendship were also found to provide psychological support, giving the children someone to lean on emotionally during times of hardship. The strong notion of unity and togetherness (deriving from harambee) was often articulated as a route to success and survival. It was used as a means of coping through difficult circumstances and tasks.

Another important source of support is the extended and immediate family. From the extended family, males were more often found to contribute monetarily, whilst female family members more often visited the household and supported them with food and nursing care. The children who did benefit from their extended family network reported little negotiation with their extended family members in order to access support, reflecting a perceived obligation to help their own kin in times of need. Caregiving was often a shared responsibility between immediate family members, with siblings often assisting with dayto-day activities (such as cooking, fetching water and firewood). However, it is often the oldest child living at home who takes the role as head of house.

While responsibilities differ according to the circumstances present in each household, all the children in this study were found to contribute significantly to the wider household subsistence efforts, more often as part of a collective effort, with only a few doing so single-handedly. To cope with the lack of resources and food, boys and girls engaged in a variety of income-generating and farming activities. They sometimes had to negotiate access to land, animals and competitive market prices.

Most children reported on the importance of animals in generating food and income for various expenses. Thirteen-year-old Samuel took a photo of a cow that helps sustain his household: "I took this photo of a cow to show the benefits we get from it, like school fees, uniforms and money." By selling the milk, Samuel was able to cover some of his needs. Many caregiving children have not only their own needs in mind, but also those of their guardians. Animals were seen to help caregiving children diversify the diet within the household, and enabled them to purchase medicines and nutritious foods for their ailing guardians. This was expressed by 17 -year-old Edith in a Photovoice essay, "if I am caring for a sick person and do not have money, I can sell a cow or the milk to get money to help with the treatment of the sick." 
Cows, goats and chickens not only serve as important lifelines in sustaining the daily living of most caregiving children, but also give some of them hope for a brighter future when their animals reproduce and serve as insurance and an asset. The children fortunate to have livestock or fruit trees relied on them as insurance during times of hardship. In describing one of her photos, 13-yearold Susan said, "I love our goats and that is why I took the picture. These goats are important to me, they can help us when we don't have money, and we can sell them to get money for other things."

As this study took place in a rural area, the 'shamba' (garden, piece of land used for farming) played an important role for all the children. The shamba enabled many children to grow vegetables and generate money through selling the produce. Nearly all the children made reference to the importance of fruit trees and vegetables in generating income, often with reference to how it helps them purchase school equipment and drugs for their ailing guardian. These activities illustrate their competencies in participating in activities that sustain them. The children were aware of their competencies and took great pride in their achievements, pointing out the value of being an active agent. Twelve-year-old Joyce, in reflecting on her active role in sustaining her livelihood, proudly said, "I feel happy because everything I have done will help me in future."

Although gender only played a small role in duties carried out at home, supplementary income-generating activities carried out in public places were highly gender-specific. Boys frequently engaged in the making and selling of charcoal (used for cooking), while girls offered more domestic services such as laundry and working in the garden for a small fee, typically to more affluent community members. Younger children, regardless of gender, typically fetched firewood and took it to the nearest market place for selling, contributing significantly to the daily income of their household.

What these findings indicate is that local understandings of childhood as a time of duty and service are materialised through the socialisation of children, and their active participation in sustaining their households, exacerbated by poverty and disease. As in many other rural African locations, this context encourages and recognises children who show agency and competence in engaging with resource generating or social support activities in order to cope with difficult circumstances. 


\section{Conclusion}

The findings presented here suggest that many children are able to draw on a myriad of coping strategies and manage their difficult circumstances extraordinarily well. Many children manage not only to provide nursing care for their guardians, but also contribute to household economic survival through subsistence farming and income-generating activities. These findings are similar to observations made in Ethiopia (Abebe \& Kjørholt 2009) and Tanzania (Porter 1996). The study also found that the children maintained and developed their psychosocial well-being by actively drawing on local understandings of childhood to participate in community life and make sense of their circumstances. These findings suggest that caregiving children are as active and competent as their social environments allow (Hutchby \& Moran-Ellis 1998).

As a result, the children were able to actively navigate and negotiate social support. Within the immediate family, siblings share responsibilities; in turn, the extended family (such as uncles, aunts and grandparents) was often observed to provide support with money or food. Although support can be affected by stigma associated with AIDS and by poverty, assistance from community members and groups remains a critical coping mechanism. While women and home based care groups were mentioned, of particular interest to this study is the finding that children were also able to mobilise very effective friendship networks. Similar observations have been made elsewhere (Belle 1989; Berndt 1989; Nestmann \& Hurrelmann 1994), however it remains an understudied phenomenon with children affected by AIDS.

In their study of the social representations of orphaned and vulnerable children in South Africa, Meintjies and Giese (2006) observe how the tendency towards framing orphan care and support policies and interventions within the framework of victimological Western representations of childhood (as a time of protection and play) could serve to undermine or displace local representations of childhood as a time of service and duty. Yet it is these very representations that enabled so many children in this study to cope with difficult circumstances.

What this study has argued is that the application of adult-centred theories and methodologies, often developed in the West, ignores some of more meaningful perspectives and processes that help us understand and promote 
the psychosocial well-being of children living in households affected by AIDS. It is therefore critical that NGO workers and researchers working with caregiving children reconsider their tendency to universalise what are, in fact, their own very culturally specific assumptions about what should constitute a 'normal' childhood and mental health, and their tendency to implicitly or explicitly depict those that fall outside these assumptions as 'at risk'. To overcome this dilemma, I have shown that by using participatory learning and action techniques (cf. Freire 1996; Rifkin \& Pridmore 2001), such as Photovoice and draw-and-write exercises within the framework of action research, one is able to derive more child-centred and culturally appropriate perspectives of how children cope and maintain their psychosocial well-being. Taking a child-centred approach, I have been able to document that many caregiving children, as a result of their enabling social context, are able to actively construct effective coping strategies and mobilise the social resources available to them, making it appropriate to view many of them as competent and active 'copers'.

\section{References}

Abebe, T. \& A. KJøRholt (2009), Social actors and victims of exploitation: Working children in the cash economy of Ethiopia's South. Childhood 16(2): 175-194.

Aldridge, J. \& S. BeCKer (1993), Children who care: Inside the world of young carers. Loughborough, Leicestershire: Loughborough University of Technology, Department of Social Sciences.

Antonovsky, A. (1987), Unravelling the mystery of health-How people manage stress and stay well. London: Jossey-Bass Publications.

AtTRIDE-STIRLING, J. (2001), Thematic networks: An analytic tool for qualitative research. Qualitative Research 1(3): 385-405.

Ayıеко, M. (1997), From single parents to child-headed households: The case of children orphaned by AIDS in Kisumu and Siaya Districts. New York: UNDP.

Bauman, L., G. Foster, E. Silver, R. Berman, I. Gamble \& L. Muchaneta (2006), Children caring for their ill parents with HIV/AIDS. Vulnerable Children and Youth Studies 1(1): 56-70.

Bauman, L., E. Johnson Silver, R. Berman, \& I. Gamble (2009), Children as caregivers to their ill parents with AIDS. In: K. Shifren, ed., How caregiving affects development: Psychological implications for child, adolescent and adult caregivers, pp. 37-63. Washington: American Psychological Association.

BeLLE, D. (1989), Children's social networks and social supports. New York: Wiley-Interscience.

BERndT, T. (1989), Obtaining support from friends during childhood and adolescence. In: D. Belle, ed., Children's social networks and social supports, pp. 308-331. New York: John Wiley and Sons. 
Boris, N., L. Brown, T. Thurman, J. Rice, L. Snider, J. Ntaganira, et al. (2008), Depressive symptoms in youth heads of household in Rwanda-Correlates and implications for intervention. Archieves of pediatrics and adolescent medicine 162(9): 836-843.

Canino, G. \& M. Alegria (2008), Psychiatric diagnosis-Is it universal or relative to culture. Journal of Child Psychology and Psychiatry 49(3): 237-250.

Christensen, P. (2004), Children's participation in ethnographic research: Issues of power and representation. Children and Society 18: 165-176.

Cluvver, L., F. Gardner \& D. Operario (2007), Psychological distress amongst AIDS-orphaned children in urban South Africa. Journal of Child Psychology and Psychiatry 48(8): 755-763.

Cluver, L. \& M. Orkin (2009), Cumulative risk and AIDS-orphanhood: Interactions of stigma, bullying and poverty on child mental health in South Africa. Social Science \& Medicine 69(8): 1186-1193.

Commonwealthtube (Writer) (2007), Addressing the needs of young carers UK: YouTube. URL: http://www.youtube.com/watch?v=Kn2VV9WECsw (accessed 29/02/o8).

CreE, V. (2003), Worries and problems of young carers: Issues for mental health. Child and Family Social Work 8(4): 301-309.

Dearden, C. \& S. Becker (1995), Young carers: The facts. Sutton: Reed Business Publishing.

- (2000), Growing up caring: Vulnerability and transition to adulthood-Young carers' experiences. Leicester: Youth Work Press for the Joseph Rowntree Foundation.

- (2004), Young carers in the UK: The 2004 report. London: Carers UK.

Donald, D. \& G. Clacherty (2005), Developmental vulnerabilities and strengths of children living in child-headed households: A comparison with children in adult-headed households in equivalent impoverished communities. African Journal of AIDS Research 4(1): 21-28.

Euwema, M., D. De GraAfF, A. De Jager \& B. Kalksma-Van Lith (2008), Research with children in war-affected areas. In: P. Christensen \& A. James, eds, Research with childrenPerspectives and practices, pp. 189-204. Oxon: Routledge. Second edition.

Evans, R. \& S. BECKER (2009), Children caring for parents with HIV and AIDS: Global issues and policy responses. Bristol: Policy Press.

Freire, P. (1996), Pedagogy of the oppressed. London: Penguin Books Ltd.

-. (2005), Education for critical consciousness. London: Continuum.

Hutchiy, I. \& J. Moran-Ellis (1998), Children and social competence: Arenas of action. London \& Washington, D.C.: Falmer Press.

James, A., C. Jenks \& A. Prout (1998), Theorising childhood. Cambridge: Polity Press.

Kesby, M., F. Gwanzura-Ottemoller \& M. Chizororo (2006), Theorising other, 'other childhoods': Issues emerging from work on HIV in urban and rural Zimbabwe. Children's Geographies 4(2): 185-202.

KIRK, S. (2007), Methodological and ethical issues in conducting qualitative research with children and young people: A literature review. International Journal of Nursing Studies 44: $1250-1260$.

Lewin, K. (1946), Action research and minority problems. Journal of Social Issues 2(4): 34-46.

Li, X., S. NaAr-King, D. Barnett, B. Stanton, X. Fang \& C. Thurston (2008), A developmental psychopathology framework of the psychosocial needs of children orphaned by HIV. Journal of the Association of Nurses in AIDS Care 19(2): 147-157.

Martin, R. (2006), Children's perspectives: Roles, responsibilities and burdens in home-based care in Zimbabwe. Journal of Social Development in Africa 21(1): 106-129.

MeAD, G.H. (1934), Mind, self, and society from the standpoint of a social behaviorist. Chicago: University of Chicago Press.

Meintjes, H. \& S. Giese (2006), Spinning the epidemic-The making of mythologies of orphanhood in the context of AIDS. Childhood 13(3): 407-430.

NACC (2005), Kenya HIV/AIDS data booklet 2005. Republic of Kenya: National AIDS Control Council.

Nestmann, F. \& K. Hurrelmann (1994), Social networks and social support in childhood and adolescence. Berlin \& New York: Walter de Gruyter. 
Nyamukapa, C., S. Gregson, B. Lopman, S. Saito, H. Watts, R. Monasch et al. (2008), HiVassociated orphanhood and children's psychosocial distress: Theoretical framework tested with data from Zimbabwe. American Journal of Public Health 98(1): 133-141.

O'KANE, C. (2008), The development of participatory techniques: Facilitating children's views about decisions which affect them. In: P. Christensen \& A. James, eds, Research with Children: Perspectives and Practices, pp. 125-155. New York: Routledge. Second edition.

Olsen, R. (1996), Young carers: Challenging the facts and politics of research into children and caring. Disability and Society 11(1): 41-54.

Patel, V. (1998), Culture and common mental disorders in Sub-Saharan Africa. East Sussex, UK: Psychology Press Ltd.

Pereira, B., G. Andrew, S. Pednekar, R. Pai, P. Pelto \& V. Patel (2007), The exploratory models of depression in low income countries: Listening to women in India. Journal of Affected Disorders 102:209-218.

Porter, K. (1996), The agency of children, work and social change in the South Pare Mountains, Tanzania. Anthropology and Work Review 17(1-2): 8-19.

Punch, S. (2002), Research with children-the same or different from research with adults? Childhood 9(3): 321-341.

RIFKIN, S. \& P. PRIDMORE (2001). Partners in planning. Information, participation and empowerment. London: TALC/Macmillan Education Ltd.

Roberts, H. (2008), Listening to children and Hearing Them. In: P. Christensen \& A. James, eds, Research with Children-Perspectives and practices, pp. 260-275. New York: Routledge. Second edition.

Robson, E. (2000), Invisible carers: Young people in Zimbabwe's home-based health care. Area 32: $59-69$.

-. (2004), Hidden child workers: Young carers in Zimbabwe. Antipode 36(2): 227-248.

Robson, E. \& N. Ansell (2000). Young carers in Southern Africa: Exploring stories from Zimbabwean secondary school students. In: S. Holloway \& G. Valentine, eds, Children's geograpahies: Playing, living, learning, pp. 174-193. London: Routledge.

Robson, E., N. ANSell, U. Huber, W. Gould \& L. van Blerk (2006), Young caregivers in the context of the HIV/AIDS pandemic in sub-Saharan Africa. Population, Space and Place 12: 93-111.

Ruiz-CAsares, M. (2007), How did I become the parent? Gendered responses to new responsibilities among Namibian child-headed households. In: S. LaFont \& D. Hubbard, eds, Unravelling taboos: Gender and sexuality in Namibia, pp. 148-166. Windhoek, Namibia: Legal Assistance Centre.

Skovdal, M., V. Ogutu, C. Aoro \& C. Campbell (2009), Young carers as social actors: Coping strategies of children caring for ailing or ageing guardians in Western Kenya. Social Science and Medicine 69(4): 587-595.

Stack, R., C. Magill \& K. McDonagh (2004), Engaging youth through photovoice. Health promotion practice 5(1): 49-58.

Summerfield, D. (2000), Childhood, war, refugeedom and trauma: Three core questions for mental health professionals. Transcultural Psychiatry 37(3): 417-433.

- (2004), Cross cultural perspectives on the medicalisation of human suffering. In: G. Rosen, ed., Posttraumatic stress disorder: Issues and controversies, pp. 233-246. Chichester: John Wiley.

TCSUK. (2006). A newsletter written by young carers attending the symposium. Paper presented at the An International Symposium for Practitioners and Policy Specialists on addressing the needs of Young Carers (Orphans and vulnerable children), Nairobi.

Thurman, T.R., L. Snider, N. Boris, E. Kalisa, L. Nyirazinyoye \& L. Brown (2008), Barriers to the community support of orphans and vulnerable youth in Rwanda. Social Science \& Medicine 66(7): 1557-1567.

UNAIDS/WHO (2007), 2007 AIDS Epidemic Update. Geneva: UNAIDS/WHO.

WANG, C. \& M. Burris (1997), Photovoice: Concept, methodology, and use for participatory needs assessment. Health Education \& Behaviour 24(3): 369-387. 


\section{About the authors}

Tatek Abebe is a Postdoctoral Fellow at the Norwegian Centre for Child Research, Norwegian University of Sciences and Technology (NTNU), where he also teaches graduate courses in Childhood Studies and Development Studies. His current research interests include young people's livelihoods in the rural and urban informal economic sector, child-focused research methodologies as well as how young people in East Africa are affected by and respond to processes of development and rapid social change. He has previously written on orphanhood, begging, rural-urban childhoods, intergenerational relationships and children's work. He has contributed several chapters to books and, as a sole author or co-author, published articles in various international journals. Abebe holds BA in Geography from Addis Ababa University, M.Phil in Development Studies and PhD in Geography from NTNU.

Edien Bartels (1948), PhD 1993 (about Arabic women, symbols and power relations between men and women) is senior research fellow at the VU University, department of Social and Cultural Anthropology. Together with Oka Storms (1982), who studied Cultural Anthropology at the University of Utrecht and conducted her master research in Morocco on the reform of the Muddawana (family law), she conducted research on return migrant and abandoned children in Morocco in April 2008. June de Bree (1983) studied Development Studies at the Radboud University of Nijmegen and conducted her master research on return migrants in Northeast Morocco.

This is a digital offprint for restricted use only | ( 2011 Koninklijke Brill NV 
Lorenzo I. Bordonaro is a post-doctoral researcher at the Centre for Research in Anthropology (CRIA) in Lisbon, Portugal. He has conducted research in the Bijagós Islands (Guinea Bissau) since 1993, focussing on the wish to be modern of a group of young men on the island of Bubaque, showing the local appropriation of the categories of development and progress and their tactical use in intergenerational dynamics. Presently he is working on youth and childhood issues in Cape Verde, focusing on urban poverty, street children and younger prisoners in local penitentiaries, youth and childhood policies and criminality.

Sandra J.T.M. Evers, Ph.D. (Amsterdam 2001), is associate professor and senior researcher at the Department of Social and Cultural Anthropology, VU University Amsterdam. She specialises in Africa and South West Indian Ocean studies, with a particular focus on Madagascar, the Seychelles and Mauritius. Dr Evers' principal areas of research cover the anthropology of children, (forced) migration, slavery, memory and cognition, frontier societies within the context of globalisation, natural resource management, poverty and sustainable development. She is the director of a joint research programme on natural resource management and poverty of the Department of Social and Cultural Anthropology (VU University Amsterdam) and the Institut de Civilisations/ Musée d'Art et Archéologie (Université d'Antananarivo). She also acts as convener of an international working group on the anthropology of children: http:// www.anthropologyofchildren.net.

Catrien Notermans is an anthropologist working as a senior researcher and lecturer at the Department of Cultural Anthropology and Development Sociology at Radboud University Nijmegen. Her fields of interest include religion (African Christianity, witchcraft, Hinduism, material religion, pilgrimage) and kinship (polygyny, fosterage, transnational kin networks). Her regional expertise includes Cameroon, France, the Netherlands, and India. One of her articles, "The emotional world of kinship: Children's experiences of fosterage in East Cameroon" appeared in Childhood: A global journal of child research (2008). She is currently one of the project leaders of the international research program, Gender, Nation, and Religious Diversity in Force at European Pilgrimage Sites, 
funded by NORFACE. As part of this program she is conducting fieldwork on African migrants going to Marian pilgrimage sites in Western Europe.

Claudia Seymour is a $\mathrm{PhD}$ student of Development Studies at the School of Oriental and African Studies, researching children's experience of conflict and violence. Between 2002-2009, Ms. Seymour served as a staff member and consultant with the United Nations in New York, Liberia, the Central African Republic, and the Democratic Republic of Congo. She is currently based in Bukavu, eastern DRC, where she continues her field research and consults with various protection and child protection agencies.

Morten Skovdal attained his PhD (psychology) from the London School of Economics and Political Science where he works for the Health, Community and Development Research Group. His research interests are community responses to the AIDS epidemic, looking specifically at how communities can hinder or support children's coping and psychosocial well-being. Morten has worked in Kenya since 2004, first with an international NGO, then with the World Bank and now as founder and trustee of WVP Kenya-a youth focused local NGO operating in Western Kenya.

South African born, Cilel Smith is a PhD candidate at the Institute of Education, University of London, finalizing her research and thesis on the Learning Experiences of Refugee Children, during pre-migration, migration and post migration. She is a lecturer at Northampton University and an independent Education Consultant, providing professional development for teachers and teaching assistants who work with Refugee Children and New Arrivals in UK Schools. She has developed a set of board games, My New School, resource packs and a Model for Meaningful learning, using the illuminative approach for Induction, Inclusion and Assessment of New Arrivals and children new to schooling. She works closely with most Local Authorities in the UK and is a member of the London Refugee Steering Committee. Cilel has developed models and systems in evaluation and assessment for educators in the UK and South Africa, but were mainly concerned with rural education, interrupted learning and new to schooling, developing infrastructure and the training of teachers. 
Yisak Tafere is a $\mathrm{PhD}$ candidate at the Norwegian Centre for Child Research, Norwegian University of Science and Technology. He is the Lead Qualitative Researcher for the Young Lives project (run by Oxford University, UK) in Ethiopia. He has an MA in Social Anthropology and a BA in Philosophy from Addis Ababa University. Previously, he worked for different organizations including as a Research Officer and Manager for Wellbeing and Developing Countries, ESRC Research Group run by University of Bath, UK. His research has mainly focused on demobilization and reintegration, qualitative methods, youth development, children's vulnerabilties and resilience, social protection, child labour and education, children's aspirations, childhood poverty, lifecourse and intergenerational transfer of poverty, and the socio-cultural construction of child well-being and transition.

Mienke van der Brug is a $\mathrm{PhD}$ candidate at the department of Social and Cultural Anthropology, VU University Amsterdam. Her research is on bereavement and well-being of children orphaned by AIDS, and communication practices within families on the loss of parents in Namibia. She is trained as an anthropologist and child psychologist.

Diana van Dijk received her $\mathrm{PhD}$ in 2008 in social sciences from Radboud University Nijmegen, The Netherlands. For the Phd project she conducted fieldwork for one and a half years in Port Elizabeth, South Africa. The research focussed on child-headed households. She is a Dutch partner for two SANPAD research projects; at the University of Johannesburg on child-headed households; and at the North-West University on resilience of orphaned children. She is currently working as a researcher for the Centre for Social Policy Studies and International Affairs in Rotterdam, which focuses mainly on vulnerable groups in The Netherlands.

Erik van Ommering is a $\mathrm{PhD}$ candidate at the Department of Social and Cultural Anthropology, VU University Amsterdam, where he attained his MSc in 2007. His research focuses on children's experiences of primary education in contexts of violent conflict, and on the roles of schools in processes of conflict transformation. The regional focus of his study is Lebanon. 


\section{Index}

Abandoned children $15,174,176-178$, $180-181,188,190-193$

Adulthood 4, 8, 32, 71-73, 88, 149-150, 156, 175

Age $3-4,14,23,26,29,32,45,52,72-73$,

$84-85,119,142,150,155-157,165$,

$174-175,178,191,193,227-228,237,253$, 256

Agency

and structure $3,12,18,225,238,264$

and victimization 130

Ancestors 95, 99-100, 108

Applied research 16-17

Armed conflict $\quad 13,223-225,227-243$

Asylum-seeking children 16, 197, 200

Belonging $14-16,97,115,120,142,174-178$, $182-183,191-193,231,240$

Cameroon 14

Cape Verde 13

Caregiving children $\quad 255-66$

Chagos Archipelago $16,96,112$

Child

headed households 4, 249

labour/working children 14, 128, 139-141, 149, 167-169, 256

migrants $143-144$ protection interventions $16-17$, $224-225,228,238,242-243$

rights $74,92,243$

soldiers $16-17,225,227-230,232-238$

well-being $10-11,70-75,80-92,248$, 252, 265 orphaned children $21-23,25,30-32$,

$43-46,55-69,62,65-66,87$

Childhood, conceptualization of $1-4,7,17$, $74,89,242,251-252,255-258,265$

Colonialism 8, 10, 52, 96, 107, 231

Communication $8-9,37,52,74-75,106$, $183-184$

Convention on the Right of the Child 4, 224

Coping strategies 24, 248, 252, 260-263, 265

Creoles 106-108, 110-112, 121

Criminality $36,109,141$

Culture $3-4,13,32,74,98,106-108$, $142-143,154-161,175,183,179,192-193$, 203-204, 209, 255-258

Democratic Republic of Congo 13, 16-17, $225,227-243$

Diaspora 16, 96

Disarmament, demobilization and reintegration(DDR) programmes 227-229, 234-237

Economy/livelihood 14, 76-77, 148-151, $154,158-161,166-167,169,239,256-257$, 263-264

Education 2, 16,71-73, 84-87, 110-112, 150-151, 155-156, 165-166, 202-204, 229, 259-261 educational policy $110-111$ learning milieu 202, 204-207 refugee education $204-207,220$

Emotions 15, 118, 241-242

Empowerment 128, 140-141, 143-144 
Ethics 3, 80, 255

approval 26-27, 98, 255

confidentiality 255

emotions 27,49

informed consent 27-28, 48, 211-212

power relations $7,8,10,12-15,255$

rewards $48-49$

Ethiopia 69-70, 75-77, 92

Ethnography 3,8

Family $\quad 14-15,73,263$

extended $22-25,30-33,45,132-134,263$

nuclear $30-31,58-59$,

single parent 132

Fosterage $14^{-15}$

Freud 1

Friendship 249, 263

Gender 14, 52, 117-118, 135, 157-160, 264

Generation

age hierarchy 142

generational rules $32-35,40$

Health $73,81,247,249$

History $97-98,105,110,155,231-232$

HIV/Aids 17, 247, 250, 252, 259, 265

households $46,55-57$

orphans $44-47,51,55-59$

Home $13,15,22-23,31,45,51,56-57,65$, $131-135,165,177,228-229$

Household 4, 14, 22-23, 26, 28-29, 33-34, $45-46,57-58,132,154,158-160,166-168$, 249-250, 263

Humanitarianism 17

Identity $17,107-108,190,204,230-231$, 233

Imagination $97,113-116,118-119$

Intervention $35,132,149,225-229,238$, $242-243,252-253,265-266$

Kenya 253-254

Kinship 14-15

construction of kinship 30,118

Language $106,185-188,215,255$

Malinowski, Bronsilaw 2

Mauritius 95-97, 106-109

Mead, Margaret 2

Memory 97, 182

Mental health 241, 249-253

Methodology $3,6-12,69-75,182-184,208$, 232-233
Methods

addressing sensitive issues 9-10, 232-233

board games 207-210

body mapping $\quad 77-78,81-82$

draw-and-tell 77,89

group interviews $9,51-53,60,77$

home visits $46,56-57$

illuminative approach 198-201, 206-207

interviews $26-27,46-47,77,130-131$, 152-153, 204, 207-210

Kids Club Method 50-52

life-course approach $\quad 70-75,77-79,84-89$

life histories $182-183$

longitudinal research 73

participant observation $98,130,183$

participatory $11,17,73-74,253$

photo elicitation $98,117,131,183-184$

Photovoice 254

progressive interviewing 206, 210 , 214-217

sampling 76,80

self-reporting $69,91-92$

visual $9-10,53-54,131$

word association 183

Migration 2, 15, 16

forced 200

return 176-177, 192

right of return 96,116

street-ward 125, 127-128

Mobility 127-128, 132, 139

Morocco 15, 174-175

Namibia $\quad 43-45$

Netherlands, the $15,27,174,178-179$

Orphanhood 21

Poverty 258-260

Power relations $12,14-15,99$

Psychosocial care $17,228,248,250-253$, 255-258, 261, 266-266, 271

Refugees 233 children 198-207

Religion 261

Resilience 5, 12, 225-226, 239-242, 248, 250, 260

Risk 47, 59, 212, 240-241, 250-252

Rwanda 231, 233

Siblings $26,29,31,33,36,58-59,165,238$, 263

Social workers $127,136-138,230,233$

Socialisation $31,155-156,202-203$

South Africa $23,25-27$ 


\section{Strategy \\ coping strategies $24-25,117,250,252$, $260-264$}

survival strategies $13,128,135,142-143$

Street children $13,126-129,136,138-139$, 142-143

Support 4, 13-14, 17, 22-27, 30-31, 34-36, $134,137,228-229,240,252-253,259-261$, 263

Taboo 251

Tanzania 250, 265
United Kingdom 16, 249

United Nations 199, 224

Victimization $3,5,13-14,248,250-251,261$, 265

Violence 2, 223-225, 238-240

domestic violence 135-136

Vulnerability 223-225, 238-241

Vygotsky 2

This is a digital offprint for restricted use only | ( 2011 Koninklijke Brill NV 
